\title{
Dynamic modal analysis and optimization of C-130 Project Oculus' mechanical arm/pod sensor deployment system using the finite element method
}

\author{
Adam C. Naternicola \\ West Virginia University
}

Follow this and additional works at: https://researchrepository.wvu.edu/etd

\author{
Recommended Citation \\ Naternicola, Adam C., "Dynamic modal analysis and optimization of C-130 Project Oculus' mechanical \\ arm/pod sensor deployment system using the finite element method" (2004). Graduate Theses, \\ Dissertations, and Problem Reports. 1504. \\ https://researchrepository.wvu.edu/etd/1504
}

This Thesis is protected by copyright and/or related rights. It has been brought to you by the The Research Repository @ WVU with permission from the rights-holder(s). You are free to use this Thesis in any way that is permitted by the copyright and related rights legislation that applies to your use. For other uses you must obtain permission from the rights-holder(s) directly, unless additional rights are indicated by a Creative Commons license in the record and/ or on the work itself. This Thesis has been accepted for inclusion in WVU Graduate Theses, Dissertations, and Problem Reports collection by an authorized administrator of The Research Repository @ WVU. For more information, please contact researchrepository@mail.wvu.edu. 
Dynamic Modal Analysis and Optimization of C-130 Project Oculus' Mechanical Arm/Pod Sensor Deployment System Using the Finite Element Method

Adam C. Naternicola

A thesis submitted to the College of Engineering and Mineral Resources at West Virginia University In partial fulfillment of the requirements for the degree of

Master of Science

In

Mechanical Engineering

James E. Smith, PhD., Chair

Kenneth H. Means, PhD. Gregory J. Thompson, PhD.

Department: Mechanical and Aerospace Engineering Major: Mechanical Engineering

\section{West Virginia University}

Morgantown, WV

2004

Keywords: Modal Analysis, Finite Element Method, Mechanical Arm Design

Copyright Adam C. Naternicola, 2004. All rights Reserved 


\title{
ABSTRACT \\ The West Virginia University Guide to the Preparation of Master's Theses and Doctoral Dissertations
}

\begin{abstract}
Adam C. Naternicola
The Department of Defense (DoD) and the United States Army National Guard (USARNG) have sponsored West Virginia University's Center for Industrial Research Applications (CIRA) to design, fabricate, test and optimize an articulating, mechanical $\mathrm{arm} /$ pod system. The mechanical arm/pod system will be designed to accommodate a 500-pound sensor payload deployable in flight from a C-130 Hercules military aircraft used for counter narco-terrorism efforts. During the overall deployment (translation and rotation) of the mechanical arm/pod system and in the final resting position for optimal operating conditions for the data acquisition sensors (DAS), the mechanical structure will be subjected to a variety of forces and vibrations from numerous sources.

Once a frequency range with assigned magnitudes is established, a formal vibration analysis will be conducted utilizing the Finite Element Method (FEM) and Modal Analysis with Pro-Engineer and Pro-Mechanica. The natural frequency modes for the mechanical arm/pod system will be computed in the $\mathrm{x}, \mathrm{y}$ and $\mathrm{z}$ directions with three different geometrical configurations of the structural cross-member supports. Modifying the structural cross-members will affect the stiffness of the overall system, which in turn will vary the natural frequency range. Consequently, the goal is to design the mechanical $\mathrm{arm} /$ pod system as a function of mass and stiffness in order to increase or decrease the natural frequencies of the system to ensure resonance occurs outside the general vibration profile generated from the Rake test and to ensure adequate dampening of the vibrations occurs within the sensors' vibration tolerance values to ensure optimal performance.
\end{abstract}




\section{Table of Contents}

Title Page i

$\begin{array}{ll}\text { Abstract } & \text { ii }\end{array}$

Table of Contents iii

List of Figures $\quad$ v

List of Tables $\quad$ xiii

$\begin{array}{ll}\text { Nomenclature } & \mathbf{x v}\end{array}$

$\begin{array}{ll}\text { Acknowledgements } & \text { xvii }\end{array}$

$\begin{array}{ll}\text { Chapter 1.0 Introduction } & 1\end{array}$

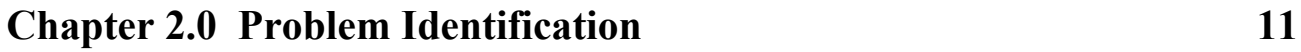

$\begin{array}{ll}\text { Chapter 3.0 Introduction to Vibration } & 12\end{array}$

3.1 Sources and Effects of Structural Vibration 13

3.2 Minimizing Structural Vibration $\quad 15$

3.3 Analysis of Structural Vibration 16

3.4 The Vibrations of Continuous Structures 20

$\begin{array}{ll}\text { 3.5 Theoretical Background } & 21\end{array}$

3.6 The Finite Element Method 24

$\begin{array}{lr}\text { Chapter 4.0 Vibration Profile } & 28\end{array}$

4.1 Aerodynamic Flutter, Buffeting and Vibroacoustics 29

$\begin{array}{ll}\text { 4.1a Flutter } & 29\end{array}$

4.1b Buffeting 31

4.1c Vibroacoustics $\quad 32$ 
4.3 Gust Loads on Aircraft and Appendages Due to Atmospheric Turbulence

Chapter 5.0 Rake Test $\quad 42$

5.1 Description of Rake and Data Acquisition Components 44

5.2 Test Procedures and Analysis 48

$\begin{array}{ll}5.3 \text { Results } & 50\end{array}$

5.4 Conclusions $\quad 54$

Chapter 6.0 Dynamic Modal Analysis of Mechanical Arm/Pod 55 System

$\begin{array}{ll}6.1 \text { Results } & 60\end{array}$

$\begin{array}{ll}\text { 6.2 Conclusions } & 73\end{array}$

$\begin{array}{lll}\text { Chapter 7.0 } & \text { Future Work and Considerations } & 77\end{array}$

$\begin{array}{ll}\text { Chapter 8.0 Vita } & 79\end{array}$

$\begin{array}{lr}\text { Chapter 9.0 References } & \mathbf{8 0}\end{array}$

$\begin{array}{lr}\text { Appendix A } & 82\end{array}$

$\begin{array}{lr}\text { Appendix B } & 103\end{array}$

$\begin{array}{ll}\text { Appendix C } & 130\end{array}$

$\begin{array}{lr}\text { Appendix D } & 140\end{array}$ 


\section{$\underline{\text { List of Figures }}$}

Figure 1.0a: C-130 aircraft during flight. [1] 2

$\begin{array}{ll}\text { Figure 1.0b: } \text { Model of operator station. [1] } & 6\end{array}$

Figure 1.0c: Mechanical Arm/Pod system mounted on standardized reinforced $\quad 7$ C-130 pallet. [1]

Figure 1.0d: Schematic layout of mechanical system on ramp of C-130 Hercules aircraft [1].

Figure 1.0e: Illustration of applicable base excitations from C-130 ramp transmitted throughout arm/pod system and random gust loads applied laterally to the system itself.

Figure 3.2a: Diagram of vibration sources and dynamic responses of structural systems (Beards, 1983)

Figure 3.2b: Effects of mass and stiffness changes for dynamic response of system.

Figure 3.3a: Beard's 3-stage approach to structural vibration analysis.

Figure 4.1a: Finite element analysis (FEA) of aircraft wing structure subjected to coupling from flutter [8].

Figure 4.1b: Photograph of shed vortices or karmon street vortices produced by a blunt body in an airstream [9].

Figure 4.1c: Diagram of internal vibroacoustics in the high frequency range in a fixed wing-aircraft fuselage [10].

Figure 4.2a: Illustration of airstream flow generating severe turbulence in atmosphere [11].

Figure 4.2b: Illustration of the effects of altitude turbulence intensities with altitude variation. [11]

Figure 4.3a: Illustration of resultant force with components consisting of a vertical gust velocity and velocity of airflow due to forward speed.

Figure 4.3b: Illustration of a lateral gust velocity combined with the velocity of airflow due to forward speed.

Figure 5.0a: Rake structure fully deployed on C-130 ramp in the opened position ( 0 degrees with horizontal). Each rake column consists of 7 pitot tubes facing directly into airflow and 3 pitot tubes facing perpendicular to airflow. One accelerometer is positioned in middle of the rakes cross members.

Figure 5.0b: Zoomed image of right column of the rake to illustrate distribution of pitot tubes. 
Figure 5.1a: Tension, compression and shear piezoelectric accelerometers. [14]

Figure 5.1b: Schematic of Pitot tube and pressure transducer [14].

Figure 5.2a: C-130 ramp in the fully opened position or horizontal position (0 degrees from the horizontal).

Figure 5.3a: Normalized frequency power spectrum of vibrations in the left-right motion for velocity of 130 knots. Peak values occur at $18 \mathrm{hz}$ and $967 \mathrm{hz}$.

Figure 5.3b: Normalized frequency power spectrum of vibrations in the fore-aft motion for velocity of 130 knots. Peak value occurs at $549 \mathrm{hz}$ with negligible power levels.

Figure 5.3c: Normalized frequency power spectrum of vibrations in the up-down motion for velocity of 130 knots. Peak value occurs at $18 \mathrm{hz}$ with negligible power levels.

Figure 5.3d: Normalized frequency power spectrum of vibrations in the left-right motion for velocity of 145 knots. Peak values occur at $18 \mathrm{hz}, 679 \mathrm{hz}$ and $1040 \mathrm{hz}$.

Figure 5.3e: Normalized frequency power spectrum of vibrations in the fore-aft motion for velocity of 145 knots. Peak values occur at $238 \mathrm{hz}$ and $550 \mathrm{hz}$.

Figure 5.3f: Normalized frequency power spectrum of vibrations in the up-down motion for velocity of 145 knots. Peak values occur at $18 \mathrm{hz}$ with negligible power levels.

Figure 6.0a: Illustration of $X, Y \& Z$ constraints on surface of inner shaft whole for each arm

Figure 6.0b: Study \#1 Part (A): Arm without braces.

Figure 6.0c: Study \#1 Part (B): Arm with Center Cross-Braces

Figure 6.0d: Study \#1 Part (C): Arm w/ Cross-Braces and Side V-Braces.

Figure 6.0e: Illustration of $X, Y \& Z$ constraints applied on surface of arm support.

Figure 6.0f: Study \#2 Part (A): Pod Frame without skin.

Figure 6.0g: Study \#2 Part (B): Pod Frame with 1/2in support plate and 1/8-inch side panels.

Figure 6.0h: Study \#3 Part (A): Assembled Arm/Pod System with Center Cross-Brace, 1/2in Plate and 1/8in Side Panels.

Figure 6.0i: Study \#3 Part (B): Assembled Arm/Pod System with Center Cross-Brace, V-Braces, 1/2in Plate and 1/8in Side Panels. 
Figure 6.1a: Varying the cross-brace configurations had no affect on the torsion and for-aft motions, however the right-left motion frequency response increased incrementally, $7 \mathrm{hz}, 18 \mathrm{hz}$ and $45 \mathrm{hz}$, respectively.

Figure 6.1b: Nonlinear Relationship of Mode Shapes and Natural Frequencies for all 10 modes in Study \#1 (Arm w/out Bracing), (Arm w/ Cross-Brace) and (Arm w/ Cross \& V-Braces) as mass and stiffness are increased.

Figure 6.1c: Illustration of Mode 1 with corresponding Natural Frequencies:

(A) (Right-Left Motion) arm with out braces resonated at 7hz,

(B)(Right-Left Motion) arm with center cross-brace resonated at $18 \mathrm{hz}$,

(C) (Right-Left Motion) arm with cross-braces \& V-braces resonated at $45 \mathrm{hz}$,

(D-F) (Fore-Aft Motion) with arm in 3 geometrical configurations with Natural Frequency constant at $16 \mathrm{hz}$, respectively, and (G-H) (Torsion Motion) with arm in 3 geometrical configurations with Natural Frequency constant at 22hz, respectively.

Figure 6.1d: Varying mass and stiffness parameters of pod frame by adding $1 / 2$-inch plate and 1/8-inch panels. In the (Right-Left) motion the natural frequencies increased from $56 \mathrm{hz}$ to $154 \mathrm{hz}$. In the (Vertical Bending) motion the natural frequencies decreased from $68 \mathrm{hz}$ to $60 \mathrm{hz}$. In the (Torsion) motion the natural frequencies increased from $87 \mathrm{hz}$ to $92 \mathrm{hz}$.

Figure 6.1e: Nonlinear Relationship of Mode Shapes and Natural Frequencies for the Pod Study as stiffness and mass are increased with the $1 / 2$ in plate and $1 / 8$-in side panels.

Figure 6.1f: Illustration of Mode 1 with corresponding Natural Frequencies:

(A) (Right-Left Motion) of Pod Frame resonated at 56hz,

(B) (Right-Left Motion) of Modified Pod resonated at 154hz,

(C) (Vertical Bending Motion) of Pod Frame resonated at $68 \mathrm{hz}$,

(D) (Vertical Bending Motion) of Modified Pod with Natural Frequency of $60 \mathrm{hz}$,

(E) (Torsion Motion) of Pod Frame with Natural Frequency at $87 \mathrm{hz}$ and

(F) (Torsion Motion) of Modified Pod with Natural Frequency at $92 \mathrm{hz}$.

Figure 6.1g: Varying mass and stiffness parameters of Arm/Pod mechanical for system 1: center cross-brace and system 2: center cross-brace and $\mathrm{V}$-braces. In the (Right-Left) motion the natural frequencies increased from $11 \mathrm{hz}$ to $31 \mathrm{hz}$. In the (Fore-Aft) motion the natural frequencies remained constant at $12 \mathrm{hz}$. In the (Torsion) motion the natural frequencies increased from $14 \mathrm{hz}$ to $18 \mathrm{hz}$.

Figure 6.1h: Nonlinear Relationship of Mode Shapes and Natural Frequencies for the complete Arm/Pod systems as mass and stiffness are increased by the addition of assembling the two Arm \& Pod components and adding the V-braces to the second complete system. 
Figure 6.1i: Illustration of Mode 1 with corresponding Natural Frequencies:

(A) (Right-Left Motion) of Arm/Pod system (1) resonated at 11hz,

(B) (Right-Left Motion) of Arm/Pod system (2) resonated at 31hz,

(C) (Fore-Aft Motion) of system (1) resonated at 12hz,

(D) (Fore-Aft Motion) of system (2) with Natural Frequency of 12hz,

(E) (Torsion Motion) of system (1) with Natural Frequency at $14 \mathrm{hz}$ and

(F) (Torsion Motion) of system (2) with Natural Frequency at $18 \mathrm{hz}$.

Figure 7.0a: Schematic of Horizontal Load represented by directional cosine components as a function of misalignment error.

Figure 0-A: X-Direction (Left-Right Motion) Acceleration Frequency Analysis of Ramp Measured During Test 1 (V=130 knots, Ramp open, 0 degree deck)

Figure 1-A: $X-D i r e c t i o n$ (Left-Right Motion) Acceleration Signal for Ramp Measured During Test 1 (V=130 knots, Ramp open, 0 degree deck

Figure 2-A: Y-Direction (Fore-Aft Motion) Acceleration Frequency Analysis of Ramp Measured During Test 1 (V=130 knots, Ramp open, 0 degree deck)

Figure 3-A: Y-Direction (Fore-Aft Motion) Acceleration Signal for Ramp Measured During Test 1 (V=130 knots, Ramp open, 0 degree deck)

Figure 4-A: Z-Direction (Vertical) Acceleration Frequency Analysis of Ramp Measured During Test 1 (V=130 knots, Ramp open, 0 degree deck)

Figure 5-A: Z-Direction (Vertical) Acceleration Signal for Ramp Measured During Test 1 knots, Ramp open, 0 degree deck)

Figure 6-A: X-Direction (Left-Right Direction) Acceleration Frequency Analysis of Ramp Measured During Test 2 (V=130 knots, Ramp open, 0 degree deck)

Figure 7-A: X-Direction (Right-Left Motion) Acceleration Signal for Ramp Measured During Test 2 (V=130 knots, Ramp open, 0 degree deck)

Figure 8-A: Y-Direction (Fore-Aft Motion) Acceleration Frequency Analysis of Ramp Measured During Test 2 (V=130 knots, Ramp open, 0 degree deck)

Figure 9-A: Y-Direction (Fore-Aft Motion) Acceleration Signal for Ramp Measured During Test 2 (V=130 knots, Ramp open, 0 degree deck)

Figure 10-A: Z-Direction (Vertical) Acceleration Frequency Analysis of Ramp Measured During Test 2(V=130 knots, Ramp open, 0 degree deck)

Figure 11-A: Z-Direction (Vertical) Acceleration Signal for Ramp Measured During Test 2 (V=130 knots, Ramp open, 0 degree deck)

Figure 12-A: X-Direction (Left-Right Motion) Acceleration Frequency Analysis of Ramp Measured During Test 3 (V=130 knots, Ramp open, 0 degree deck)

Figure 13-A: X-Direction (Right-Left Motion) Acceleration Signal for Ramp Measured During Test 3 (V=130 knots, Ramp open, 0 degree deck) 
Figure 14-A: Y-Direction (Fore-Aft Motion) Acceleration Frequency Analysis of

Ramp Measured During Test 3 (V=130 knots, Ramp open, 0 degree deck)

Figure 15-A: Y-Direction (Fore-Aft Motion) Acceleration Signal for Ramp Measured During Test 3 ( $\mathrm{V}=130$ knots, Ramp open, 0 degree deck)

Figure 16-A: Z-Direction (Vertical) Acceleration Frequency Analysis of Ramp Measured During Test 3 (V=130 knots, Ramp open, 0 degree deck)

Figure 17-A: Z-Direction (Vertical) Acceleration Signal for Ramp Measured During Test 3 ( $V=130$ knots, Ramp open, 0 degree deck)

Figure 18-A: Average Velocity Measured in Direction of Flight for Test 1 (130 knots, ramp open, 0 deg deck angle)

Figure 19-A: X-Direction (Right-Left Motion) Acceleration Frequency Analysis of Ramp Measured During Test 1 (V=145 knots, Ramp open, 0 degree deck)

Figure 20-A: X-Direction (Right-Left Motion) Acceleration Signal for Ramp Measured During Test 1 ( $V=145$ knots, Ramp open, 0 degree deck)

Figure 21-A: Y-Direction (Fore-Aft Motion) Acceleration Frequency Analysis of Ramp Measured During Test 1 ( $\mathrm{V}=145$ knots, Ramp open, 0 degree deck)

Figure 22-A: Y-Direction (Fore-Aft Motion) Acceleration Signal for Ramp Measured During Test 1 ( $\mathrm{V}=145$ knots, Ramp open, 0 degree deck)

Figure 23-A: Z-Direction (Vertical) Acceleration Frequency Analysis of Ramp Measured During Test 1 ( $\mathrm{V}=145$ knots, Ramp open, 0 degree deck)

Figure 24-A: Z-Direction (Vertical) Acceleration Signal for Ramp Measured During Test 1 ( $\mathrm{V}=145$ knots, Ramp open, 0 degree deck)

Figure 25-A: X-Direction (Right-Left Motion) Acceleration Frequency Analysis of Ramp Measured During Test 2 ( $\mathrm{V}=145$ knots, Ramp open, 0 degree deck)

Figure 26-A: X-Direction (Right-Left Motion) Acceleration Signal for Ramp Measured During Test 2 (V=145 knots, Ramp open, 0 degree deck)

Figure 27-A: Y-Direction (Fore-Aft Motion) Acceleration Frequency Analysis of Ramp Measured During Test 2 ( $\mathrm{V}=145$ knots, Ramp open, 0 degree deck)

Figure 28-A: Y-Direction (Fore-Aft Motion) Acceleration Signal for Ramp Measured During Test 2 ( $\mathrm{V}=145$ knots, Ramp open, 0 degree deck)

Figure 29-A: Z-Direction (Vertical) Acceleration Frequency Analysis of Ramp Measured During Test 2 (V=145 knots, Ramp open, 0 degree deck)

Figure 30-A: Z-Direction (Vertical) Acceleration Signal for Ramp Measured During Test 298 ( $\mathrm{V}=145$ knots, Ramp open, 0 degree deck)

Figure 31-A: X-Direction (Right-Left Motion) Acceleration Frequency Analysis of Ramp 99 Measured During Test 3 (V=145 knots, Ramp open, 0 degree deck) 
Figure 32-A: X-Direction (Right-Left Motion) Acceleration Signal for

Figure 33-A: Y-Direction (Fore-Aft Position) Acceleration Frequency Analysis of Ramp Measured During Test 3 ( $\mathrm{V}=145$ knots, Ramp open, 0 degree deck)

Figure 34-A: Y-Direction (Fore-Aft Position) Acceleration Signal for Ramp Measured During Test 3 (V=145 knots, Ramp open, 0 degree deck)

Figure 35-A: Z-Direction (Vertical) Acceleration Frequency Analysis of Ramp Measured During Test 3 (V=145 knots, Ramp open, 0 degree deck

Figure 36-A: Z-Direction (Vertical) Acceleration Signal for Ramp Measured During Test 3 ( $\mathrm{V}=145$ knots, Ramp open, 0 degree deck)

Figure 37-A: Average Velocity Measured in Direction of Flight for Test 1

(145 knots, ramp open, 0 deg deck angle)

Figure 1-B: (A) Mode Shape 1 with 1 node (Right-Left Motion) at 7hz,

(B) Mode Shape 2 with 1 node (Fore-Aft Motion) at 16hz,

(C) Mode Shape 3 with center node (Twisting Motion) at $22 \mathrm{hz}$ and

(D) Mode Shape 6 with 2 nodes (Right-Left motion of arms at $47 \mathrm{~Hz}$.

Figure 2-B: (E) Mode 7 with 2 nodes (Right-Left Motion) at 50hz,

(G) Mode 8 with 2 nodes (Fore-Aft Motion) at 100hz,

$(\mathrm{H})(\mathrm{G})$ Mode 9 with 3 nodes (Right-Left Motion) at $101 \mathrm{~Hz}$.

Figure 3-B: (A) Mode 1 with a node (Fore-Aft Motion) at 16hz,

(B) Mode 2 with 1 node (Right-Left Motion) at 18hz,

(C) Mode 3 with center node (Torsion Motion) at $22 \mathrm{~Hz}$.

Figure 4-B: (D) Mode 4 with 2 nodes (Right-Left Motion) of outer arms at 47hz,

(E) Mode 6 with 2 nodes (Right-Left Motion) of center piece at 58hz,

(F) Mode 7 with 2 nodes (Fore-Aft Motion) at 93hz,

(G) Mode 8 with 3 nodes (Right-Left Motion) of outer arms at 104hz.

Figure 5-B: Mode Shape 10 with 3 nodes (Torsion Motion) of center Cross-Brace at $117 \mathrm{hz}$.

Figure 6-B: (A) Mode 1with 1 node (Fore-Aft Motion) at 16hz,

(B) Mode 2 with center node (Torsion Motion) at $22 \mathrm{hz}$,

(C) Mode 3 with 1 node (Right-Left Motion) at 45hz,

(D) Mode 4 with 2 nodes (Right-Left Motion) at 89hz.

Figure 7-B: (E) Mode 5 with 2 nodes (Fore-Aft Motion) at 94hz,

(F) Mode 6 with center node (Torsion Motion) and 2 bending nodes

(Fore-Aft Motion) at $121 \mathrm{hz}$,

(G) Mode 7 with 2 nodes (Bending and Twisting Motion) of Center Brace at 125hz,

(H) Mode 9 with 2 nodes (Torsion Motion) of two outer arms at $141 \mathrm{hz}$. 
Figure 8-B: (A) Mode 1 with 1 node (Right-Left Motion) at 56hz,

(B) Mode 2 with 3 nodes (Torsion Motion) at $68 \mathrm{hz}$,

(C) Mode 3 with center node (Torsion Motion) at $87 \mathrm{hz}$.

Figure 9-B: (D) Mode 4 (Torsion Motion) at 88hz,

(E) Mode 5 with 4 nodes (Torsion Motion) at $118 \mathrm{hz}$,

(F) Mode 6 with 5 nodes (Torsion Motion) at 140hz.

Figure 10-B: (G) Mode 8 with 2 nodes (Vertical Bending Motion) at 170hz,

(H) Mode 10 with (Vertical Bending and Torsion Motion) at 186hz.

Figure 11-B: (A) ) Mode 1 with 2 nodes (Vertical Bending Motion) at $60 \mathrm{hz}$,

(B) Mode 2 with 3 nodes (Vertical Bending and Torsion Motion) at 92hz,

(C) Mode 3 with 3 nodes (Torsion Motion) at 108hz

Figure 12-B: (D) Mode 4 with 3 nodes (Vertical Bending Motion) at 147hz,

(E) Mode 5 with 4 nodes (Vertical Bending and Torsion Motion) at 154hz,

(F) Mode 7 with 2 nodes (Vertical Bending Motion) at $175 \mathrm{hz}$.

Figure 13-B: (G) Mode 9 with 4 nodes (Vertical Bending Motion) at 209hz,

(H) Mode 10 with 6 nodes (Vertical Bending and Torsion Motion) at 224hz.

Figure 14-B: (A) Mode 1 with 1 node (Right-Left Motion) at 11hz,

(B) Mode 2 with 1 node (Fore-Aft Motion) at $12 \mathrm{hz}$,

(C) Mode 3 with center node (Torsion Motion) at 14hz,

(D) Mode 4 with 2 nodes (Lateral Torsion Motion) at 40hz.

Figure 15-B: (E) Mode 5 (Right-Left Motion) of outer Arms at 43hz,

(F) Mode 7 with 2 nodes (Right-Left Motion) at 51hz,

(G) Mode 8 with 4 nodes (Multiple Torsion Motion) at 55hz and

(H) Mode 9 with 5 nodes (Multiple Torsion Motion) at $73 \mathrm{hz}$.

Figure 16-B: Mode 10 with 3 nodes (Right-Left Motion) at 82hz

Figure 17-B: (A) Mode 1 with 1 node (Fore-Aft Motion) at 12hz,

(B) Mode 2 with center node (Torsion Motion) at $18 \mathrm{hz}$,

(C) Mode 3 with 1 node (Right-Left Motion) at $31 \mathrm{hz}$ and

(D) Mode 4 with 2 nodes (Torsion Motion) at 40hz.

Figure 18-B: (E) Mode 5 with 3 nodes (Multiple Torsion Motion) at 55hz,

(F) Mode 6 with 2 nodes (Right-Left Motion) at 73hz,

(G) Mode 8 with 4 nodes (Multiple Torsion Motion) at $92 \mathrm{hz}$ and

(H) Mode 9 with 3 nodes (Multiple Bending Motion) of Cross-Brace and $1 / 2$ inch Plate at $111 \mathrm{hz}$.

Figure 19-B: Mode 10 with 6 nodes (Multiple Bending and Torsion Motion) at 118hz

Figure 0-D: AutoCAD drawings of mechanical Arm/Pod system mounted on C-130 Ramp. 141 
Figure 1-D: Zoomed picture of vibration isolators and isolated sensor plate.

Figure 2-D: Revised Mechanical Arm/Pod System for Project Oculus.

Figure 3-D: Ideal Mechanical Arm/Pod System for C-130 Project Oculus (back view). 


\section{$\underline{\text { List of Tables }}$}

Table 4.2a: Wind Sheer CAT with Wind Speed 60 Knots or Greater 35

Table 4.2b: Turbulence Classification Table from Airman's Information Manual, Ch. $7 \quad 38$

Table 5.2a: Components and Test Schematic for C-130 Rake Test. 49

Table 6.0a: List of multiple components and systems to be analyzed with 56 corresponding properties.

Table 6.0b: Material properties of Al 6061-T6 which apply to all 56 components and systems.

Table 6.1a: List of Natural Frequency Results Relative to Indicated Mode Shapes in Numerical Format. Grey indicates Mode Shape, Red indicates the Natural Frequencies close to the $18 \mathrm{hz}$ peak (Right-Left Motion) from the Rake test and orange highlights reflect the frequency mode shapes for vibration isolator inspection.

Table 6.1b: Calculated Mass (lbm) and Moment of Inertia for systems and components. $\quad 60$

Table 6.1c: Frequency values for mode 1 with corresponding direction of motion. 62

Table 6.1d: Frequency values for mode 1 with corresponding direction of motion. 66

Table 6.1e: Frequency values for mode 1 with corresponding direction of motion. $\quad 70$

$\begin{array}{ll}\text { Table 1-B: Natural Frequencies of Mechanical Arm Structure } & 104\end{array}$ without Cross-Brace Support.

Table 2-B: P-Pass Convergence within 10\% of Modal Frequency 104

Table 3-B: Natural Frequencies of Mechanical Arm Structure with 107 Center Cross-Brace Support

$\begin{array}{ll}\text { Table 4-B: P-Pass Convergence within 10\% of Modal Frequency } & 107\end{array}$

Table 5-B: Natural Frequencies of Mechanical Arm Structure with Center Cross-Brace $\quad 110$ and Sid V-Brace Supports.

Table 6-B: P-Pass Convergence within 10\% of Modal Frequency 111

Table 7-B: Natural Frequencies of Pod Frame 114

Table 8-B: P-Pass Convergence within 10\% of Modal Frequency for Pod Frame 114

Table 9-B: Natural Frequencies of Pod Frame with Plate and Panel Components 118 
Table 10-B: P-Pass Convergence within 10\% of Modal Frequency for Pod Frame with Skin.

Table 11-B: Natural Frequencies of Arm/Pod System with Cross-Brace and Pod Skin

Table 12-B: P-Pass Convergence within 10\% of Modal Frequency for Arm/Pod System.

Table 13-B: Natural Frequencies of Arm/Pod System with Cross-Brace, V-Braces and Pod Skin.

Table 14-B: P-Pass Convergence within 10\% of Modal Frequency for Arm/Pod System. 


\section{Nomenclature}

DoD

USARNG

CIRA

DAS

FEM

FEA

FAA

FFT

Pro/E

Pro/M

Frequency / Hz / Hz

C-130 H

$\mathrm{m}$

$\mathrm{k}$

M

K

C

Nodes

Modes

$\mathrm{N}_{1}$
Department of Defense

United States Army National Guard

Center for Industrial Research Applications

Data Acquisition Sensors

Finite Element Method

Finite Element Analysis

Federal Aviation Administration

Fast Fourier Transform

Pro/ENGINEER

Pro/MECHANICA

Cycles per second

C-130 Hercules Military Aircraft

Mass

Stiffness

Global Structural Mass Matrix

Global Structural Stiffness Matrix

Global Structural Damping Matrix

Points with zero vibration amplitude

Mode shapes of vibration

Number of degrees of freedom 
$\mathrm{N}_{2}$

$\{\ddot{x}\}$

$\{\mathrm{x}\}$

$\{\mathrm{x}\}$

$\{x\}$

omega

$\{f\}$

row

V

E

$\{$ phi $\}$

lambda

CAT

g-forces

$\mathrm{P}$

$\mathrm{lb}$

in

$\mathrm{ft}$

WVU

NGB-CD

FOV
Total number of data points

Acceleration vector

Velocity Vector

Displacement Vector

Frequency $(\mathrm{Hz})$

Harmonic excitation force

Density (Slugs $/ \mathrm{ft}^{3}$ )

Velocity (ft/s)

Modulus of Elasticity

Eigen Vector

omega $^{2}$

Clear air turbulence

Gravitational Forces $\left(32.2 \mathrm{ft} / \mathrm{sec}^{2}\right)$

Pressure (psi or psf)

Pounds

Inches

Feet

West Virginia University

National Guard Bureau Counter-Drug Office

Field of View 


\section{Acknowledgements}

This publication would not have been possible without the dedicated efforts of many individuals. In the spirit of multiple-agency collaboration, the author would like to acknowledge contributions made by Bruce Corso, Program Manager for the DoDCNTPO, and Maj. Michael Thomas, Technical Projects Manager for the NGB-CD. Sincere thanks also go to Col. James Hoyer, Col. Frye and all members of the WV-NG and ANG who provided guidance for the planning and development of this technology. Furthermore, the author would like to express gratitude to all the WVU participants for their timeless efforts that have insured the success of this program. Additionally, the author would like to give special thanks to his advisor and chairperson, Dr. James Smith, and to his committee members, Dr. Kenneth Means and Dr. Gregory Thompson, for the guidance, knowledge, and encouragement that they have contributed. Finally, the author would like to give thanks to his parents, Joseph and Nancy Naternicola Jr., and family for the support, love, and motivation throughout the years, and to his fiancée, Kristy Withrow, for studying so much that he had to have something to do! 


\subsection{Introduction}

Throughout history, the National Guard (NG) has had to fulfill a dual mission for the United States. That mission is to provide the nation with units trained, equipped, and ready to defend the United States and its interests all over the globe and to protect life and property here in the United States. [1]

One of the biggest threats to life and property in the United States is the continuing presence of a large and often-organized illicit drug trade, which supplies the United States with drugs sourced from home and abroad. The role of the National Guard in combating the drug trade is to support counter-drug law enforcement efforts by providing personnel and equipment resources. These resources are limited to what is already in inventory with no immediate plans for large additions to the fleet. [1]

The National Guard provides instrumental support to the Department of Defense as well as civilian sectors. Within this context, the National Guard leverages programs, research, and technology from a wide variety of sources in order to meet present and future mission demands. This includes Government, University, Industry, and Non-profit organizations. With these and other groups, the National Guard focuses their efforts on the transferring and insertion of confirmed technologies and programs that will directly assist their missions.

Similar to military and law enforcement agencies, the missions of the NG necessitate the investigation and implementation of field deployable and often time's novel technologies to meet demanding and changing needs. The National Guard has a requirement to support counter-drug law enforcement efforts through the National Guard Bureau Counter-drug Office (NGB-CD). In this role the NG provides resources, technical 
and personnel, to support civil authorities in counter-drug activities. To supplement this effort, the National Guard uses technology to enhance and advance counter-drug law enforcement agency efforts. [1]

The National Guard has only recently begun investigating using other aircraft (other than the C-26) in assistance with counter-drug missions. One of the most available and versatile aircraft in the National Guard fleet is the C-130 Hercules. The abundance of C-130 aircraft available to National Guard units across the United States and around the world gives it an immediate access advantage over other aircraft in the National Guard fleet.

The C-130 aircraft is manufactured by Lockheed Martin and has been produced since the mid 1950 's. The C-130 aircraft is primarily utilized as a medium range tactical airlift and as the prime transport for paratroop and equipment drops into hostile areas. The $\mathrm{C}-130$ has also been modified into specialized platforms including gun ships and electronic warfare platforms. Figure 1.0a shows a C-130 aircraft in flight. [1]

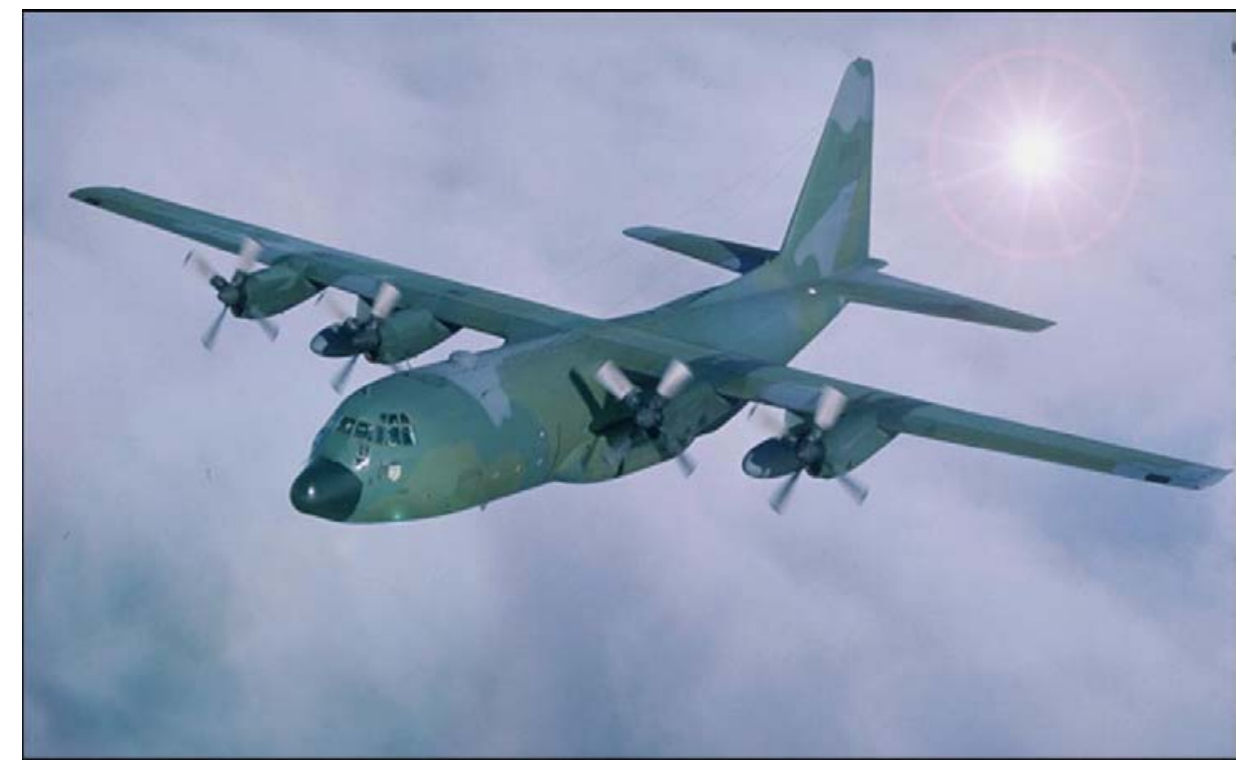

Figure 1.0a: C-130 aircraft during flight. 
The C-130 aircraft encompasses a cargo floor approximately four feet above the ground, a roll-on/roll-off rear loading ramp, and an unhindered, fully pressurized cargo hold area. The C-130 is capable of holding more than 42,000 pounds of cargo distributed through four 463L pallet positions in addition to a rear cargo ramp pallet position. The 463L pallets are military standard pallets that are developed for use on the C-130 aircraft as well as other military aircraft. These pallets are easily maneuvered throughout the aircraft by a roller system integrated into the cargo hold and ramp. Another important feature of the C-130 aircraft is that it has the capability of flying while the rear cargo door is down. This feature was developed for the use of parachute drops during flight.

West Virginia University has been tasked with the needs assessment, design, and fabrication of a sensor platform that is capable of operating remote sensors for use aboard the $\mathrm{C}-130$ military aircraft. To this end WVU proposed the design and construction of a transportable roll-on roll-off sensor pallet(s) that will deploy via the rear cargo door of the aircraft while in flight. Criteria that must be met for this final design include immediate compatibility, universality for the C-130, transportability, reliability, and durability.

The individual selected sensors to be installed on the pallet determine, in part, the requirements for this sensor pallet design process. The pallet must provide the sensors with a useable field of view (FOV) so that the sensor can see ground targets unobstructed. The pallet must also be designed to operate the sensor within its designed limits for vibration and temperature. The pallet must have provisions for all the support equipment including, but not limited to, computers, communication links, instrument panels, and displays. An additional preference for this proposed platform is that the sensors should 
be interfaced, where possible, so that a single workstation can control, view, and analyze the information from all sensors. This system may also be required to have provisions for georectification of the collected imagery. Sensor and data fusion can make the operation of this pallet much simpler for the operator while the georectification allows maps to be made available to the operator on a near real-time basis. [1]

The final design must be able to be deployed while the craft is in flight and it cannot interfere with other mission requirements. All features and functions of the pallet are determined by the physical limitations of the $\mathrm{C}-130$ airframe and the minimum mission profile. This includes that no modifications be made to the $\mathrm{C}-130$ airframe because the C-130's main roles must not be compromised. A second requirement for the final design is that the pallet system must be compatible with all C-130 aircraft. This is because the $\mathrm{C}-130$ has been produced in $\mathrm{A}$ through $\mathrm{H}$ variants for almost fifty years in appreciable numbers. It is also important to consider that the final pallet must not exceed weight distribution restrictions because this can impair the safe operation of the aircraft. All safety and flight considerations for the aircraft must also be addressed, preferably before the final design is approved for the construction of the delivered product. [1]

The pallet itself must be lightweight and weather tight in order to be transported by truck and stored between deployments. Additionally, the pallet should be flexible enough to allow hardware/software upgrades and sensor reconfiguration. The sensor interfaces must be standardized and the support equipment must be packaged in a modular design (i.e. plug and play). [1]

Operator requirements pertain to the personnel that must install and remove the pallet and those that must operate the sensors on the pallet during a mission. This requires 
that the pallet must be simple enough to be installed and maintained by existing personnel, and the pallet must mount in the same fashion as standard cargo pallets and the tools and supplies used to maintain the physical pallet must be the same as for other DoD equipment. The operation of the platform must be executed with a simple PC-type interface to allow enlisted, or drug enforcement personnel to be trained to operate the system easily. [1]

The first assembly exists as an enclosure placed in the main cargo hold of the aircraft. This enclosure (Operator Station) houses the operators along with the control computers for the sensor array and the communications equipment. It also supports a power converter. WVU's intended design for the operator's station is to allow ease of access during operation and will not obstruct personnel passage through the aircraft. This station will be built using the design of a standard cargo shelter upon a standardized flat pallet that will insure that it will be securable and transportable. This operator station will have provisions for all the support equipment including, but not limited to, computers, instrument panels, and displays. The palleted station is also designed to operate control equipment, data collection and, if found cost feasible, data storage within the limits of available power, vibration, and temperature. Ideally, the pallet system can be stored long-term with an adequate power supply capable of actuating fans to maintain the necessary airflow required to protect the computer systems within the weather sealed station from thermal and moisture damage. Figure 1.0b shows a computerized model of the operator station. [1] 


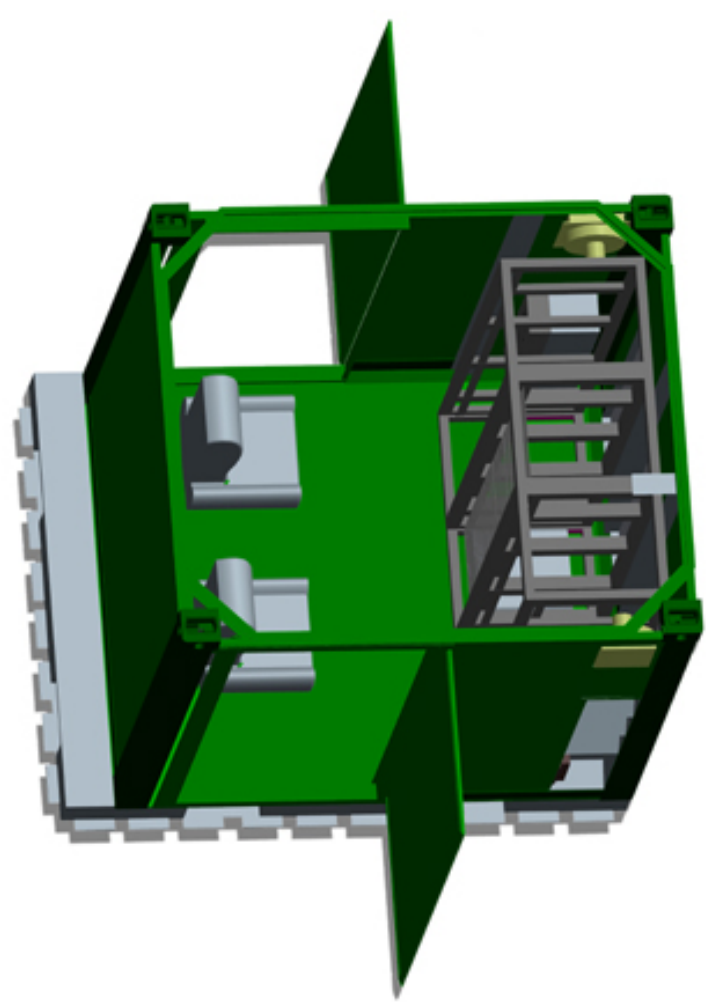

Figure 1.0b: Model of operator station. [1]

The second, smaller pallet (Sensor Platform) attaches to the rear ramp of the aircraft. This pallet supports an extendable arm upon which the sensor array is installed onto a modular attachment bar. In flight, the rear doors of the aircraft open and the sensor arm rotates the sensor array outside the rear of the aircraft to perform its mission. Figure 1.0c shows a computer-generated model of the sensor platform system. [1] 


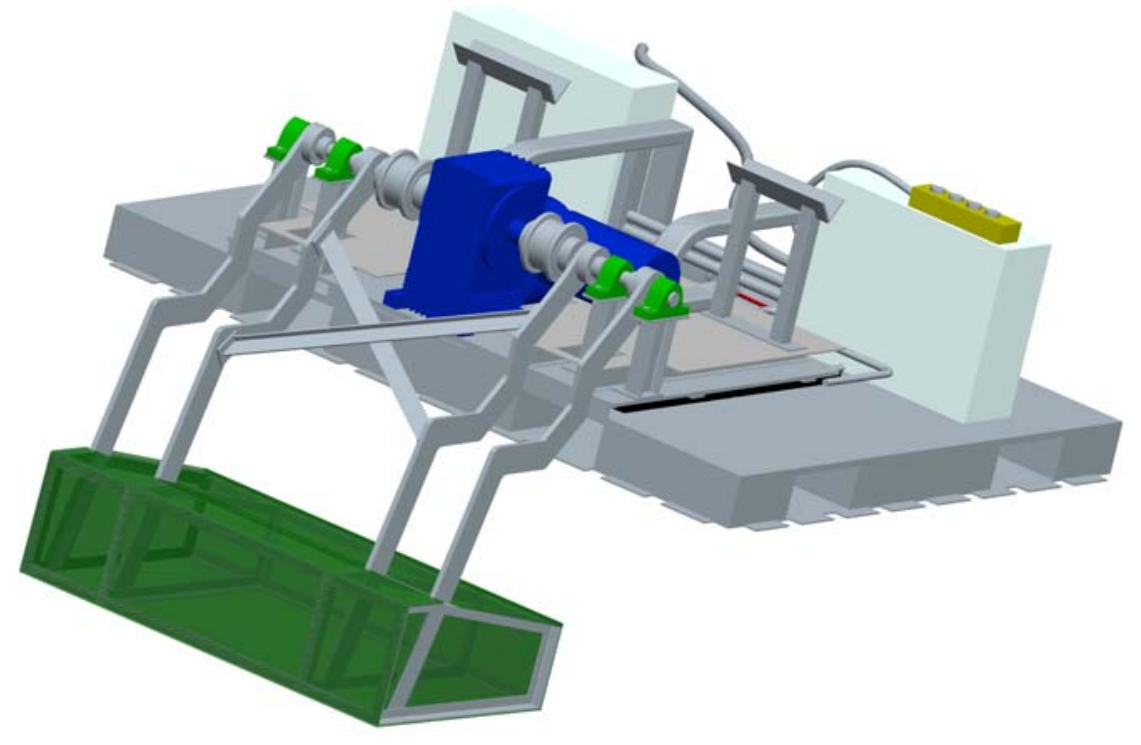

Figure 1.0c: Mechanical Arm/Pod system mounted on standardized reinforced C-130 pallet. [1]

Both systems make up the entire standardized sensor pallet. A concept diagram of the complete system is shown in figure $1.0 \mathrm{~d}$.

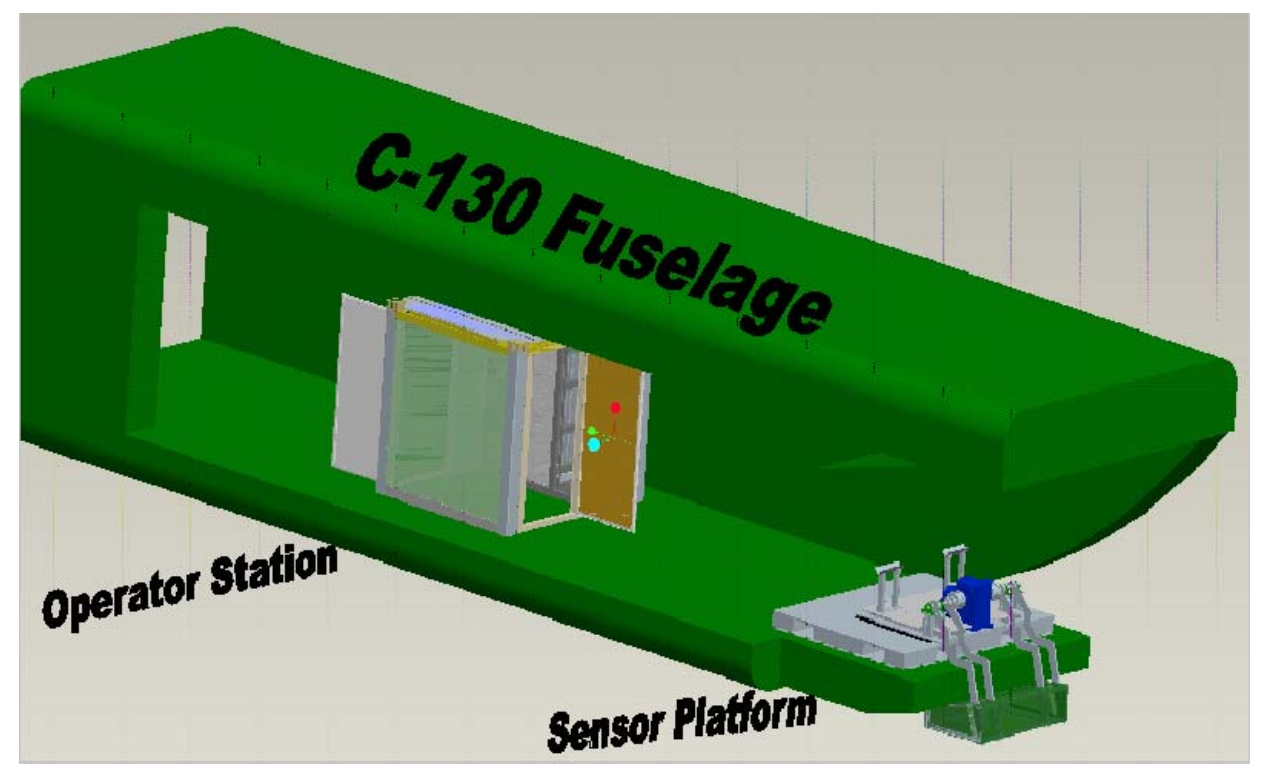

Figure 1.0d: Schematic layout of mechanical system on ramp of C-130 Hercules aircraft [1]. 
In a complex and imperfect world, premature fatigue and catastrophic failures in structures occur from a number of different sources such as material defects, undetected crack existence and propagation, unforeseen external forces, stress concentrations and unwanted resonant vibrations. Although most are controlled during the initial process, resonance is often neglected in the early design and analysis stages. We see neglect in resonance accountability in bridges such as the London Millennium Footbridge, which was unexpectedly resonated at its fundamental frequency by vibrations produced by walking pedestrians [2]. The bridge experienced maximum lateral deflections in the frequency range of less than three (3) $\mathrm{Hz}$ and was closed for two years for inspections and implementing solutions. These vibrations will be the topic of interest in this study of the mechanical arm/pod sensor deployment system design, analysis and optimization.

The Department of Defense (DoD) and the United States Army National Guard (USARNG) have sponsored West Virginia University's Center for Industrial Research Applications (CIRA) to design, fabricate, test and optimize an articulating, mechanical arm/pod sensor deployment system entitled "Project Oculus". The mechanical arm/pod system will be designed to accommodate a 500-pound sensor payload deployable in flight from a C-130 Hercules military aircraft used for counter narco-terrorism efforts. During the overall deployment (translation and rotation) of the mechanical arm/pod system and in the final resting position for optimal operating conditions for the data acquisition sensors (DAS), the mechanical structure will be subjected to a variety of forces and vibrations from numerous sources. 
A general vibration profile for the mechanical arm/pod will be compiled from the plane's four T-56-A-15 turboprop engines, the atmospheric turbulence from the body of the aircraft transmitted as base excitation, and random gust loads on the system itself. A pitot-accelerometer sensor probe will be utilized in the Rake test (Chapter 5.0) to obtain vibration data for the $\mathrm{C}-130$ ramp, which acts as the base platform for the system, during a light turbulence category for indicated airspeeds of 130 knots and 145 knots. The mid/low frequency values with worse case scenario magnitudes induced by buffeting, flutter, and gust loads will be computed and interpolated, accordingly.

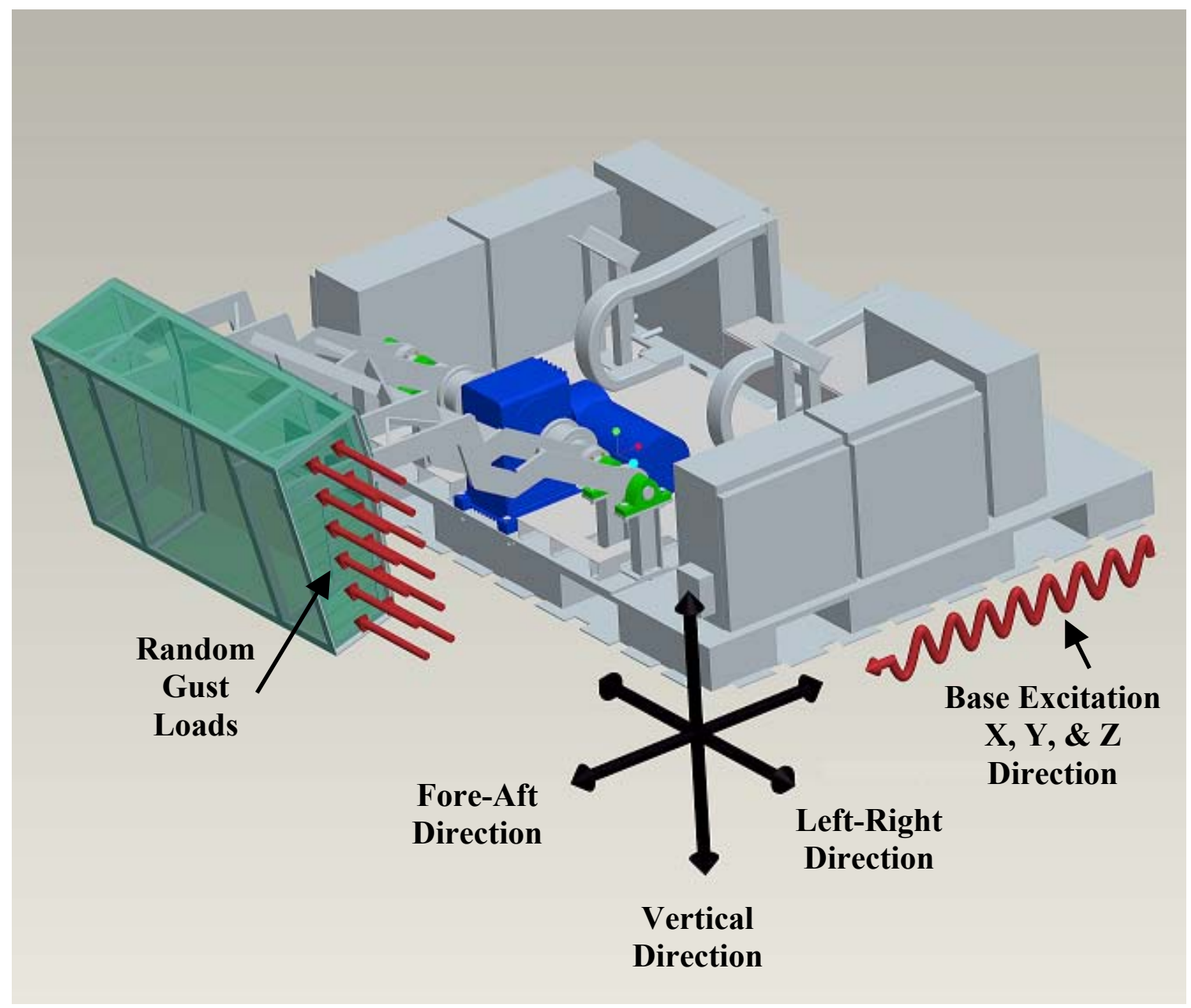

Figure 1.0e: Illustration of applicable base excitations from C-130 ramp transmitted throughout arm/pod system and random gust loads applied laterally to the system itself. 
Once a frequency range with assigned magnitudes is established, a formal vibration analysis will be conducted utilizing the Finite Element Method (FEM) and Modal Analysis with Pro-Engineer and Pro-Mechanica. The natural frequency modes for the mechanical arm/pod system will be computed in the $\mathrm{x}, \mathrm{y}$ and $\mathrm{z}$ directions with three different geometrical configurations of the structural cross-member supports. Modifying the structural cross-members will inherently affect the stiffness of the overall system, which in turn will vary the natural frequency range. Therefore, the goal is to design the mechanical arm/pod system as a function of mass and stiffness in order to increase or decrease the natural frequency of the system to ensure resonance occurs outside the general vibration profile generated from the Rake test and to ensure adequate dampening of the vibrations occurs within the sensors' vibration tolerance values to induce optimal performance. 


\subsection{Problem Identification}

This study addresses the issue of minimizing vibration resonance within the system as a function of mass and stiffness in order to control the natural frequencies and force them to remain outside the expected peak vibration frequencies derived from the rake experiment and approximated external, lateral gust loads for which the system will be subjected. Controlling the vibration will ensure the system will operate efficiently throughout its designed lifecycle without early fatigue as a product of resonance.

Initially, the vibration analysis of the mechanical system will be simplified by dividing it into two components, the arm and pod frame. A basic modal analysis will be conducted utilizing Pro-Mechanica to determine the characteristic mode shapes and natural frequencies. From this point, the stiffness and mass parameters of the arms will be optimized with cross-braces to adjust for the most favorable natural frequencies relative to the expected vibrations. Likewise, the stiffness and mass parameters of the pod frame will be optimized with plates and side panels (pod skin) to, again, reduce the displacement amplitudes caused by the expected vibration. Since the isolated sensor vibration plate's natural frequency was designed to resonate at $32 \mathrm{~Hz}$, the Pod's fundamental frequencies must sufficiently exceed this value (See Appendix D, figure 0-D \& 1-D). As a final analysis, the components will be assembled as a representative realistic model where, once more, a vibration analysis will be conducted to solve for reactions, mode shapes, and natural frequencies. 


\subsection{Introduction to Vibration}

Over the last 200 years, with the advent of relatively strong, lightweight materials such as steel, aluminum and titanium, and increased knowledge of material properties and structural loading, the mass of structures built to fulfill a particular function has decreased. For example, the efficiency of engines has improved and, with higher rotational speeds, the magnitude of the vibration exciting forces has increased. This process of increasing excitation while reducing structural mass and damping has continued at an increasing pace to the present day where few, if any, structures can be designed without carrying out the necessary vibration analysis, if their dynamic performance is to be acceptable. Thus, careful design and analysis is necessary to avoid resonance or an undesirable dynamic performance. [3]

Generally, a structure is defined as a combination of parts fastened together to create a supporting framework, which may be part of a building, ship, machine, space vehicle, engine or some other system. The vibration that occurs in most machines, structures, components and dynamic systems is undesirable, not only because of the resulting motions, the noise and the dynamic stresses which may lead to fatigue and failure of the structure or machine, but also because of the energy losses and the reduction in performance that accompany these vibrations. There have been several cases of systems failing or not meeting performance targets because of resonance, fatigue or excessive vibration of one component. Beards (1983) explicitly states, it is essential that a vibration analysis be carried out as an inherent part of the design process in order to eliminate vibration or at least reduce them to a tolerable amount. This process will be instrumental in the design of the mechanical arm's mass and stiffness parameters in order 
to adjust the natural frequencies to accommodate the external vibration load profile. This chapter provides a basic overview of analyses of vibrations and ways of producing solutions to general vibration problems in the design phase.

\subsection{Sources and Effects of Structural Vibration}

According to Beards (1983), there are two factors that control the amplitude and frequency of vibration in a structure: the excitation applied and the response of the structure to that particular excitation. Changing either the excitation or the dynamic characteristics of the structure will change the vibration stimulated.

A large percentage of the mechanical arm's vibration will arise from external sources such as ground or foundation vibrations transmitted throughout the C-130 fuselage and ramp from the four turbo-prop engines, and aerodynamic buffeting and flutter. These excitation forces and motions can be periodic or harmonic in time or random in nature, due to shock or impulse loadings.

The response of the structure to excitation depends upon the method of application and the location of the exciting force or motion, and the dynamic characteristics of the structure such as its natural frequencies and inherent damping level.

According to Bruel \& Kjaer (1982), a body is said to vibrate when it describes an oscillating motion about a reference position. The number of times a complete motion cycle takes place during the period of one second, called the frequency, and is measured in Hertz $(\mathrm{Hz})$. The motion can consist of a single component excited at a single frequency, as a tuning fork, or several components excited simultaneously. A diagnostic vibration analysis may be conducted by isolating the individual frequency components 
and graphing them with the vibration amplitude, a process known as the frequency spectrogram technique. When analyzing machine vibrations, engineers normally find a number of prominent periodic frequency components, which are directly related to the fundamental movements of various parts of the machine. By conducting such an analysis, researchers are able to track down the source of undesirable vibrations or alter the machine's overall reaction and displacement amplitudes caused by the excitation.

The primary goal of performing a structural vibration analysis is to calculate the natural frequencies of a structure and the response to the expected excitation. The data yielded from the analysis can determine whether or not a structure will fulfill its intended function and the results of the dynamic loadings acting on a structure can be predicted, such as the principle and von Mises stresses, fatigue life and noise levels. The integrity and usefulness of a structure can then be maximized and maintained. Additionally, from the analysis it can be made apparent which structural parameters most affect the dynamic response so that if an improvement or change in the response is required, the structure can be modified in the most economical and appropriate way. Very often the dynamic response can only be effectively controlled by changing the damping in the structure. There are many sources of damping in structures to consider and the ways of changing the damping using both active and passive methods require an understanding of their mechanisms and control. 


\subsection{Minimizing Structural Vibration}

Research indicates that the intensity of vibration can be managed by reducing either the excitation or the response of the structure to that excitation, or both. In the design phase the excitation forces or oscillatory motions may be reduced by changing the location of the structure or by isolating the structure with vibration isolators to prevent the transmission of vibrations to the structure. Additionally, the structural response can be altered by changing the mass or stiffness of the structure (see figure 3.2a), since the moment of inertia properties and the dynamic response are a function of the parameters.

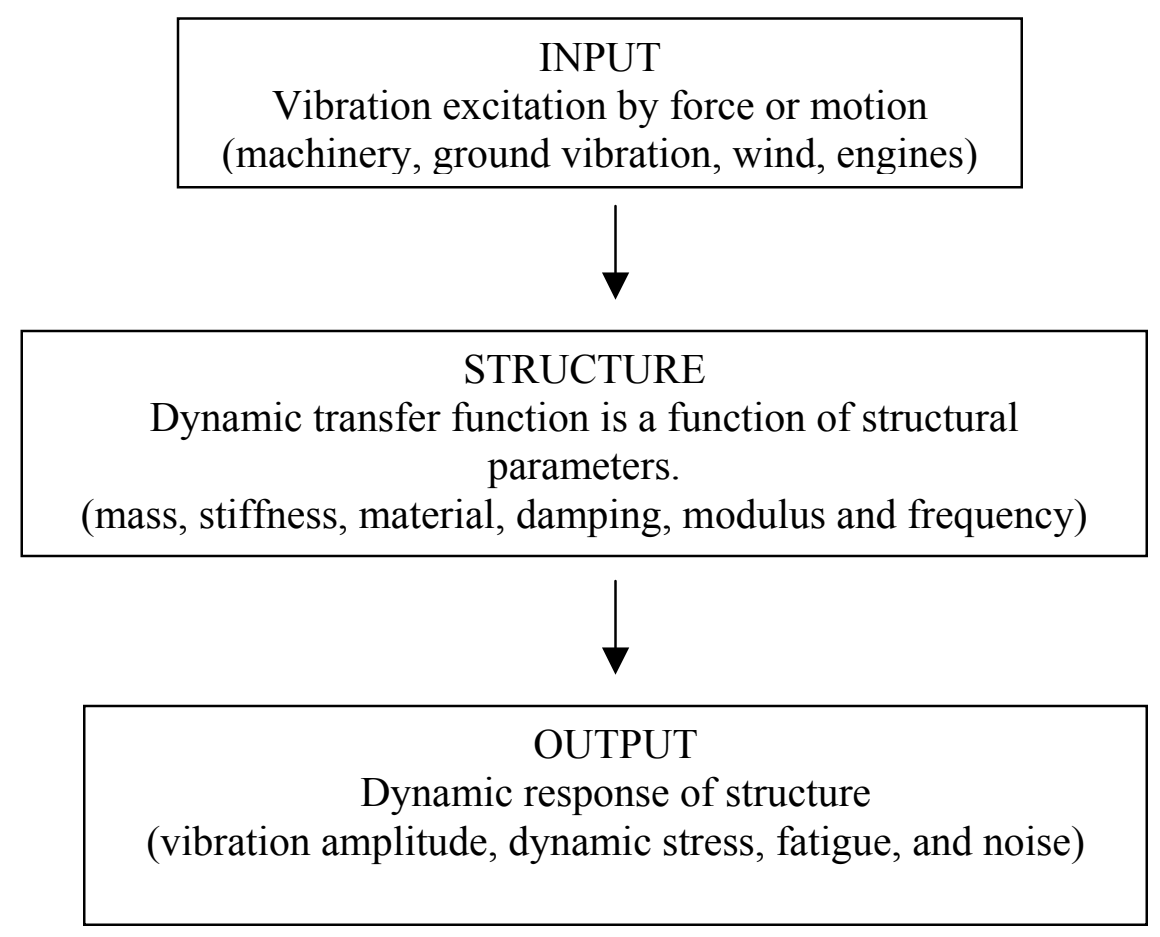

Figure 3.2a: Diagram of vibration sources and dynamic responses of structural systems [3]

For instance, if the natural frequency of a system needs to be increased, then simply reducing the mass $(\mathrm{m})$ or increasing the stiffness $(\mathrm{k})$ of the system (See figure $3.2 \mathrm{~b}$ ) will provide the increase. 


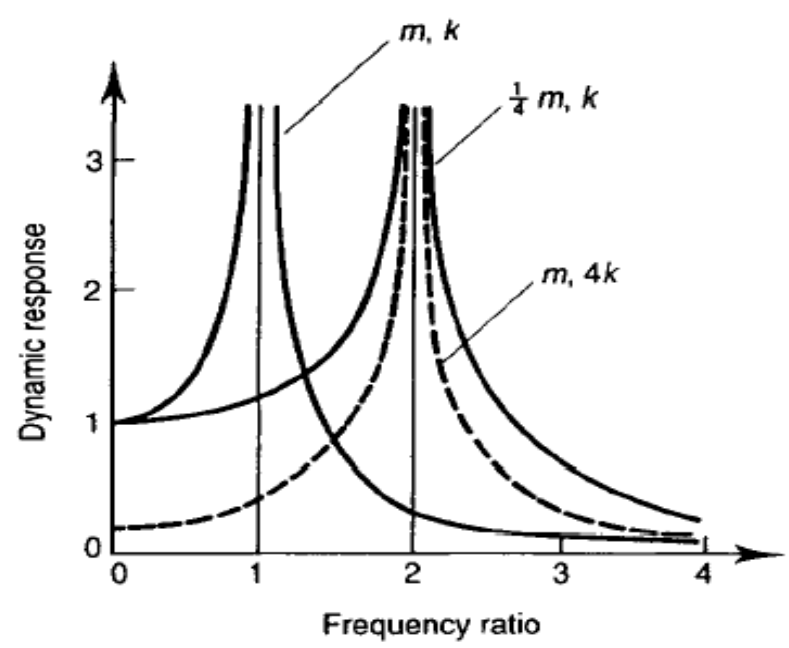

Figure 3.2b: Effects of mass and stiffness changes for dynamic response of a system [3].

There is a distinct trade off ratio between mass and stiffness; consequently, the increase in mass relative to distribution decreases a system's natural frequencies while the addition of stiffness increases the natural frequencies.

\subsection{Analysis of Structural Vibration}

The natural frequencies of a system must be computed and found, because if the system is excited at one of these natural frequencies, very high vibration-displacement amplitudes, dynamic stresses and noise levels will result. Thus, conducting a structural vibration analysis is imperative in order to predict the natural frequencies and the response to the anticipated excitation. Beards (1983) states accordingly, resonance should be avoided and the structure designed so that it is not encountered during normal conditions; this often means that the structure only needs to be analyzed over the expected frequency range of excitation. The vibration data compiled from the rake test (chapter 5) yielded an expected frequency range between $0-1200 \mathrm{~Hz}$. Consequently, the natural frequencies of the system's components studied will be solved for the lower, fundamental frequencies of this range. 
During the vibration analysis, it will be desirable to predict the location of nodes for multiple modes of frequency within the structure. The nodes are points with zero vibration or displacement amplitude and are therefore favorable locations for the mounting of sensitive equipment. Beards (1983) emphasizes an interesting fact that forces applied at one of the system's nodes cannot excite a particular mode of vibration. A mode of vibration is defined as the characteristic shape the model exhibits when excited at one of its natural frequencies, whether it is bending, torsion or elongation. A system is composed of many modes of vibration, dependent on mass, stiffness, geometry, thermal properties, and inertia. The quantity of modes defined within the analysis will be dependent on the range of the frequencies evaluated. The larger the frequency range, the larger the number of modes the computer must calculate.

Generally, a vibration analysis can be carried out most conveniently by adopting Beard's three-stage approach.

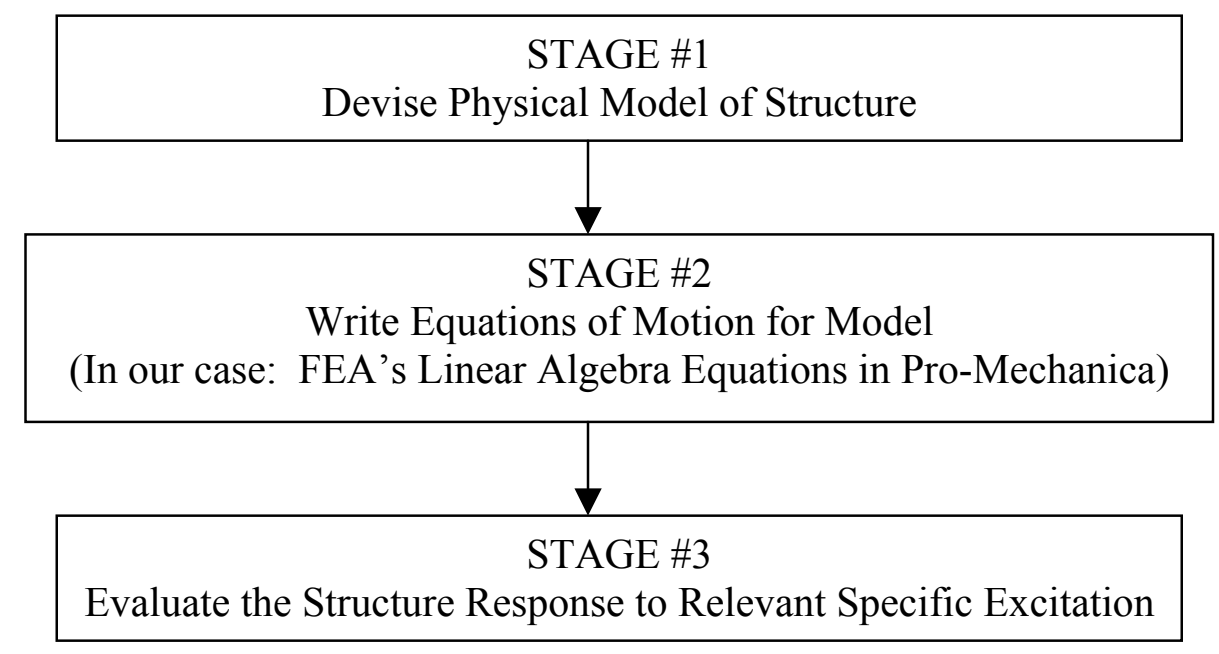

Figure 3.3a: Beard's 3-stage approach to structural vibration analysis [3]. 


\section{Stage \#1 The Mathematical Model}

Though it appears that analyzing the complete dynamic infrastructure of the system is the most practical approach, this usually leads to a very long and complicated analysis. A good engineer must always consider simplifying and reducing the complexity of the model in order to produce accurate results in the most economical way.

Beards (1983) states that all real structures possess an infinite number of degrees of freedom; that is, an infinite number of coordinates are necessary to specify completely the position of the structure at any instant of time. A structure possesses as many natural frequencies as it has degrees of freedom, and if excited at any of these natural frequencies a state of resonance will exist, yielding a very large amplitude vibration response. For each natural frequency the structure has a particular way of vibrating so that it has a characteristic shape or mode of vibration at each natural frequency. Fortunately, it is not usually necessary to calculate all the natural frequencies of a structure; this is because many of these frequencies will not be excited and in any case they may give small resonance amplitudes because the damping is high for that particular mode of vibration.

To model any real structure a number of simplifying assumptions can be made. For example, the effect of damping in the structure may be ignored, particularly if only resonance frequencies are needed or the responses required at frequencies are well away from a resonance. Additionally, forces and certain elements may be ignored if their effects are negligible.

Consequently, a compromised median must be sought between a simple representation that is easy to analyze but may not be very accurate and a complicated but more realistic model, which is difficult to analyze but gives more useful results. 


\section{Stage \#2 Equations of Motion}

Several methods are available for obtaining the equations of motion from the mathematical model, the choice of method often depending upon the particular model and personal preference. For example, analysis of the free-body diagrams drawn for each body of the model usually produces the equations of motion in a timely manner, but it can be very advantageous in some cases to use an energy method such as the Lagrange equation or the matrix method.

The matrix method for analysis is a convenient way of handling several equations of motion. Furthermore, specific information about a structure, such as its lowest natural frequency, can be obtained without carrying out a complete and detailed analysis. The matrix method of analysis is particularly important because it forms the basis of many computer solutions to vibration problems such as Pro-Mechanica's Finite Element Method (FEM) for modal/vibration analyses. From the equations of motion the characteristic or frequency equation is obtained, yielding data on the natural frequencies, modes of vibration, general response, and stability.

\section{Stage \#3 Response to Specific Excitation}

During the design process it is critical to understand the actual response of the structure to the environmental excitations. It is imperative to know and understand this response in order to determine such quantities as dynamic stress or noise for a range of force or motion inputs, including harmonic, step and ramp. This is achieved by computing the equations of motion with the excitation function present. 


\subsection{The Vibrations of Continuous Structures}

Continuous structures such as beams, rods, cables and plates can be modeled by discrete mass and stiffness parameters and analyzed as multi-degree of freedom systems. However, mass and elasticity cannot always be separated in models of real systems and therefore must be considered as distributed or continuous parameters. For the analysis of structures, with distributed mass and elasticity, it is necessary to assume a homogeneous, isotropic material that follows Hooke's law. [3]

Generally, free vibration is the sum of the principal modes. However, in the unlikely event of the elastic curve of the body in which motion is excited coinciding exactly with one of the principle modes, only that mode will be excited. In most continuous structures the rapid damping out of high-frequency modes often leads to the fundamental mode predominating. [3] 


\subsection{Theoretical Background}

Most physical structures or systems encountered in practical situations have distributed properties, such as mass and stiffness. Mass or inertial elasticity and damping are basic elements of any vibratory system. Mass permits an element within the body to transfer momentum to adjacent elements and elasticity exerts a force on displaced element to return to its equilibrium position. These systems involve an infinite number of degrees of freedom. However, an acceptable description of the motion of physical system may be made by considering the system as being composed of finite number of masses, which are interconnected by springs and dampers. [4]

The parameters and motion can be represented by the following equation:

$$
[\mathbf{M}]\{\ddot{\mathbf{x}}\}+[\mathbf{C}]\{\dot{\mathbf{x}}\}+[\mathbf{K}]\{\mathbf{x}\}=\{\mathbf{f}\}
$$

where,

$[\mathrm{M}]=\mathrm{N} x \mathrm{~N}$; mass matrix

$[\mathrm{K}]=\mathrm{N} \times \mathrm{N}$; stiffness matrix

$[\mathrm{C}]=\mathrm{N} \times \mathrm{N}$; damping matrix

$\mathrm{N}=$ number of degrees of freedom considered for description of dynamic system.

$\{\mathrm{x}\},\{\mathrm{x}\}$ and $\{\mathrm{x}\}$ are $\mathrm{N} \mathrm{x} 1$ acceleration, velocity and displacement vectors of each point in the system, respectively. Here equation (1) governs the inertia force, spring force and damping force acting on the system. [4]

From equation (3.5a) the response model is obtained as the frequency response function, $\mathrm{H}(\omega)$, or

$$
\mathbf{H}(\omega)=\{\mathbf{x}\} /\{\mathbf{f}\}=\mathbf{1} /[\mathbf{K}]+[\mathbf{C}] \omega-\omega^{2}[\mathbf{M}]
$$


Assuming an undamped system with free vibrations the normal or natural mode properties become,

$$
[\mathbf{K}]-\omega^{2}[\mathbf{M}]=\mathbf{0}
$$

This is for the condition that the solution exists in the form of,

$$
\{\mathbf{x}(\mathbf{t})\}=\{\mathbf{x}\} \sin (\omega \mathbf{t})
$$

Where equation $(3.5 \mathrm{c})$ is the eigen value problem which gives $\mathrm{N}$ eigen values and eigen vectors which are the natural frequencies and mode shapes of the structure. Equations (3.5a) \& (3.5c) yield the modal properties main natural frequencies and mode shapes of the structure, which are determined by the mass and stiffness properties of the structure.

According to Kalsule, Askhedkar, and Sajanpawar (1999), a harmonic response analysis is a technique used to determine the steady state response of a linear structure for the excitations due to the forces that vary sinusoidally, i.e. harmonically, with time. The idea is to calculate the structure's response at several frequencies representing the peak frequencies with the stresses reviewed at those peak frequencies. This gives the ability to predict the sustained dynamic behavior of the structure, which aids in verifying the reliability of the design of the structure and to successfully overcome resonance fatigue and other harmful effects of forced vibrations.

All the points in the structure are moving at the same known frequency, however not necessary in phase. From governing equation (3.5a) and the response function represented by equation (3.5b), the harmonic exciting force may be calculated by

$$
\{\mathbf{f}\}=\{\mathbf{F}\} \sin (\omega \mathbf{t})
$$

From equation (3.5e) we can write the response equation as

$$
\{\mathbf{x}\}=\{\mathbf{f}\} /\left([\mathbf{K}]-\omega^{2}[\mathbf{M}]+[\mathbf{C}] \omega\right)
$$


Equation (3.5f) represents that the displacement at any point for a given exciting force for any frequency can be predicted.

The Finite Element Method (FEM) analysis technique is used to compute the modal properties of the structure. Hence, it is necessary to perform an analytical modal analysis of the structure, which leads to the description of the structure's characteristics. 


\subsection{The Finite Element Method}

The Finite Element Method (FEM) is quite possibly the most important tool added to the mechanical design engineer's toolbox in the last 20 years, and can be used to obtain more accurate design computations in complex situations [5]. This process allows for improvements in both the design procedure and products. Many complex structures such as a ship hull, an engine crankcase or in our case the mechanical arm/pod system are too complicated to be analyzed by classical techniques and therefore an approximation method must be utilized. Beards (1983) states that breaking a dynamic structure down into a large number of substructures is a useful analytical technique, provided that sufficient computational facilities are available to solve the resulting equations. The finite element method (FEM) of analysis extends this method to the consideration of continuous structures containing a number of elements, connected to each other by conditions of compatibility and equilibrium. Complicated structures can thus be modeled as the aggregate of simpler structures.

The principle advantage of the FEM is its generality; it can be used to calculate the natural frequencies and mode shapes of any linear elastic system. However, it is a numerical technique that requires a large number of computer calculations and like any FEM, great care must be taken into considering the sensitivity of the computer output resulting from small changes in input.

For beam type systems the FEM is similar to the lumped mass method, because the system is considered to be a number of rigid mass elements of finite size connected by massless springs, similar to the engine and transmission assembly study [6]. The infinite number of degrees-of-freedom associated with a continuous system can thereby 
be reduced to a finite number of degrees of freedom, which can be examined individually.

The basic principles used in the FEM to formulate the mass and stiffness matrices are minimum potential energy, virtual work, etc. The Finite Element model is the mathematical idealization of real systems. Nodes, elements and boundary conditions are the best followers of the FEM to describe the real behavior of structures. The equation of motion for the Finite Element (FE) analysis can be written as,

$$
[\mathbf{M}]\{\ddot{x}\}+[\mathbf{K}]\{\mathbf{x}\}=\{\mathbf{f}\},
$$

where, $[\mathrm{M}]$ is the global structural mass matrix which can be described as,

$$
\mathbf{m}^{\mathrm{e}}=\int \rho \mathrm{N}^{\wedge} t \mathrm{~N} \mathbf{d v}
$$

and where $[\mathrm{K}]$ is the global structural stiffness matrix which can be described as,

$$
\mathbf{K}^{\mathrm{e}}=\mathbf{E}^{\mathrm{e} *} \mathbf{A}^{\mathrm{e} *} \mathbf{I}^{\mathrm{e} * \mathbf{B}^{\mathrm{T}} * \mathbf{B}}
$$

For these equations N, B, A, I are four (4) geometrically related parameters and p, E are the material properties of that structure.

For steady state conditions assuming $\mathrm{x}=\mathrm{X} \sin (\omega \mathrm{t})$, then

$$
[\mathbf{K}]\{\mathbf{X}\}=\omega^{2}[\mathbf{M}]\{\mathbf{X}\}
$$

where $\{\mathrm{X}\}$ is a vector of nodal amplitudes of vibration and $\omega$ is circular frequency.

Therefore, equation (3.6d) can be generalized by,

$$
[\mathbf{K}]\{\phi\}=\lambda[\mathbf{M}]\{\phi\} .
$$

Equation (3.6e) is the eigen value problem with $\lambda=\omega^{2}$ as an eigen value and $\phi$ is an eigen vector that can be solved by using different numerical algorithms. 
The FEM therefore consists of dividing the dynamic system into a series of elements by imaginary lines or tetrahedral elements, and connecting the elements only at the intersections of these lines. These intersections are called nodes or mesh nodes. However, this intersection should not be confused with the node used to describe a region with zero vibration of amplitude referred to in the vibration analysis section earlier. The stresses and strains in each element are then defined in terms of the displacements and forces at the nodes and the mass of the elements is lumped at the nodes. A series of equations is, consequently, produced for the displacement of the nodes and the system. By solving these equations the stresses, strains, natural frequencies and mode shapes of the system can be determined. The accuracy of the finite element method is greatest in the lower modes and increases as the number of elements in the model increases or the polynomial factor increases depending on which method is used, H-element or P-element convergence.

The Finite Element Package chosen for the vibrational analysis was Pro/MECHANICA, also referred to as Pro/M. What sets Pro/M apart from other FEA programs is that it uses the convergence of P-Elements instead of the classical HElements. The difference between these is that the $\mathrm{H}$ stands for the size of the element in the mesh, and the P stands for the order of polynomial in the interpolating equation. When using the H-element approach, the FEA program uses low order polynomials as the governing equations mentioned earlier, and for accurate results this requires that there be many elements. For example, strain is obtained by taking the derivatives of the displacement field and the stress are computed from the material strain. For a first order interpolating polynomial within the element, this means that the strain 
and stress components within the element are constant everywhere. This also means that if the elements are not small enough, errors will occur within the FEA. Also, areas with larger gradients will be very inaccurate because of the constant values through the elements. The means for solving this in the past was to use finer meshes so that the elements would be smaller, however the finer the mesh the greater the required computing power. This is due to the increased amount of equations from the increased amount of elements in the finer mesh. By using the method of mesh refinement, a convergence test could be done; but if the computing power is lacking, the user will never truly know if the test converged. [5]

The alternative to the H-element method is the P-element method, and this uses higher order interpolating polynomial equations. Therefore, instead of continually refining the mesh, the degree of the interpolating polynomial is increased until convergence is reached. This allows for the mesh to stay the same for each test, and uses far less interpolating equations. Pro/M allows for the order of the interpolating polynomial to reach as high as a ninth order. In most FEA software packages the mesh refinement method does work to reduce the errors. However, the amount of mesh refinements it would take to match the accuracy of the higher order P-element would involve an incredible amount of elements. This is why the P-element method is much easier and faster to use. [5] 


\subsection{Vibration Profile}

\section{Introduction}

The mechanical arm/pod system will be deployed from the rear of the C-130 aircraft in flight. The mechanical system will undergo two different foundations of vibrations. The first source considered would be the vibrations transmitted through the body or fuselage of the aircraft onto the ramp where the base of the actuating system will be mounted. These oscillations will be generated by the engines, flutter and buffeting of the aircraft structures and random clear air turbulence, which will act as base vibrations transmitted through the arm. These vibrations will consist of a wide range of frequencies from low to mid to high range vibrations. The second source of vibrational loads will come from the combination of direct pressure of the airflow at 130-145 knots and random horizontal wind gusts, which will be directly applied to the end of the appendage yielding large moments of bending stress. These will generally be in the lower to mid frequency range. This chapter outlines the diverse types of sources of forces and loads existing in the environment located outside the rear door of a C-130 aircraft traveling at 130-145 knots. 


\subsection{Aerodynamic Flutter, Buffeting and Vibroacoustics}

Alford and Knarr (1999) states that airframe vibration comprises three distinct areas: flutter and aero-elastic instabilities, dynamic loads and vibroacoustics. Flutter is characterized by the dynamically unstable elastic coupling of the airframe with the air stream and occurs primarily in the lowest frequency airframe elastic modes. Dynamic loads deal with the forced vibration resulting from buffeting, atmospheric turbulence, gust loads, landing impact, sharp maneuvers, and heavy store release; which additionally exist in the lowest frequency airframe elastic modes. Finally, vibroacoustics deals with the forced vibrations of the airframe in the higher frequency local modes as driven by jet noise, aerodynamic turbulence, unbalancing in rotating equipment, and propeller aerodynamic disturbances [7].

\section{1a Flutter}

Flutter is the dynamic instability of an elastic body in an airstream. Other than increased g-forces, flutter is the largest threat to the structural integrity of the system due to the harmonic nature of the load at low frequencies. If the mechanical arm and pod's

fundamental frequency (mode 1) was exited with the localized, self-sustaining and increasing flutter frequency; the displacement amplitude of the arm/pod component could propagate beyond the maximum elastic strain values causing a catastrophic failure from premature fatigue. 
Flutter speed (Uf) and the corresponding frequency (vf) are defined as the lowest airspeed and frequency at which a flying structure will exhibit sustained, simple harmonic oscillations.

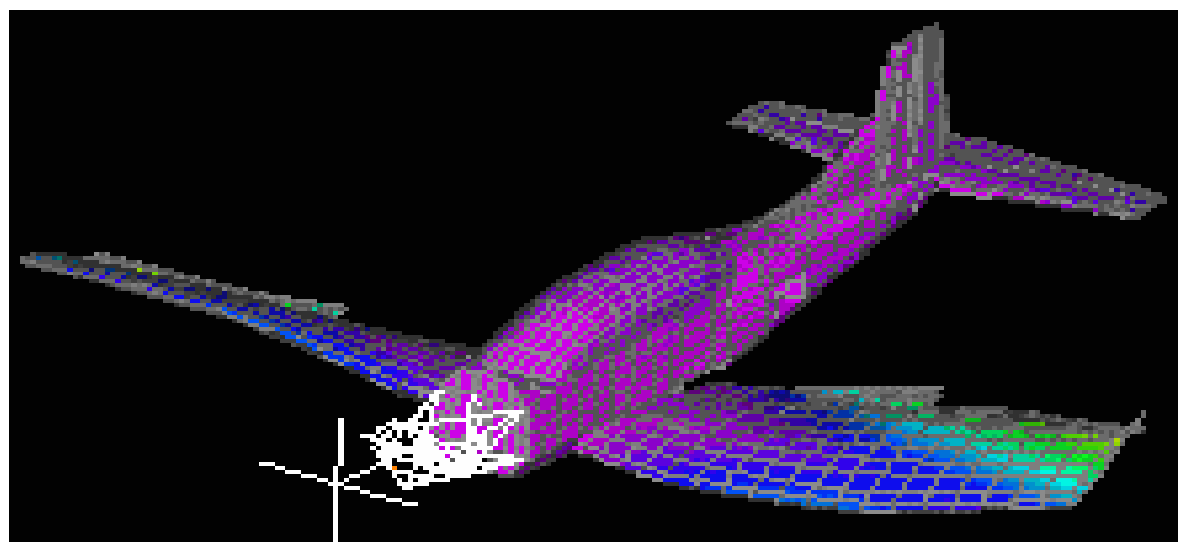

Figure 4.1a: Finite element analysis (FEA) of aircraft wing structure subjected to coupling from flutter [8].

In aircraft, a change to the general exterior, structural component or airflow about the skin may result in a degradation of performance in the aircraft or failure of a structure or component. Aircraft are designed such that their airframe flutter will occur at airspeeds and conditions outside the aircraft envelope or operational airspeed by a safety factor of 1.5 [7]. Modifications that change the vibrational modes of an aircraft cause the flutter speed to change, which in turn alters the aircraft envelope.

Interestingly enough, a direct correlation exists between frequency and structural stiffness. The frequency and airspeed, at which flutter occurs, typically increases with structural stiffness. Consequently, a vast increase in stiffness in a structural component changes the vibrational frequencies of that component; which may result in changes of frequencies of the overall mechanical system. A change in the natural frequency of the overall aircraft structure may produce premature fatigue by inducing flutter during normal operating speeds. 


\section{1b Buffeting}

Buffeting is the elastic structural response of the airframe in the lower frequency modes induced by aerodynamic flow separation or shed vortices.

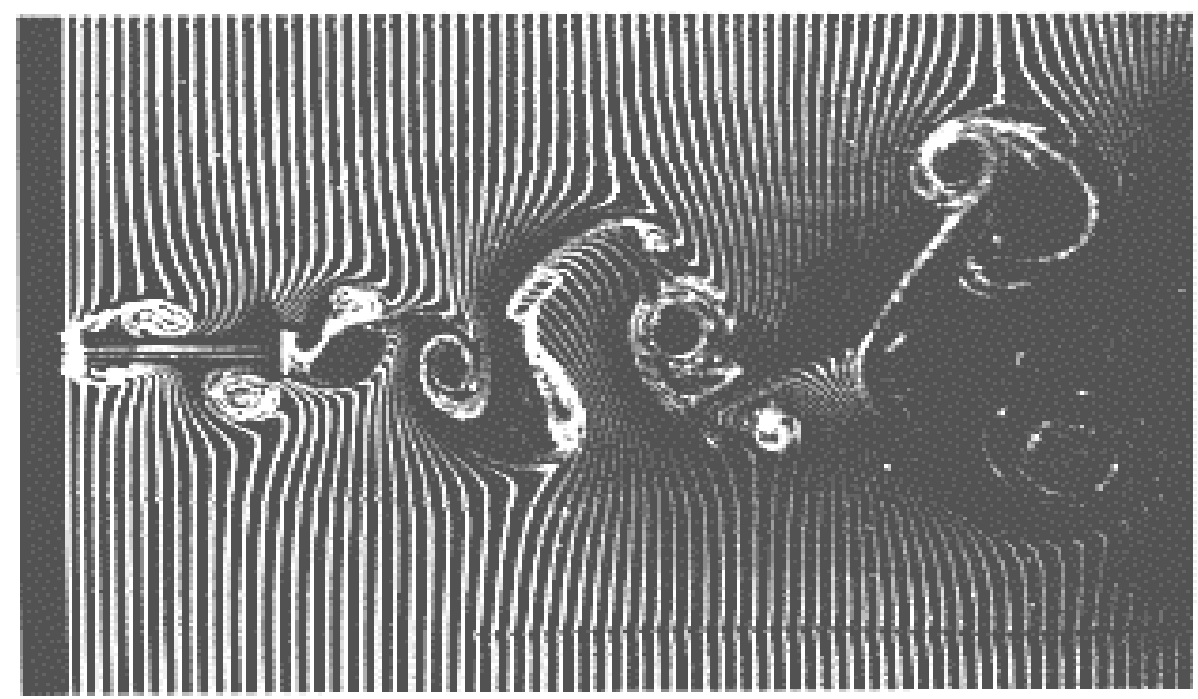

Figure 4.1b: Photograph of shed vortices or karmon street vortices produced by a blunt body in an airstream [9].

Flight surfaces (wings, tail surfaces, etc.) buffet due to the oscillating forces as flow separates and reattaches over local areas [7]. Additionally, buffeting occurs when surfaces downstream of flow separations are elasticity excited by the flow turbulence or shed vortices. Consideration must be taken into the design of the overall pod, pod skin and associated components to ensure buffeting is not excited at one of the system's natural frequencies. If excess buffeting occurs at the natural frequency or inside the 1.5 factor of safety parameter for the design loads, complications may occur such as: exceeded sensor vibration tolerance, propagation of mechanical looseness and early structural fatigue causing failure. 


\section{1c Vibroacoustics}

The third classification, vibroacoustics, is the elastic response of the higher frequency modes of the airframe to the boundary layer of turbulence, jet noise and other high-frequency load and pressure oscillations. According to Alfred and Knarr (1998) the primary source of vibration excitation in propeller aircraft is the pressure field that rotates with and flows aft of the propeller. High frequency vibrations can result in fatigue failure of structures, especially lightweight structures inserted directly into the slipstream such as the mechanical arm/pod structure.

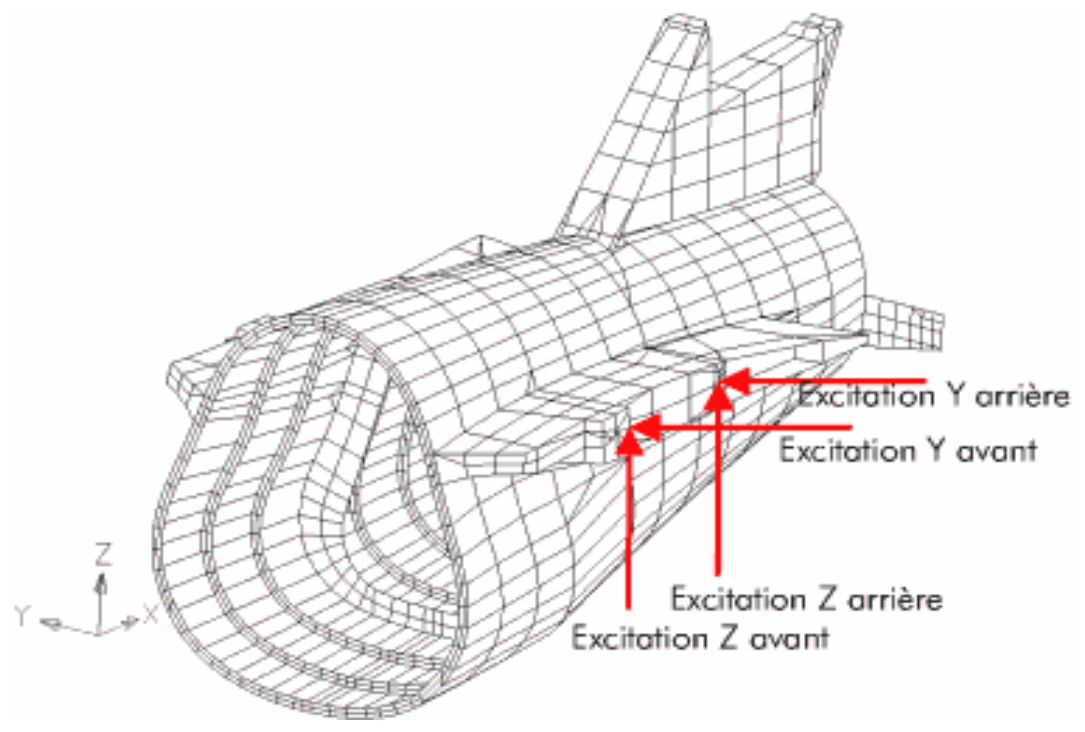

Figure 4.1c: Diagram of internal vibroacoustics in the high frequency range in a fixed wing-aircraft fuselage [10]. 


\subsection{Vibration Excitation by Atmospheric Turbulence}

In designing the mechanical arm/pod system, the engineer must take into consideration all-possible external forces produced by Mother Nature in order to formulate a worse case scenario for survivability and, since atmospheric turbulence is one of the main contributors to airplane vibrations, they will be thoroughly evaluated.

In general, atmospheric turbulence may be defined as irregular and instantaneous motions of air that are compiled from a number of small eddies that progress throughout the air current. These eddies are generated by relatively tight gradients which can either exist in the horizontal or vertical planes. According to the NASA Goodard Space Flight Center (1997) the greater the change in the magnitude and direction of the air current, the more rigorous the turbulence.

The Airman's Information Manual (1985), states that the atmosphere is considered turbulent when irregular whirls or eddies of air affect the motion of the aircraft and a series of abrupt jolts or bumps (g-forces) are felt by the pilot. Although eddies have a vast range of sizes and magnitudes in the atmosphere, those generating the greatest vibrations and deflections in the aircraft are those having equivalent sizes as the aircraft's dimensions and usually occur in a random sequence imparting sharp translation or angular motions to the aircraft's structure [20]. Additionally, the intensity of the disturbances to the aircraft varies not only with the intensity and frequency of the irregular motions of the atmosphere but is also a function of flight speed, weight stability and size. 


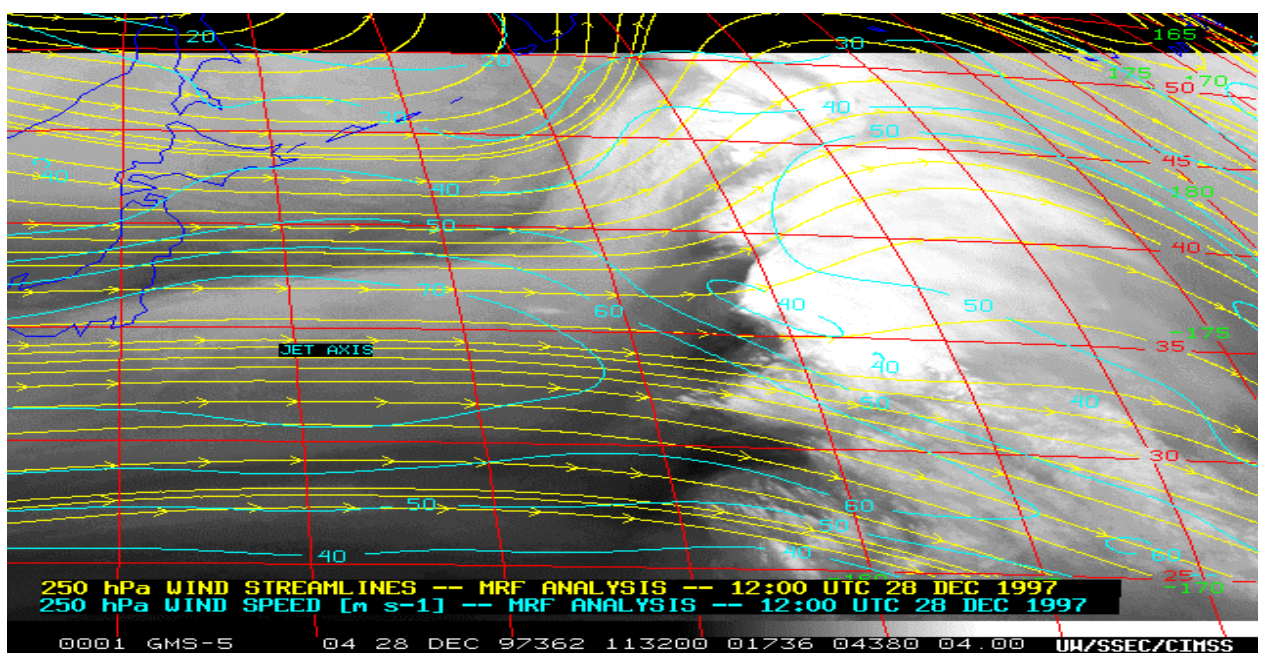

Figure 4.2a: Illustration of airstream flow generating severe turbulence in atmosphere [11].

As indicated by the NASA Goddard Space Flight Center (1997), turbulent flight conditions are often found in the vicinity of the jet stream where large shears in the horizontal and vertical planes propagate. Since this type of turbulence can occur without any visual warning, it is often referred to as clear air turbulence or CAT. Since the nature of project Oculus' mission is to seek and acquire ground/surface data through the use of sophisticated data acquisitions systems, the pilots will mostly fly in ideal weather conditions and will primarily be exposed to clear air turbulence. However, nature is unpredictable and therefore the system must be analyzed and designed within the most extreme vibration load profiles. Seventy-five (75) percent of high-level turbulence is found in a cloud-free atmosphere. A narrow zone of wind shear, with its accompanying turbulence, is often encountered when aircraft ascend or descend through a temperature inversion. Hoblit (1988) states that particular sources of CAT include wind shear, jet stream, wind over ground, wind over and between mountains and convection due to morning warming of air close to the ground, especially over the desert. 
Considering the nature of the versatile environmental conditions within the United States and as far south as Columbia, we must expect and design for all aspects and sources of clear air turbulence.

Additionally, studies have found that associated areas of steady updrafts and downdrafts may extend to heights from two (2) to twenty (20) times the height of the mountain peaks. Under these conditions when the air is stable, large waves tend to form and may extend one hundred fifty (150) to three-hundred (300) miles downwind from the source.

Table 4.2a: Wind Sheer CAT with a Wind Speed of 60 Knots or Greater

\begin{tabular}{|c|c|c|}
\hline & & \\
Horizontal Shear ( Naut / MI ) & Vertical Shear (Per 1,000 ft) & CAT Intensity \\
\hline $25 \mathrm{k} / 90$ & $9-12 \mathrm{k}$ & Moderate \\
\hline $25 \mathrm{k} / 90$ & $12-15 \mathrm{k}$ & Moderate - Severe \\
\hline $25 \mathrm{k} / 90$ & above 15k & Severe \\
\hline
\end{tabular}

According to the Airman's Informational Manual (1985) the classification and intensity of turbulence can be referenced to four standard classifications: extreme, severe, moderate and light (See table $4.2 \mathrm{~b}$ for Reaction of Turbulence).

Extreme turbulence is a rarely encountered condition, which is usually confined to the strongest forms of convection and wind shear such as the following: 
- Mountain waves in or near the rotor cloud, usually found at low levels, leeward of the mountain ridge when the wind normal to the mountain ridge exceeds fifty $(50)$ knots.

- In severe thunderstorms - it is more frequently encountered in organized squall lines than in isolated thunderstorms.

The second classification of turbulence, severe turbulence, is categorized when large, abrupt changes in altitude and variations in indicated airspeed take place. Severe turbulence may cause the aircraft to momentarily be out of control. Severe turbulence may also subsist in the following:

- In mountain waves:

- When the wind normal to the mountain ridge exceeds fifty (50) knots. The turbulence may extend to the tropopause and at a distance of one-hundred-fifty (150) miles leeward. A reasonable mountain wave turbulence layer is approximately five-thousand $(5,000)$ feet thick.

- When the wind normal to the mountain ridge is twenty-five (25) to fifty (50) knots, the turbulence may extend up to fifty (50) miles leeward of the ridge and from the mountain ridge up to several thousand feet. 
- Near jet streams within layers characterized by horizontal wind shears greater than forty (40) knots and vertical wind shears in excess of six (6) knots / onethousand $(1,000)$ feet.

Moderate turbulence is denoted when the forces exerted on the aircraft yield amplitudes of deflection that cause rapid bumps or jolts without appreciable changes in aircraft altitude. During missions, the deployed mechanical arm and pod system will generally be subjected to moderate and light turbulent excitation. Moderate turbulence may be found in the following:

- In mountain waves:

- When the wind normal to the mountain ridge exceeds fifty (50) knots. Moderate turbulence may be found from the ridgeline to as much as three-hundred (300) miles leeward.

- When the wind normal to the ridge is twenty-five (25) to fifty (50) knots, moderate turbulence may be found from the ridgeline to as much as one-hundred-fifty (150) miles leeward.

- Near jet streams and in upper level troughs, cold lows and fronts aloft where vertical wind shears exceed six $(6)$ knots / one-thousand $(1,000)$ feet or horizontal wind shears exceed ten (10) knots per one-hundred (100) miles.

- At low altitudes, usually below five-thousand $(5,000)$ feet, when surface winds exceed twenty-five (25) knots, or the atmosphere is unstable due to strong insulation or cold advection.

The more common class of turbulence, light turbulence, momentarily causes minute erratic changes in pitch, roll or yaw in the aircraft. Similar to moderate 
turbulence, light turbulence produces a lesser form of slight, rapid and rhythmic

bumpiness without appreciable changes in altitude. Light turbulence subsides in the

following areas:

- In mountainous areas with very light winds

- In and near the tropopause and cumulus clouds

- At low altitudes when winds are under fifteen (15) knots or the air is colder than the underlying surface

Table 4.2b: Turbulence Classification Table [12]

\begin{tabular}{|c|c|c|}
\hline Intensity & Aircraft Reaction & Reaction Inside Aircraft \\
\hline Light & $\begin{array}{c}\text { Causes slight, erratic changes } \\
\text { in altitude, pitch, roll or yaw } \\
\text { or } \\
\text { Causes rapid and rhythmic } \\
\text { bumpiness without appreciable } \\
\text { changes in altitude }\end{array}$ & $\begin{array}{l}\text { Occupants may feel a slight } \\
\text { strain against seat belts or } \\
\text { shoulder straps. Unsecured } \\
\text { objects may be displaced } \\
\text { slightly. }\end{array}$ \\
\hline Moderate & $\begin{array}{l}\text { Causes rapid bumps or jolts } \\
\text { without appreciable changes } \\
\text { in aircraft altitude }\end{array}$ & $\begin{array}{c}\text { Occupants feel definite strain } \\
\text { against seat belts or shoulder } \\
\text { straps. Unsecured objects are } \\
\text { dislodged. }\end{array}$ \\
\hline Severe & $\begin{array}{c}\text { Causes large, abrupt changes } \\
\text { in altitude and attitude. It } \\
\text { usually causes large variations } \\
\text { in indicated airspeed. Aircraft } \\
\text { may be momentarily out of } \\
\text { control }\end{array}$ & $\begin{array}{l}\text { Occupants are forced violently } \\
\text { against seat belts or shoulder } \\
\text { straps. Unsecured objects are } \\
\text { tossed about. Food service and } \\
\text { walking is impossible. }\end{array}$ \\
\hline Extreme & $\begin{array}{c}\text { Turbulence in which the aircraft } \\
\text { is violently tossed about and is } \\
\text { practically impossible to } \\
\text { control. It may cause } \\
\text { structural damage. }\end{array}$ & N/A \\
\hline
\end{tabular}




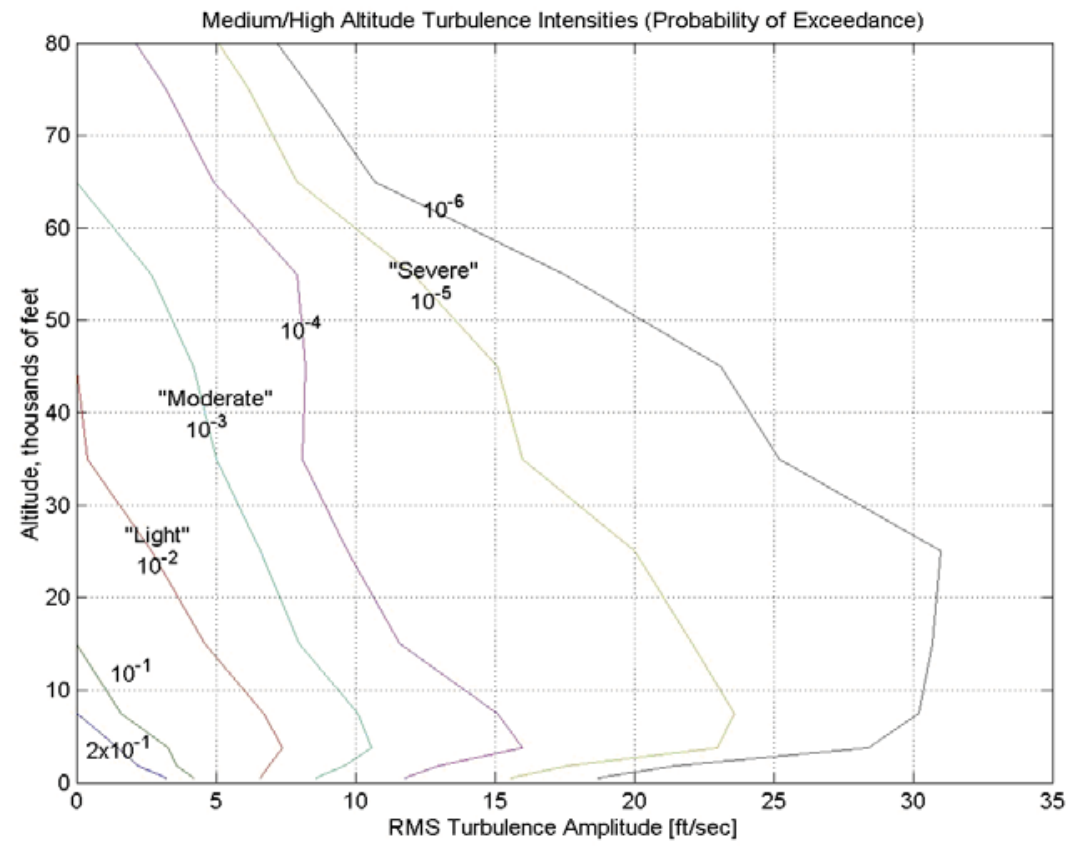

Figure 4.2b: Illustration of the effects of altitude turbulence intensities with altitude variation. [11]

Altitude ranges, encompassing project Oculus missions, are between 1,000 to 10,000 feet and therefore reemphasizes the fact that the most frequent turbulence applied to the mechanical system will be in the moderate-light range (See figure 4.2b).

Consequently, the mechanical arm/pod system will be designed to survive a $4 \mathrm{~g}$ turbulent force within its designated 1.5 factor of safety envelope. 


\subsection{Gust Loads on Aircraft and Appendages Due to Atmospheric Turbulence}

Gust Loads, whether due to discrete gusts or continuous turbulence, are ordinarily considered to be the result of a change in angle of attack due to a component of gust velocity at right angles to the flight path. Vertical and lateral gusts fall into this category. The change in angle of attack, in radians, is equal to the gust velocity divided by the forward speed [13]. (See figures 4.3a \& 4.3b)

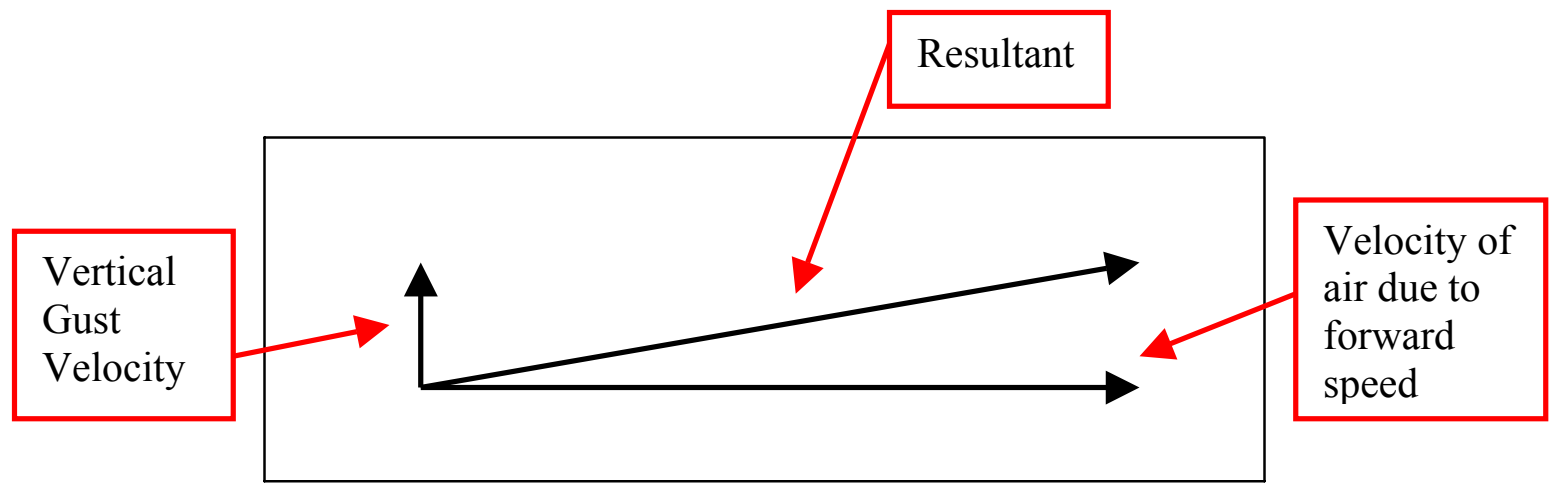

Figure 4.3a: Illustration of resultant force with components consisting of a vertical gust velocity and velocity of airflow due to forward speed.

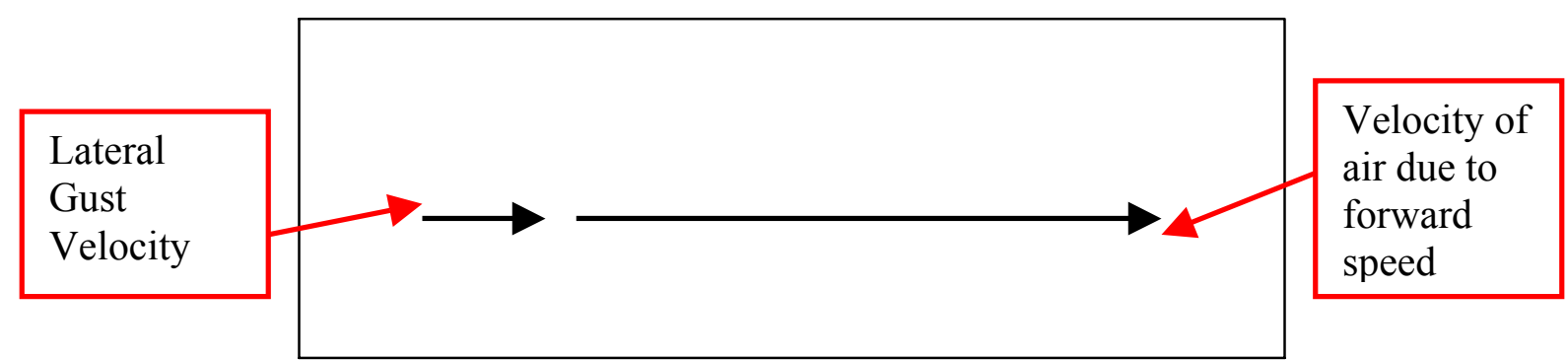

Figure 4.3b: Illustration of a lateral gust velocity combined with the velocity of airflow due to forward speed.

The vertical and lateral gust profiles tend to be continuous and irregular and are generally applied to the aircraft as isolated pulses in the low frequency range.

Additionally, atmospheric turbulence generated by gusts is isotropic or equivalent in all 
directions. Thus, along a given path through turbulence, the lateral and vertical gust profiles will share the same general characteristics, including identical peak values [13].

Typical laterally applied gust loads that may be exerted on the side-surface of the mechanical Arm/Pod system will probably not exceed 50 miles per hour in a med-low clear air turbulence profile and therefore a resultant impulse force may be calculated as follows (See Appendix D, figure 1-D for illustration of side-surface):

$$
\mathbf{F}=\text { Area } * \text { Pressure }=\mathbf{A} *\left(1 / 2 \rho * \mathbf{V}^{2}\right)
$$

Where $\mathrm{A}=3.58 \mathrm{ft}^{2}, \rho=0.00238 \mathrm{slugs} / \mathrm{ft}^{3}$ and $\mathrm{V}=73.33 \mathrm{ft} / \mathrm{sec}$ for variables in worse case scenario. Therefore,

$$
\mathrm{F}=3.58 *\left(0.5 * 0.00238 * 73.33^{2}\right)=\mathbf{2 2 . 9 0} \mathbf{~ l b}
$$

Thus, we can expect the mechanical Arm/Pod system to randomly absorb a $\mathbf{2 2 . 9 0} \mathbf{l b}$ lateral impulsive force, which is not extremely significant, but must be analyzed and accounted for, accordingly. 


\subsection{Rake Test}

Determining a good and reliable vibration profile for the environment or fixture for which the mechanical arm structure will be mounted is one of the most important elements in reducing and isolating vibration excitation and preventing premature fatigue. In order to better understand the vibrations on the C-130 aircraft a mechanical "rake" structure was designed and equipped with piezoelectric accelerometers and pitot tubes to measure the acceleration and vibration in the $\mathrm{x}, \mathrm{y}$ and $\mathrm{z}$ directions, and the velocity of the airflow around the C-130 ramp in flight (See figures 5.0a \& 5.0b). These vibrations will act as base excitations on the mechanical system.

Ideally, the mechanical arm system will be fastened to a customized 6.5-inch reinforced standard military $\mathrm{C}-130$ pallet, which will be the foundation and anchor for the arm. The pallet will then be locked and secured onto the C-130 ramp, making the plane and mechanical arm act as one rigid body leaving the arm with two degrees of freedom. Therefore, the rake's accelerometer will measure the vibration and acceleration of the C130 ramp and the pitot tubes will measure the airflow 12-16 inches below the C-130 ramp door in the open position (0-degrees) in flight at two indicated airspeeds of 130 knots and 145 knots. The results will be utilized to ensure the design and optimization of the overall mechanical arm's natural frequencies will be outside the power spectrum frequency range of the vibration profile found. This will generate minimal amplitudes of deflection in the principle $\mathrm{X}, \mathrm{Y}$ and $\mathrm{Z}$ directions and reduce the probability of early fatigue. 


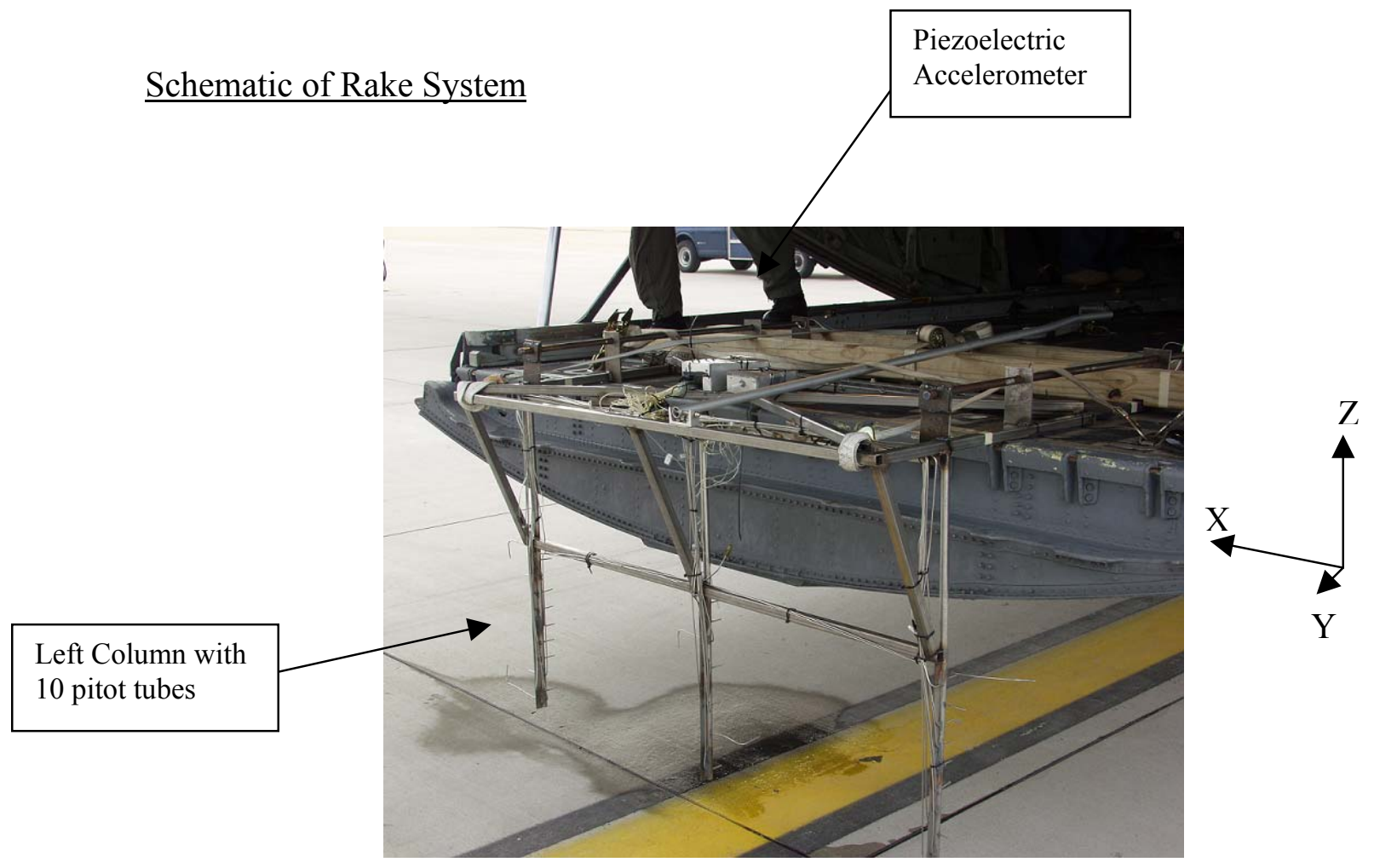

Figure 5.0a: Rake structure fully deployed on C-130 ramp in the opened position ( 0 degrees with horizontal). Each rake column consists of 7 pitot tubes facing directly into airflow and 3 pitot tubes facing perpendicular to airflow. One accelerometer is positioned in middle of the rakes cross members.

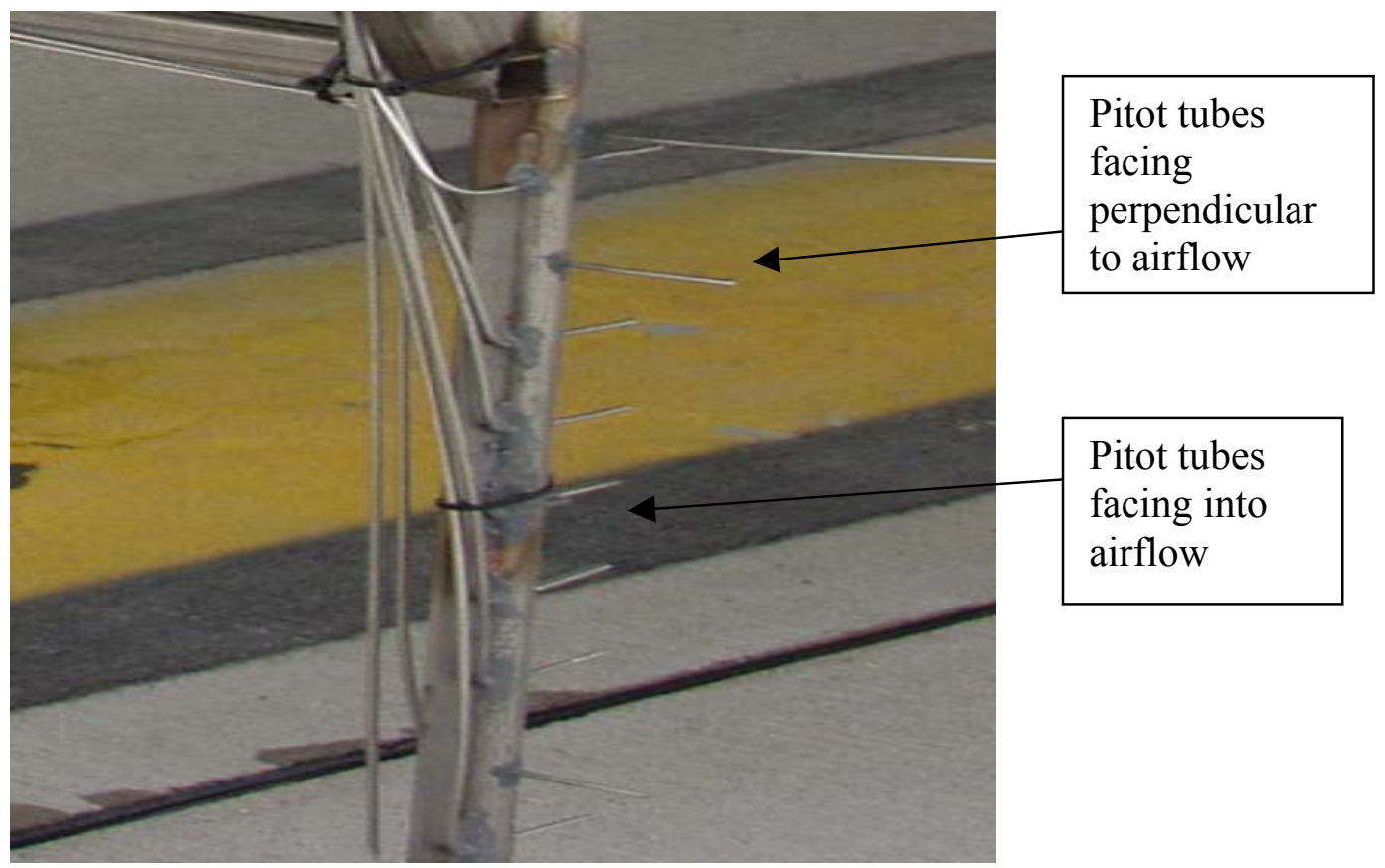

Figure 5.0b: Zoomed image of right column of the rake to illustrate distribution of pitot tubes. 


\subsection{Description of Rake and Data Acquisition Components}

Piezoelectric Accelerometer

The transducer, which is universally used for vibration measurements, is the piezoelectric accelerometer (See figure 5.1a). It has very wide frequency and dynamic ranges with good linearity throughout the ranges and it is relatively robust and reliable so that its characteristics remain stable over a long time period. Additionally, the piezoelectric accelerometer is self-generating, thus it doesn't need a power supply. Its acceleration proportional output can be integrated to give velocity and displacement proportional signals. The heart of the piezoelectric accelerometer is the slice of piezoelectric material, an artificially polarized ferroelectric ceramic, which exhibits the unique piezoelectric effect. When the material is mechanically stressed, either in tension, compression or shear, it generates an electrical charge across its pole faces, which is proportional to the applied force. [14]

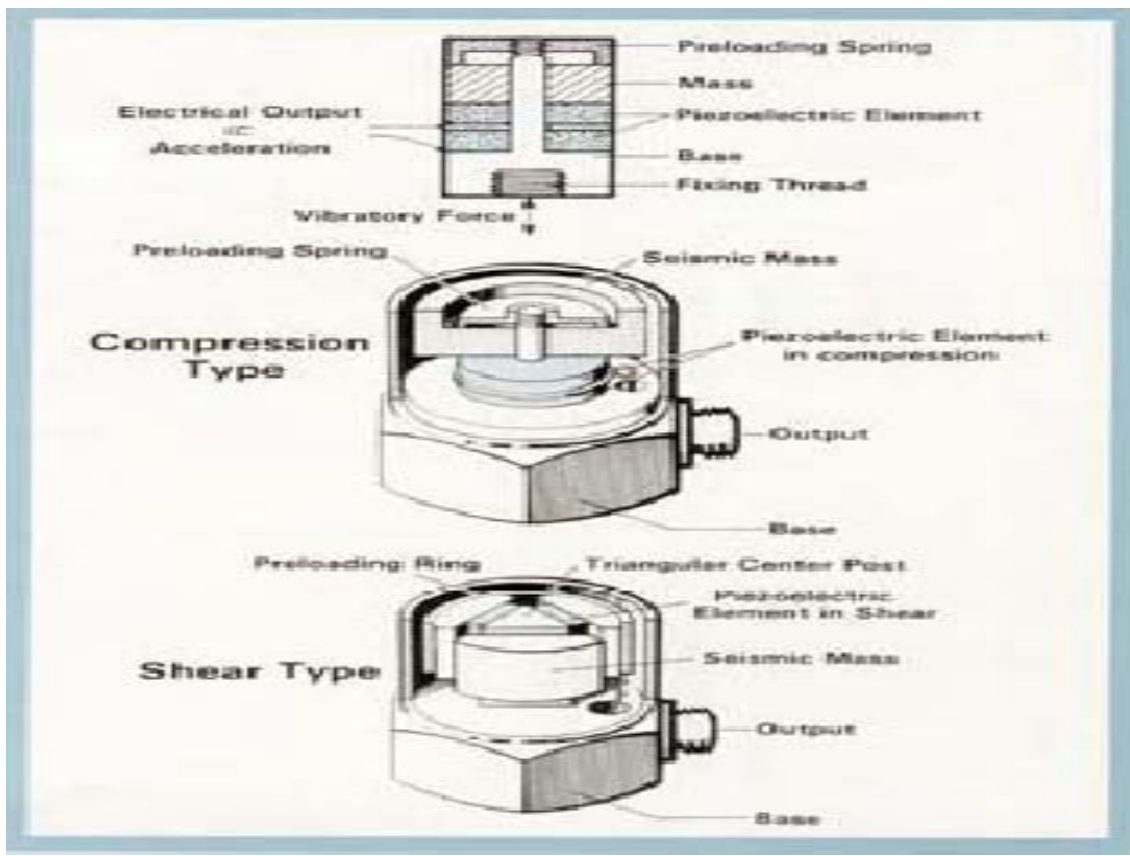

Figure 5.1a: Tension, compression and shear piezoelectric accelerometers. [14] 
Pitot Tubes

Pitot tubes are utilized in aircrafts for measuring the airspeed of the plane. The Pitot tube measures a fluid velocity by converting the kinetic energy of the flow into potential energy (See figure 5.1b). The conversion takes place at the stagnation point, located at the Pitot tube entrance. A pressure higher than the free stream or dynamic pressure results from the kinematic to potential conversion. The pitot tube designed and utilized on the rake test had several small holes drilled around the outside of the tube and a center hole drilled down the axis of the tube. The outside holes are connected to one side of a device called a pressure transducer. The center hole in the tube is kept separate from the outside holes and is connected to the other side of the transducer. The transducer measures the difference in pressure in the two groups of tubes by measuring the strain in a thin element using an electronic strain gauge. The pitot tube is mounted on the aircraft such that the center tube is always pointed in the direction of travel and the outside holes are perpendicular to the center tube. [14]

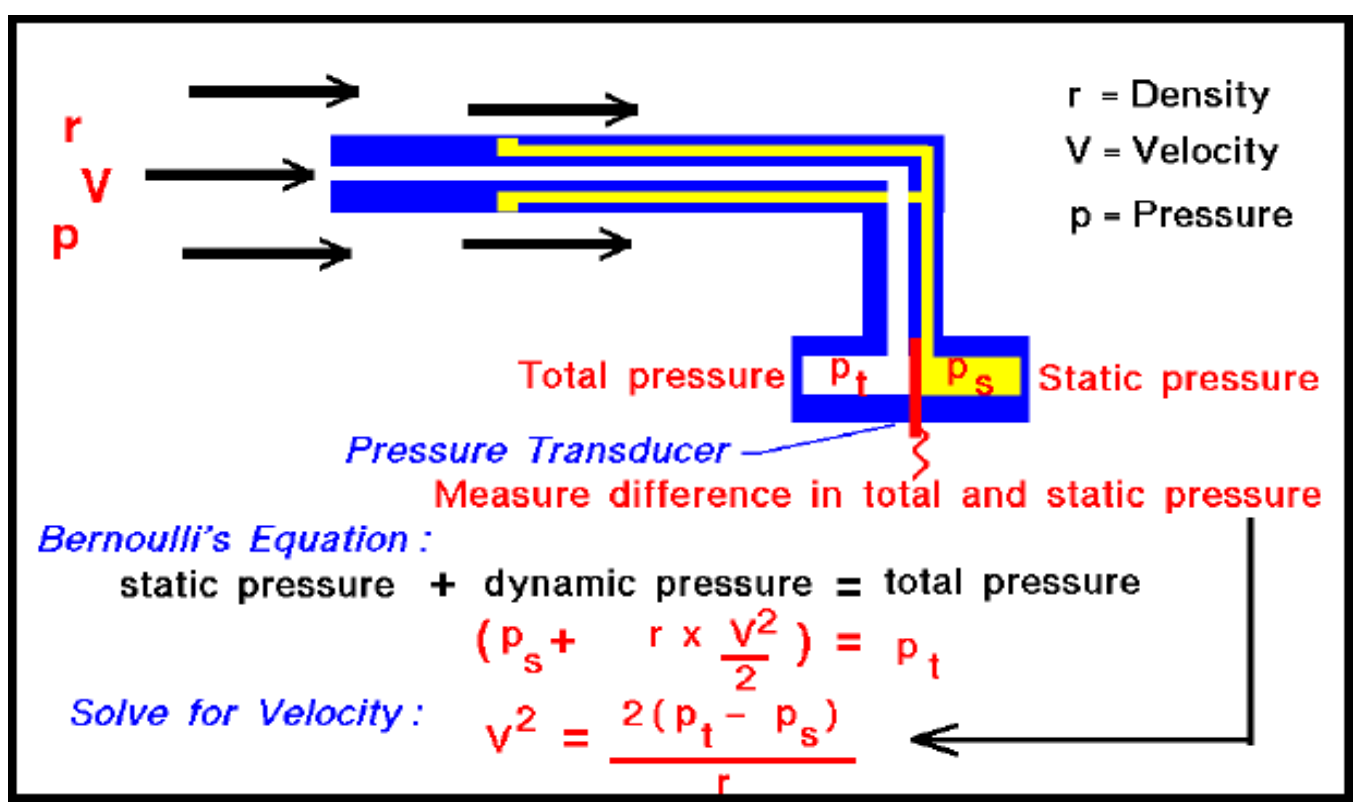

Figure 5.1b: Schematic of Pitot tube and pressure transducer [14]. 


\section{Fast Fourier Transform (FFT)}

A signal or function can be viewed from two different standpoints:

- The time domain

- The frequency domain

The one, which is most familiar, is the time domain. This is like the trace on an oscilloscope where the vertical deflection is the signal's amplitude, and the horizontal deflection is the time variable. The second representation is the frequency domain. This is like the trace on a spectrum analyzer, where the horizontal deflection is the frequency variable and the vertical deflection is the signal's amplitude at that particular frequency. Any given signal can be fully described in either of these domains. [15]

Developed by Tukey and Cooley in 1965, the fast Fourier Transform is simply a mathematical algorithm that transforms a function from the time domain and converts it into a frequency spectrum in the frequency domain. Consequently, a fatigue analysis can be performed in the frequency domain based on the stress response [16].

The frequency domain of the function will yield different representations of the data being analyzed, thus the Fourier transform frequency domain contains exactly the same information as that of the original function; they differ only in the manner of presentation of the information [17]. The fast Fourier Transform, in essence, decomposes or separates a waveform or function into sinusoids of different frequency which sum to the original waveform. It identifies or distinguishes the different frequency sinusoids and their respective amplitudes and thus the data can be described in terms of the power spectral density values [18]. The General FFT equation is governed by: 


$$
\mathbf{X}(\mathbf{k})=\sum_{n=0}^{N-1} X(n) e^{-\mathbf{j} \mathbf{2} \pi \mathbf{n} / \mathbf{N}}, \quad \mathbf{n}=\mathbf{0}, \mathbf{1}, \ldots, \mathbf{N}-\mathbf{1}
$$

where, $\omega=\mathbf{e}^{-\mathrm{j} 2 \pi \mathrm{n} / \mathrm{N}}$

In applying the FFT, we often consider only real functions of time whereas the frequency functions are, in general, complex. Thus, a single computer program in this case Matlab can be written to determine the fast Fourier Transform algorithm by the following equation [19]:

$$
\mathbf{H}(\mathbf{n})=\mathbf{1} / \mathbf{N} \sum_{K=0}^{N-1}[h r(K)+j h i(K)] \mathbf{e}^{-\mathbf{j} \mathbf{2} \pi \mathbf{n} / \mathbf{N}}
$$




\subsection{Test Procedures and Analysis}

Procedure

The Rake test took place at the West Virginia Air National Guard $130^{\text {th }}$ Airlift Base in Charleston, WV where a C-130 Hercules military aircraft was employed to conduct the vibration data acquisition sequence. The aircraft was flown in optimal atmospheric conditions in a straight path at a constant altitude of $1000 \mathrm{ft}$ at two different airspeeds, 130 knots and 145 knots. The goal was to obtain vibration data for the C-130 ramp in the open position while being subjected to the vibrations for the two airspeeds. Once the plane converged on a straight, steady path, the C-130 ramp door was opened halfway (45 degrees to the horizontal) position to allow for proper and safe manual deployment of the rake with minimal aero-resistant force. Once the rake was completely actuated and secured, the ramp was lowered to the horizontal position (See figure 5.2a).

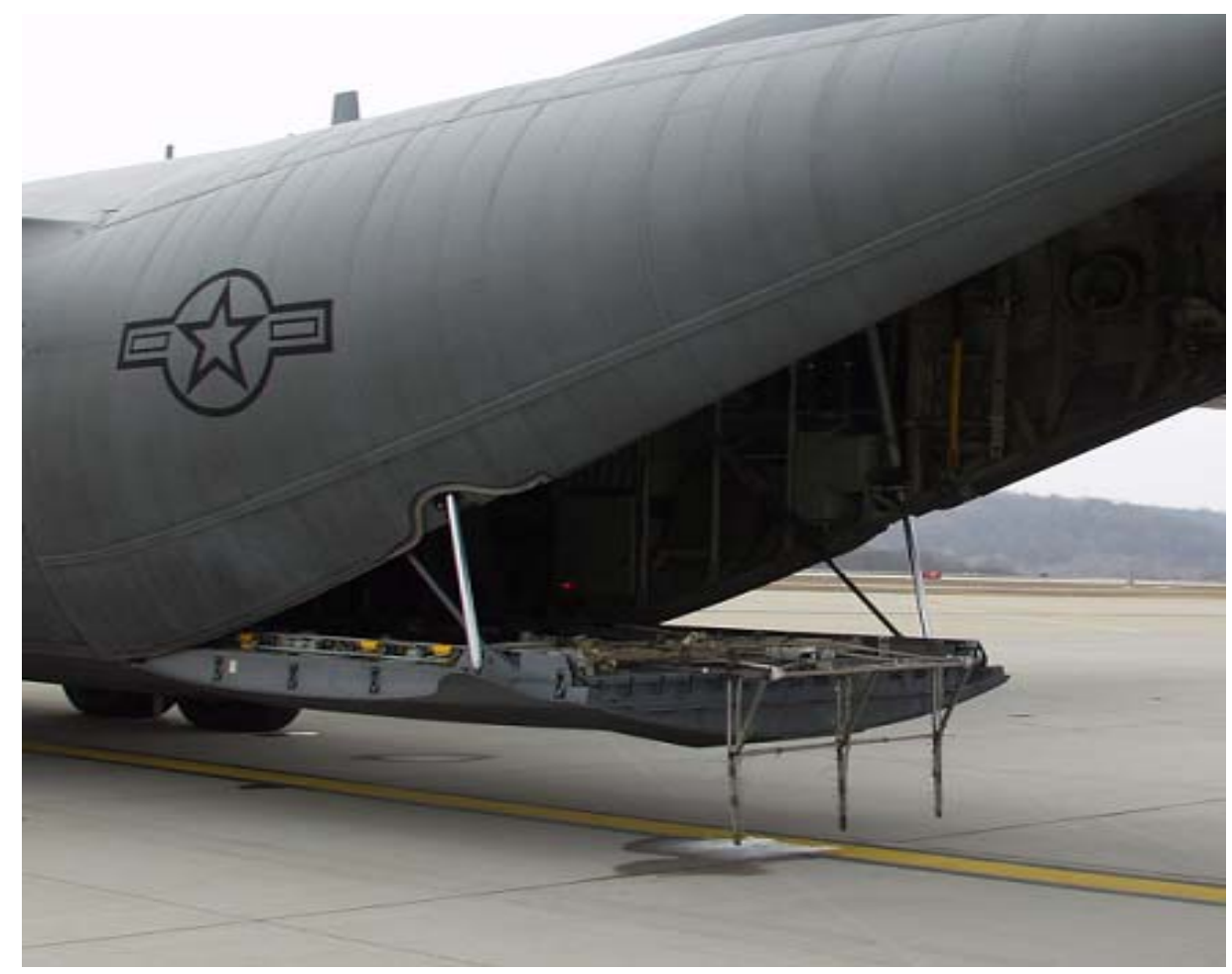

Figure 5.2a: C-130 ramp in the fully opened position or horizontal position ( 0 degrees from the horizontal). 
From this point, after the plane converged on the first initial test velocity of 130 knots, data acquisition initiated with three (3) tests consisting of one minute time intervals for each test. When completed, the plane increased the airspeed to the second test velocity of 145 knots. Again data was collected in three (3) tests, recording in one-minute time intervals (See table 5.2a).

Table 5.2a: Components and Test Schematic for C-130 Rake Test

\begin{tabular}{|c|c|c|c|c|}
\hline Rake Test Elements & Quantity & $\begin{array}{c}\text { Velocity Test 1 } \\
\text { (knots) }\end{array}$ & $\begin{array}{c}\text { Velocity Test 2 } \\
\text { (knots) }\end{array}$ & Positions of interest for C-130 Ramp \\
\hline C-130 Hercules Aircraft & 1 & 130 & 145 & Open (0 deg in Horizontal) \\
Piezoelectric Accelerometer & 2 & & & \\
Pitot Tubes & 21 & 3 Tests & 3 Tests & \\
Q-Basic Software & 1 & & & \\
Rake Frame & 1 & 1 minute each & 1 minute each & \\
Mat lab (FFT) & 1 & & & \\
Excel & 1 & & & \\
Dell Laptop Computer & 1 & & & \\
\hline
\end{tabular}




\subsection{Results}

The raw data from each test for the two velocities, 130 knots and 145 knots, was collected and stored as Microsoft Excel Comma Separated Values (csv) files using a laptop computer. The data varied as a function of time, thus the initial presentation of the data was in the time domain and was graphically illustrated as time vs. acceleration. Once viewed from that perspective, the data was entered into Matlab software where an FFT was applied to convert and present the data in the frequency domain. The FFT produced the results in a power spectral density graph, which plotted the frequency vs. power $^{¥}$. This illustrates the occurrence of the discrete, individual frequencies with respect to power. Consequently, the 3 tests from test 1 (130 knots) were averaged together for each $\mathrm{X}, \mathrm{Y}$ and $\mathrm{Z}$ direction, and the 3 tests from test 2 (145 knots) were averaged together for each X, Y and Z direction using Matlab software (See Figures 5.3a $-5.3 f)$.

\footnotetext{
${ }^{¥}$ Note: For a List of Complete Results See Appendix A
} 


\section{TEST 1}

(Average combination of 3 tests for 130 knots)

Left-Right Motion

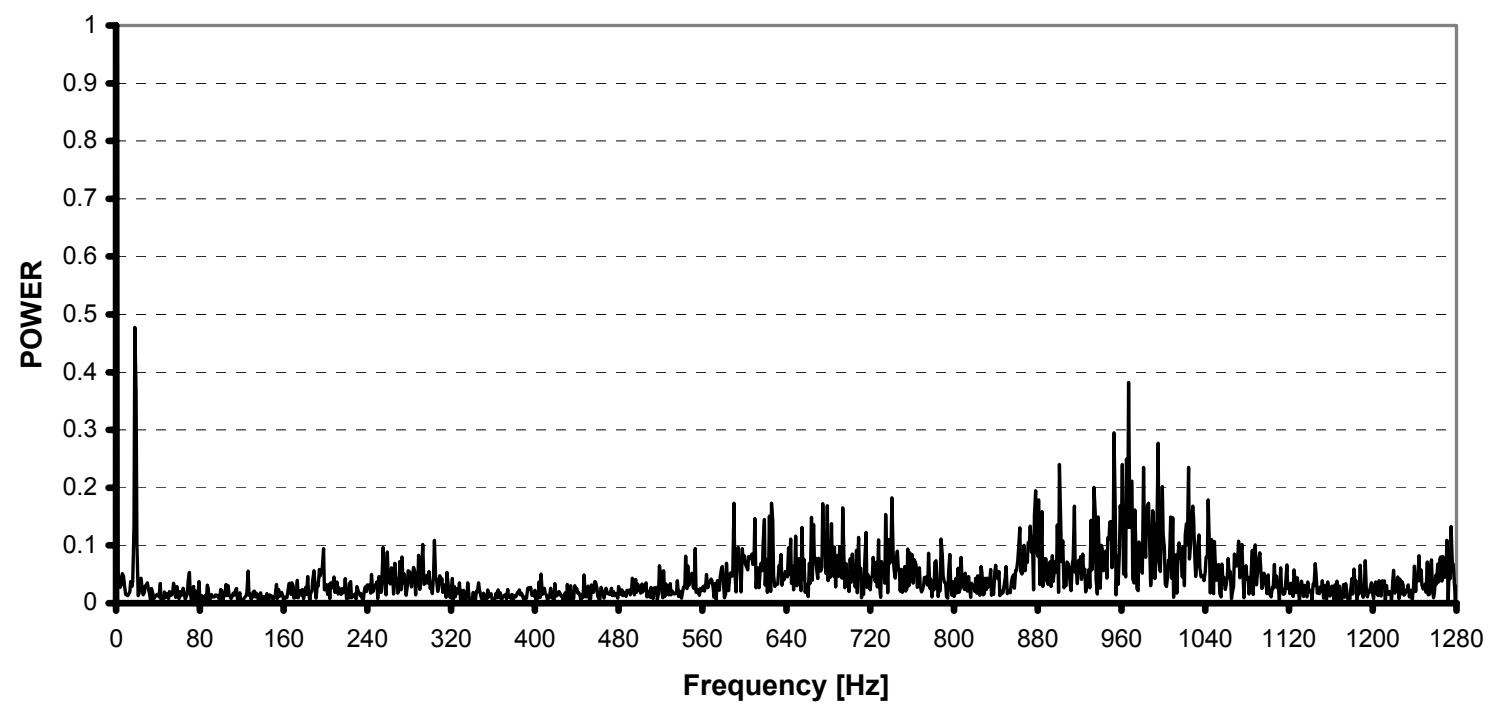

Figure 5.3a: Normalized frequency power spectrum of vibrations in the right-left motion for velocity of 130 knots. Peak values occur at $18 \mathrm{hz}$ and $967 \mathrm{hz}$.

Fore-Aft Motion

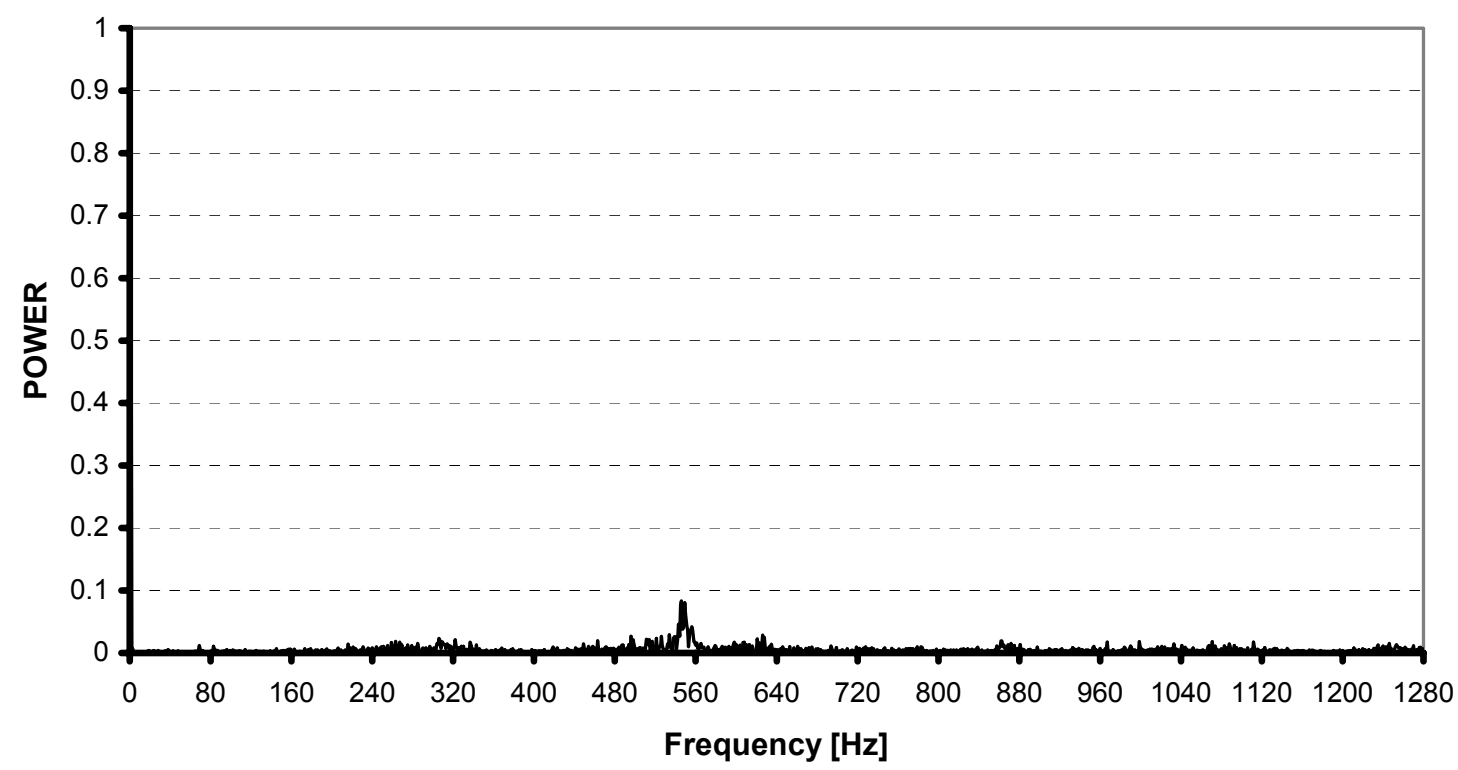

Figure 5.3b: Normalized frequency power spectrum of vibrations in the fore-aft motion for velocity of 130 knots. Peak value occurs at $549 \mathrm{hz}$ with negligible power levels. 
Up-Down Motion

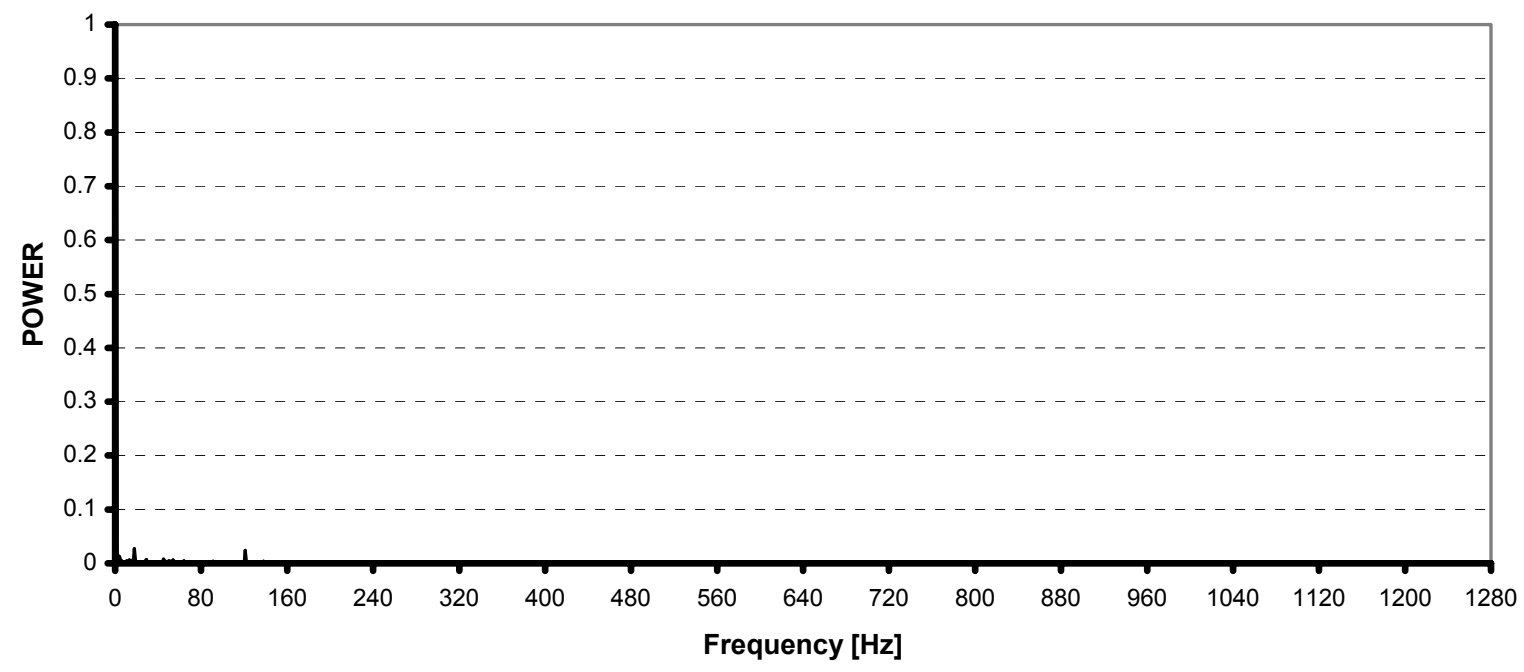

Figure 5.3c: Normalized frequency power spectrum of vibrations in the up-down (vertical) motion for velocity of 130 knots. Peak value occurs at $18 \mathrm{hz}$ with negligible power levels.

\section{$\underline{\text { Test } 2}$}

(Average combination of 3 tests for 145 knots)

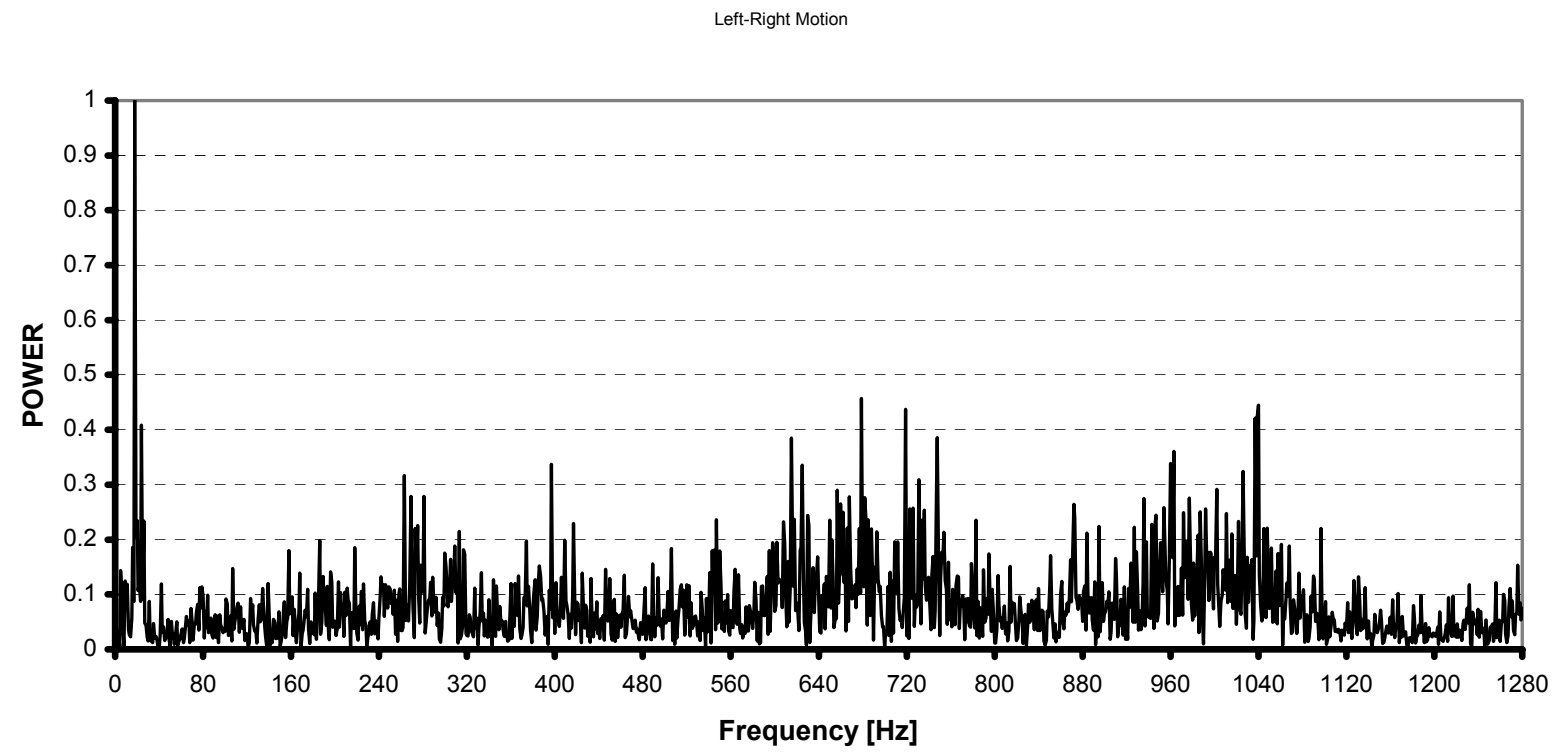

Figure 5.3d: Normalized frequency power spectrum of vibrations in the left-right motion for velocity of 145 knots. Peak values occur at $18 \mathrm{hz}, 679 \mathrm{hz}$ and $1040 \mathrm{hz}$. 


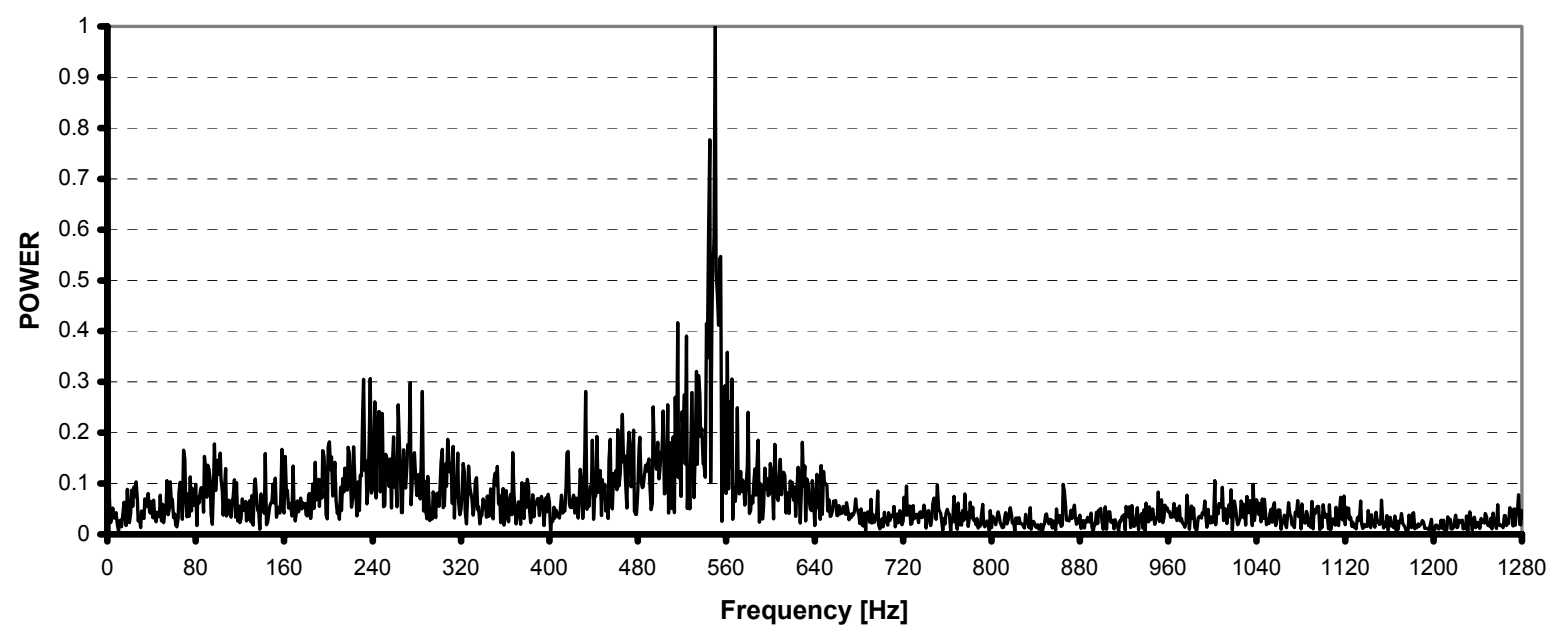

Figure 5.3e: Normalized frequency power spectrum of vibrations in the fore-aft motion for velocity of 145 knots. Peak values occur at $238 \mathrm{hz}$ and $550 \mathrm{hz}$.

Up-Down Motion

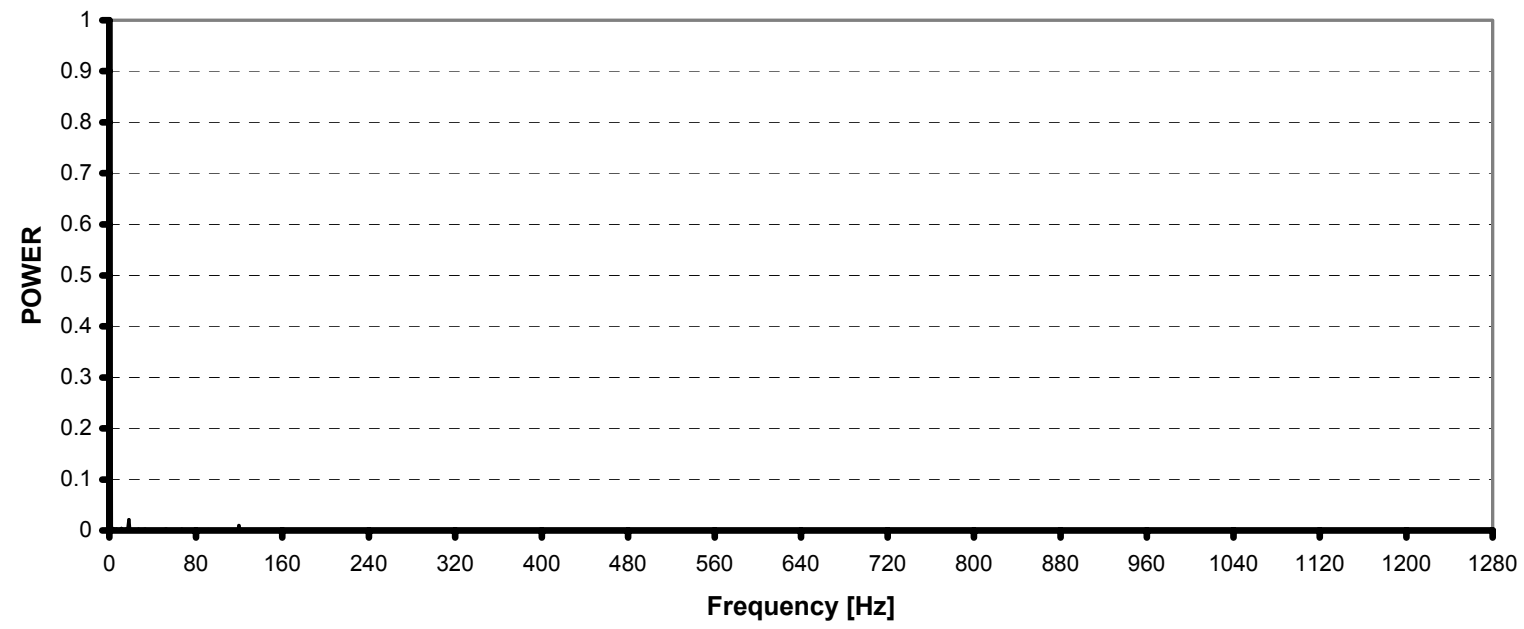

Figure 5.3f: Normalized frequency power spectrum of vibrations in the up-down motion for velocity of 145 knots. Peak values occur at $18 \mathrm{hz}$ with negligible power levels. 


\subsection{Conclusions}

Based on the results from the frequency power spectrum, the system will be subjected to a base excitation in the left-right motion in the lower frequency range of $18 \mathrm{~Hz}$ for both flight envelopes 130 and 145 knots, respectively. Furthermore, the mechanical arm/pod system will foresee fore-aft base vibrations in the mid-high frequency range of $550 \mathrm{~Hz}$. Finally, the up-down motion of the C-130 ramp yields very small vibrations during the indicated flight operations and may be considered negligible.

Since the displacement amplitudes caused by the oscillations in the lower to mid frequency range influence the most impact on stress and early fatigue, the mechanical system's mass and stiffness parameters will be optimized to produce natural frequencies outside these frequency values. 


\subsection{Dynamic Modal Analysis of Mechanical Arm/Pod System}

As previously discussed, the natural frequencies and modal shapes of the mechanical arm/pod system must be computed, analyzed and designed accordingly as to prevent harmonic resonance from occurring during operation. The two key parameters, which account for the modal adjustments, are the mass and stiffness variables of the structure. These variables will be incrementally increased and decreased correspondingly.

\section{Procedure}

Once the mechanical system is modeled in Pro/ENGINEER, Pro/MECHANICA will be utilized to conduct three (3) modal analysis studies. The first study will consist of the four (4) arms tied together by three different geometrical cross-braced configurations. By varying the mass and stiffness of the structure, a more robust product may be developed for the anticipated vibrations. The second test will focus on the sensor pod. Initially, the pod frame's vibration properties will be analyzed, then the addition of a $1 / 2$ inch plate and 1/8-in side panels will be assembled onto the pod and analyzed with the increased mass and stiffness parameters. The natural frequencies of the Pod must be greater than the designed natural frequency of the isolated sensor vibration plate of $32 \mathrm{hz}$. Finally, the third test will be similar to the first text, except it will consist of both arm and the modified pod assembled together into a complete system. This model will determine the most realistic natural frequencies, nodes and modal shapes. First, the Arm/Pod system will be composed of the arms tied together with the center cross-brace. Secondly, the Arm/Pod system with center cross-brace will undergo the addition of V-braces 
fastened in between the outer and inner mechanical arms. (See Table 6.0a for a list studies).

The Natural Frequencies and mode shapes of the systems and components close to the $18 \mathrm{~Hz}$ peak (Right-Left Motion) from the Rake test will be extracted and further analyzed for resonance and overall system optimization. Additionally, the first four (4) fundamental frequencies and mode shapes for the pod frame and modified pod frame in study \#2 will be inspected to ensure resonance is greater than $50 \mathrm{~Hz}$, since the sensor plate will be isolated at $32 \mathrm{~Hz}$ with a low pass filter.

The materials utilized for all components will be Aluminum 6061 T-6 (See Table 6.0b for material properties). Pro/MECHANICA's modal analysis FEA package will solve for the first ten (10) natural frequencies and modal shapes for each study.

Table 6.0a: List of multiple components and systems to be analyzed with corresponding properties.

\begin{tabular}{|c|l|c|c|c|}
\hline Study & \multicolumn{1}{|c|}{ Component } & Modeled & Analysis & Mass (Ibm) \\
\hline 1 & A) Arm w/no bracing & Pro/ENGINEER & Pro/MECHANICA & $1.34 \mathrm{e}+02$ \\
& B) Arm w/center cross-brace & Pro/ENGINEER & Pro/MECHANICA & $1.45 e+02$ \\
& C) Arm w/ center cross-brace \& V-braces & Pro/ENGINEER & Pro/MECHANICA & $1.48 \mathrm{e}+02$ \\
\hline 2 & A) Pod Frame & Pro/ENGINEER & Pro/MECHANICA & $6.13 e+01$ \\
& B) Pod Frame w/ 1/2in plate and 1/8in side panels & Pro/ENGINEER & Pro/MECHANICA & $1.48 e+02$ \\
\hline 3 & A) Arm/Pod System w/ center cross-brace \& pod skin & Pro/ENGINEER & Pro/MECHANICA & $2.32 e+02$ \\
& B) Arm/Pod System w/ center-brace, v-braces \& pod skin & Pro/ENGINEER & Pro/MECHANICA & $2.35 E+02$ \\
\hline
\end{tabular}

Table 6.0b: Material properties of Al 6061-T6 which apply to all components and systems.

\begin{tabular}{|c|c|c|c|c|c|}
\hline \multicolumn{5}{|c|}{ Aluminum 6061-T6 } \\
\hline $\begin{array}{c}\text { Density } \\
\text { (Ib/in^3) }\end{array}$ & Brinell Hardness & $\begin{array}{c}\text { Ultimate Tensile Strength } \\
\text { Yield Tensile Strength } \\
\text { (psi) }\end{array}$ & $\begin{array}{c}\text { Shear Strength } \\
\text { (psi) }\end{array}$ & Modulus of Elasticity & Poisson's Ratio \\
$(\mathrm{ksi})$ & \\
\hline 0.0975 & 95 & 45000 & 40,000 & 29700 & 10000 \\
\hline
\end{tabular}


For simplicity, during the modal analysis the arm components will be constrained in the $\mathrm{x}, \mathrm{y}$ and $\mathrm{z}$ directions at the inner surface of the shaft hole and the pod frame will be constrained at the surface of the 4 arm offsets. These constraints represent realistic behavioral values for the mechanical system under environmental conditions.

\section{Study \#1}

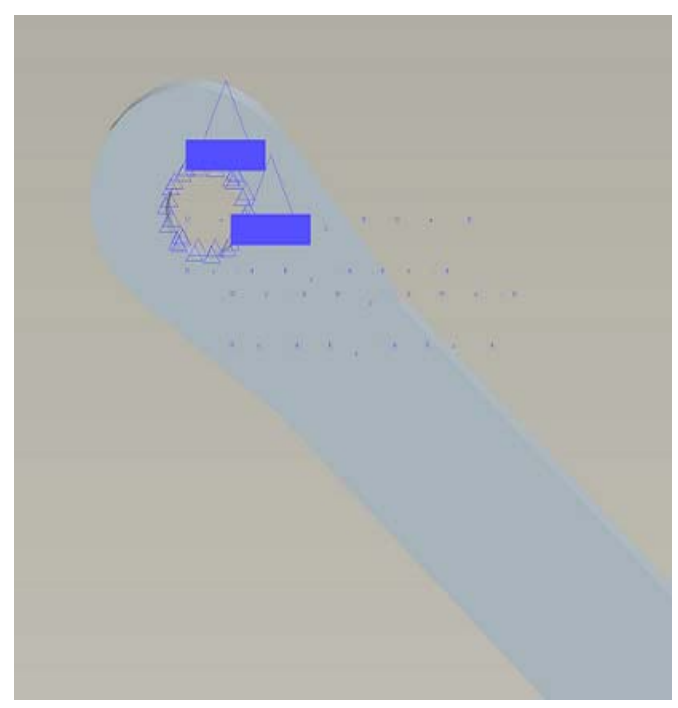

Figure 6.0a: Illustration of $\mathrm{X}, \mathrm{Y} \& \mathrm{Z}$ constraints on surface of inner shaft whole for each arm

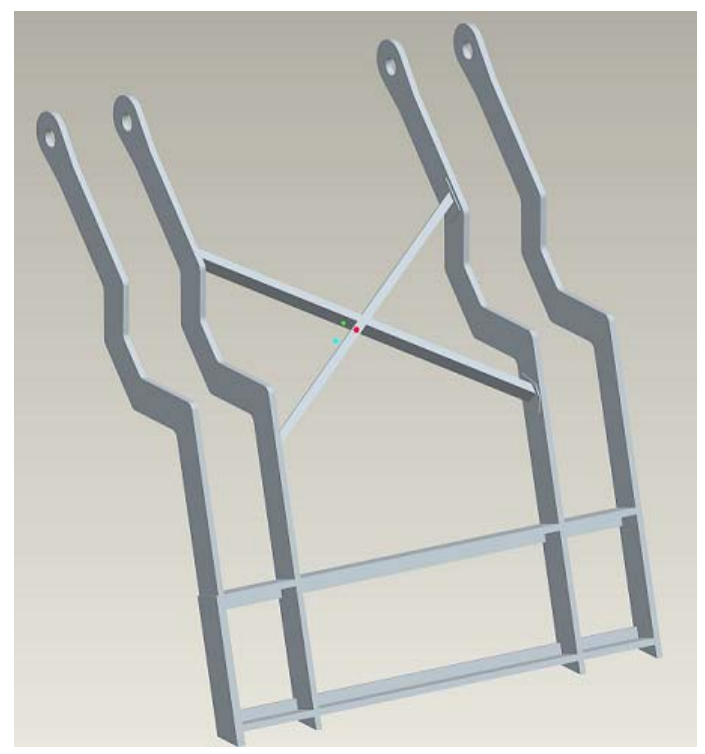

Figure 6.0c: Study \#1 Part (B): Arm with Center Cross-Braces

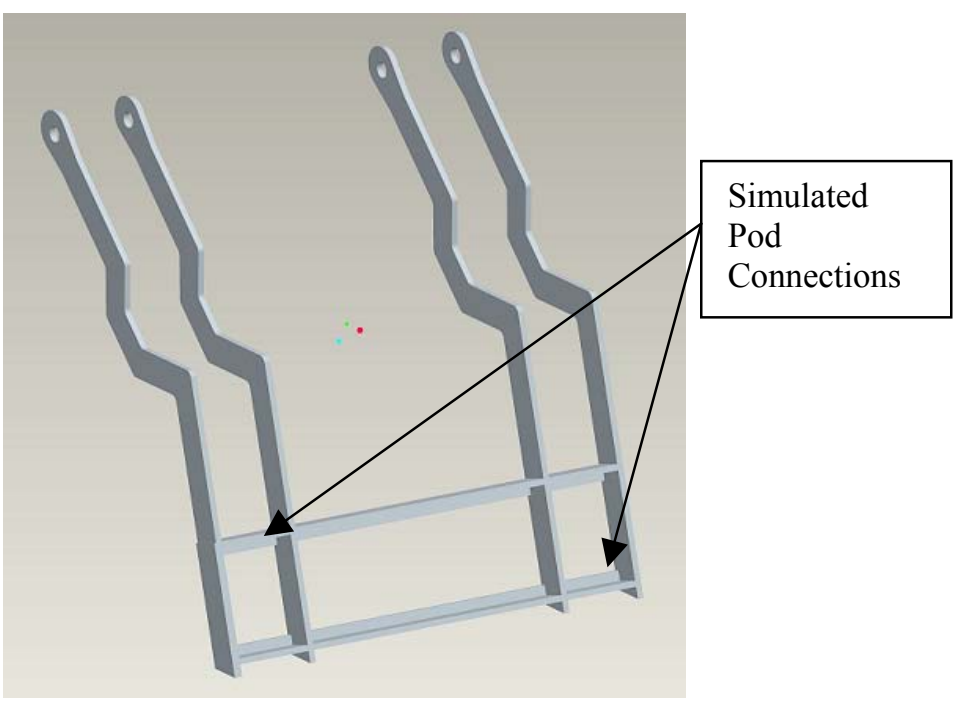

Figure 6.0b: Study \#1 Part (A): Arm without braces.

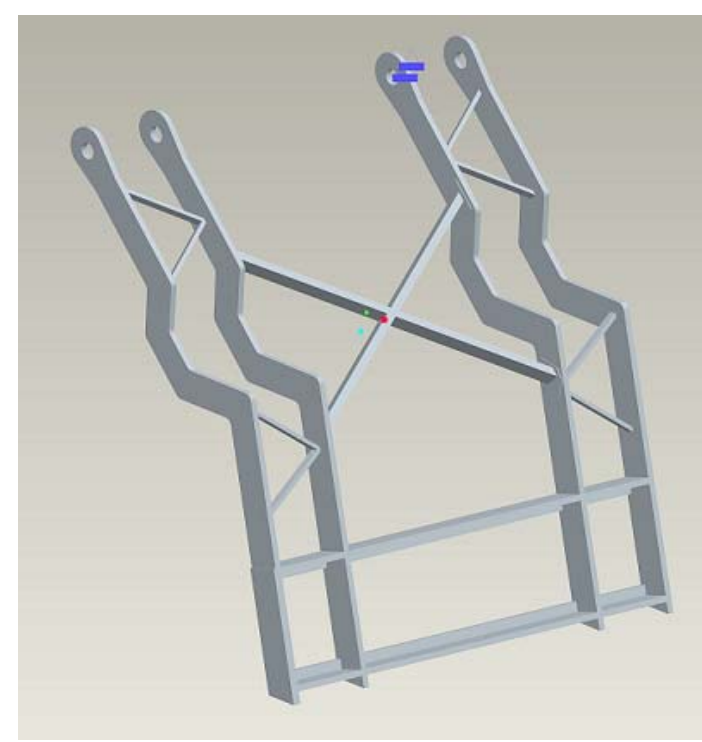

Figure 6.0d: Study \#1 Part (C): Arm w/ CrossBraces and Side V-Braces. 


\section{$\underline{\text { Study \#2 }}$}

$\mathrm{X}, \mathrm{Y} \& \mathrm{Z}$ Constrained Surfaces

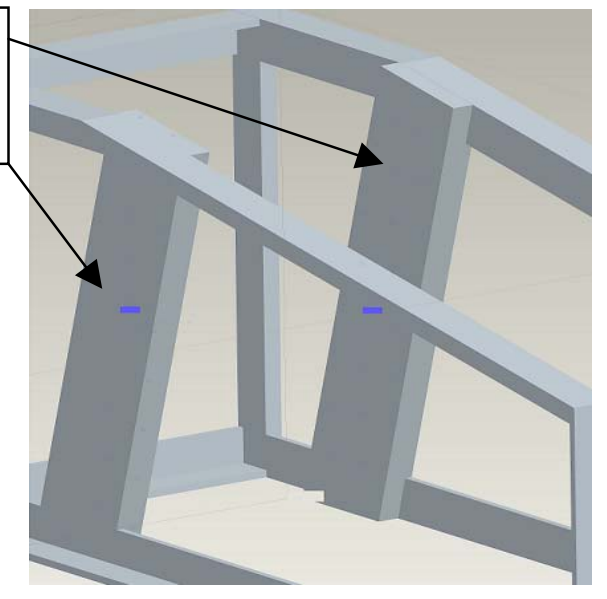

Figure 6.0e: Illustration of X, Y \& Z constraints applied on surface of arm support.

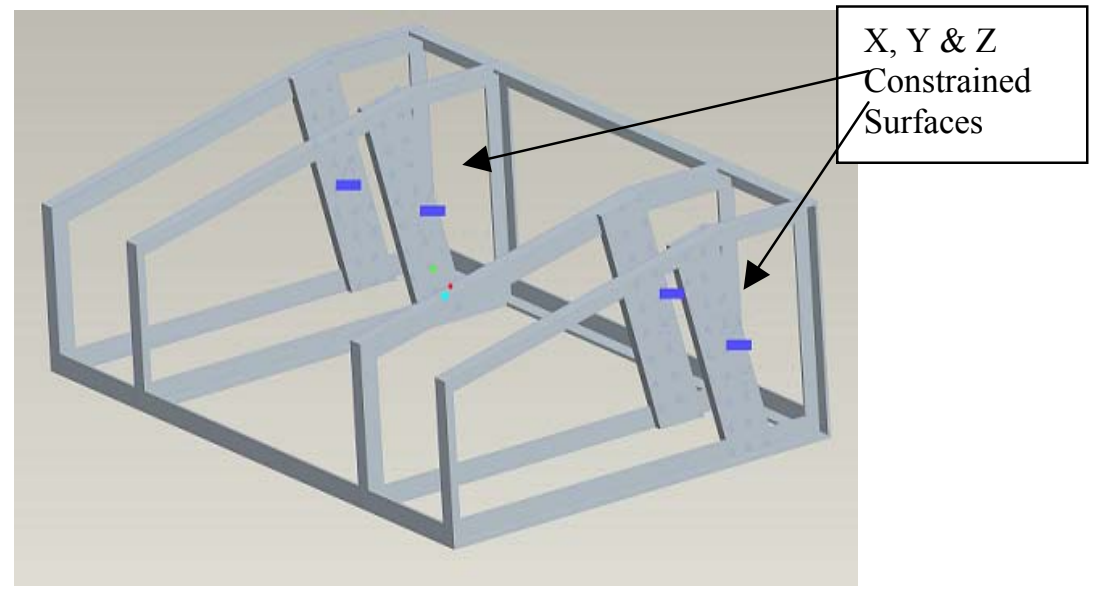

Figure 6.0f: Study \#2 Part (A): Pod Frame without skin.

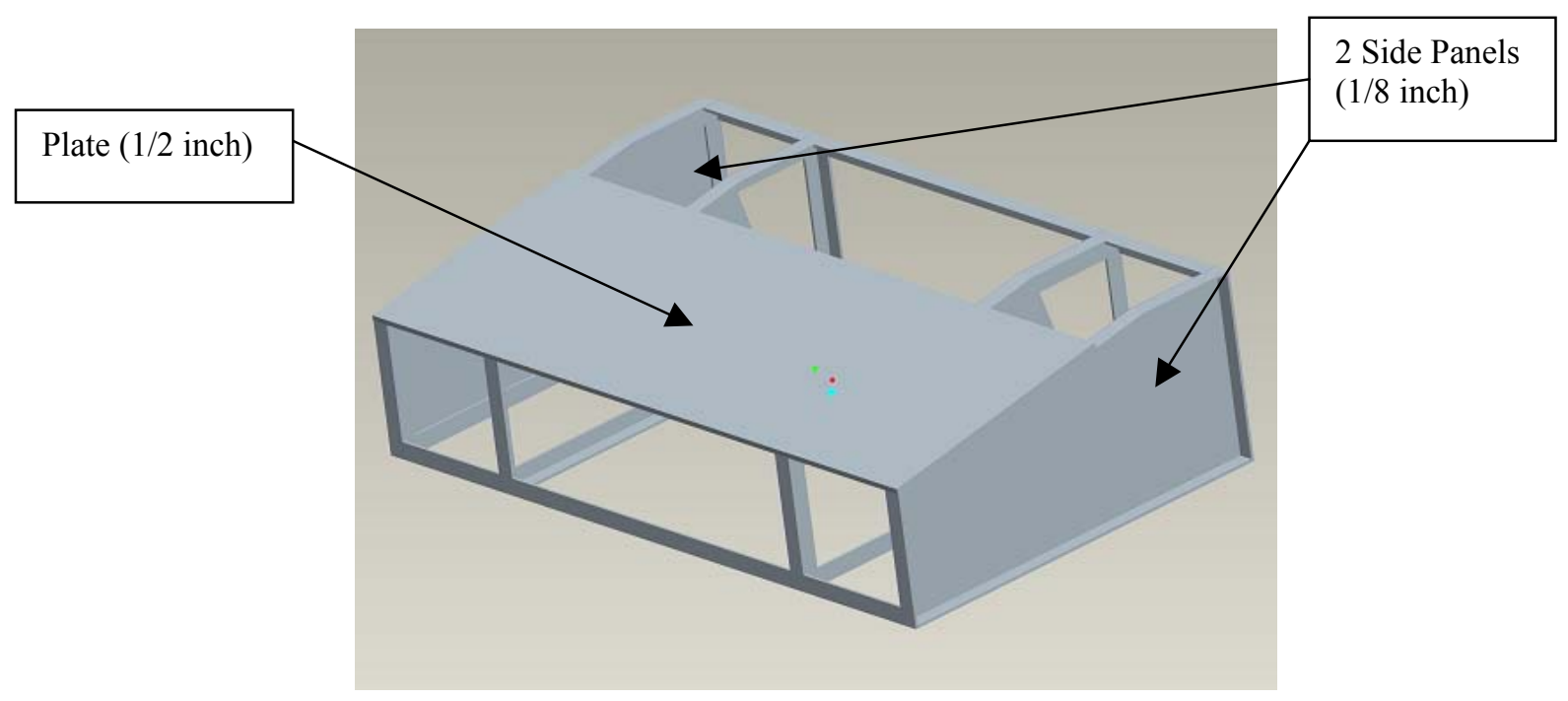

Figure 6.0g: Study \#2 Part (B): Pod Frame with 1/2in support plate and 1/8-inch side panels. 


\section{$\underline{\text { Study \#3 }}$}

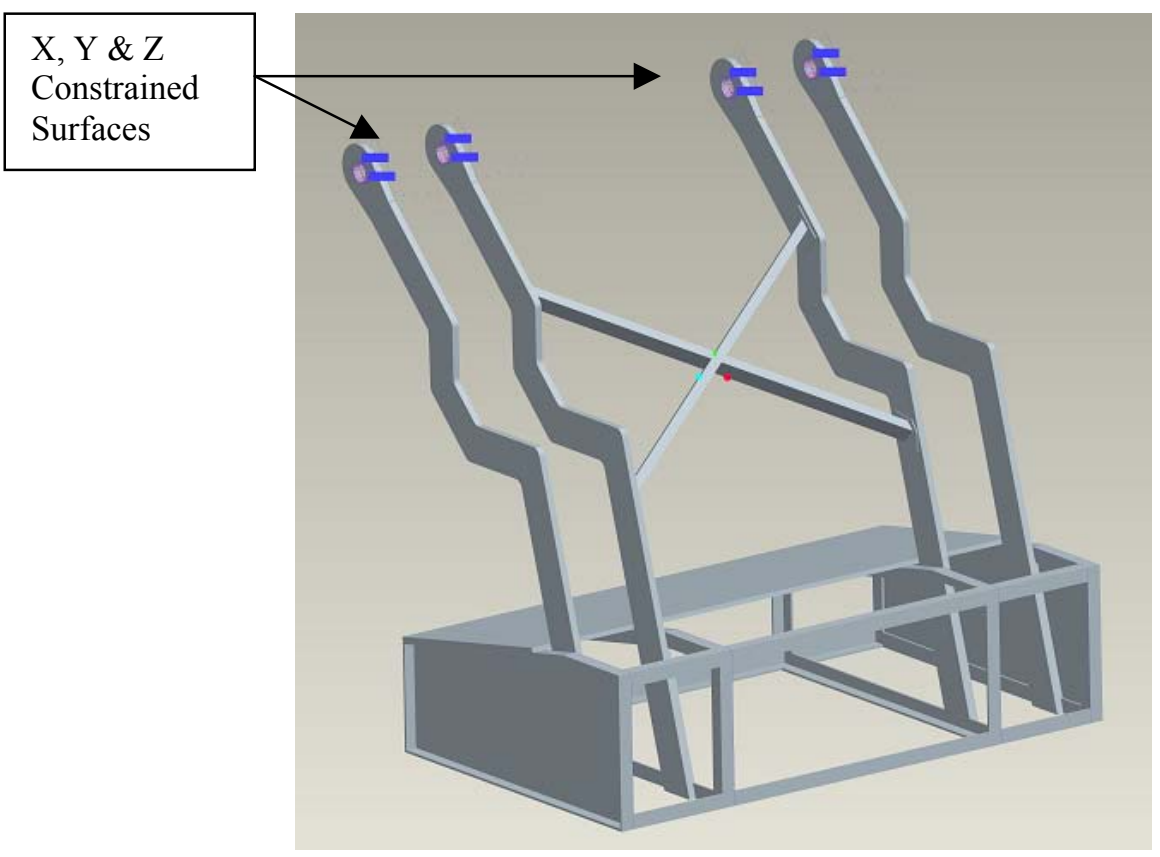

Figure 6.0h: Study \#3 Part (A): Assembled Arm/Pod System with Center Cross-Brace, 1/2in Plate and 1/8in Side Panels.

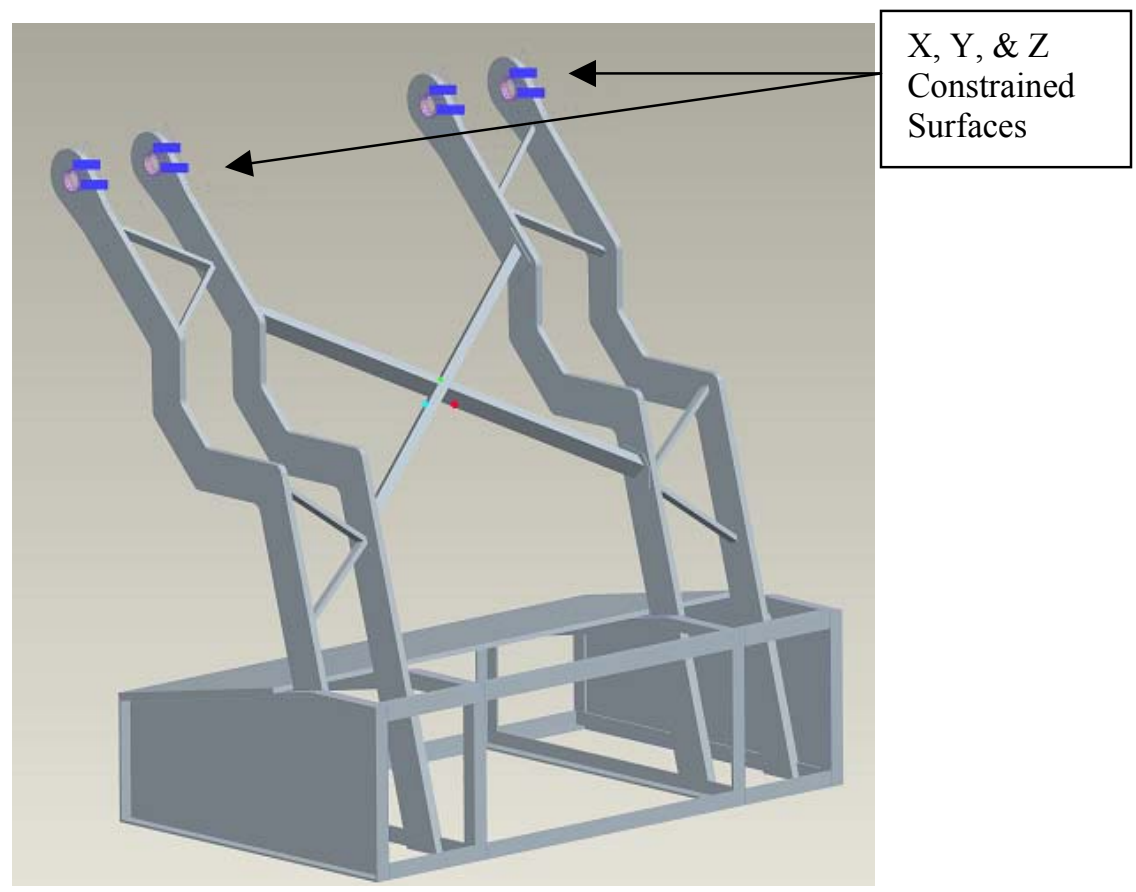

Figure 6.0i: Study \#3 Part (B): Assembled Arm/Pod System with Center Cross-Brace, V-Braces, 1/2in Plate and 1/8in Side Panels. 


\subsection{Results}

By utilizing Pro/MECHANICA’s modal analysis solver, the ten (10) fundamental mode shapes and natural frequencies were computed for three (3) studies ${ }^{¥}$. Additionally, each frequency data point converged within the $10 \%$ indicated error range for accuracy control standards. (See Table 6.1a and Table 6.1b for a list of results).

Table 6.1a: List of Natural Frequency Results Relative to Indicated Mode Shapes in Numerical Format. Grey indicates Mode Shape, Red indicates the Natural Frequencies close to the $18 \mathrm{hz}$ peak (Right-Left Motion) from the Rake test and orange highlights reflect the frequency mode shapes for vibration isolator inspection.

\begin{tabular}{|c|l|c|c|c|c|c|c|c|c|c|c|}
\hline \multicolumn{2}{|c|}{ List of Studies } & \multicolumn{4}{c|}{ Mode Shapes (1-10) w/ Natural Frequencies (Hz) } \\
\hline \multicolumn{1}{|c|}{ System / Component(s) } & 1 & 2 & 3 & 4 & 5 & 6 & 7 & 8 & 9 & 10 \\
\hline \multirow{2}{*}{ Study } & Arms w/out cross-braces & 7 & 16 & 22 & 46 & 47 & 47 & 50 & 100 & 101 & 108 \\
\cline { 2 - 11 } & Arms w/center cross-brace & 16 & 18 & 22 & 47 & 47 & 58 & 93 & 104 & 109 & 117 \\
\cline { 2 - 11 } 1 & Arms w/center cross-brace \& v-brace & 16 & 22 & 47 & 89 & 94 & 121 & 125 & 135 & 141 & 145 \\
\hline \multirow{3}{*}{2} & Pod Frame & 56 & 68 & 87 & 88 & 118 & 140 & 162 & 170 & 175 & 186 \\
\cline { 2 - 10 }$y$ & Pod Frame w/ 1/2in plate \& 1/8in panels & 60 & 92 & 108 & 147 & 154 & 170 & 175 & 175 & 209 & 224 \\
\hline \multirow{3}{*}{3} & Arm/Pod system w/center cross-brace \& pod skin & 11 & 12 & 14 & 40 & 43 & 47 & 51 & 55 & 73 & 82 \\
\cline { 2 - 11 } & Arm/Pod system w/cross \& v-braces and pod skin & 12 & 18 & 31 & 40 & 55 & 73 & 74 & 92 & 111 & 118 \\
\hline
\end{tabular}

Table 6.1b: Calculated Mass (lbm) and Moment of Inertia for systems and components.

\begin{tabular}{|c|l|c|c|c|c|c|c|c|}
\hline Study & \multicolumn{1}{|c|}{ Component } & Mass (Ibm) & IxX & lyy & IzZ & Ixy & IXZ & Iyz \\
\hline \multirow{3}{*}{1} & Arm w/no bracing & $1.34 \mathrm{e}+02$ & $1.20 \mathrm{E}+05$ & $6.59 \mathrm{E}+04$ & $6.26 \mathrm{E}+04$ & $-1.28 \mathrm{E}+04$ & $2.27 \mathrm{E}+02$ & $8.40 \mathrm{E}+02$ \\
\cline { 2 - 8 } & Arm w/ center cross-brace & $1.45 \mathrm{e}+02$ & $1.24 \mathrm{E}+05$ & $6.74 \mathrm{E}+04$ & $6.51 \mathrm{E}+04$ & $-1.35 \mathrm{E}+04$ & $2.46 \mathrm{E}+02$ & $8.81 \mathrm{E}+02$ \\
\cline { 2 - 8 } & Arm w/ center cross-brace \& V-braces & $1.48 \mathrm{e}+02$ & $1.26 \mathrm{E}+05$ & $6.90 \mathrm{E}+04$ & $6.63 \mathrm{E}+04$ & $-1.37 \mathrm{E}+04$ & $2.53 \mathrm{E}+02$ & $9.07 \mathrm{E}+02$ \\
\hline \multirow{3}{*}{2} & Pod Frame & $6.13 \mathrm{e}+01$ & $3.27 \mathrm{E}+04$ & $3.86 \mathrm{E}+04$ & $1.01 \mathrm{E}+04$ & $-8.43 \mathrm{E}+02$ & $8.19 \mathrm{E}-11$ & $2.73 \mathrm{E}-11$ \\
\cline { 2 - 8 } & Pod Frame w/ 1/2 plate \& 1/8in panels & $1.48 \mathrm{e}+02$ & $7.24 \mathrm{E}+04$ & $8.60 \mathrm{E}+04$ & $2.16 \mathrm{E}+04$ & $1.15 \mathrm{E}+03$ & $-4.50 \mathrm{E}-01$ & $2.85 \mathrm{E}-01$ \\
\hline \multirow{3}{*}{3} & Arm/Pod System w/cross-brace \& pod skin & $2.32 \mathrm{e}+02$ & $1.68 \mathrm{E}+05$ & $1.39 \mathrm{E}+05$ & $8.72 \mathrm{E}+04$ & $2.14 \mathrm{E}+04$ & $-7.49 \mathrm{E}-01$ & $1.47 \mathrm{E}+00$ \\
\cline { 2 - 8 } & Arm/Pod System w/c \& v-braces \& pod skin & $2.35 \mathrm{E}+02$ & $1.70 \mathrm{E}+05$ & $1.40 \mathrm{E}+05$ & $8.89 \mathrm{E}+04$ & $2.19 \mathrm{E}+04$ & $-4.06 \mathrm{E}+00$ & $6.84 \mathrm{E}+00$ \\
\hline
\end{tabular}

\footnotetext{
${ }^{¥}$ For a List of Complete Results See Appendix B
} 


\section{Study \#1}

\section{Results}

During study 1, the first mode shape and natural frequency for the right-left motion were optimized in parts $\mathrm{A}-\mathrm{C}$ and yielded natural frequencies for the following data: $7 \mathrm{~Hz}, 18 \mathrm{~Hz}$ and $45 \mathrm{~Hz}$, respectively. Also, the first mode of frequency for the foreaft motion was found to be constant at $16 \mathrm{~Hz}$, due to the constant 4 -inch thickness of the arms. Additionally, the mode shapes and natural frequencies for mode 1 for the torsion motion remained constant at $22 \mathrm{~Hz}$, regardless of the varied cross-members.

Consequently, the increase in cross-member stiffness and mass had no effect on the frequency response in these two directions. (See figures 6.1a-b) Overall, an increase in natural frequencies for the latter mode shapes (5-10) was apparent in all directions of motion (See figure 6.1b). 
Table 6.1c: Frequency values for mode 1 with corresponding direction of motion.

\begin{tabular}{|l|c|c|c|}
\hline \multicolumn{1}{|c|}{ Study \#1 } & Right-Left Motion & Fore-Aft Motion & Torsion Motion \\
\hline A: Arm w/no bracing & 7 & 16 & 22 \\
B: Arm w/ center cross-brace & 18 & 16 & 22 \\
C: Arm w/ center cross-brace \& V-braces & 45 & 16 & 22 \\
\hline
\end{tabular}

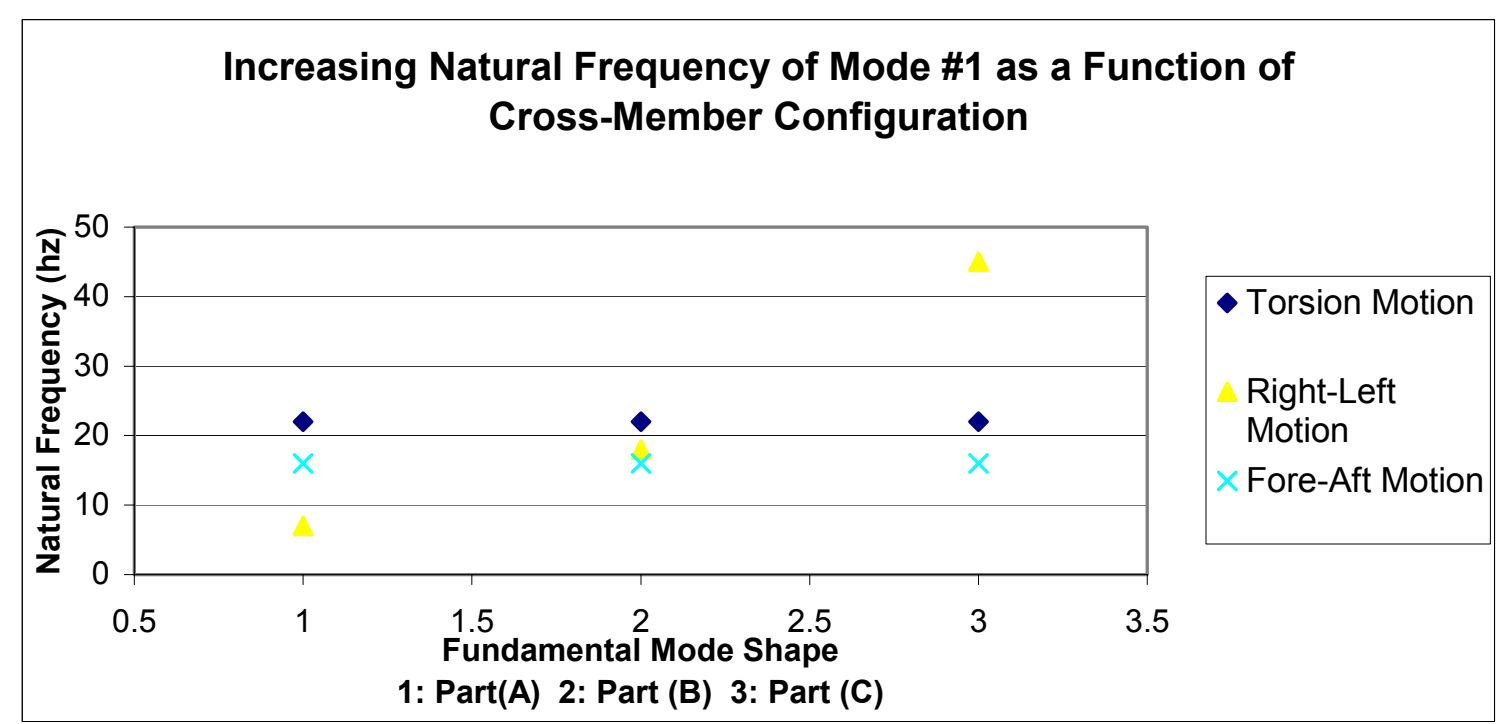

Figure 6.1a: Varying the cross-brace configurations had no affect on the torsion and for-aft motions, however the right-left motion frequency response increased incrementally, $7 \mathrm{hz}, 18 \mathrm{hz}$ and $45 \mathrm{hz}$, respectively. 


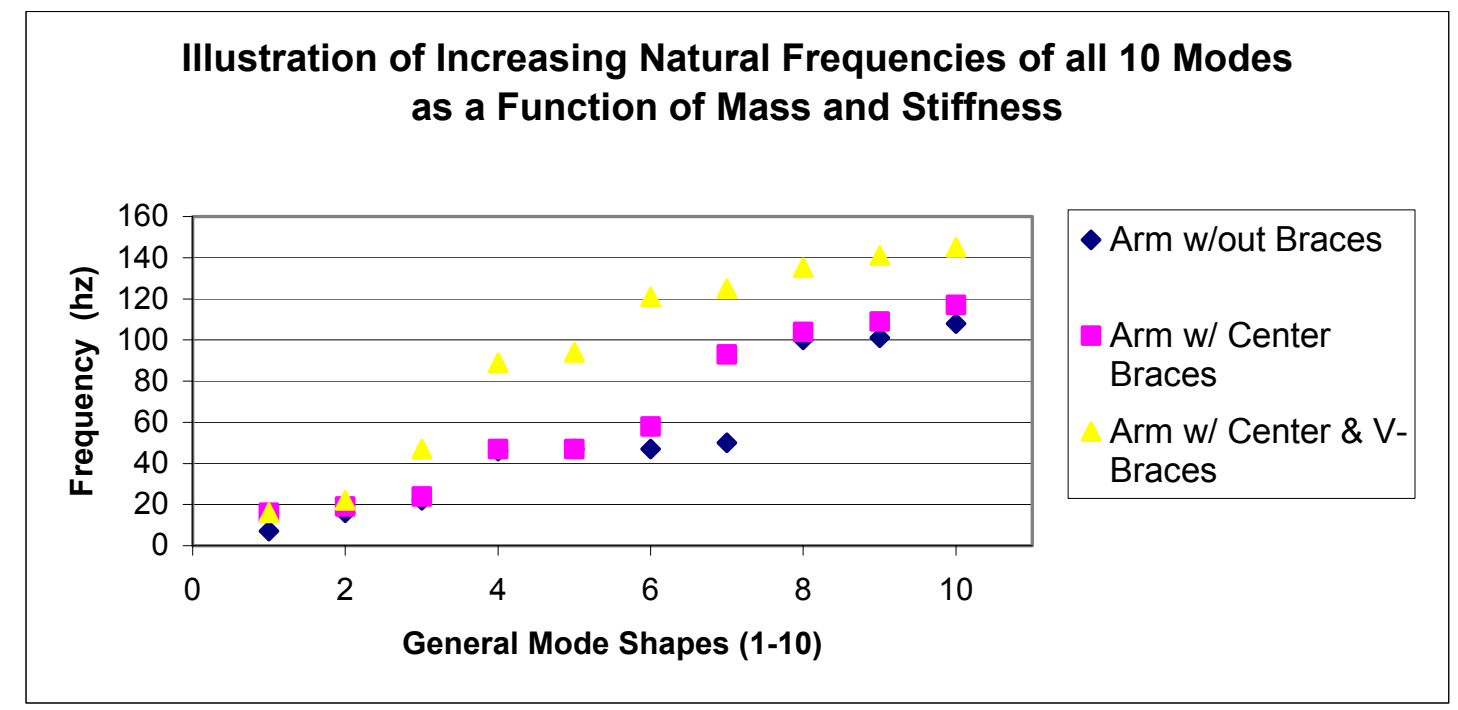

Figure 6.1b: Nonlinear Relationship of Mode Shapes and Natural Frequencies for all 10 modes in Study \#1 (Arm w/out Bracing), (Arm w/ Cross-Brace) and (Arm w/ Cross \& V-Braces) as mass and stiffness are increased.

The mode shapes for the three motions, right-left, fore-aft and torsion are

illustrated in figure 6.1c. 


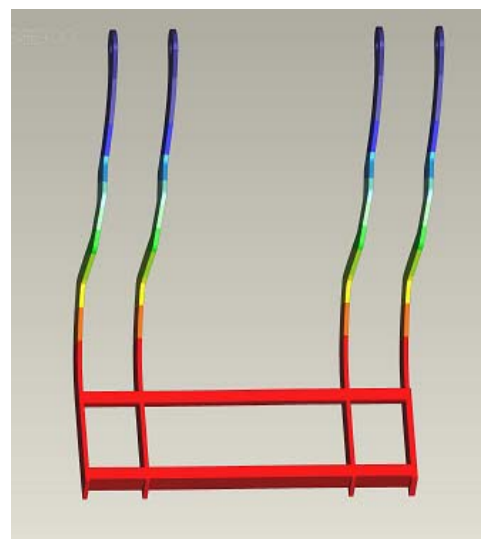

A

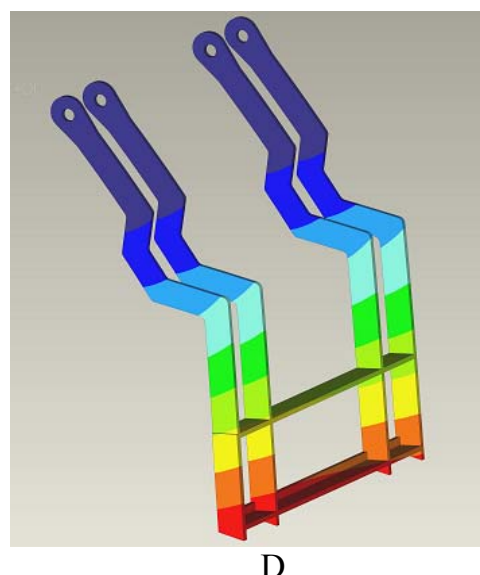

$\mathrm{D}$

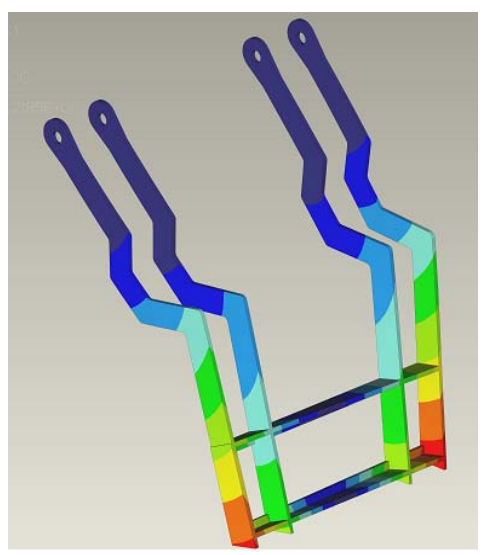

G

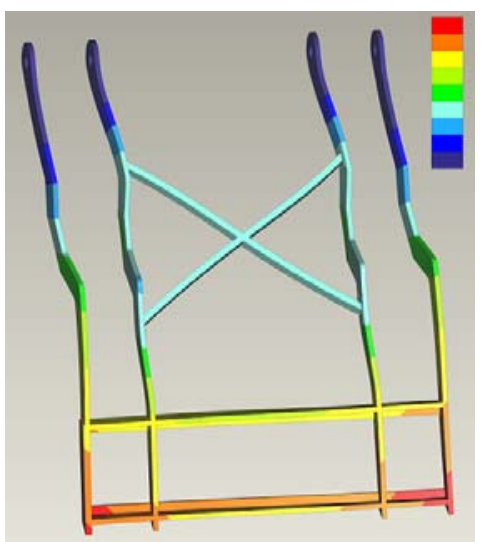

B

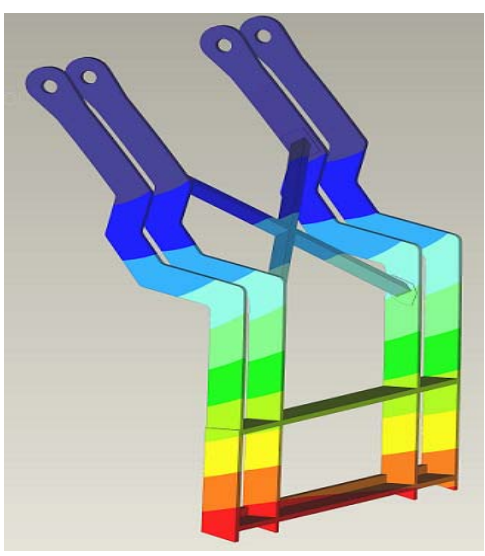

$\mathrm{E}$

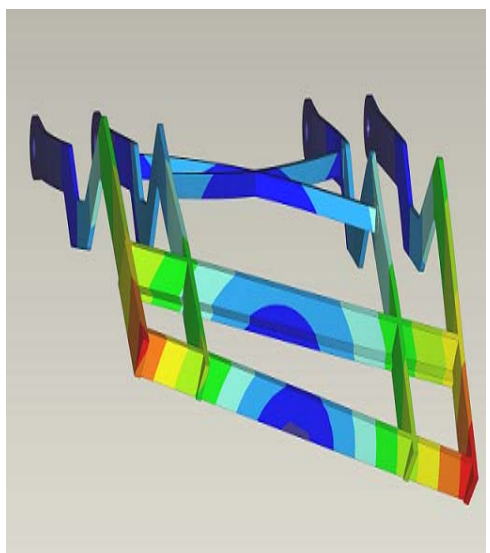

$\mathrm{H}$

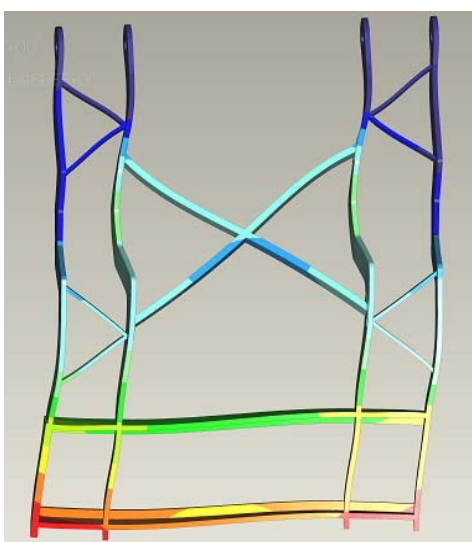

$\mathrm{C}$

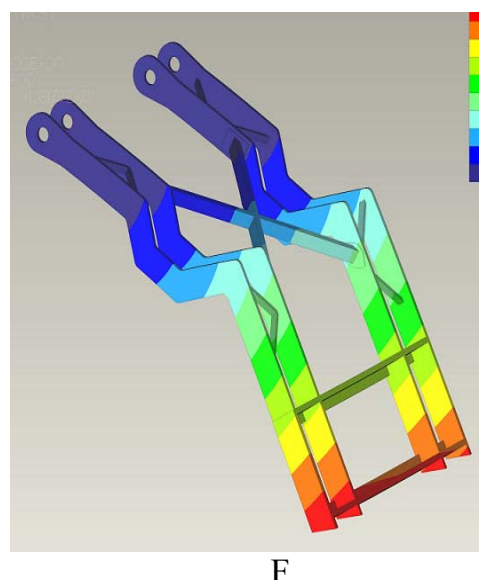

$\mathrm{F}$

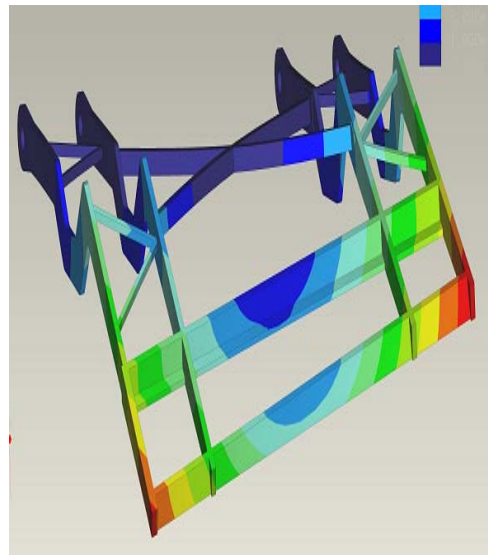

I

Figure 6.1c: Illustration of Mode 1 with corresponding Natural Frequencies: (A) (Right-Left Motion) arm with out braces resonated at 7hz, (B)(Right-Left Motion) arm with center cross-brace resonated at 18hz, (C) (Right-Left Motion) arm with cross-braces \& V-braces resonated at 45hz, (D-F) (Fore-Aft Motion) with arm in 3 geometrical configurations with Natural Frequency constant at 16hz, respectively, and (G-H) (Torsion Motion) with arm in 3 geometrical configurations with Natural Frequency constant at $22 \mathrm{hz}$, respectively. 


\section{Study \#2}

\section{Results}

In study 2 , the natural frequency for mode 1 in the (right-left motion) was found to have a value of $56 \mathrm{~Hz}$ for the pod frame and $154 \mathrm{~Hz}$ for the modified pod frame. A substantial increase took place in the natural frequency in the (right-left motion) with the addition of the $1 / 2$-inch plate and the $1 / 8$-inch side panels. In the (vertical bending motion) the pod frame yielded a natural frequency of $68 \mathrm{~Hz}$ and, with the addition of the mass of the $1 / 2$-inch plate in the modified pod, the natural frequency decreased to a value of $60 \mathrm{~Hz}$. The $60 \mathrm{~Hz}$ is, however, the fundamental frequency of the modified pod. Lastly, in the (torsion motion) for mode 1 the pod frame and modified pod possessed natural frequencies of vibration at $87 \mathrm{~Hz}$ and $92 \mathrm{~Hz}$, respectively, however the latter contained three (3) nodes as opposed to one (1). (See figure 6.1d) 
Table 6.1d: Frequency values for mode 1 with corresponding direction of motion.

\begin{tabular}{|l|c|c|c|}
\hline \multicolumn{1}{|c|}{ Study \#2 } & Right-Left Motion & Vertical Bending Motion & Torsion Motion \\
\hline A: Pod Frame & 56 & 68 & 87 \\
B: Pod Frame w/ 1/2in plate \& 1/8in panels & 154 & 60 & 92 \\
\hline
\end{tabular}

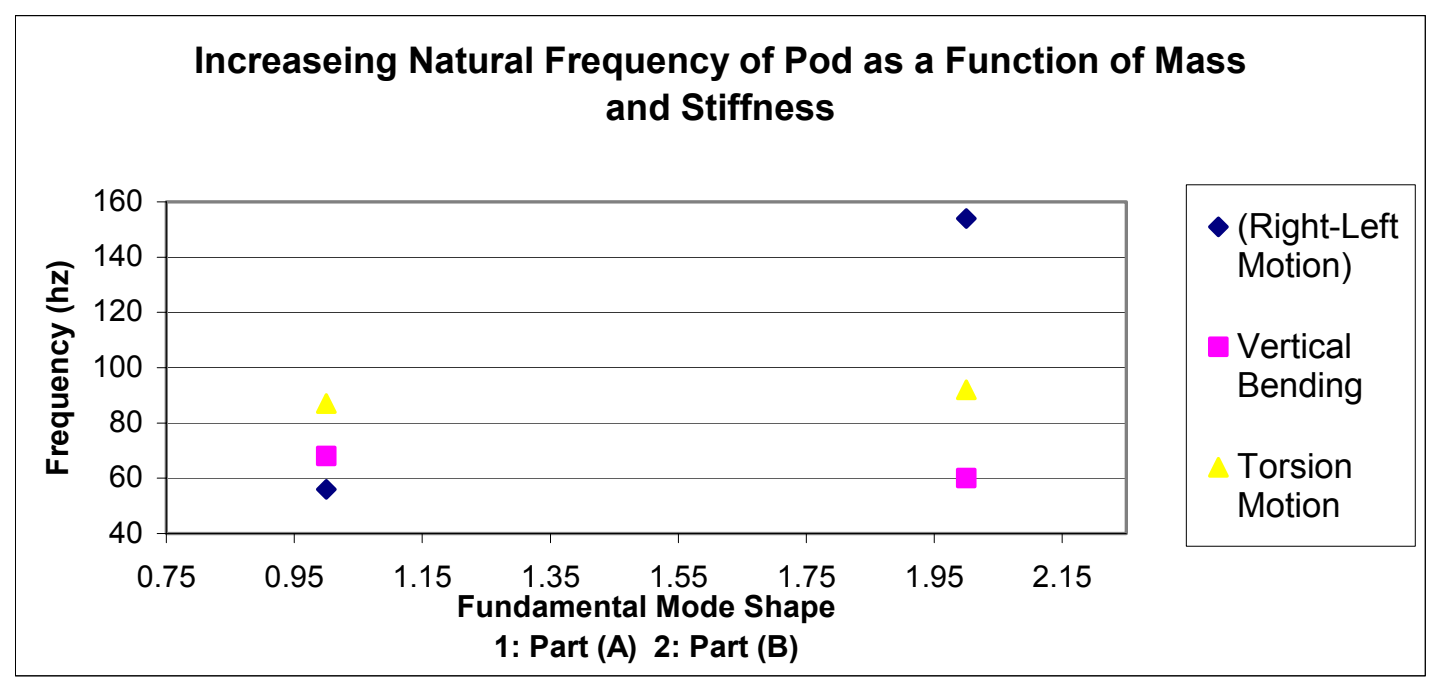

Figure 6.1d: Varying mass and stiffness parameters of pod frame by adding $1 / 2$-inch plate and $1 / 8$-inch panels. In the (Right-Left) motion the natural frequencies increased from $56 \mathrm{hz}$ to $154 \mathrm{hz}$. In the (Vertical Bending) motion the natural frequencies decreased from $68 \mathrm{hz}$ to $60 \mathrm{hz}$. In the (Torsion) motion the natural frequencies increased from $87 \mathrm{hz}$ to $92 \mathrm{hz}$.

Overall, the natural frequencies increased with the addition of the $1 / 2$-inch plate and 1/8-inch side panels for all ten (10) mode shapes of frequency with the exception of the decrease in vertical bending of the front, mid-section of the pod frame and modified pod. (See figure 6.1e for all 10 mode shapes) 


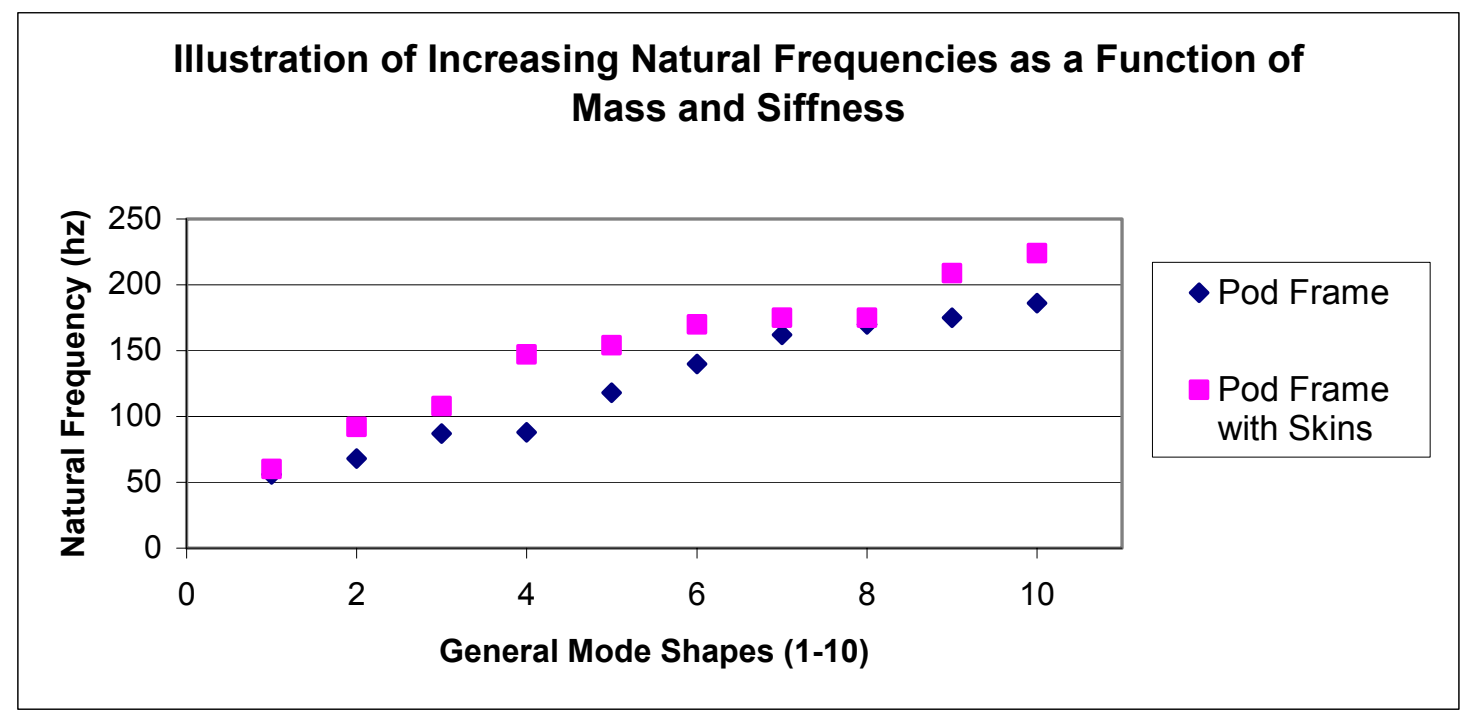

Figure 6.1e: Nonlinear Relationship of Mode Shapes and Natural Frequencies for the Pod Study as stiffness and mass are increased with the $1 / 2$ in plate and $1 / 8$-in side panels.

The mode shapes for the three motions, right-left, vertical bending and torsion are illustrated in figure $6.1 \mathrm{f}$. 


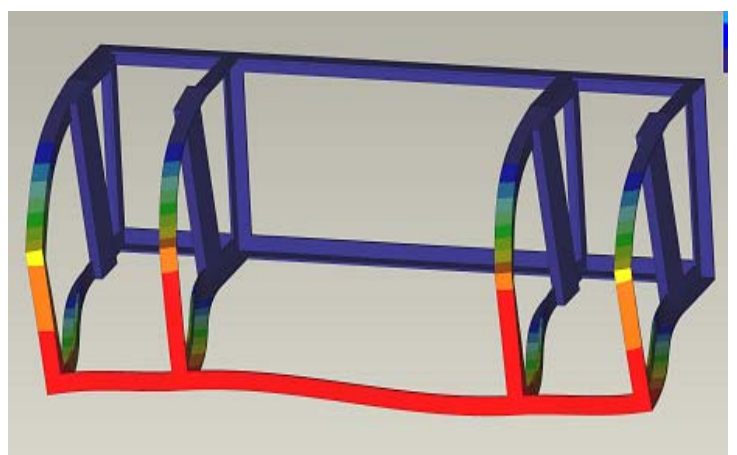

A

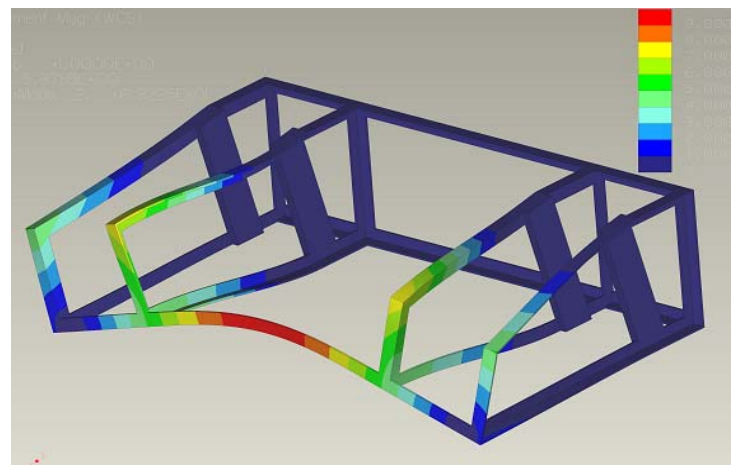

$\mathrm{C}$

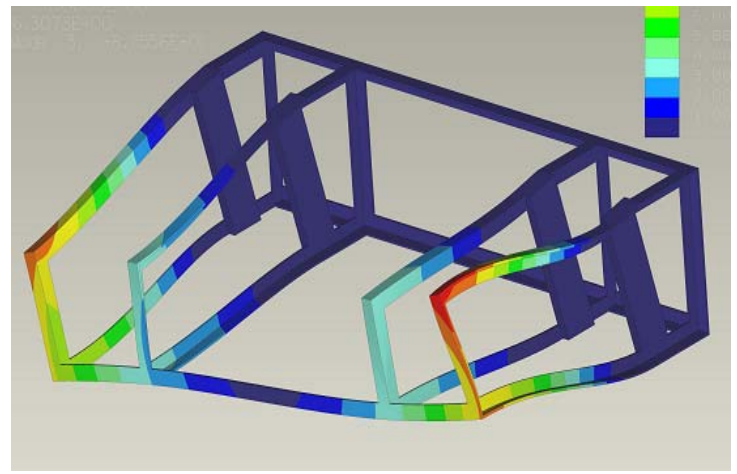

$\mathrm{E}$

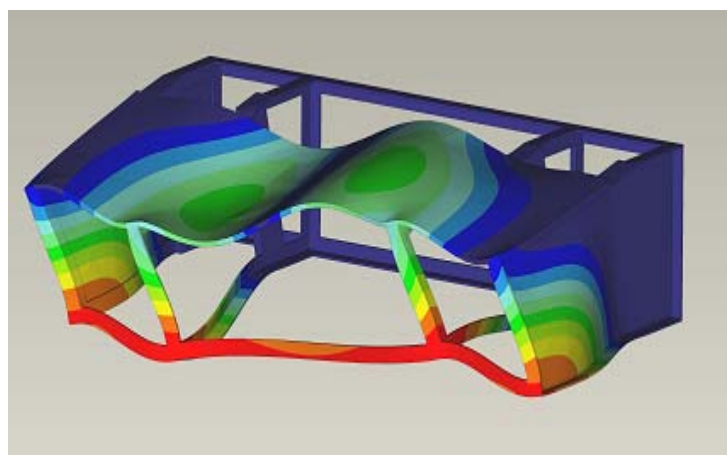

$\mathrm{B}$

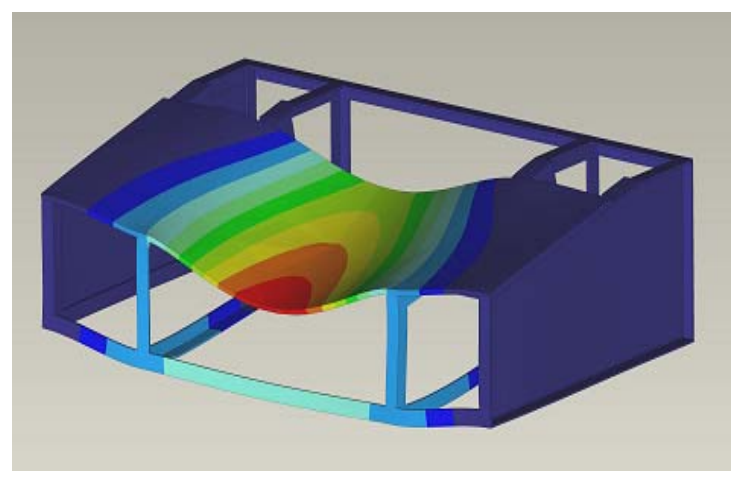

$\mathrm{D}$

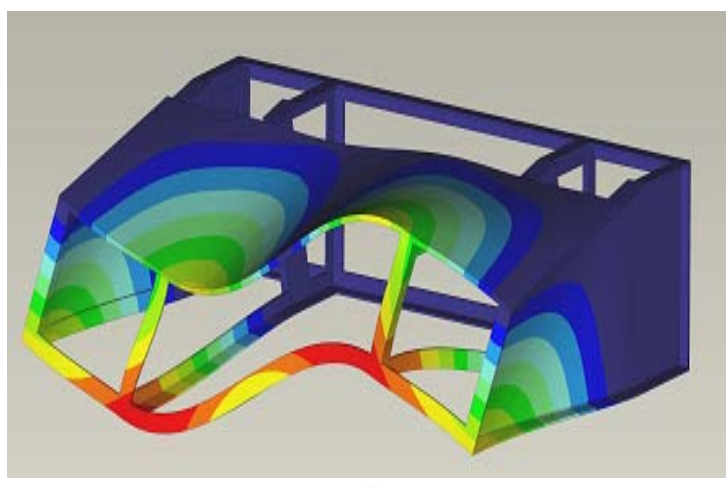

F

Figure 6.1f: Illustration of Mode 1 with corresponding Natural Frequencies: (A) (Right-Left Motion) of Pod Frame resonated at 56hz, (B) (Right-Left Motion) of Modified Pod resonated at 154hz, (C) (Vertical Bending Motion) of Pod Frame resonated at 68hz, (D) (Vertical Bending Motion) of Modified Pod with Natural Frequency of 60hz, (E) (Torsion Motion) of Pod Frame with Natural Frequency at 87hz and (F) (Torsion Motion) of Modified Pod with Natural Frequency at 92hz. 


\section{Study \#3}

\section{Results}

In the third study, the natural frequency for mode 1 in the (right-left) motion for the Arm/Pod mechanical system (1) with center cross-brace and Arm/Pod mechanical system (2) with center cross-brace and side V-braces were found to have values of $11 \mathrm{~Hz}$ and $31 \mathrm{~Hz}$, respectively. As expected, the natural frequencies for these directions increased, however, with the addition to the mass of the two elements assembled together, the overall natural frequencies decreased with respect to the individual arm configurations in study 1. Additionally, in the (fore-aft) motion for the first mode the two systems yielded equivalent natural frequencies of $12 \mathrm{~Hz}$. As seen in the first study for

mode 1 , the natural frequencies in the (fore-aft) motion were not affected by the addition of the V-braces for increased stiffness; however the overall natural frequencies of the system decreased relative to study 1 from the addition of mass from the assemblage of the arms and pod as one system. And finally, the natural frequency for mode 1 in the (torsion) motion was slightly increased from $14 \mathrm{~Hz}$ to $18 \mathrm{~Hz}$ with the addition of the $\mathrm{V}$ braces. (See figure 6.1g) 
Table 6.1e: Frequency values for mode 1 with corresponding direction of motion.

\begin{tabular}{|c|c|c|c|}
\hline Study \#3 & Right-Left Motion & Fore-Aft Motion & Torsion Motion \\
\hline Arm/Pod system w/center cross-brace \& pod skin & 11 & 12 & 14 \\
Arm/Pod system w/cross \& v-braces and pod skin & 31 & 12 & 18 \\
\hline
\end{tabular}

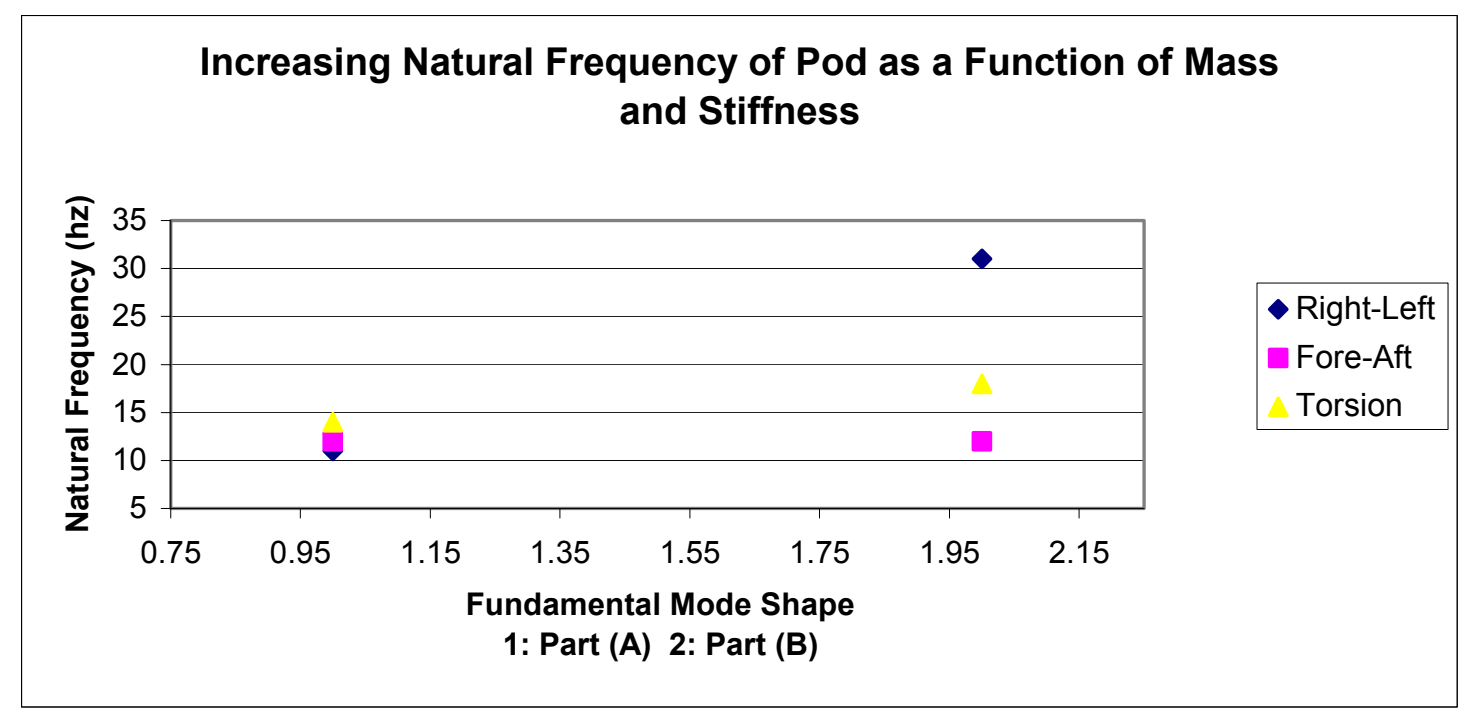

Figure 6.1g: Varying mass and stiffness parameters of Arm/Pod mechanical for system 1: center crossbrace and system 2: center cross-brace and V-braces. In the (Right-Left) motion the natural frequencies increased from $11 \mathrm{hz}$ to $31 \mathrm{hz}$. In the (Fore-Aft) motion the natural frequencies remained constant at $12 \mathrm{hz}$. In the (Torsion) motion the natural frequencies increased from $14 \mathrm{hz}$ to $18 \mathrm{hz}$.

Generally, the natural frequencies increased with the addition of the V-braces to the second Arm/Pod system for all ten (10) mode shapes of frequency with the exception of the constant frequency response in the (fore-aft) motion in mode 1 and the pod bending motion of mode 4 at $40 \mathrm{~Hz}$ (See appendix B for mode shape 4). However, with the assemblage of the two components (arms and modified pod), the system is characterized with lower natural frequencies with respect to the first study due to the increase in mass. (For all 10 mode shapes, See figure 6.1e) 


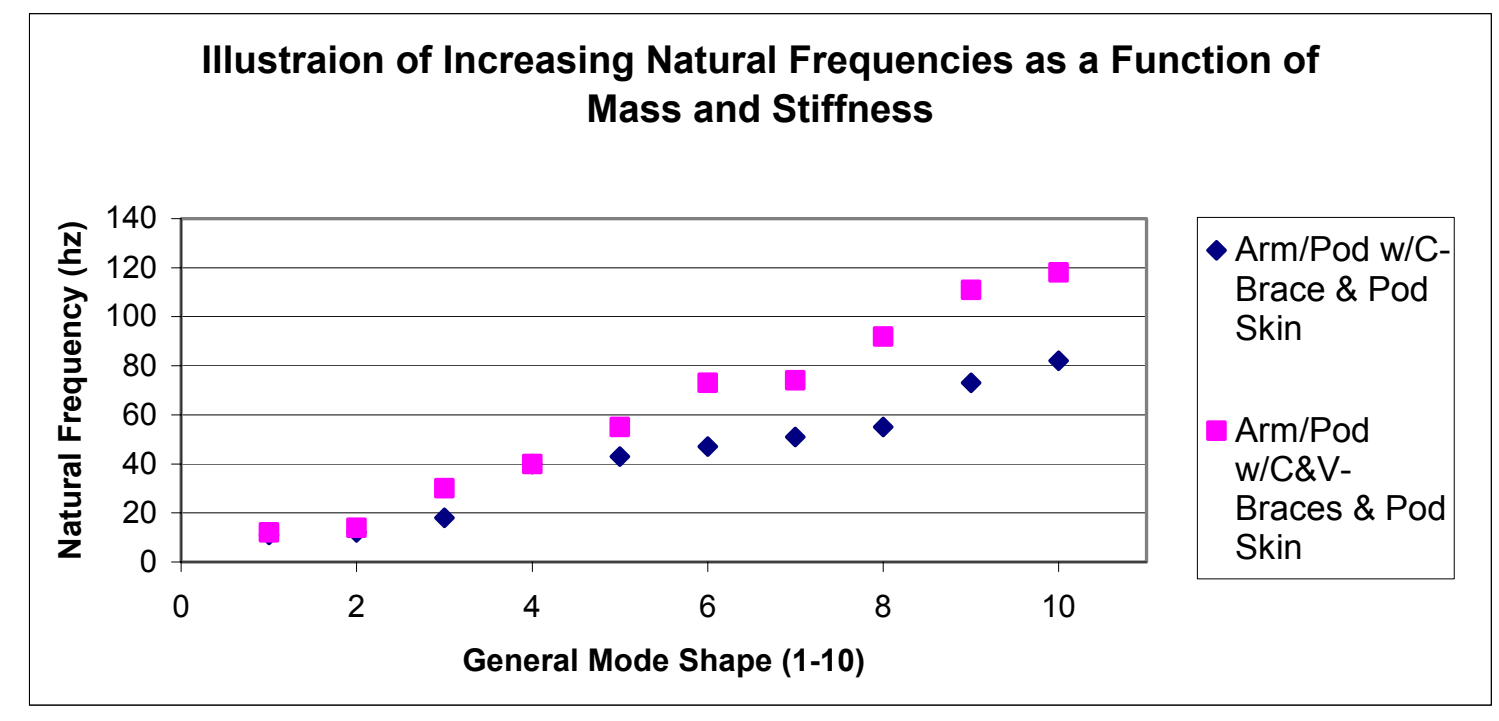

Figure 6.1h: Nonlinear Relationship of Mode Shapes and Natural Frequencies for the complete Arm/Pod systems as mass and stiffness are increased by the addition of assembling the two Arm \& Pod components and adding the V-braces to the second complete system.

The mode shapes for the three motions, right-left, fore-aft and torsion are illustrated in figure 6.1i. 


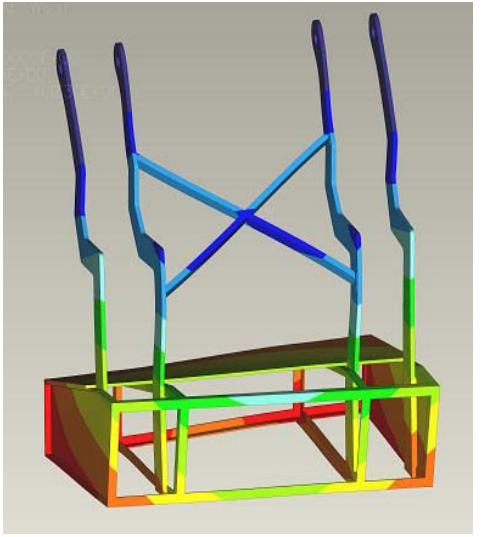

A

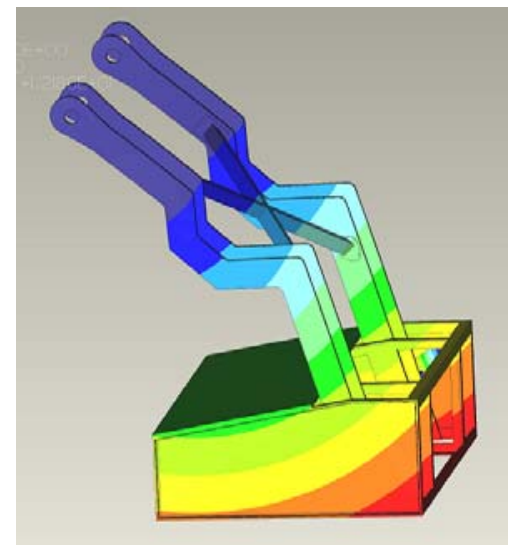

$\mathrm{C}$

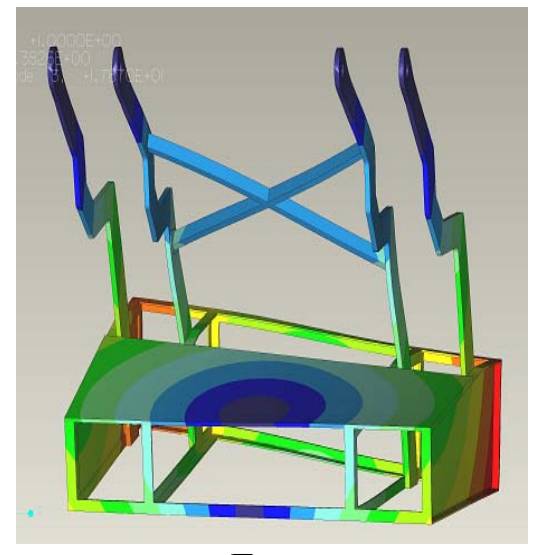

$\mathrm{E}$

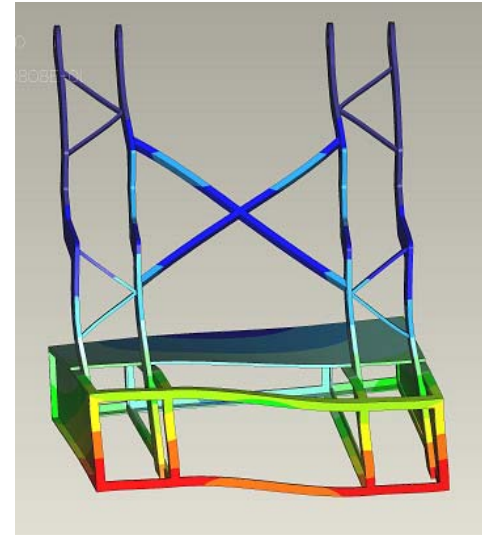

B

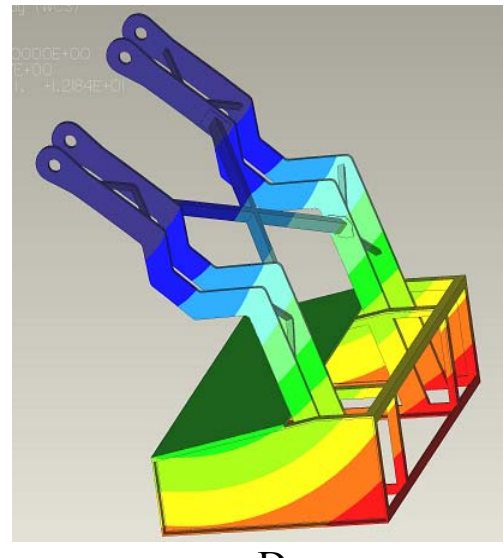

$\mathrm{D}$

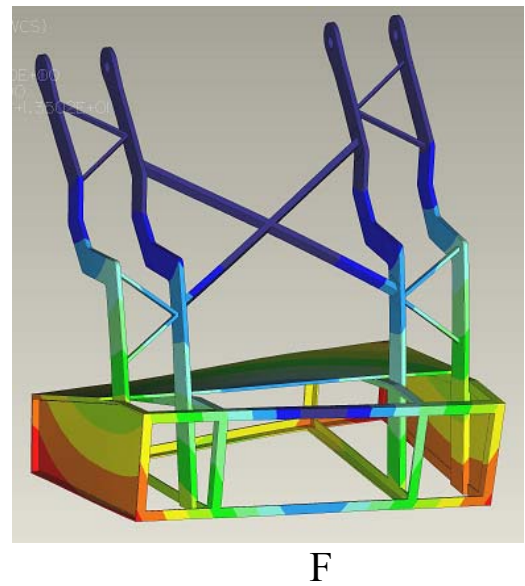

Figure 6.1i: Illustration of Mode 1 with corresponding Natural Frequencies: (A) (Right-Left Motion) of Arm/Pod system (1) resonated at 11hz, (B) (Right-Left Motion) of Arm/Pod system (2) resonated at $31 \mathrm{hz}$, (C) (Fore-Aft Motion) of system (1) resonated at 12hz, (D) (Fore-Aft Motion) of system (2) with Natural Frequency of 12hz, (E) (Torsion Motion) of system (1) with Natural Frequency at 14hz and (F) (Torsion Motion) of system (2) with Natural Frequency at $18 \mathrm{hz}$. 


\subsection{Conclusions}

Based on the experimental base vibration data from the Rake test, the natural frequencies and mode shapes were computed, analyzed and optimized for the Arm/Pod system and infrastructural components in multiple arrays and configurations in order to produce natural frequencies in ranges outside the $18 \mathrm{~Hz}$ peak of the power density spectrum in the Right-Left motion and to ensure the natural vibrations of the pod were greater than the $32 \mathrm{~Hz}$ low-pass-vibration isolated sensor plate inside the pod for which the sensors will be mounted.

\section{Study \#1}

Results concluded that when the cross-members were absent within the infrastructure of the arms, the arms exhibited a very low fundamental frequency in the right-left motion of $7 \mathrm{~Hz}$. This frequency is unacceptable in flight when the system will be subjected to random side gust winds that can resonant at this frequency with lateral forces up to $50 \mathrm{lbs}$. However, with the addition of the center crossbeam for increased stiffness and mass, the system's fundamental frequency for mode 1 in the right-left motion is increased to $18 \mathrm{~Hz}$. This frequency range is out of resonating potential for the later gust loads, however according to the Rake experiment it resonates with the right-left motion of the base excitation from the C-130 ramp and therefore is undesirable. Consequently, the addition of the V-braces in between the outer and inner arms yields a mode 1 fundamental frequency in the right-left motion of $45 \mathrm{~Hz}$. This configuration is ideal in the way that not only is the natural frequency outside and above the expected frequency envelope of the later gust loads and the right-left base excitation from the 
ramp, but the system also resonates above the natural frequency of the isolated vibration plate set at $32 \mathrm{~Hz}$ from the eight (8) vibration isolators.

Furthermore, calculations indicate that no affect is evident regarding the mode 1 fundamental frequencies for the fore-aft and torsion motions by varying different geometrical configurations of the cross members. The mode 1 natural frequencies for the fore-aft motion were unchanged at $16 \mathrm{~Hz}$ with the addition of cross members. This is because the stiffness of the system in the fore-aft direction is primarily a function of the arm thickness of 4 inches. The 4 -inch dimension was held constant throughout the experiment due to the favored optimization for torque control and limitations [6]. Although the system's frequency response is also a function of mass, the addition of the cross member's mass to the overall system is distributed symmetrically and therefore had negligible effects. On the other hand, the mode 1 fundamental frequency for the torsion motion was computed at a constant $22 \mathrm{~Hz}$. Again the addition of mass to the system was distributed symmetrically relative to the center node and therefore had no effect on the structure's response.

\section{$\underline{\text { Study \#2 }}$}

All frequencies for both the Pod Frame and the Modified Pod with 1/2-inch plate and $1 / 8$-inch side panels were found to resonate at frequencies well beyond the designed isolated sensor plate frequency of $32 \mathrm{~Hz}$ positioned inside the pod. The fundamental frequencies in the right-left motion increased significantly with the addition of the plate and side panels from $56 \mathrm{~Hz}$ to $154 \mathrm{~Hz}$, while the fundamental frequencies in the torsion motioned modestly remained unchanged from $87 \mathrm{~Hz}$ to $92 \mathrm{~Hz}$. However, the fundamental 
frequencies for the vertical bending motion of the $1 / 2$-inch plate component of the Pod Frame actually decreased from $68 \mathrm{~Hz}$ to $60 \mathrm{~Hz}$ due to the addition of mass from the $1 / 2$-inch plate relative to the contributed stiffness. Although the $1 / 2$-inch plate added substantial stiffness in other modal directions, the vertical parameter of the plate (the thickness), is diminutive in ratio with its mass addition. Therefore, if the plate thickness must increase, it is recommended that $\mathrm{C}$-channel stiffening supports be installed underneath the plate to prevent the degradation of the structures natural frequency integrity.

\section{$\underline{\text { Study \#3 }}$}

The analysis of the complete Arm/Pod system produced more realistic results due to the summation of the components' masses and stiffness parameters. With the addition of the modified pod to the base of the arms, a substantial alteration in the system's moments of inertia values, center of gravity values and stiffness and mass parameter distributions for the model will be eminent in comparison to the individual components studied previously. The addition of mass to the base of the arms will inherently decrease the overall first modal fundamental frequencies in all right-left, fore-aft and torsion motions, due to the mass contributions in relation to the stiffness contributions. The mode 1 fundamental frequency for the right-left direction of motion for the system with the single center cross-brace capitulated at $11 \mathrm{~Hz}$. Although the natural frequency is below the right-left base excitation and above the lateral gust load excitation, a stiffer system appreciably above $18 \mathrm{~Hz}$ would be more favorable. Hence, with the addition of the V-braces in between the outer and inner arms for increased stiffness, a more robust system is derived, since its mode 1 fundamental frequency in the right-left motion 
resonates at $31 \mathrm{~Hz}$. This frequency is ideal for the right-left motion based on the Rake test data values. The power density spectrum was at the lowest peak in magnitude at this frequency.

As expected, in the fore-aft motion the mode 1 fundamental frequencies remained at a constant $12 \mathrm{~Hz}$ again due to: A) a constant and unchanged arm thickness of 4-inches and B) the symmetric distribution of mass throughout the system.

The mode 1 fundamental frequencies in the torsion motion increased slightly with the addition of the V-braces from $14 \mathrm{~Hz}$ to $18 \mathrm{~Hz}$. This may or may not be suitable for the effects of shed vortices or Karmon street vortices produced from a blunt body moving through an airstreem (See figure 4.1b). 


\subsection{Future Work and Considerations}

Future work and considerations may be applied in the areas of shed vortices or karmon street vortices occurring on the blunt body of the mechanical arm/pod system traveling through $130-145$ knot airflow in the fully deployed position (See figure 4.1b). The forces accompanied by such phenomenon would result in a harmonic coupling of the system, which would produce torsion related stresses and displacements. A strong recommendation in computing and analyzing these loads would be to install piezoelectric accelerometers inside the pod during a standard flight envelope. If coupling subsists, quality in sensor data acquisition may suffer and premature fatigue from cyclic loads may occur.

Additionally, a sensitivity study in the variance of horizontal, aerodynamic loads as a function of alignment errors may be conducted (See figure 7.0a).

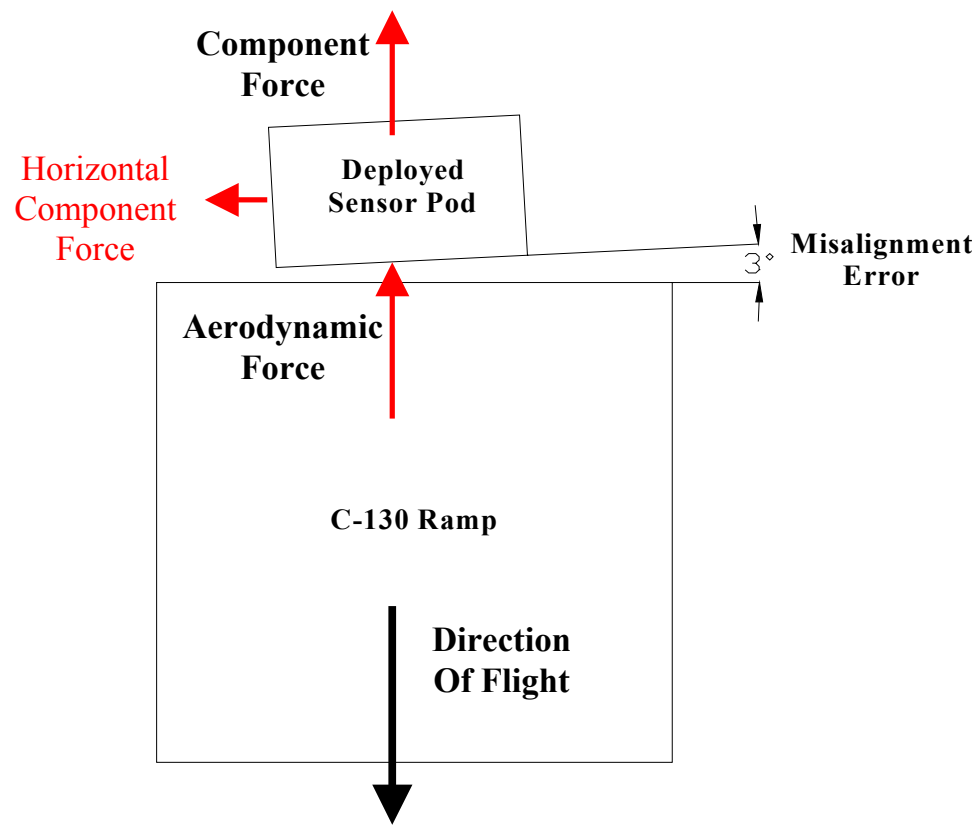

Figure 7.0a: Schematic of Horizontal Load represented by directional cosine components as a function of misalignment error. 
The load may be represented as an impulse in nature and coupled with the summation of the random gust loads could have a significant impact on fatigue life and displacement tolerance for optimum data acquisition quality control.

Furthermore, do to the varying of material properties as a function of thermal energy; expansion/contraction of joints/connections throughout the mechanical system may change the vibration dampening and natural frequencies of the system. Therefore, a sensitivity analysis of the system's vibration response should be conducted throughout the upper and lower temperature boundaries, $115^{0} \mathrm{~F}$ and $-45^{0} \mathrm{~F}$, respectfully.

Lastly, since the mechanical arm/pod model in Pro/E was a simplified version of the realistic mechanism in order to simplify the FEM matrix calculations, more accurate results may be yielded if a two (2) inch shaft was inserted through the four (4) arm hole locations as shown in figures 2-D and 3-D and constrained in the $\mathrm{X}, \mathrm{Y}$, and $\mathrm{Z}$ directions on both ends. With the addition of the shaft's mass, stiffness, and inertial properties, the overall natural frequencies would be more accurate than the data yielded in this study. 
Adam Conan Naternicola, the $2^{\text {nd }}$ of three sons of Joseph L. Naternicola Jr. and Nancy L Naternicola Jr., was born in Fairmont, West Virginia, on January $6^{\text {th }}, 1976$. As an adolescent, he was privately educated at Fairmont Catholic Grade School. He then attended the Marion County, West Virginia, Public School System, and graduated from Fairmont Senior High School in May, 1994. After serving three years in the United States Army stationed at Fort Bragg, NC, he attended West Virginia University, where he received his Bachelor of Science in Mechanical Engineering in December, 2002.

In January 2003, he entered the graduate program at West Virginia University and is a candidate for the Master of Science Degree in Mechanical Engineering in July 2004. 


\subsection{References}

[1] Wowczuk, Zenovy S., "Design of a Standardized Sensor Platform for a C-130 Aircraft," Mechanical and Aerospace Engineering Dept., West Virginia University, Morgantown, WV, 26505, Thesis, 2004

[2] Newland, David E., "Vibration of the London Millennium Footbridge: Part 2 - Cure," Department of Engineering, University of Cambridge, Trumpington St., Cambridge, CB2 1PZ, UK

[3] Beards, C.F., Structural Vibration Analysis, Ellis Horwood Limited, West Sussex, England, 1983

[4] Kalsule, K.J., Askhedkar, R.R., and Sajanpawar, P.R. "Engine Induced Vibration Control for a Motorcycle Chassis Frame by Right Combination of Finite Element Method and Experimental Techniques," SAE Paper 1999-011754, 1999

[5] Feragotti, Lawrence A., "Sensitivity Analysis of the C-130 Sensor Deployment System Arm using Finite Element Methods," Dept. Mechanical \& Aerospace Engineering, West Virginia University, Morgantown, WV 26505 Thesis 2004

[6] Miller, M., Hans-Gerald, E., Lelbach, M., Bors, W., "Reduction of Noise and Vibration in Vehicles by an Appropriate Engine Mount System and Active Absorbers," SAE Paper 960185, 1996

[7] Alford, Lionel D., Lt. Col, USAF \& Knarr, Robert C., "General Flight Test Theory Applied to Aircraft Modifications," Acquisition Review Quarterly (Spring 1999) PDF format: www.dau.mil/pubs/arq/99arq/knarr.pdf

[8] NASA Glenn Research Center, http://www.grc.nasa.gov/WWW/K12/airplane/pitot.html, Last Updated: March 10, 2004 by Tom Benson, Engine Systems Technology Branch, 21000 Brookpark Road, Cleveland, OH 44135

[9] Young, D.F., Munson, B., Okiishi, T., A Brief Introduction to Fluid Mechanics, Department of Mechanical Engineering, Iowa State, John Wiley \& Sons, Inc., New York, 1999

[10] Onera, http://www.onera.fr/ddss-en/vibtheavhe/vinunufav.html, webmaster@onera.fr, last updated: May 14, 2004, copyright C Onera 1996-2004 
[11] NASA Goddard Space Flight Center, http://cimss.ssec.wisc.edu/goes/misc/971228.html

Last Revised: May 17, 2004, Curator: Lynn Jenner, Website Development: ADB, Code 295, Website Design: TISB, Code 293, Responsible NASA Official: Mark Hess, Office of Public Affairs, Greenbelt, MD 20771

[12] Integrated Publishing, http://www.tpub.com/content/aerographer/14010/css/14010_122.htm, 26838 I-45 North, PMB 102, Spring, TX 77386, USA Copywrite 1988

[13] Hoblit, Frederic M. Gust Loads on Aircraft: Concepts and Applications, American Institute of Aeronautics and Astronautics, Inc. 370 L'Enfant Promenade, S.W., Washington, D.C. 20024 Copywrite 1988

[14] Bruel \& Kjaer http://www.vibration.addr.com/tutorials/mvibe.pdf, 2850, Naerum, Denmark, Copywrite September, 1982

[15] Hoffman, Forrest M., http://aurora.phys.utk.edu/ forrest/papers/fourier/\#introduction, University of Tennessee, Dept. of Physics and Astronomy, Knoxville, TN 37996

[16] Zhang, Yi, and Usman, Mohammad, Research Visteon Automotive Systems, "Life Prediction for Lighting Bulb Shield designs Subjected to Random Vibration," SAE Paper 1999-01-0705, 1999

[17] Brigham, E. Oran, The Fast Fourier Transform, Prentice Hall Inc., Englewood Cliffs, N.J., 1974

[18] Dean, Ford M., "Calculation of Random Vibration Fatigue Life from Finite Element Model Calculations," SAE Paper 940244, 1994

[19] Brigham, E. Oran, The Fast Fourier Transform and Its Applications, Englewood Cliffs, NJ: Prentice-Hall, Inc., 1988, 448 pp

[20] Winner, Walter P., Airman's Information Manual, Aviation Book Company; 19th edition (October 1985)

[21] Angle, Gerald, Compiled Matlab FFT and Average Computer Programs, PhD Student, West Virginia University, Morgantown, WV 26508, 2004 
Appendix A

Rake Test 1 \& 2

Vibration, Acceleration and Velocity Data 
Test 1.1 ( $V=130$ knots, Ramp open, 0 degree deck)

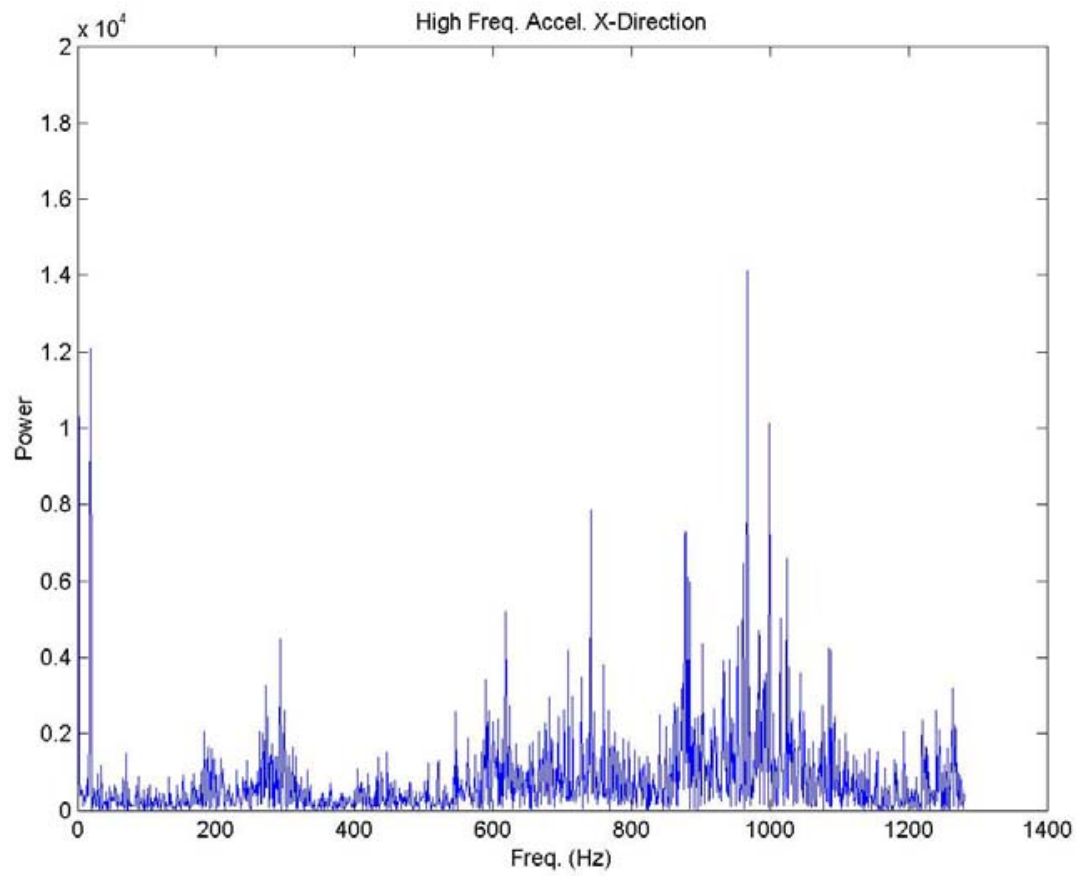

Figure 0-A: X-Direction (Left-Right Motion) Acceleration Frequency Analysis of Ramp Measured During Test 1 (V=130 knots, Ramp open, 0 degree deck)

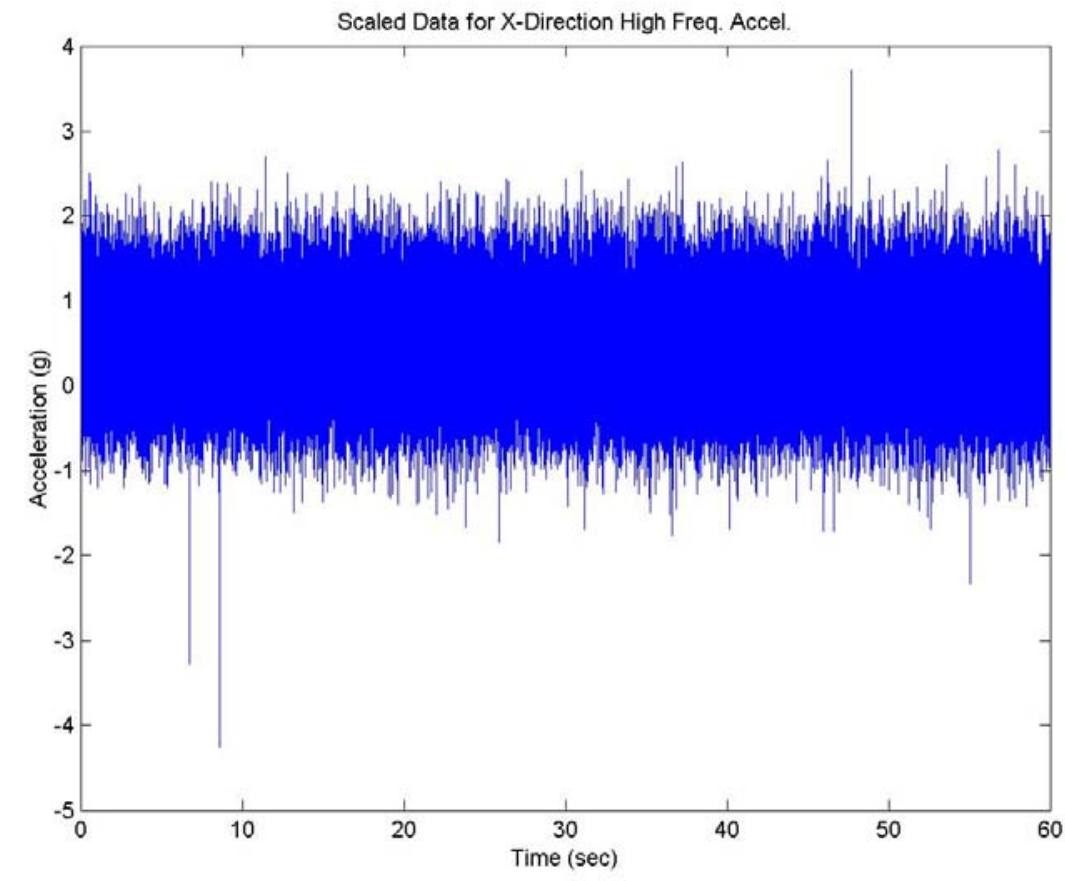

Figure 18-A: X-Direction (Left-Right Motion) Acceleration Signal for Ramp Measured During Test 1 ( $\mathrm{V}=130$ knots, Ramp open, 0 degree deck) 


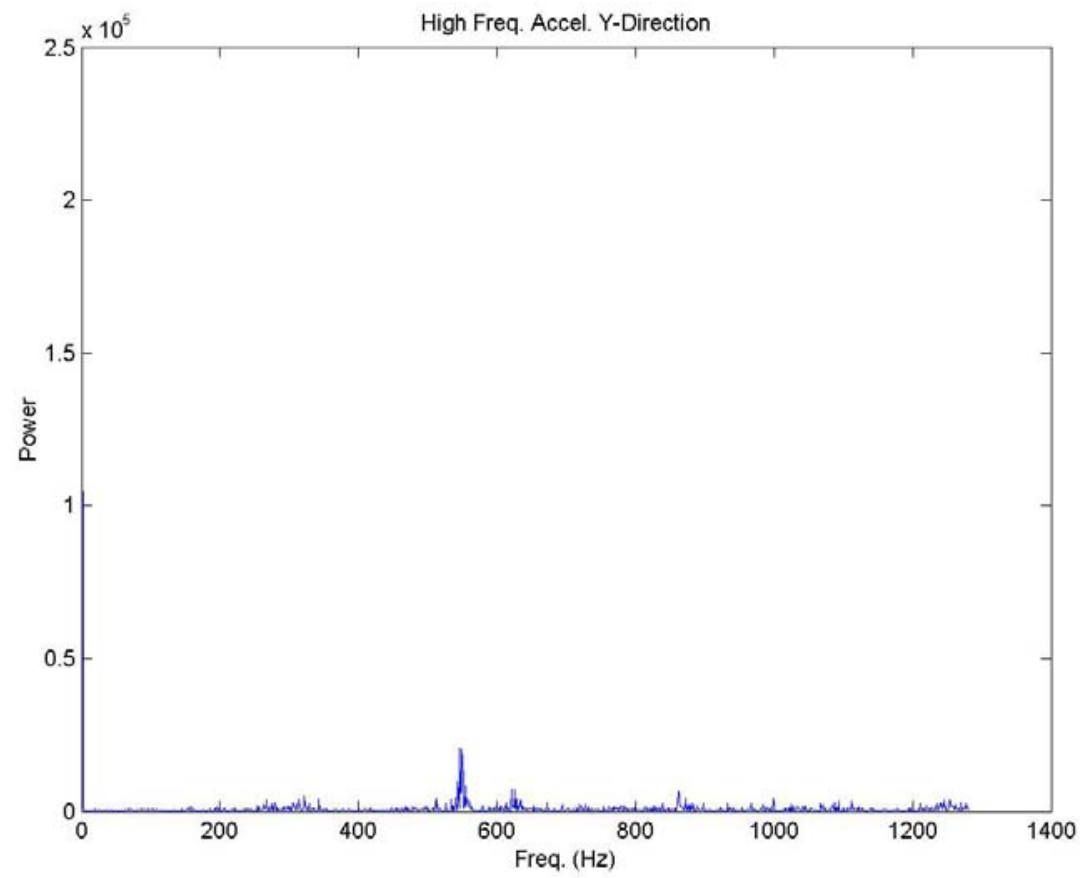

Figure 19-A: Y-Direction (Fore-Aft Motion) Acceleration Frequency Analysis of Ramp Measured During Test 1 ( $\mathrm{V}=130$ knots, Ramp open, 0 degree deck)

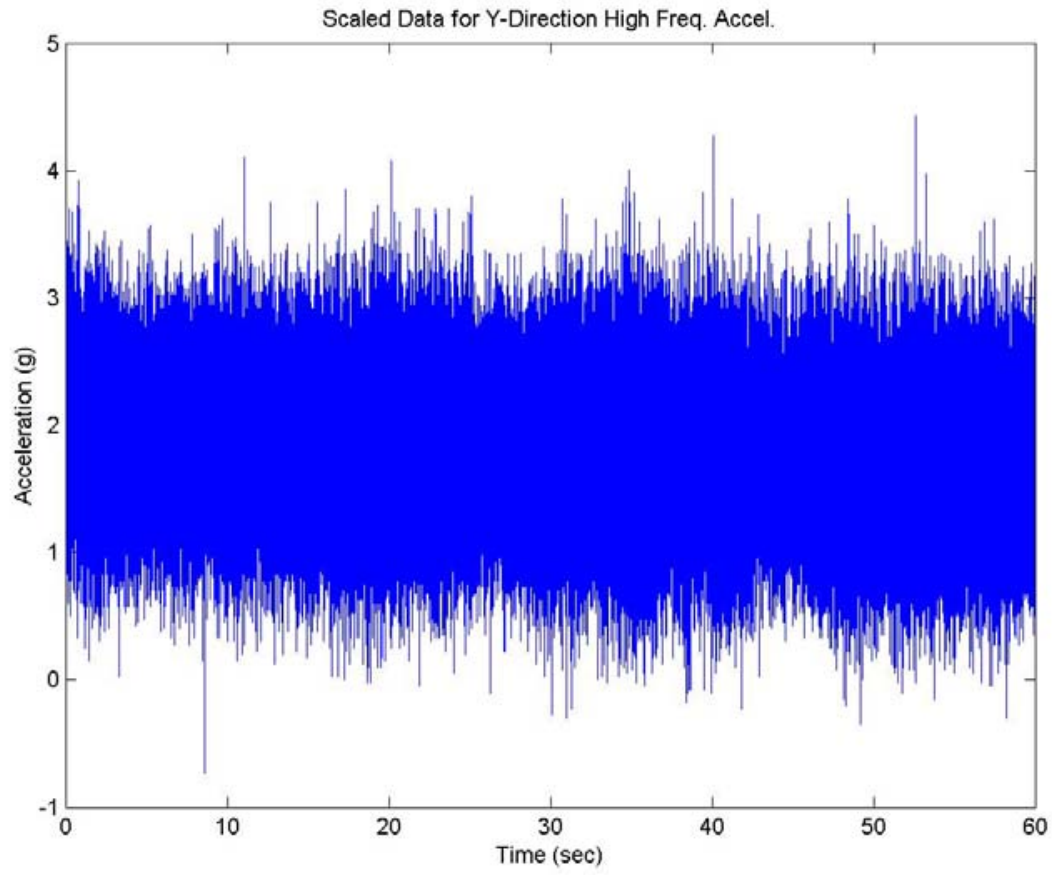

Figure 20-A: Y-Direction (Fore-Aft Motion) Acceleration Signal for Ramp Measured During Test 1 ( $\mathrm{V}=130$ knots, Ramp open, 0 degree deck) 


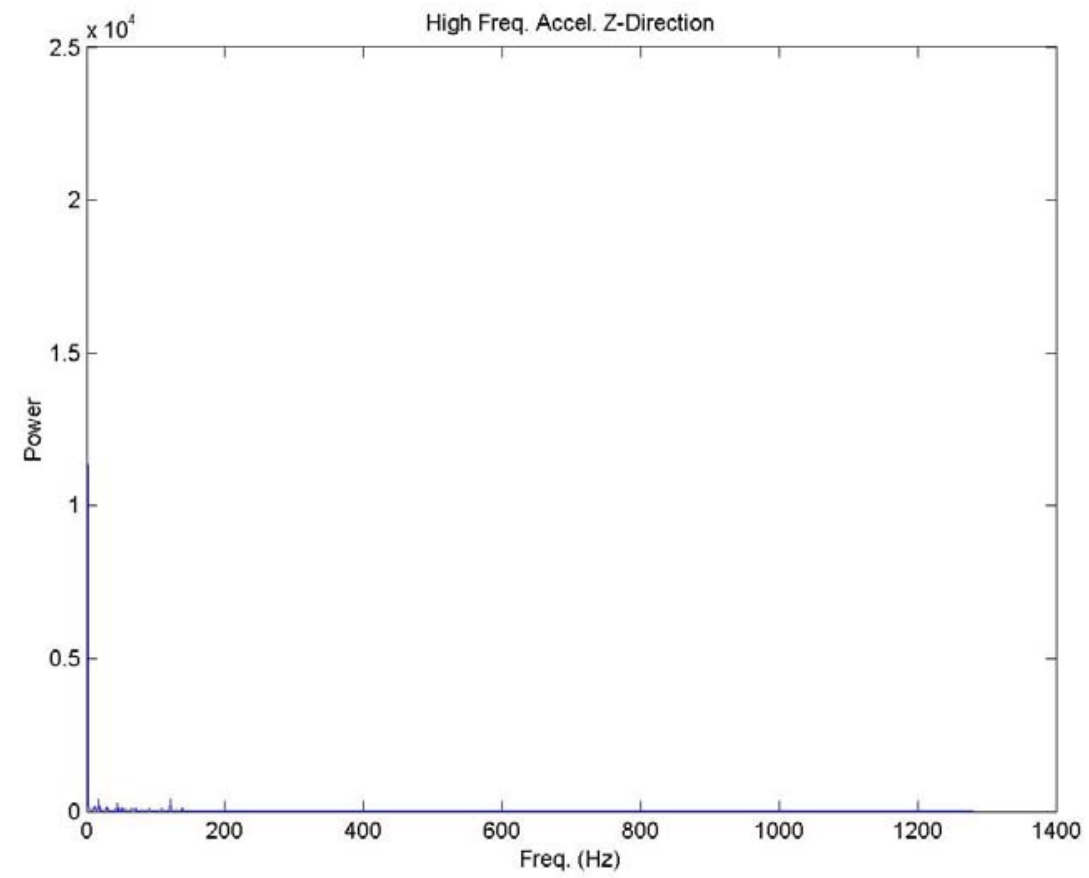

Figure 21-A: Z-Direction (Vertical) Acceleration Frequency Analysis of Ramp Measured During Test 1 (V=130 knots, Ramp open, 0 degree deck)

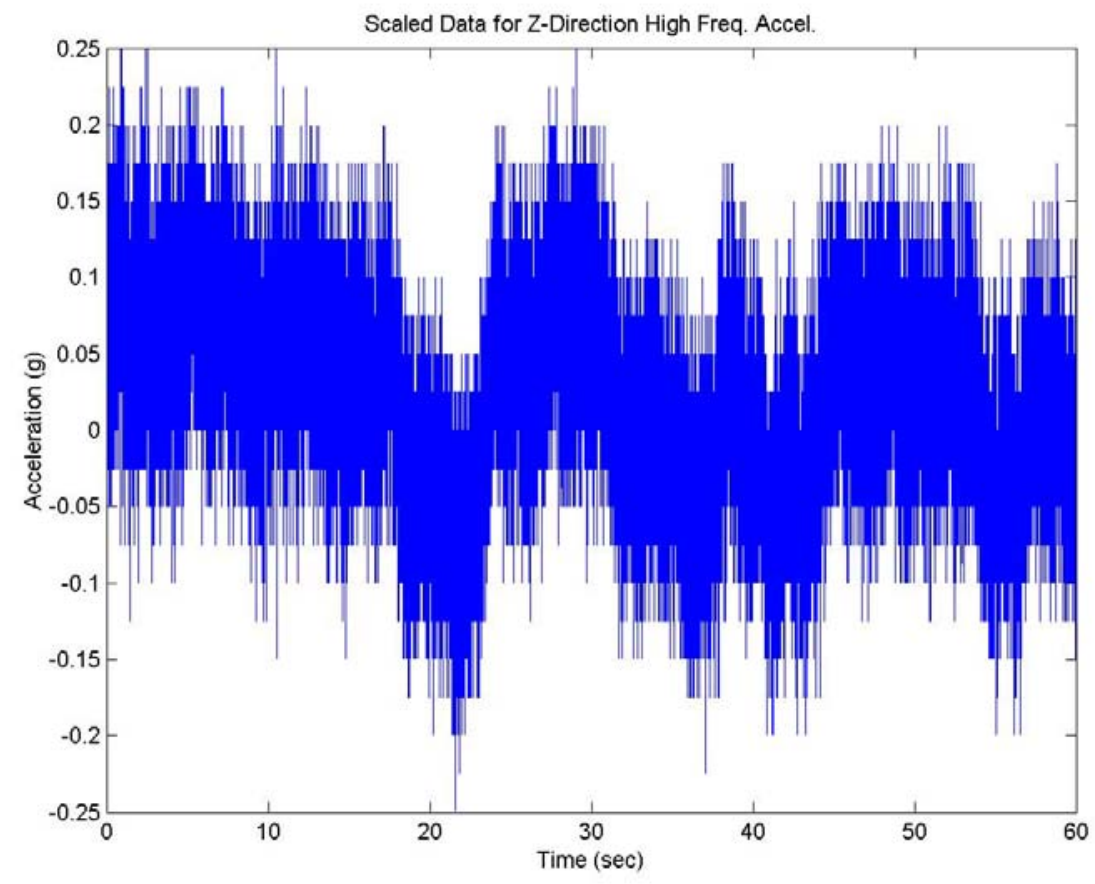

Figure 22-A: Z-Direction (Vertical) Acceleration Signal for Ramp Measured During Test 1 (V=130 knots, Ramp open, 0 degree deck) 
Test 1.2 (V=130 knots, Ramp open, 0 degree deck)

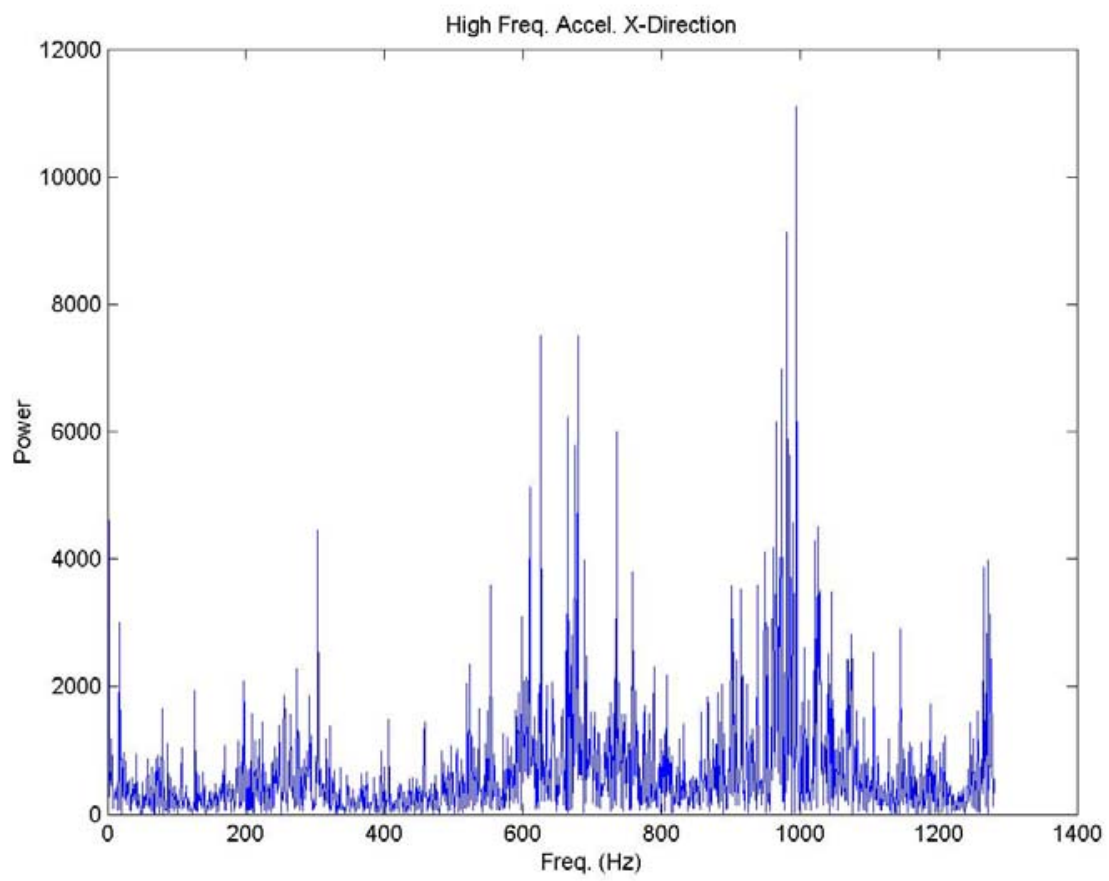

Figure 23-A: X-Direction (Left-Right Direction) Acceleration Frequency Analysis of Ramp Measured During Test 2 (V=130 knots, Ramp open, 0 degree deck)

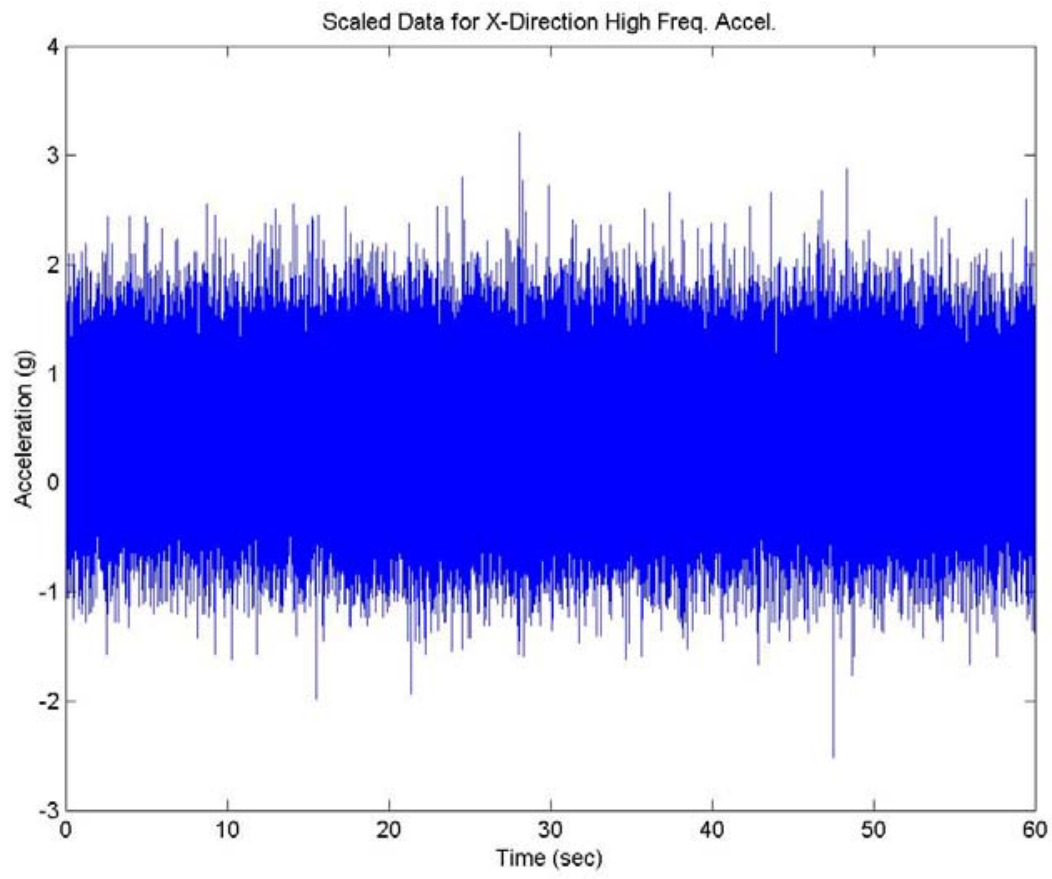

Figure 24-A: X-Direction (Right-Left Motion) Acceleration Signal for Ramp Measured During Test 2 ( $\mathrm{V}=130$ knots, Ramp open, 0 degree deck) 


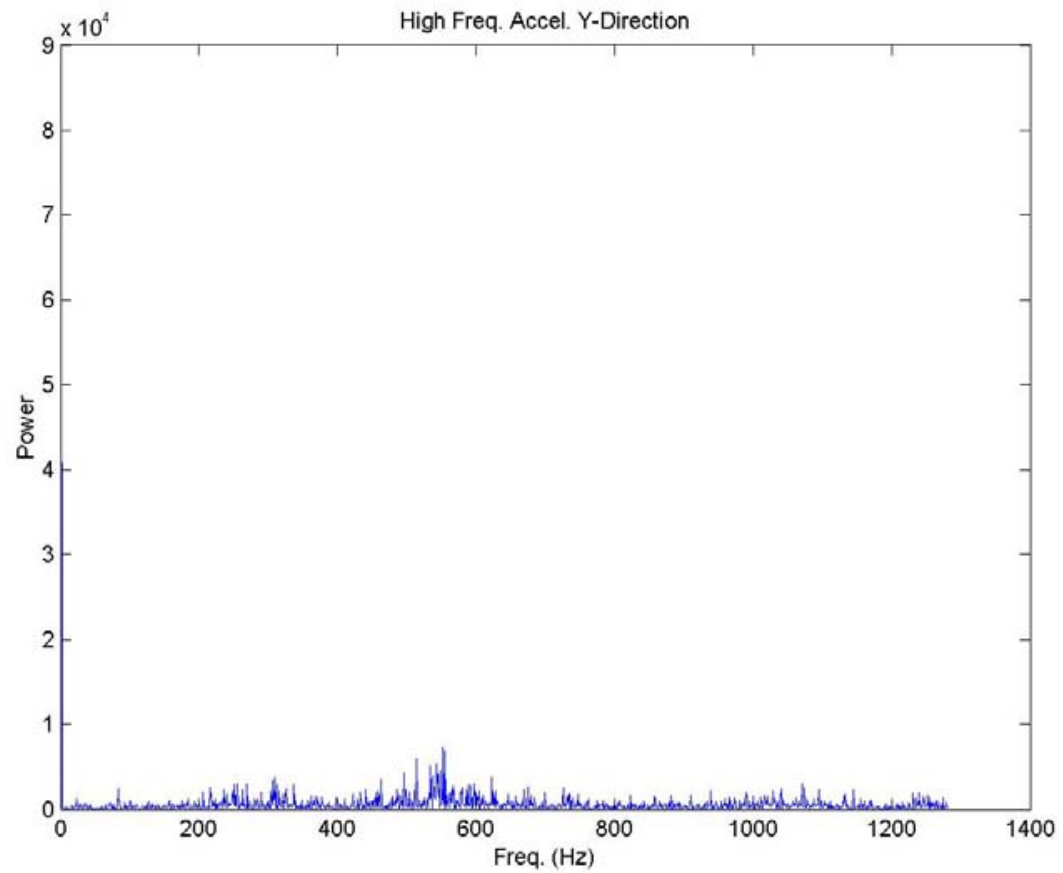

Figure 25-A: Y-Direction (Fore-Aft Motion) Acceleration Frequency Analysis of Ramp Measured During Test 2 (V=130 knots, Ramp open, 0 degree deck)

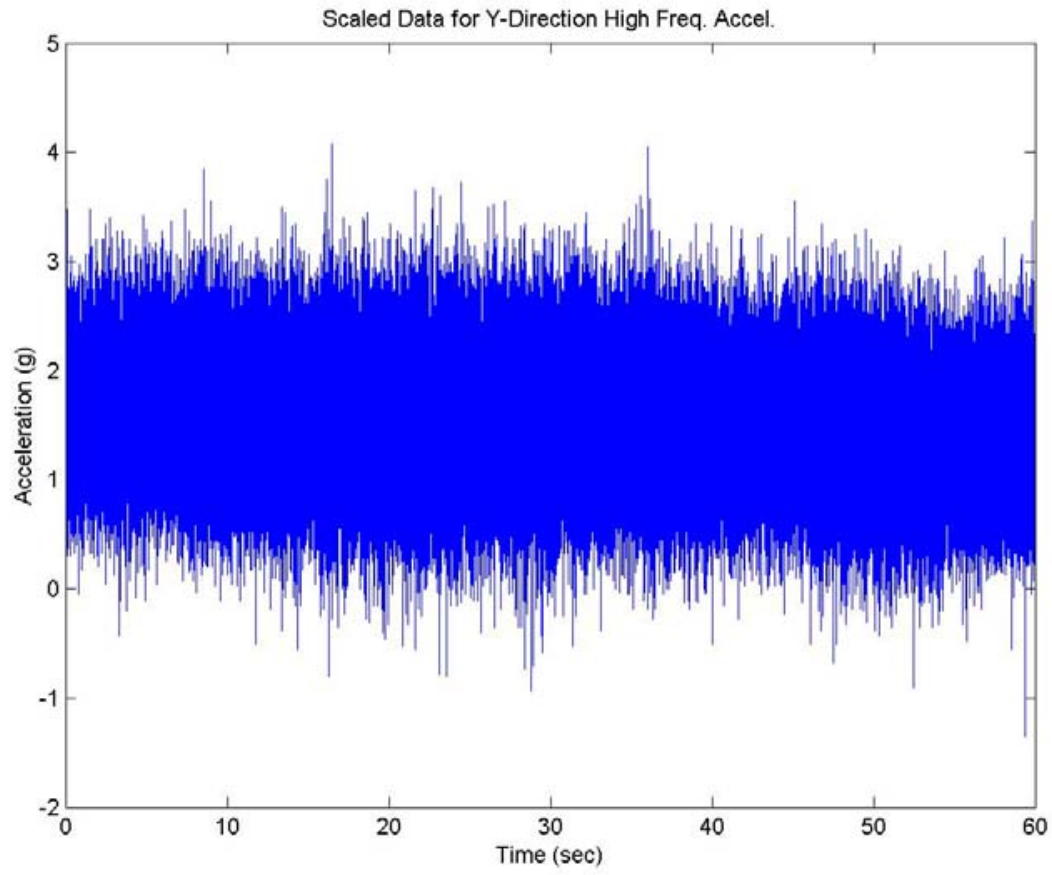

Figure 26-A: Y-Direction (Fore-Aft Motion) Acceleration Signal for Ramp Measured During Test 2 (V=130 knots, Ramp open, 0 degree deck) 


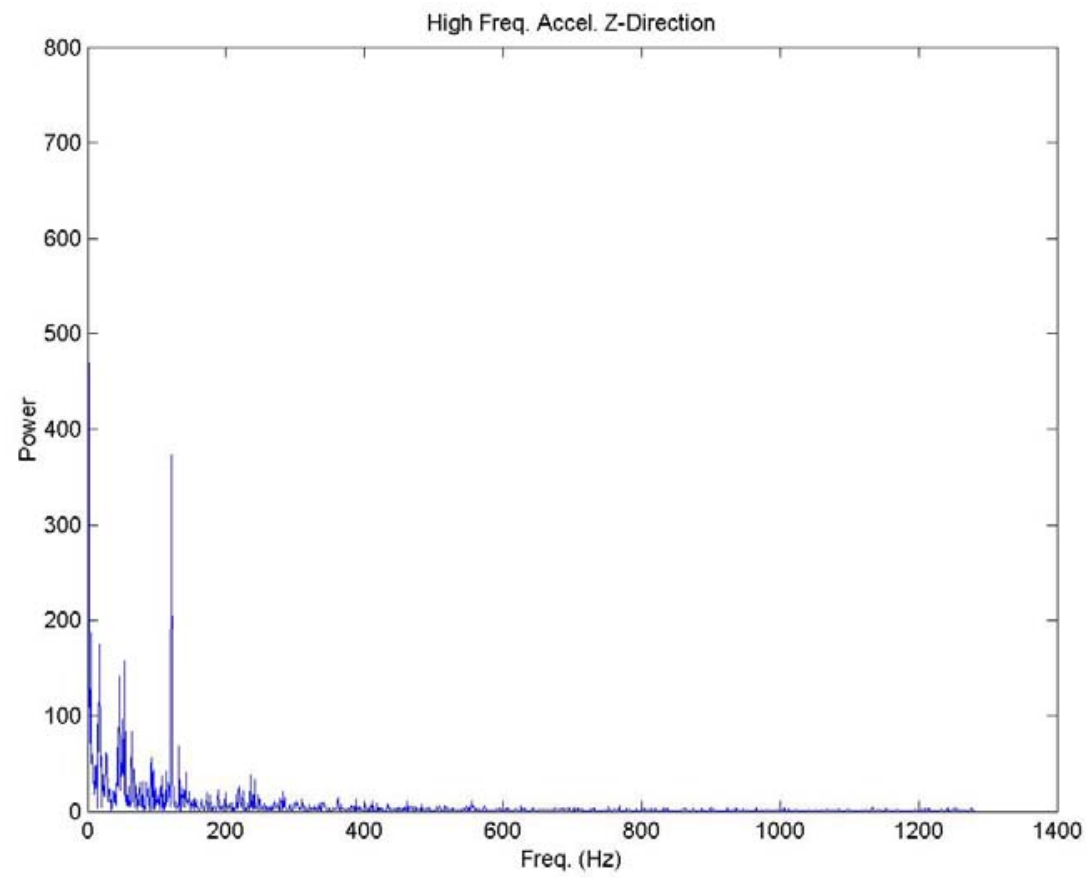

Figure 27-A: Z-Direction (Vertical) Acceleration Frequency Analysis of Ramp Measured During Test $2(\mathrm{~V}=130$ knots, Ramp open, 0 degree deck)

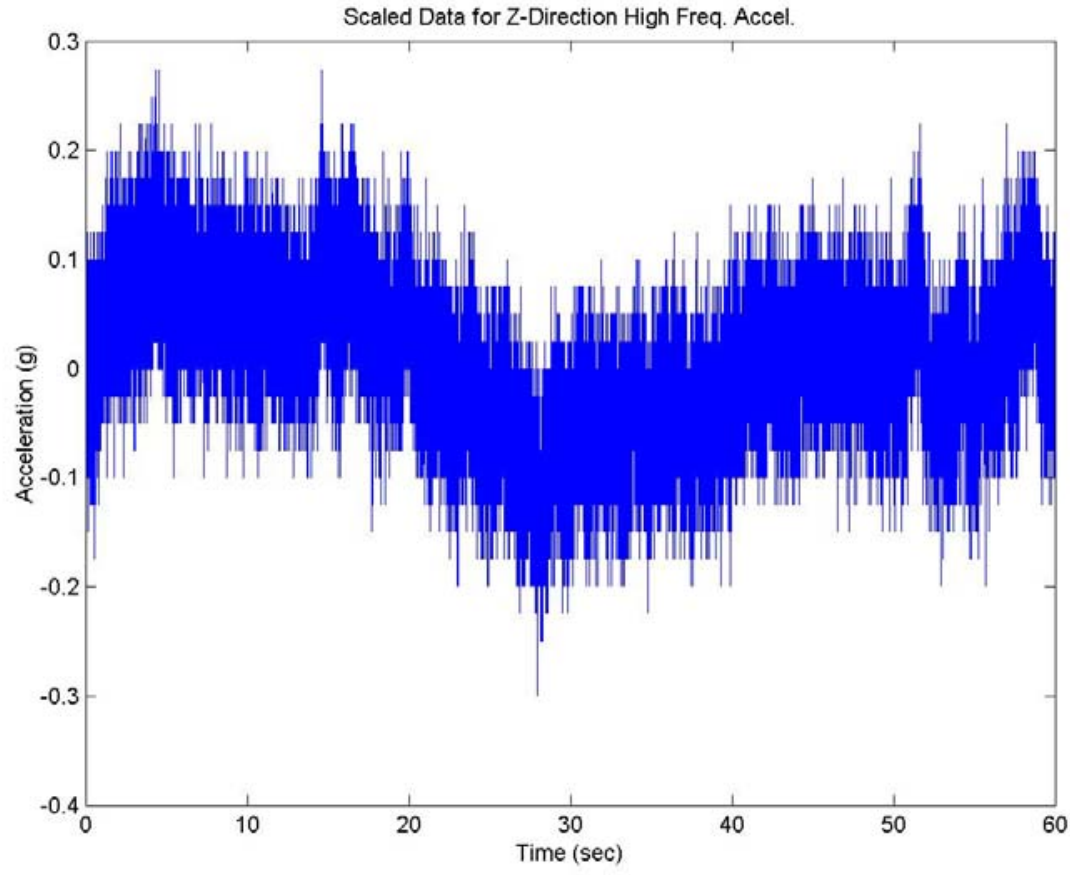

Figure 28-A: Z-Direction (Vertical) Acceleration Signal for Ramp Measured During Test 2 (V=130 knots, Ramp open, 0 degree deck) 
Test 1.3 (V=130 knots, Ramp open, 0 degree deck)

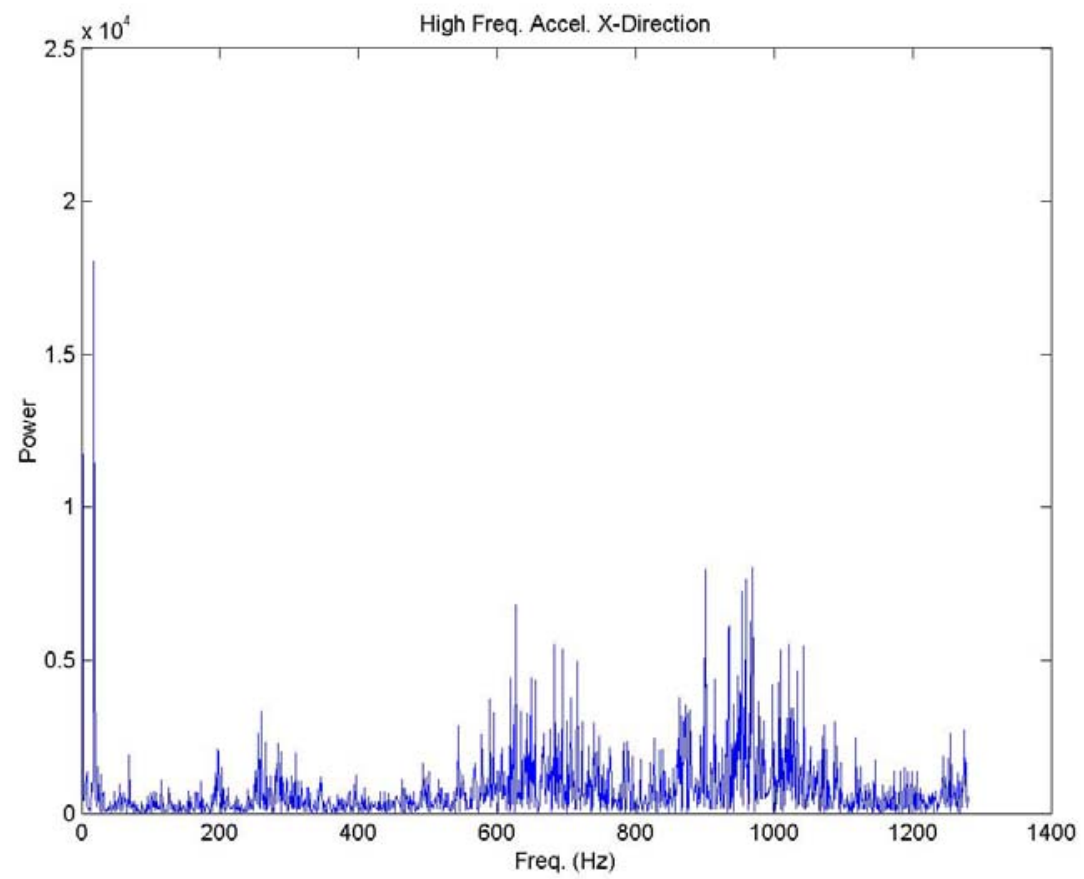

Figure 29-A: X-Direction (Left-Right Motion) Acceleration Frequency Analysis of Ramp Measured During Test 3 (V=130 knots, Ramp open, 0 degree deck)

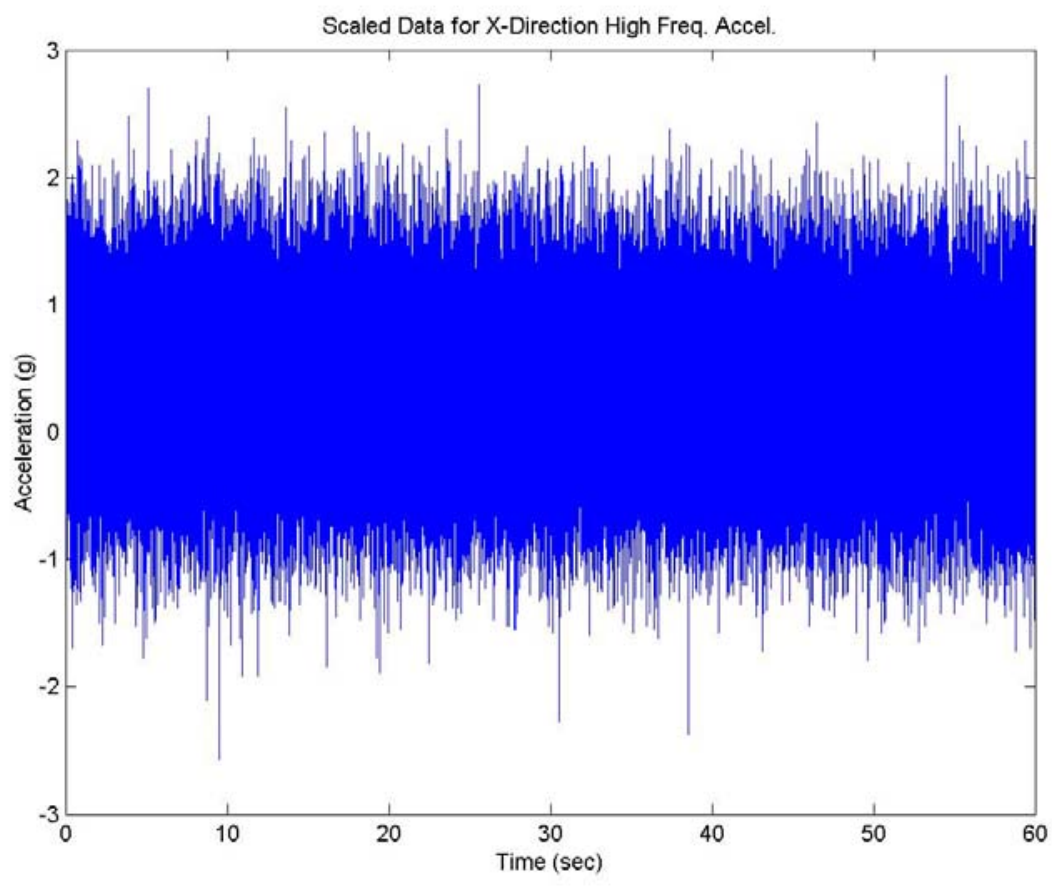

Figure 30-A: X-Direction (Right-Left Motion) Acceleration Signal for Ramp Measured During Test 3 ( $\mathrm{V}=130$ knots, Ramp open, 0 degree deck) 


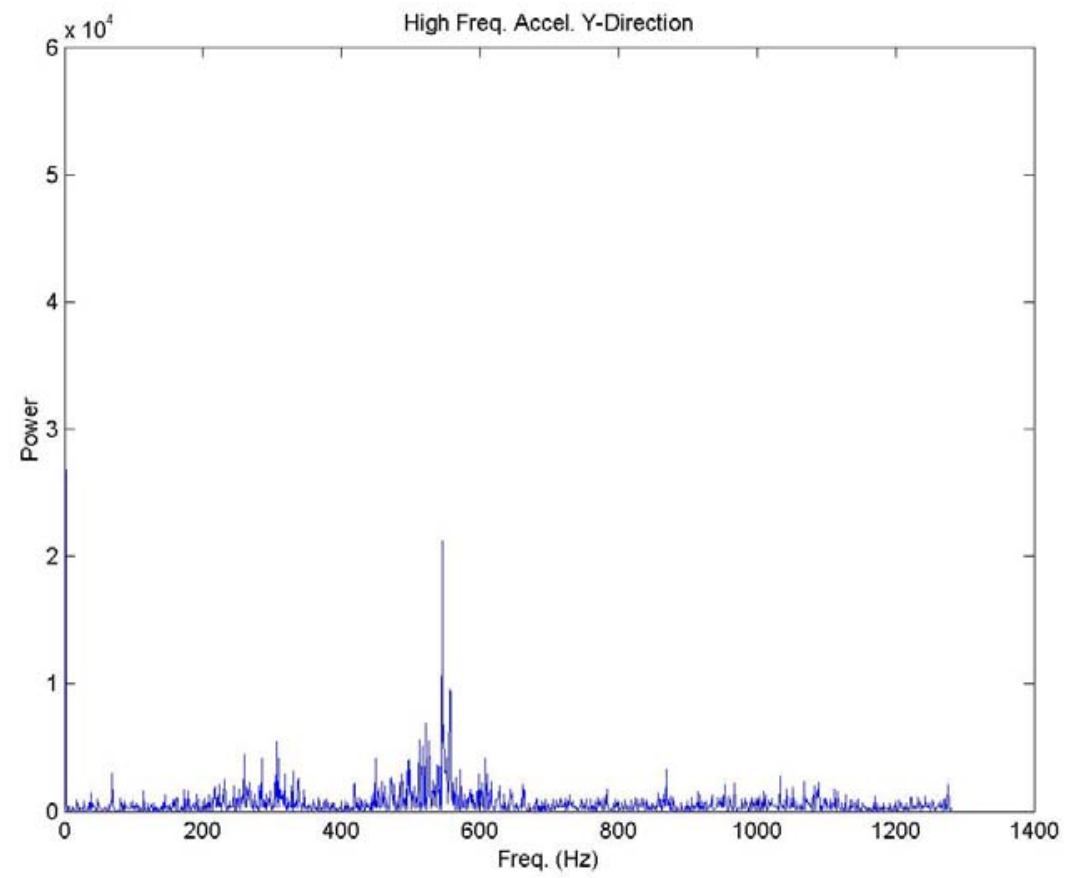

Figure 31-A: Y-Direction (Fore-Aft Motion) Acceleration Frequency Analysis of Ramp Measured During Test 3 (V=130 knots, Ramp open, 0 degree deck)

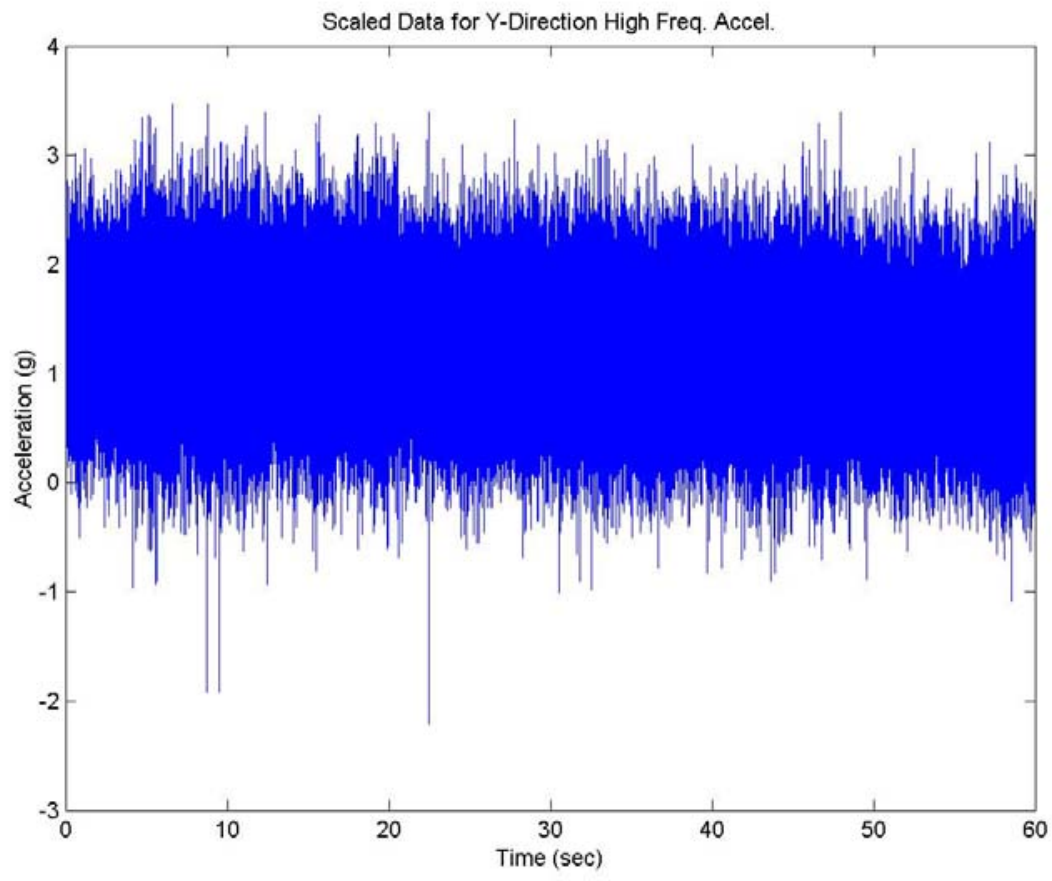

Figure 32-A: Y-Direction (Fore-Aft Motion) Acceleration Signal for Ramp Measured During Test 3 ( $\mathrm{V}=130$ knots, Ramp open, 0 degree deck) 


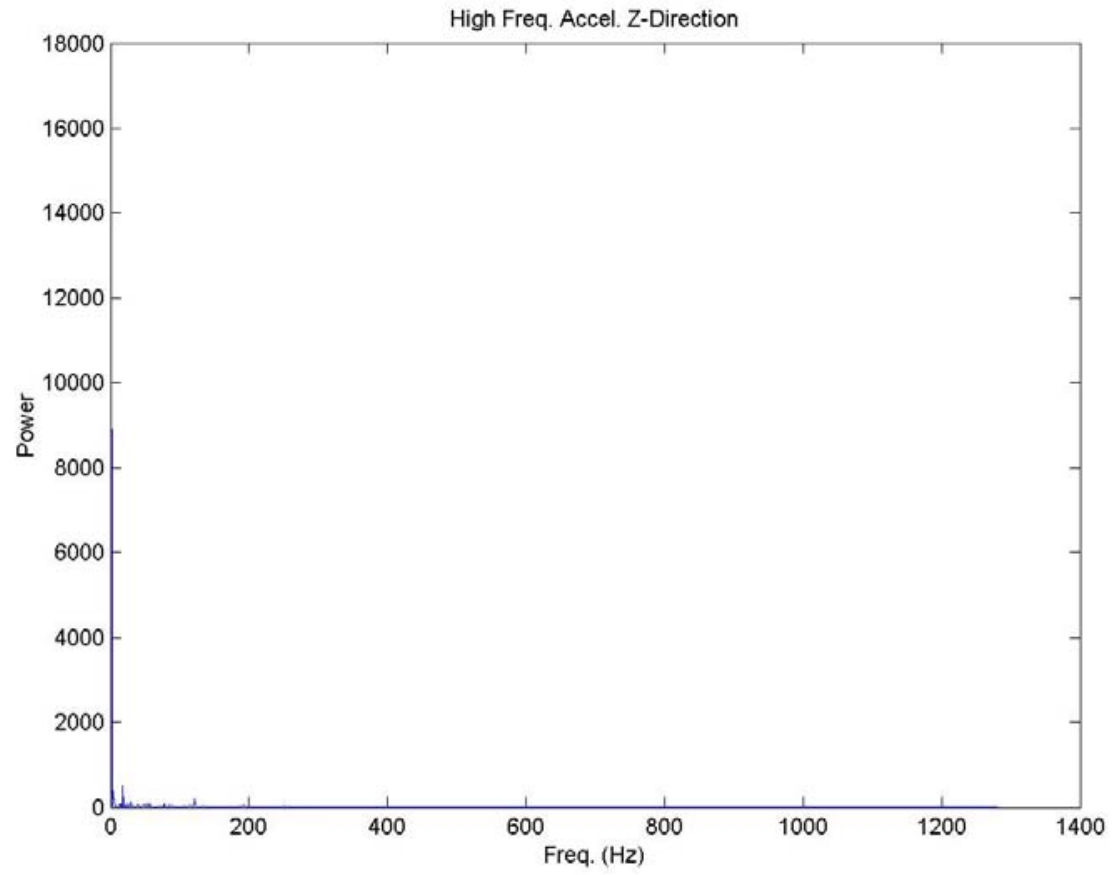

Figure 33-A: Z-Direction (Vertical) Acceleration Frequency Analysis of Ramp Measured During Test 3 ( $\mathrm{V}=130$ knots, Ramp open, 0 degree deck)

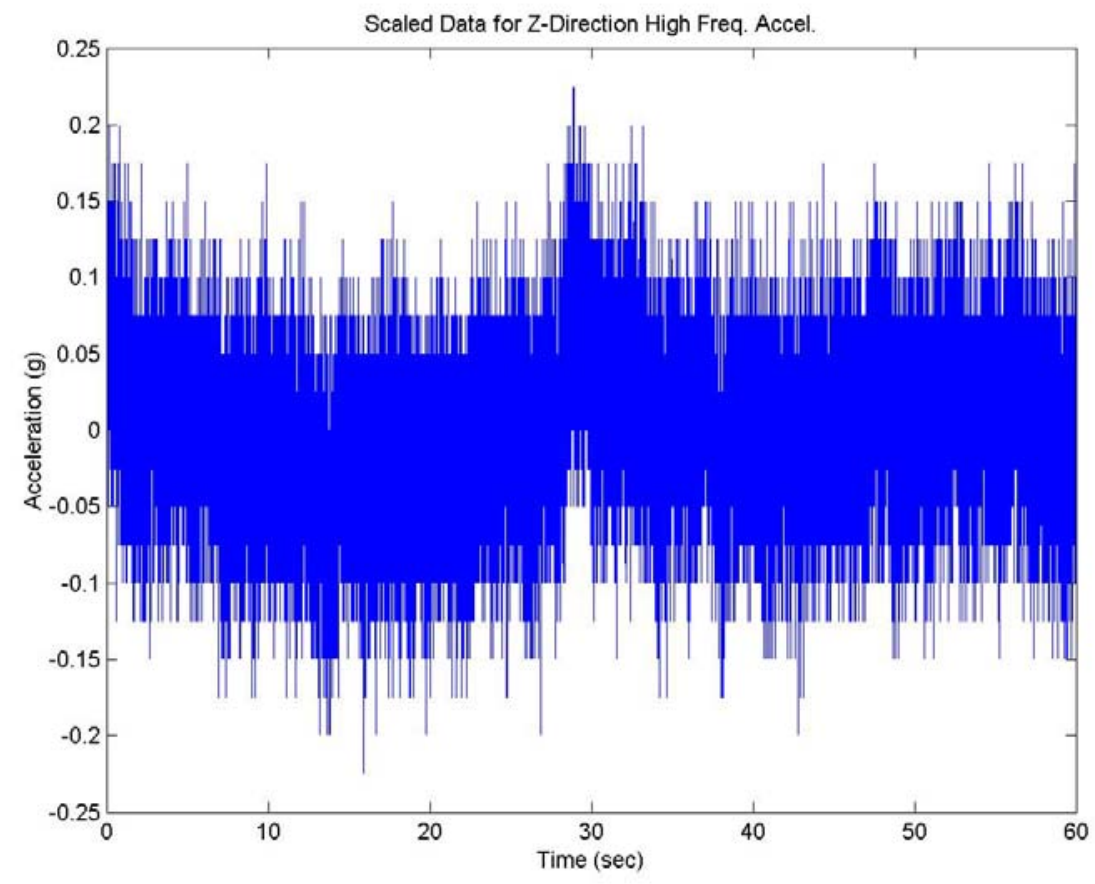

Figure 34-A: Z-Direction (Vertical) Acceleration Signal for Ramp Measured During Test 3 (V=130 knots, Ramp open, 0 degree deck) 


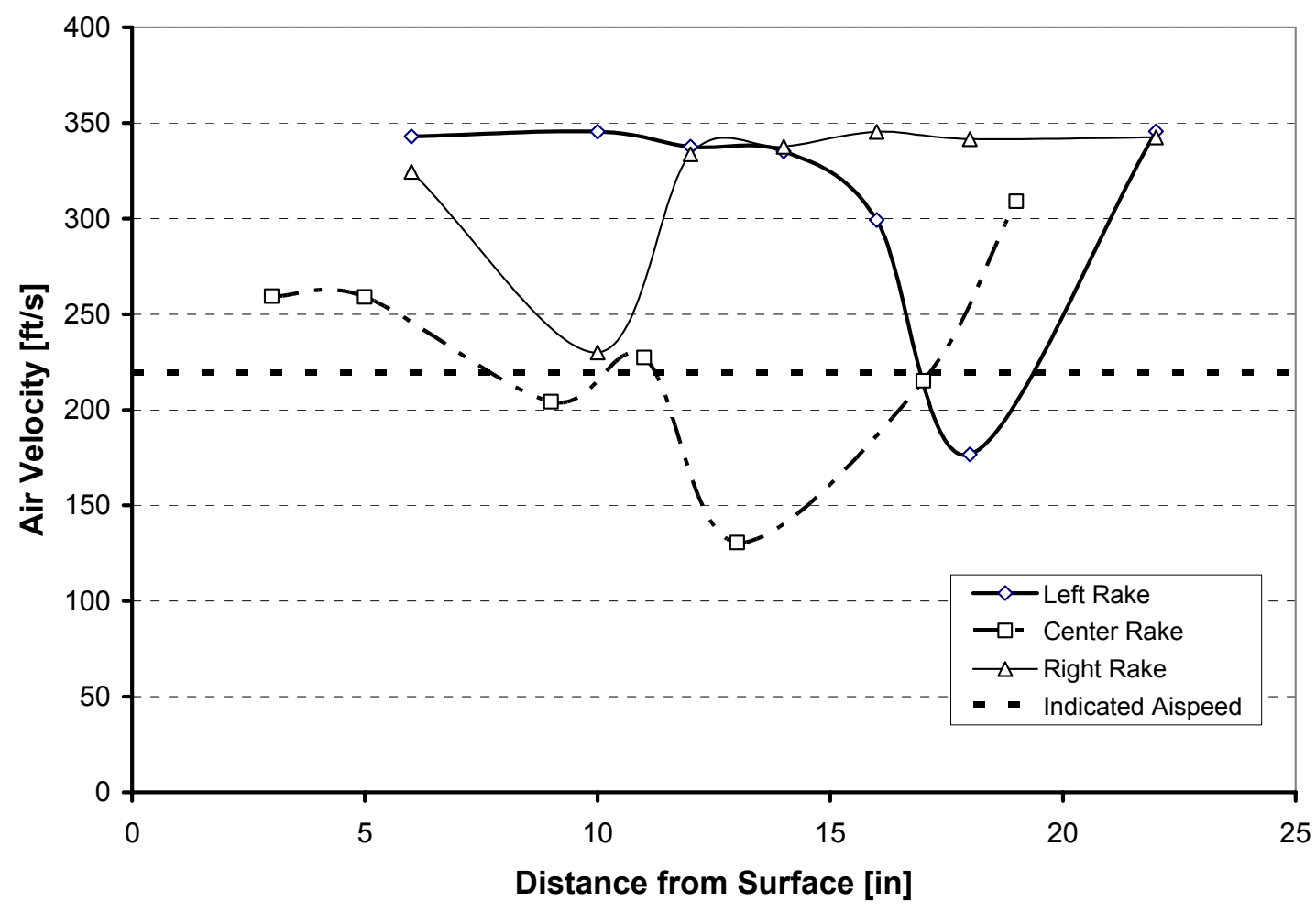

Figure 18-A: Average Velocity Measured in Direction of Flight for Test 1 (130 knots, ramp open, 0 deg deck angle) 
Test 2.1 (V=145 knots, Ramp open, 0 degree deck)

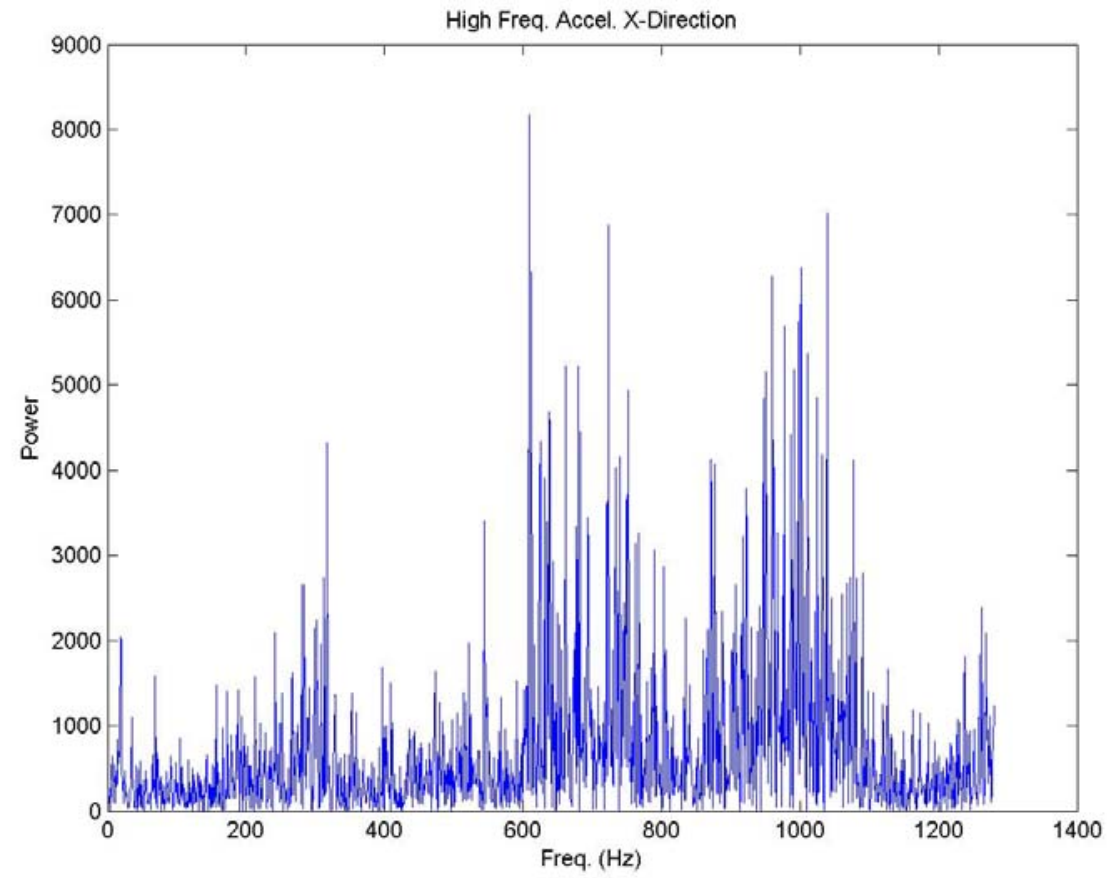

Figure 19-A: X-Direction (Right-Left Motion) Acceleration Frequency Analysis of Ramp Measured During Test 1 (V=145 knots, Ramp open, 0 degree deck)

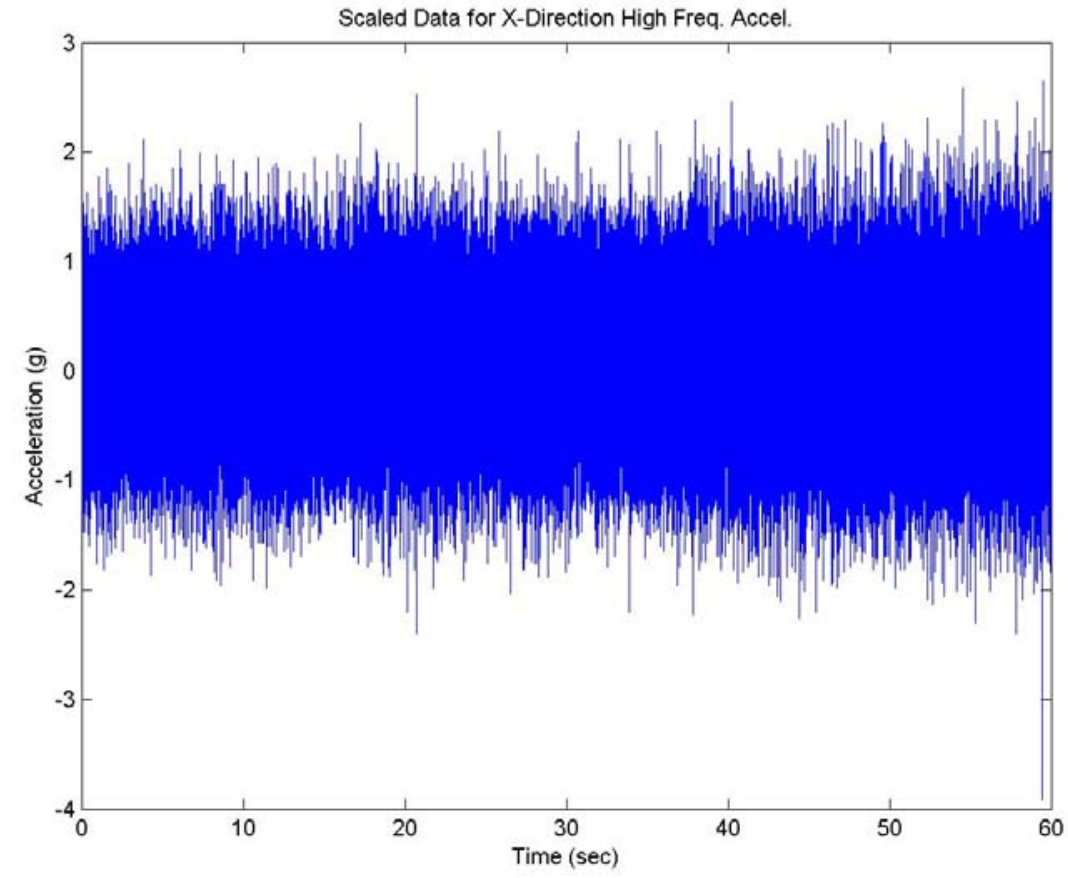

Figure 20-A: X-Direction (Right-Left Motion) Acceleration Signal for Ramp Measured During Test 1 (V=145 knots, Ramp open, 0 degree deck) 


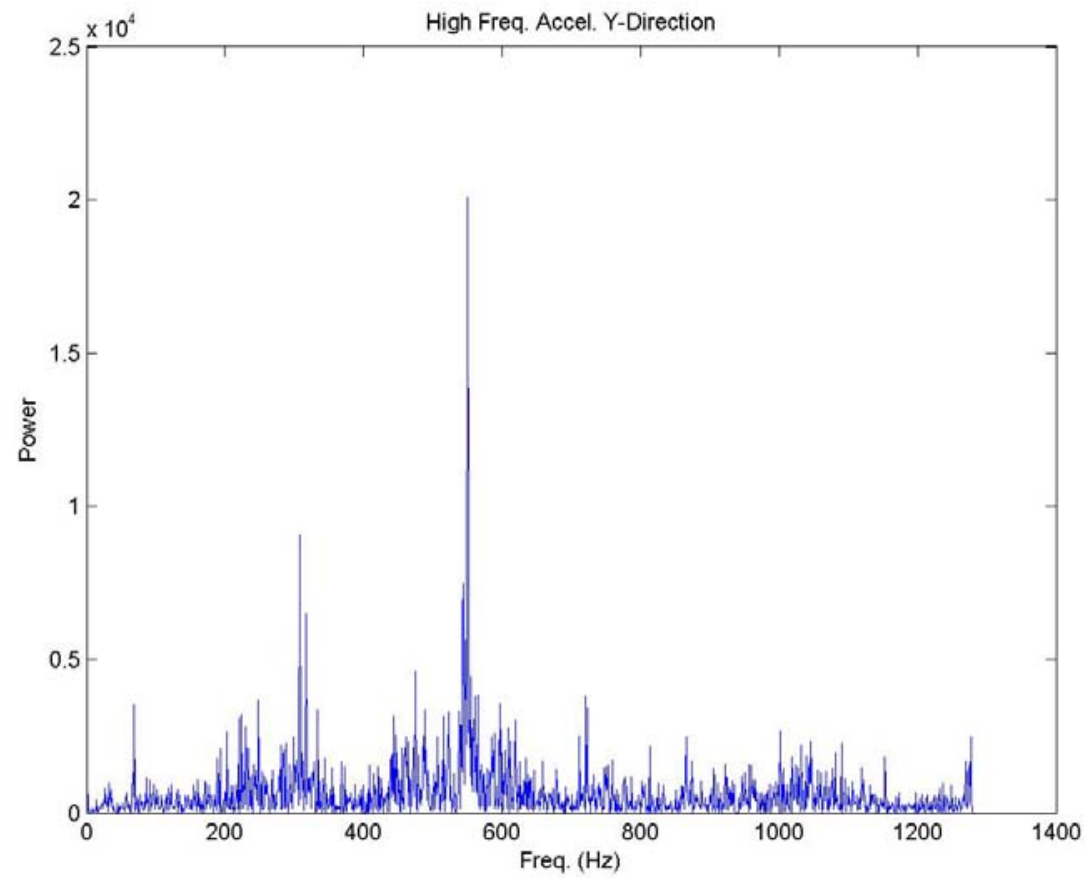

Figure 21-A: Y-Direction (Fore-Aft Motion) Acceleration Frequency Analysis of Ramp Measured During Test 1 (V=145 knots, Ramp open, 0 degree deck)

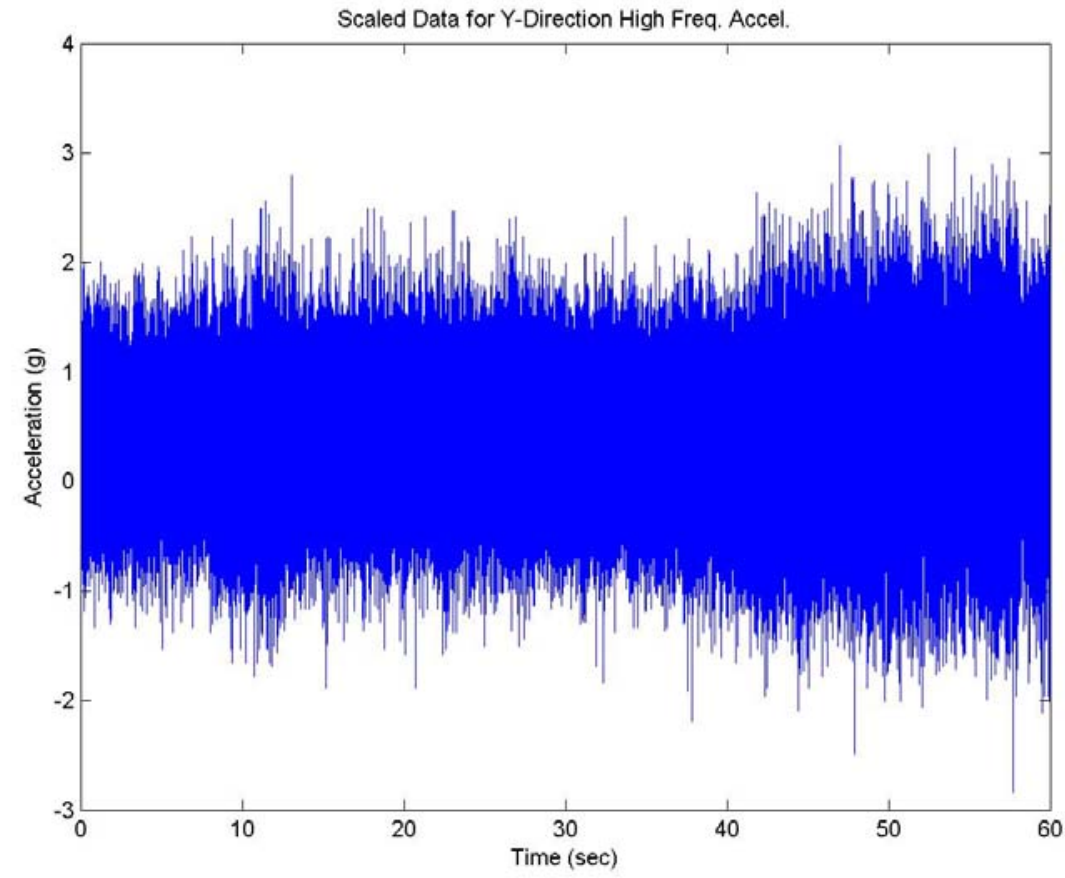

Figure 22-A: Y-Direction (Fore-Aft Motion) Acceleration Signal for Ramp Measured During Test 1 ( $\mathrm{V}=145$ knots, Ramp open, 0 degree deck) 


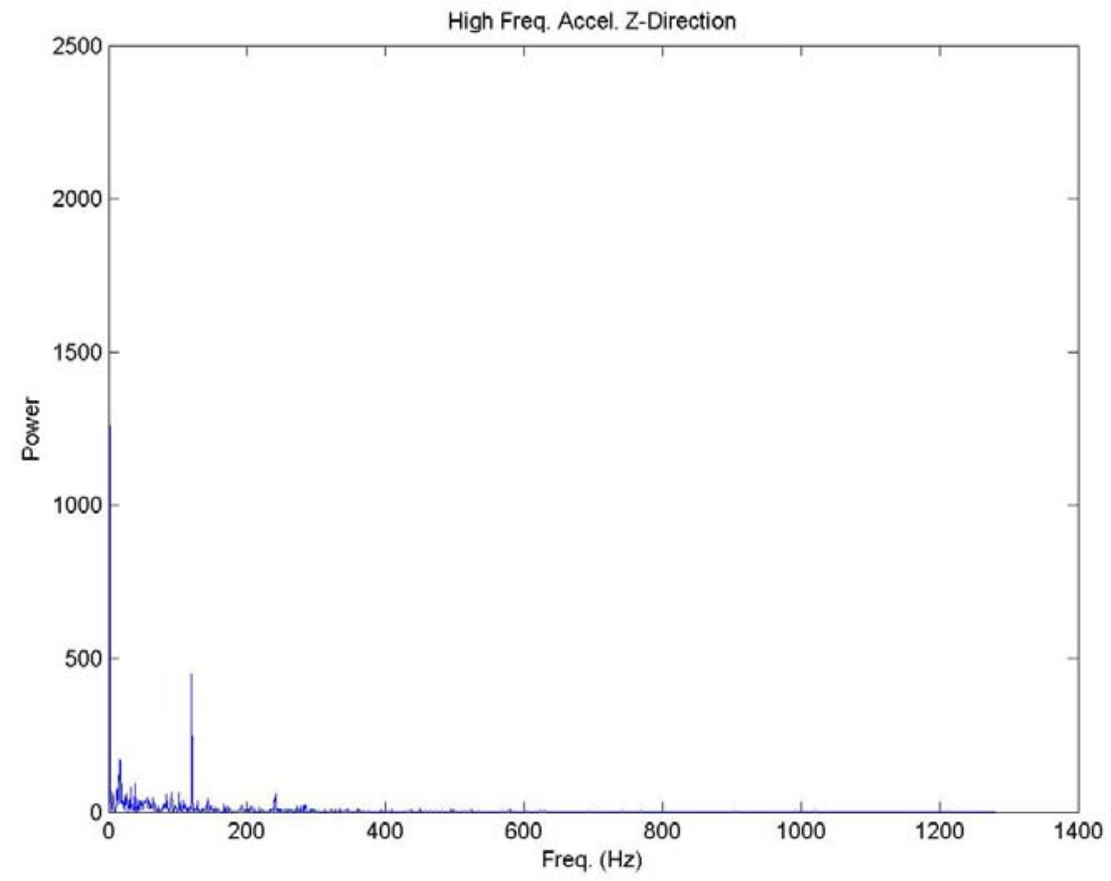

Figure 23-A: Z-Direction (Vertical) Acceleration Frequency Analysis of Ramp Measured During Test 1 (V=145 knots, Ramp open, 0 degree deck)

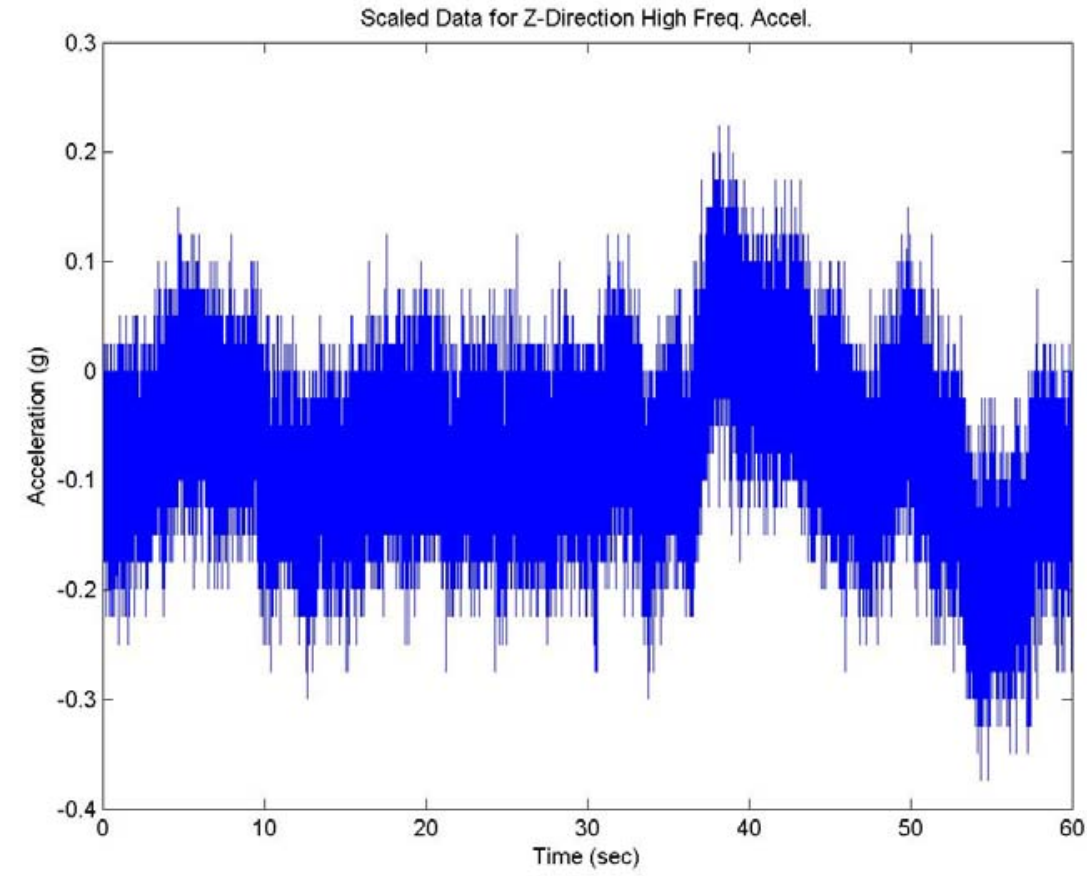

Figure 24-A: Z-Direction (Vertical) Acceleration Signal for Ramp Measured During Test 1 (V=145 knots, Ramp open, 0 degree deck) 
Test 2.2 (V=145 knots, Ramp open, 0 degree deck)

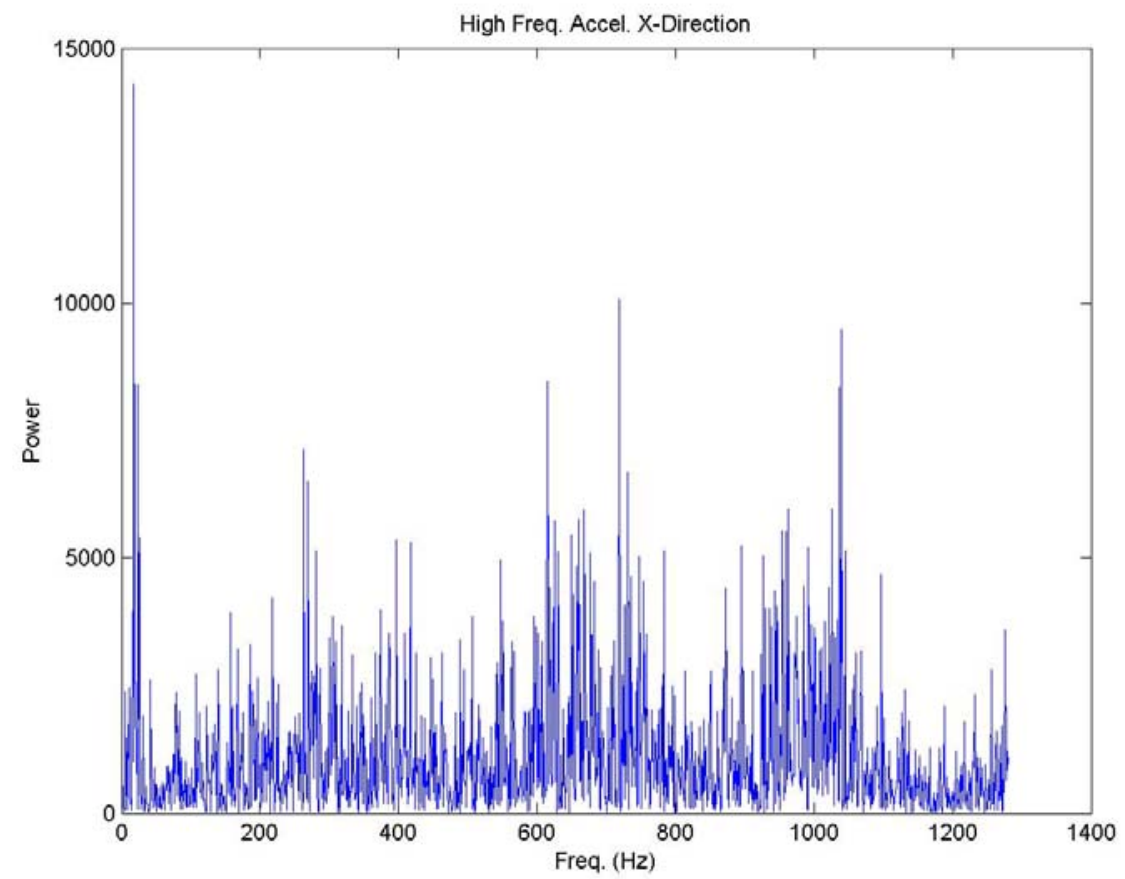

Figure 25-A: X-Direction (Right-Left Motion) Acceleration Frequency Analysis of Ramp Measured During Test 2 ( $V=145$ knots, Ramp open, 0 degree deck)

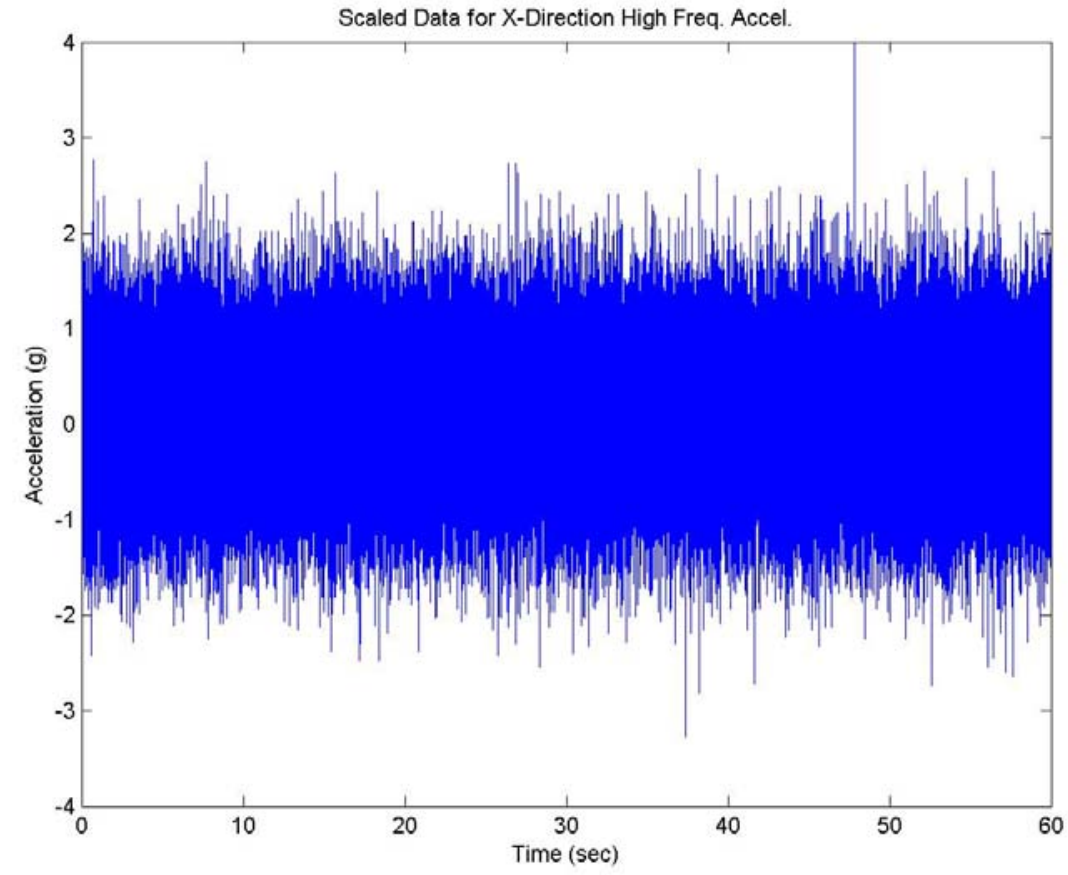

Figure 26-A: X-Direction (Right-Left Motion) Acceleration Signal for Ramp Measured During Test 2 ( $V=145$ knots, Ramp open, 0 degree deck) 


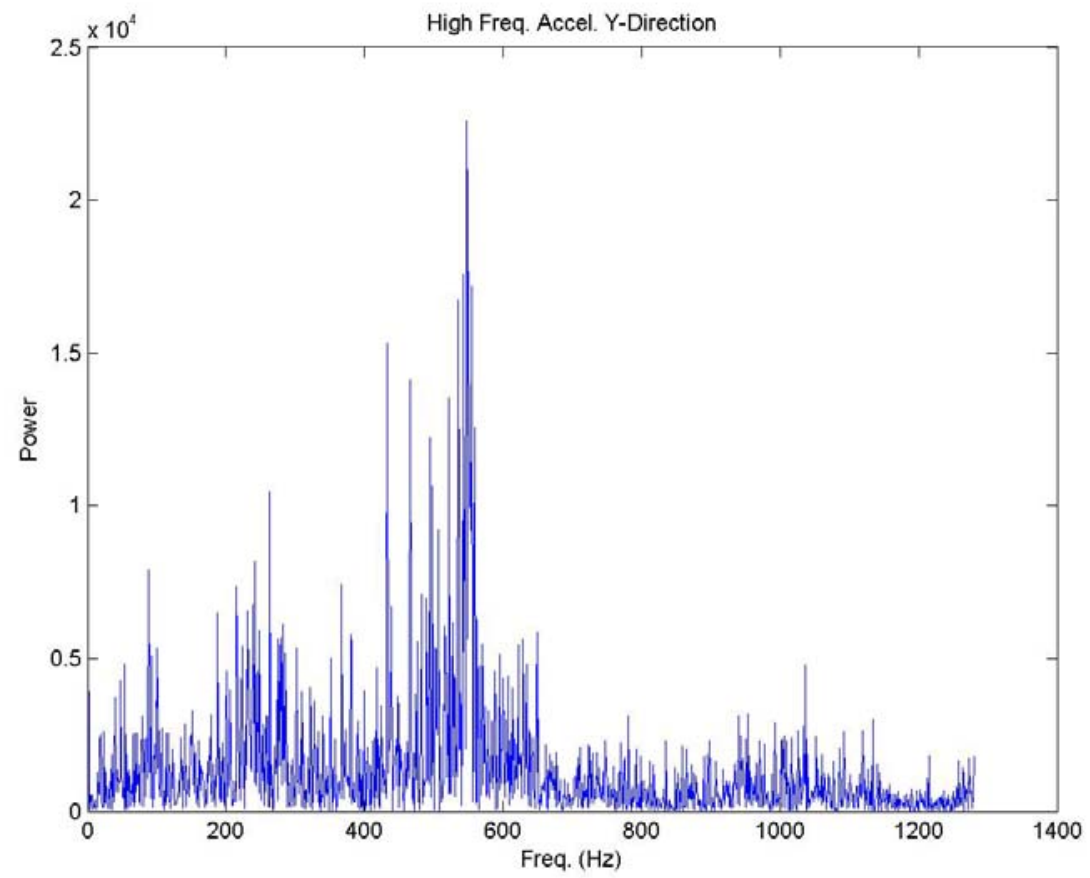

Figure 27-A: Y-Direction (Fore-Aft Motion) Acceleration Frequency Analysis of Ramp Measured During Test 2 (V=145 knots, Ramp open, 0 degree deck)

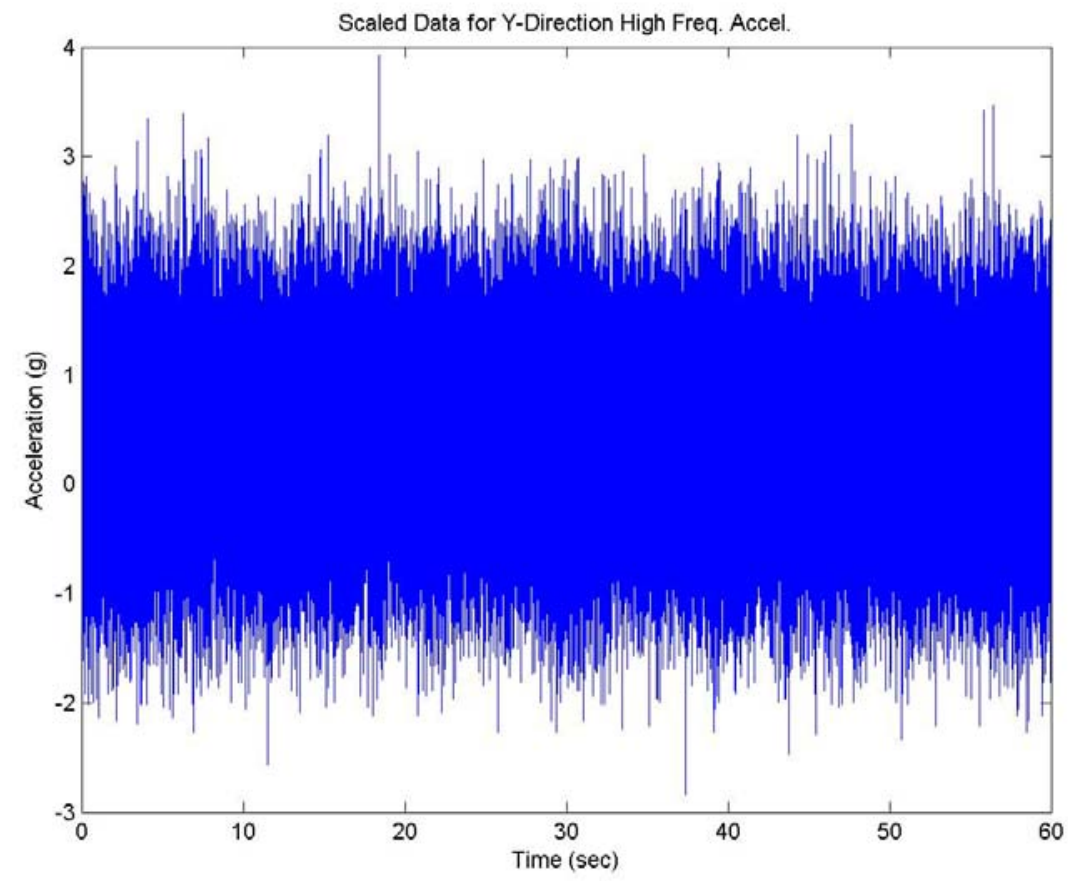

Figure 28-A: Y-Direction (Fore-Aft Motion) Acceleration Signal for Ramp Measured During Test 2 ( $\mathrm{V}=145$ knots, Ramp open, 0 degree deck) 


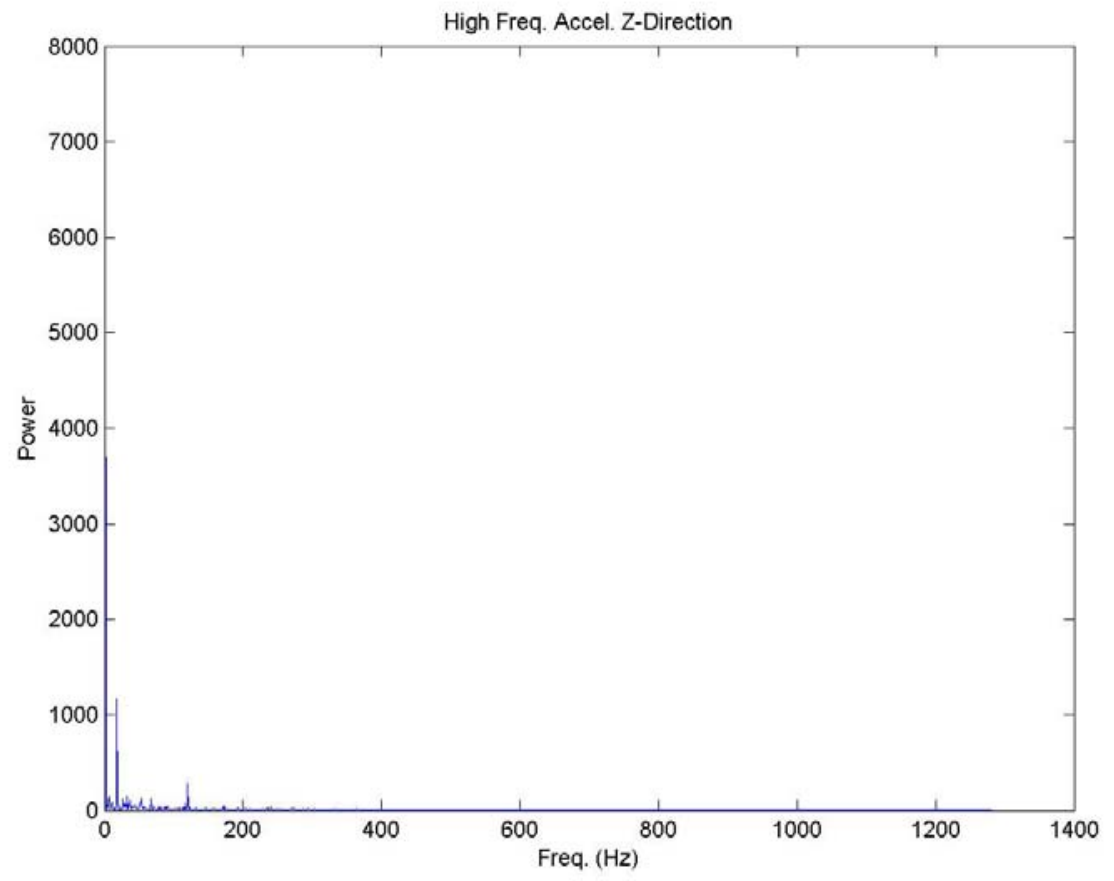

Figure 29-A: Z-Direction (Vertical) Acceleration Frequency Analysis of Ramp Measured During Test 2 ( $V=145$ knots, Ramp open, 0 degree deck)

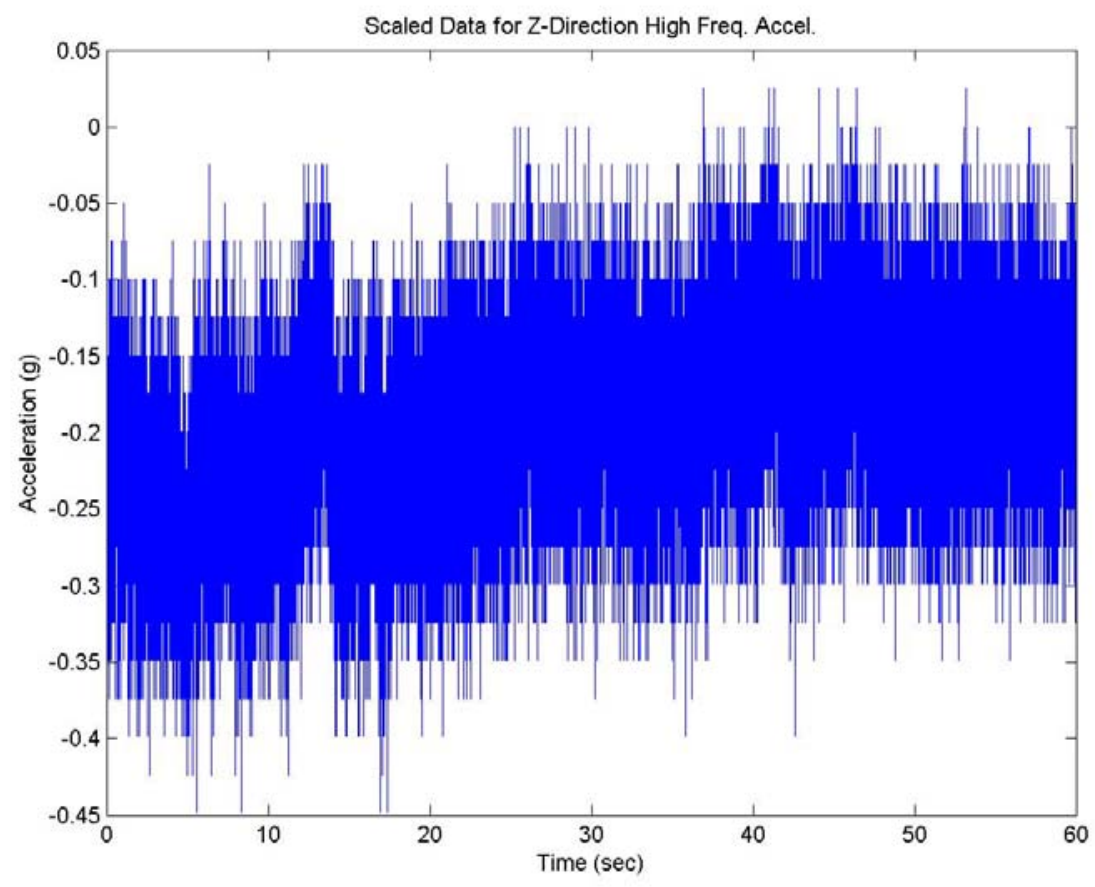

Figure 30-A: Z-Direction (Vertical) Acceleration Signal for Ramp Measured During Test $2 \quad$ (V=145 knots, Ramp open, 0 degree deck) 
Test 2.3 ( $V=145$ knots, Ramp open, 0 degree deck)

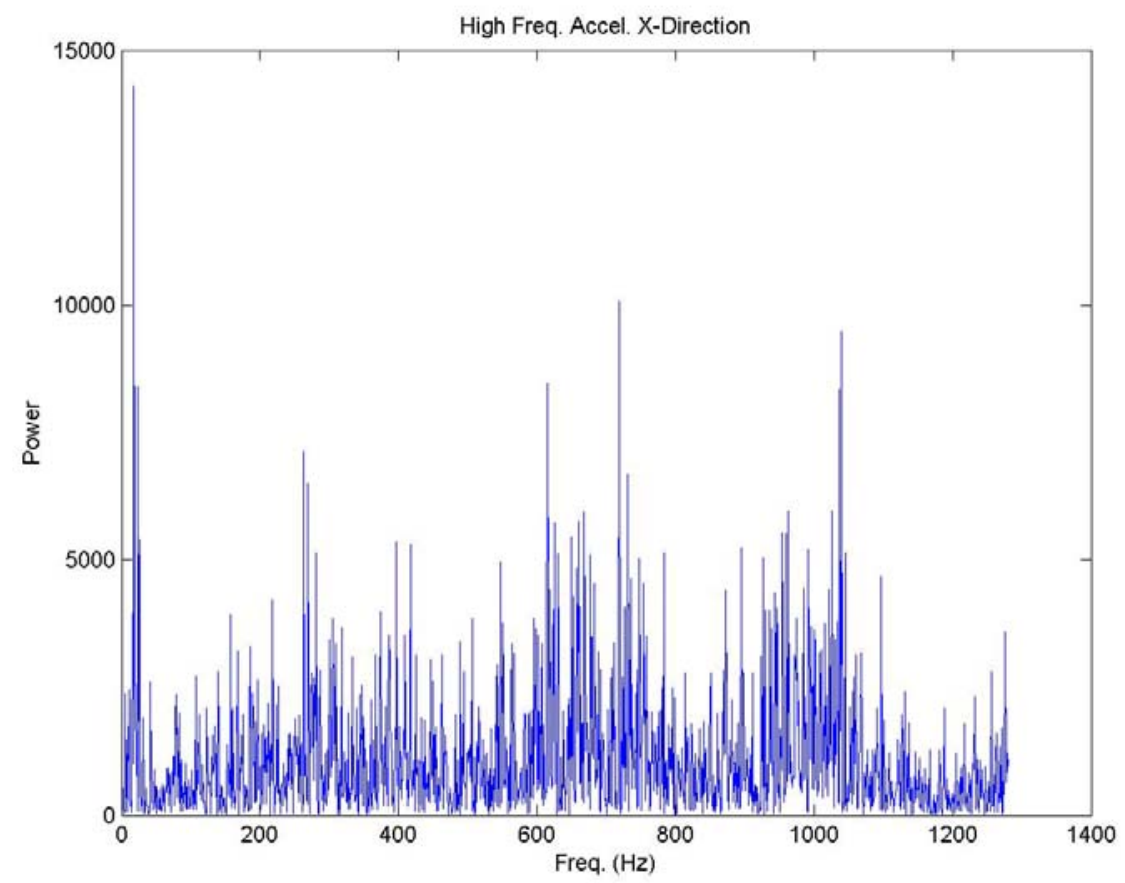

Figure 31-A: X-Direction (Right-Left Motion) Acceleration Frequency Analysis of Ramp Measured During Test 3 (V=145 knots, Ramp open, 0 degree deck)

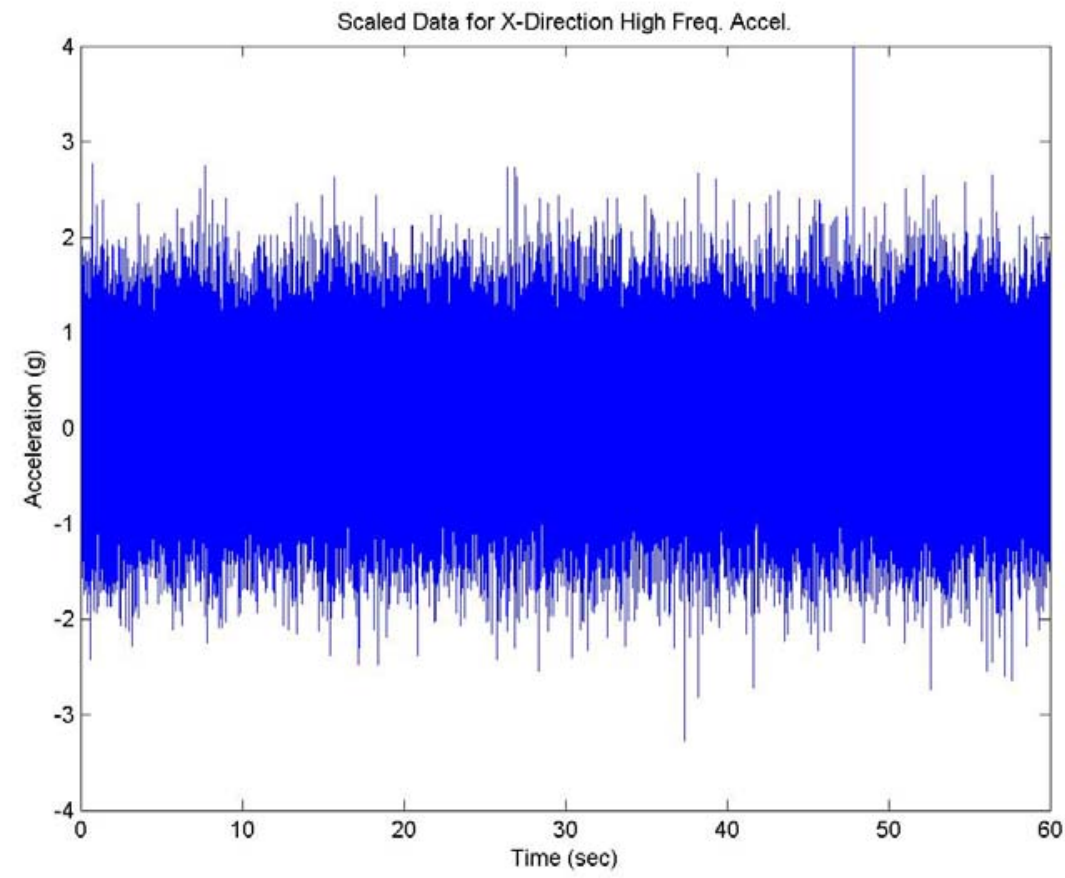

Figure 32-A: X-Direction (Right-Left Motion) Acceleration Signal for Ramp Measured During Test 3 ( $\mathrm{V}=145$ knots, Ramp open, 0 degree deck) 


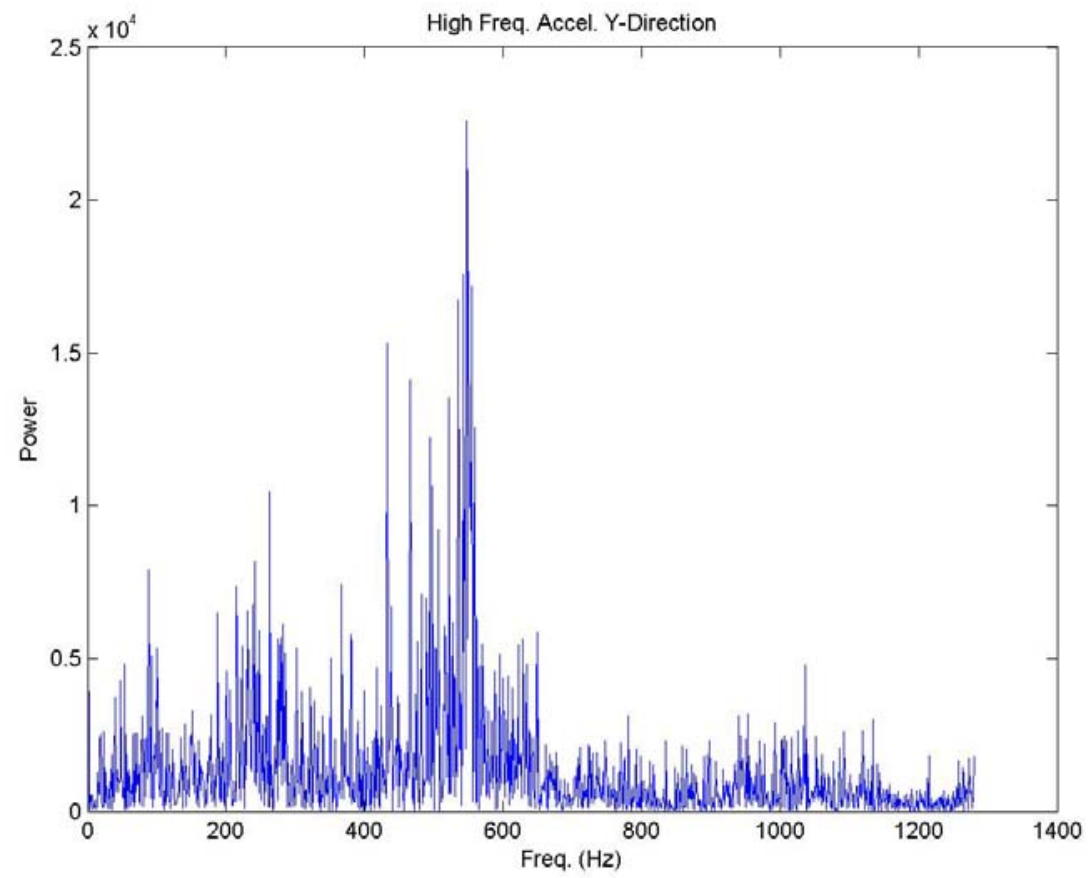

Figure 33-A: Y-Direction (Fore-Aft Position) Acceleration Frequency Analysis of Ramp Measured During Test 3 (V=145 knots, Ramp open, 0 degree deck)

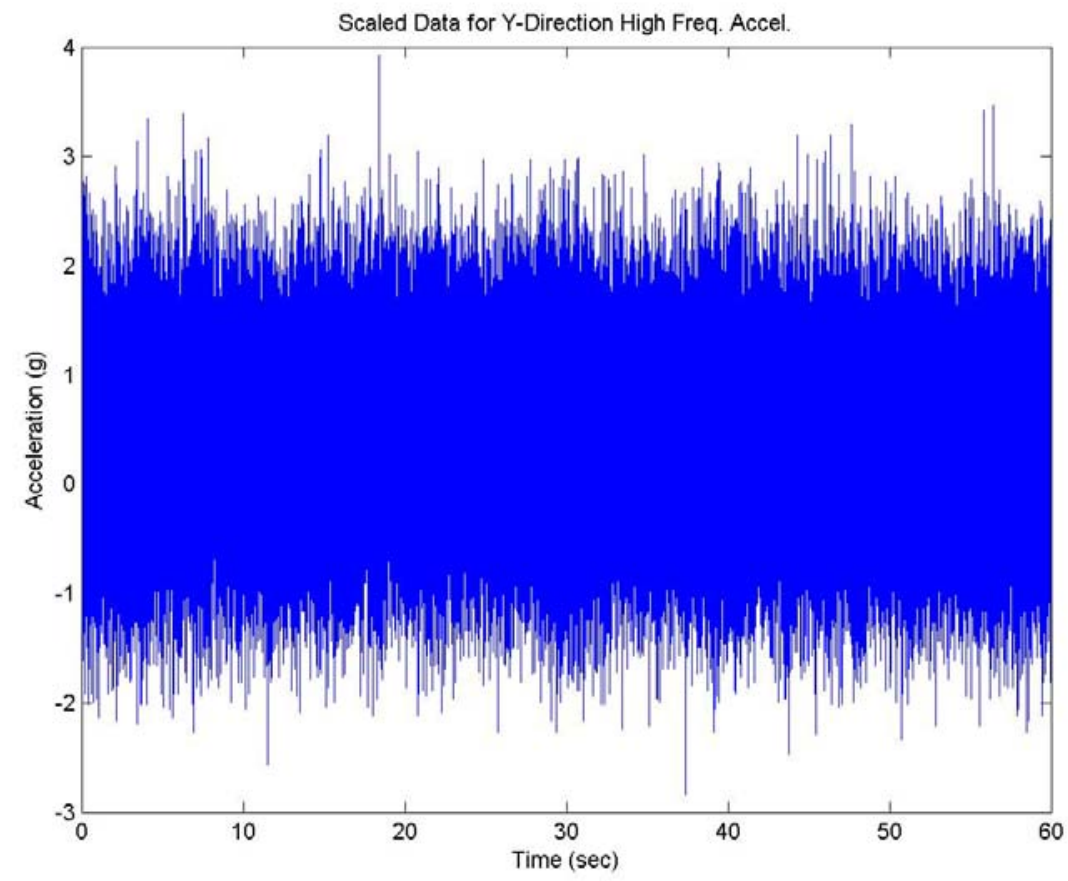

Figure 34-A: Y-Direction (Fore-Aft Position) Acceleration Signal for Ramp Measured During Test 3 ( $\mathrm{V}=145$ knots, Ramp open, 0 degree deck) 


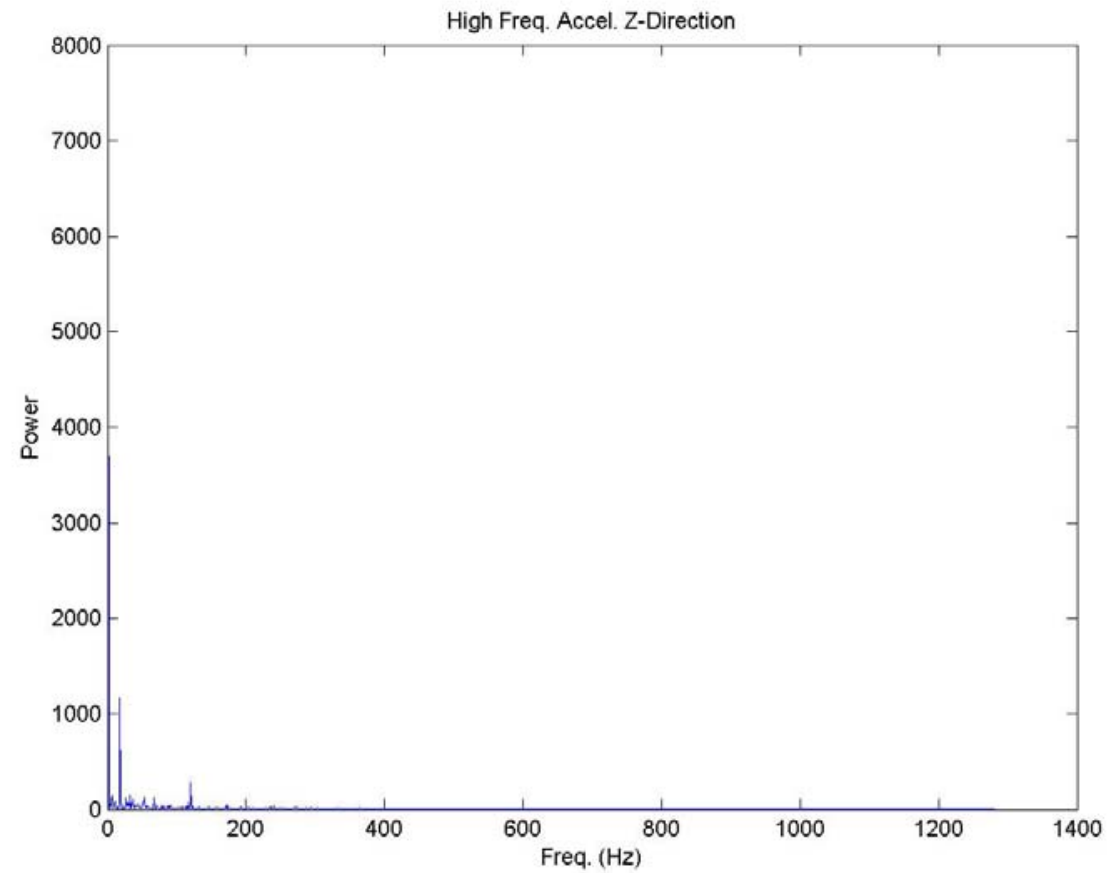

Figure 35-A: Z-Direction (Vertical) Acceleration Frequency Analysis of Ramp Measured During Test 3 ( $\mathrm{V}=145$ knots, Ramp open, 0 degree deck)

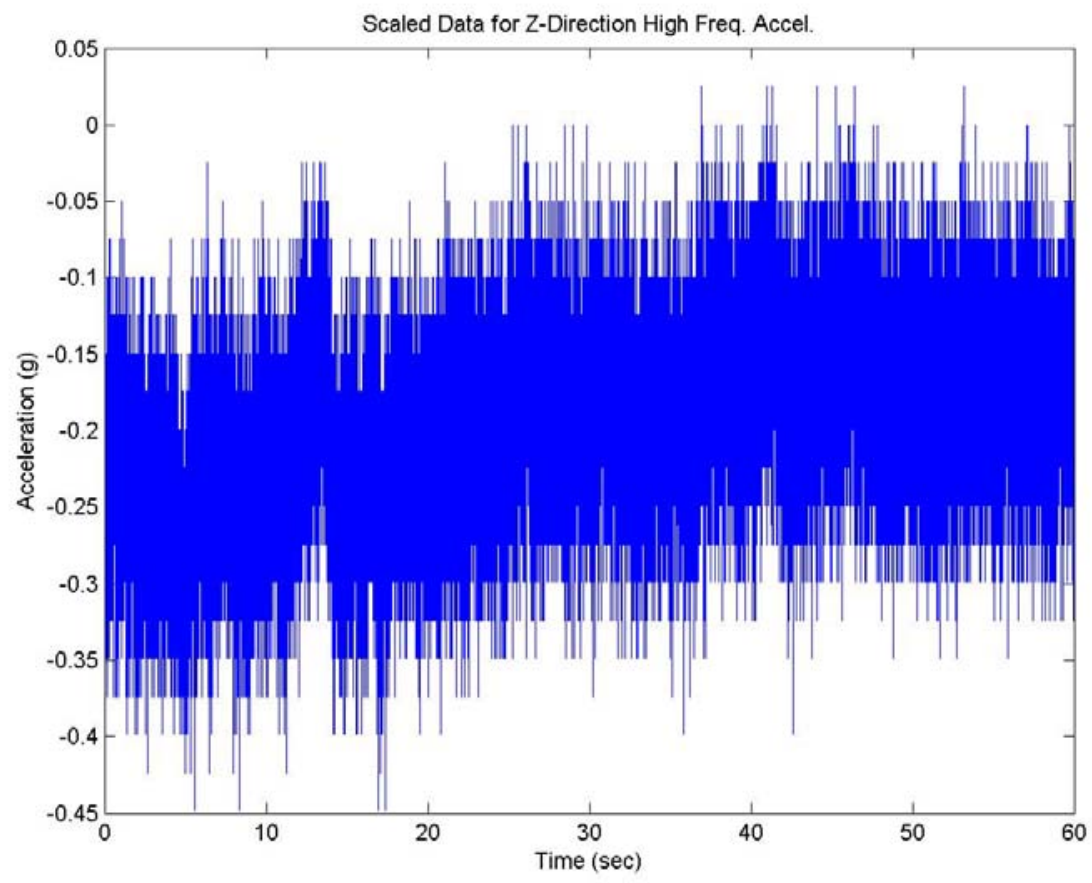

Figure 36-A: Z-Direction (Vertical) Acceleration Signal for Ramp Measured During Test $3 \quad$ (V=145 knots, Ramp open, 0 degree deck) 


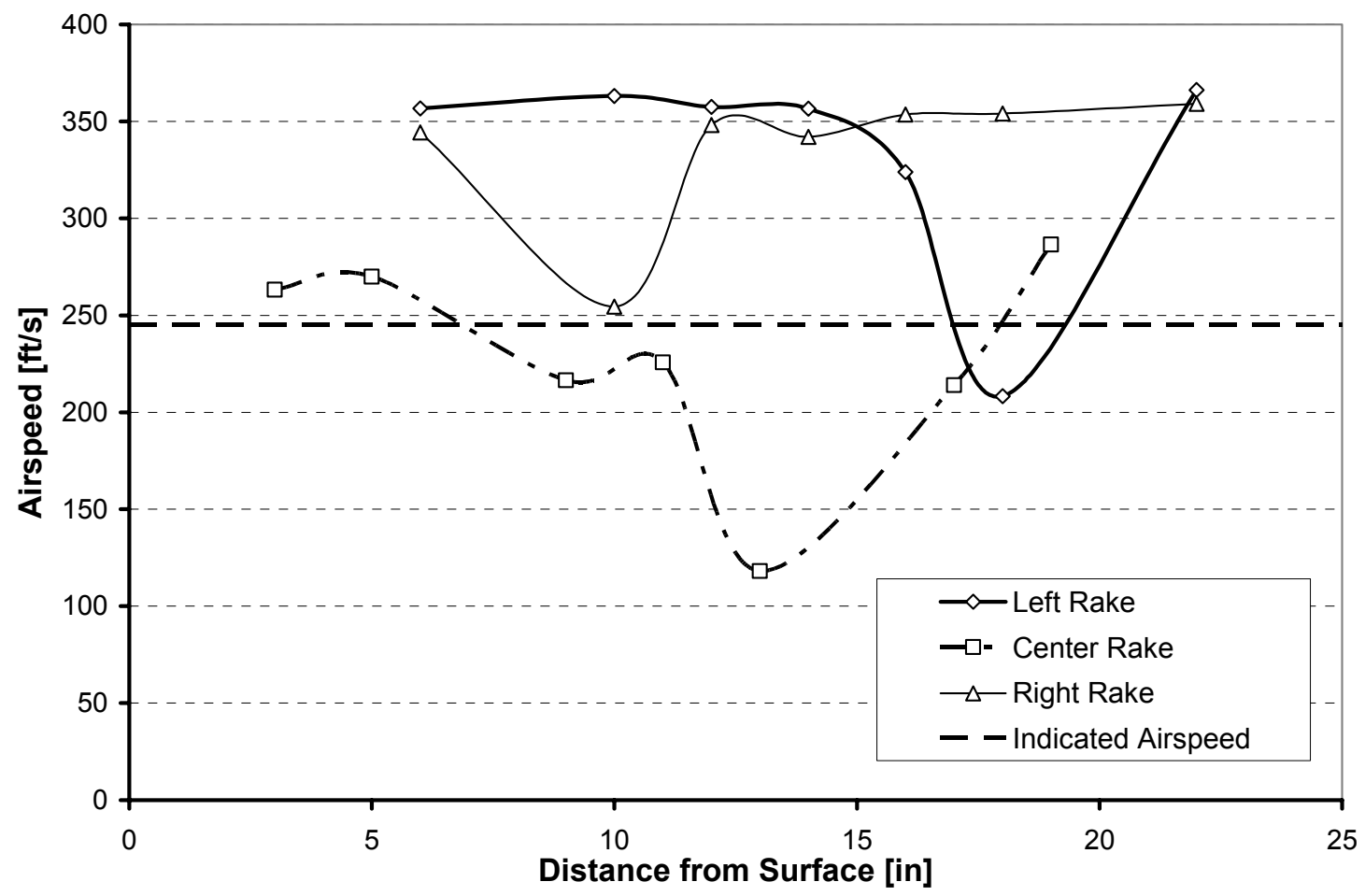

Figure 37-A: Average Velocity Measured in Direction of Flight for Test 1 (145 knots, ramp open, 0 deg deck angle) 
Appendix B

Modal Analysis

3 Studies 


\section{Study \#1}

\section{Part A: Arm without Cross-Braces}

Table 1-B: Natural Frequencies of Mechanical Arm Structure without Cross-Brace Support

\begin{tabular}{|c|c|c|}
\hline \multicolumn{3}{|c|}{ Arm w/out Braces } \\
\hline Mode & Natural Frequencies & Convergence (\%) \\
\hline 1 & 7 & 0.6 \\
2 & 16 & 0.3 \\
3 & 22 & 0.5 \\
4 & 46 & 0.8 \\
5 & 47 & 0.8 \\
6 & 47 & 0.9 \\
7 & 50 & 0.9 \\
8 & 100 & 0.4 \\
9 & 101 & 1 \\
10 & 108 & 1.2 \\
\hline
\end{tabular}

Table 2-B: P-Pass Convergence within 10\% of Modal Frequency.

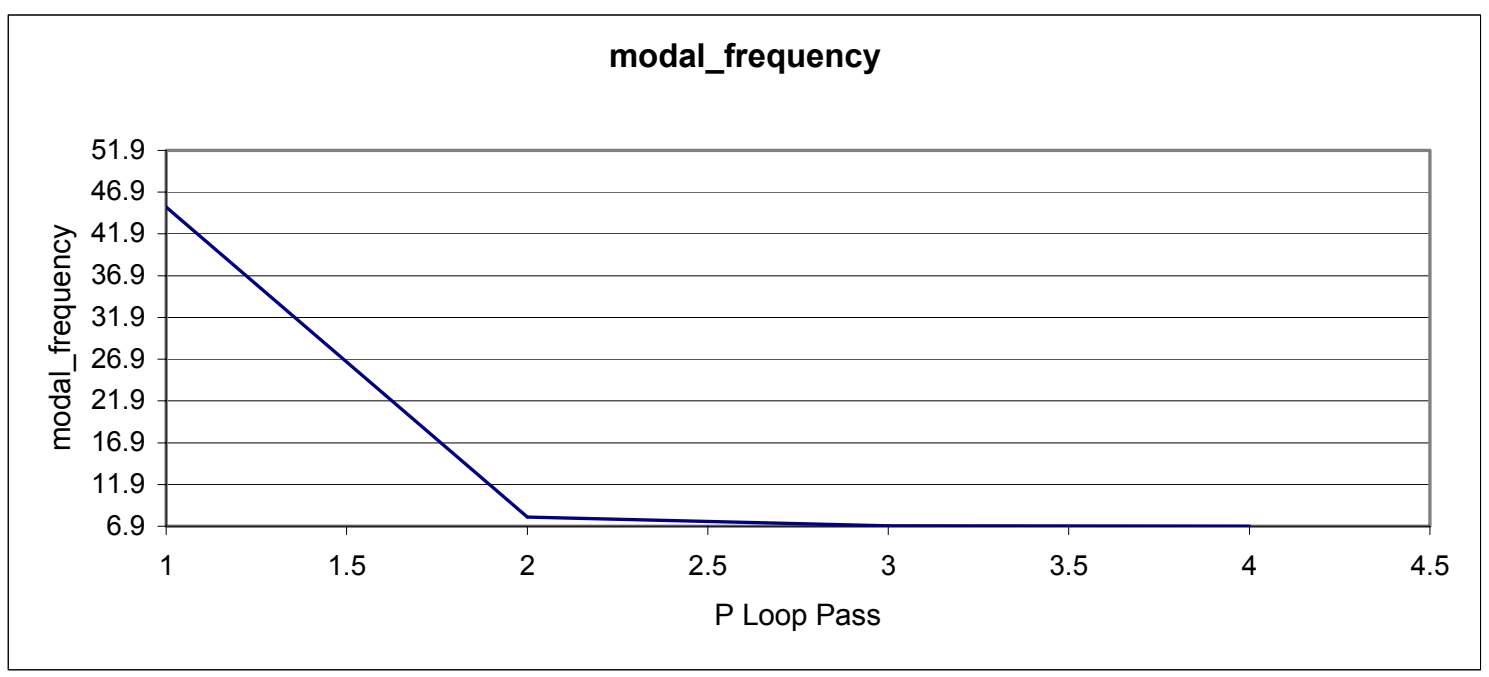




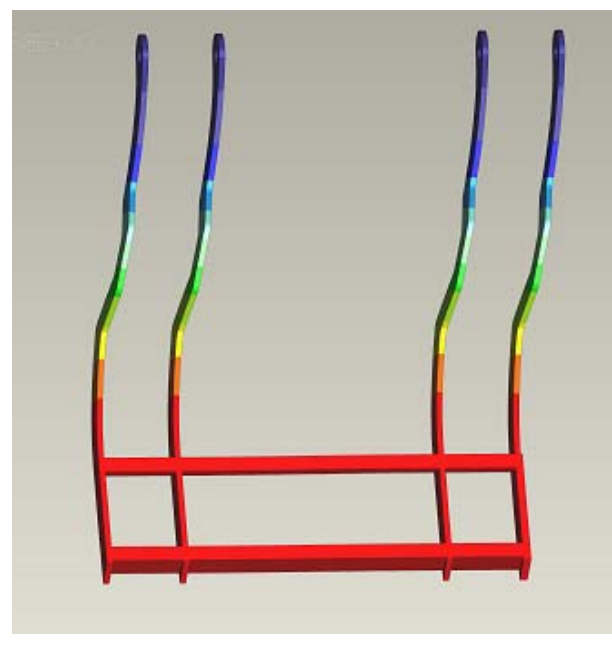

A

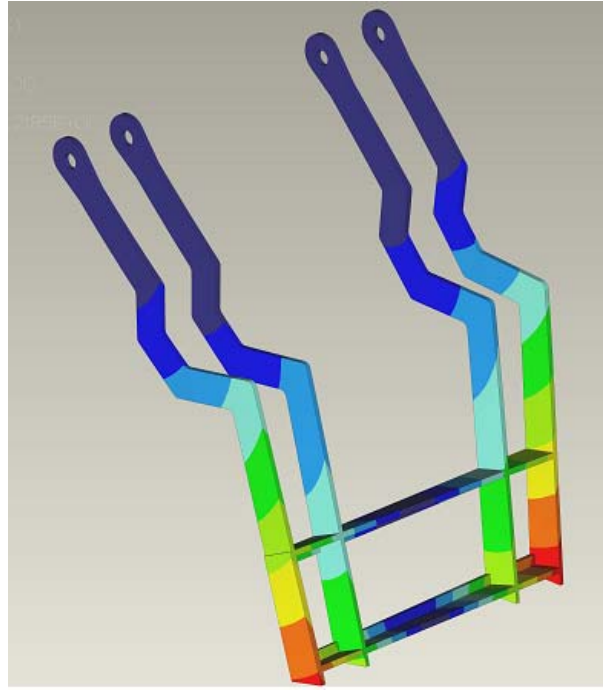

$\mathrm{C}$

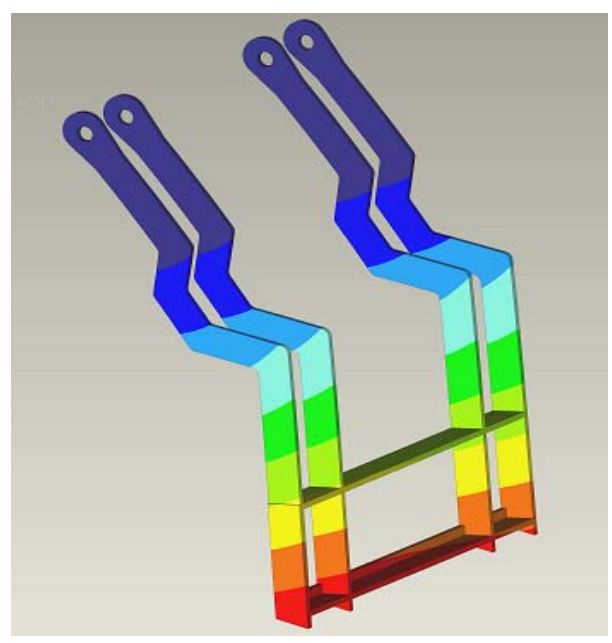

B

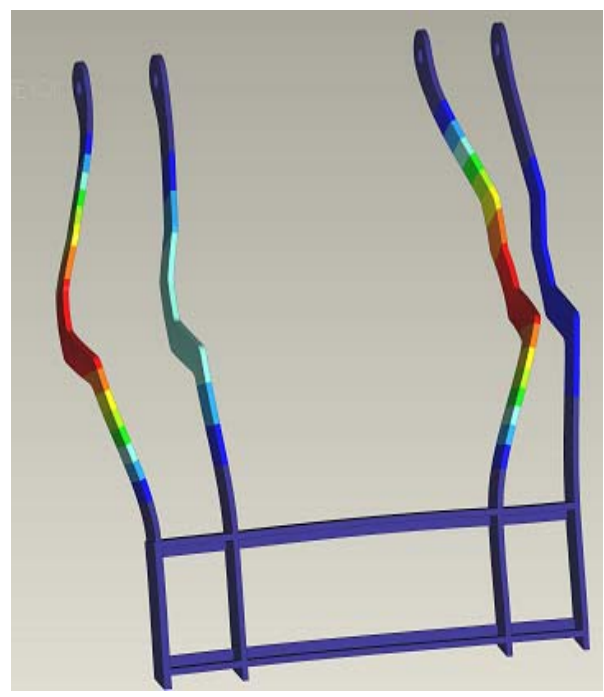

$\mathrm{D}$

Figure 1-B: (A) Mode Shape 1 with 1 node (Right-Left Motion) at 7hz, (B) Mode Shape 2 with 1 node (Fore-Aft Motion) at 16hz, (C) Mode Shape 3 with center node (Twisting Motion) at $22 \mathrm{hz}$ and (D) Mode Shape 6 with 2 nodes (Right-Left motion of arms at $47 \mathrm{~Hz}$. 


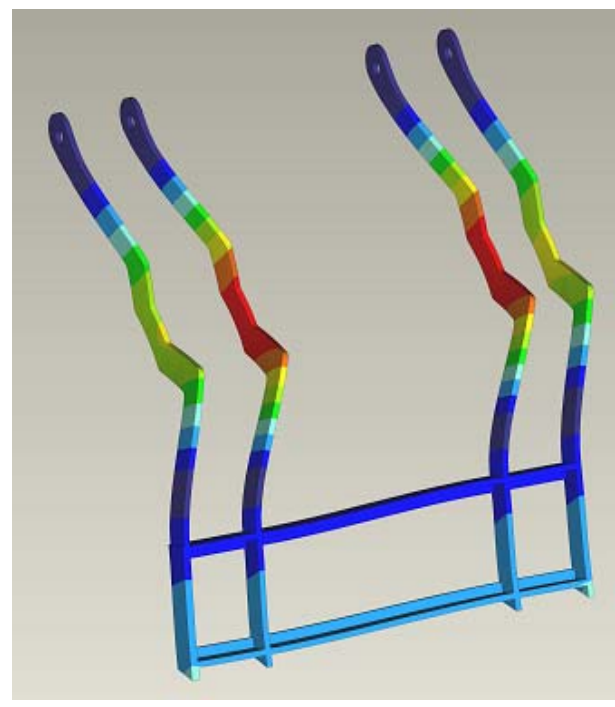

$\mathrm{E}$

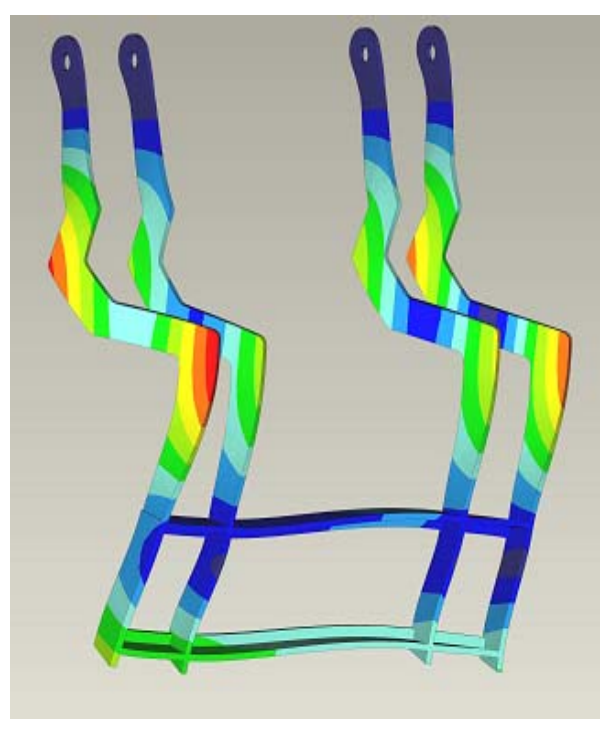

G

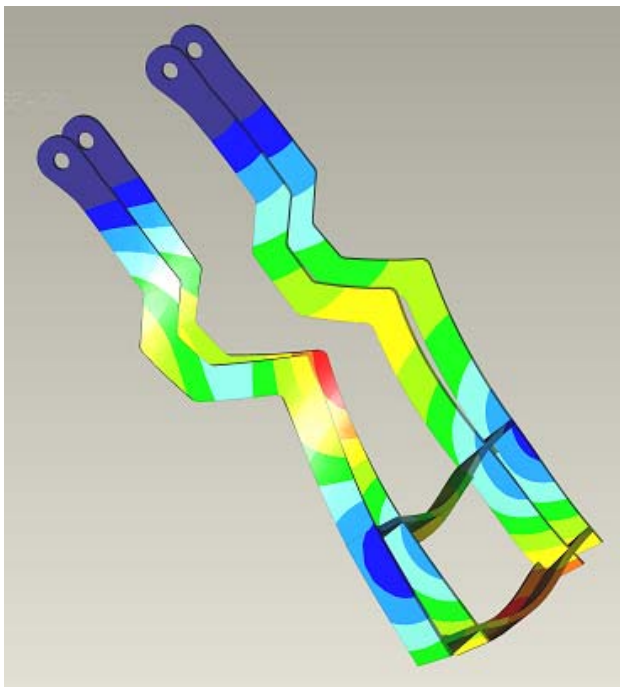

$\mathrm{F}$

Figure 2-B: (E) Mode 7 with 2 nodes (Right-Left Motion) at 50hz, (F) Mode 8 with 2 nodes (Fore-Aft Motion) at 100hz, (G) Mode 9 with 3 nodes (Right-Left Motion) at $101 \mathrm{~Hz}$. 


\section{Part B: Arm with Center Cross-Brace}

Table 3-B: Natural Frequencies of Mechanical Arm Structure with Center Cross-Brace Support

\begin{tabular}{|c|c|c|}
\hline \multicolumn{3}{|c|}{ Arm w/Center Cross-Brace } \\
\hline Mode & Natural Frequencies & Convergence (\%) \\
\hline 1 & 16 & 0.3 \\
2 & 18 & 0.9 \\
3 & 22 & 0.8 \\
4 & 47 & 1.1 \\
5 & 47 & 1.1 \\
6 & 58 & 1.2 \\
7 & 93 & 0.5 \\
8 & 104 & 1.5 \\
9 & 109 & 1.5 \\
10 & 117 & 0.8 \\
\hline
\end{tabular}

Table 4-B: P-Pass Convergence within 10\% of Modal Frequency.

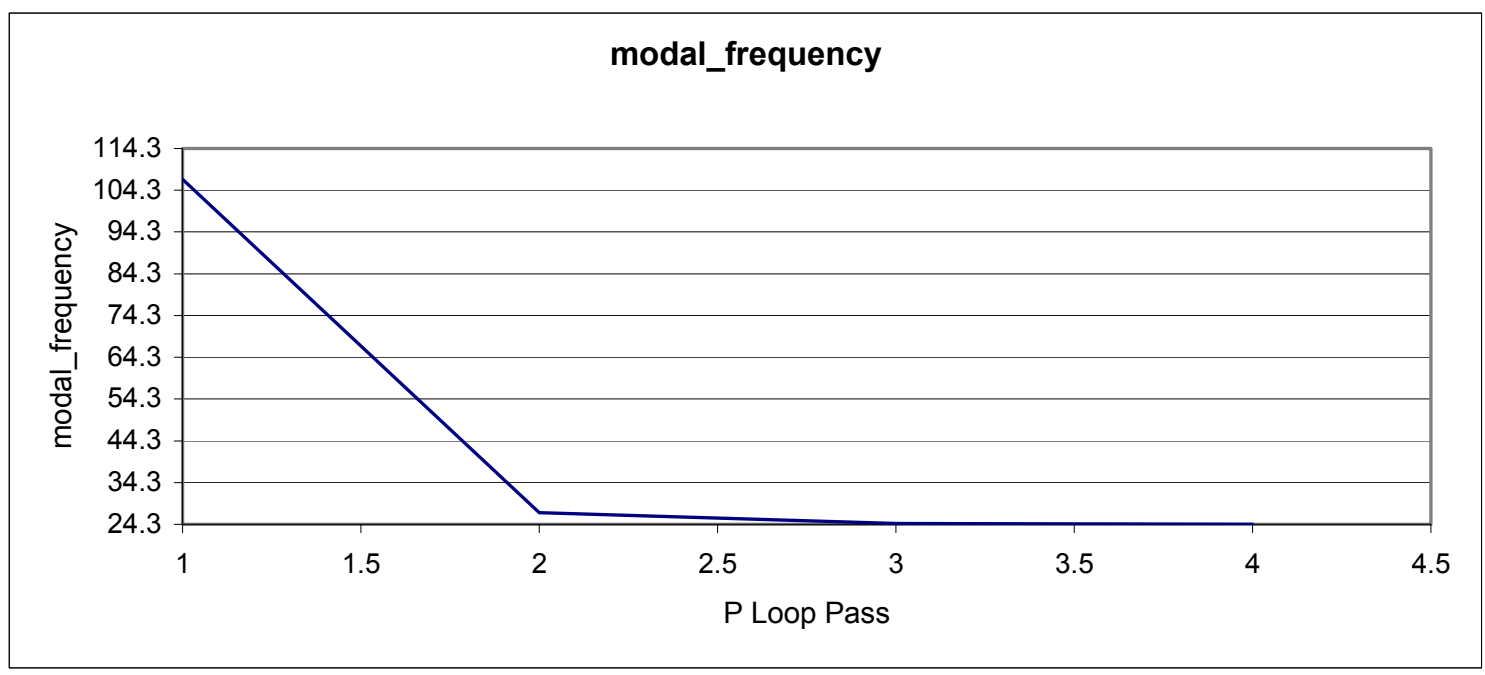




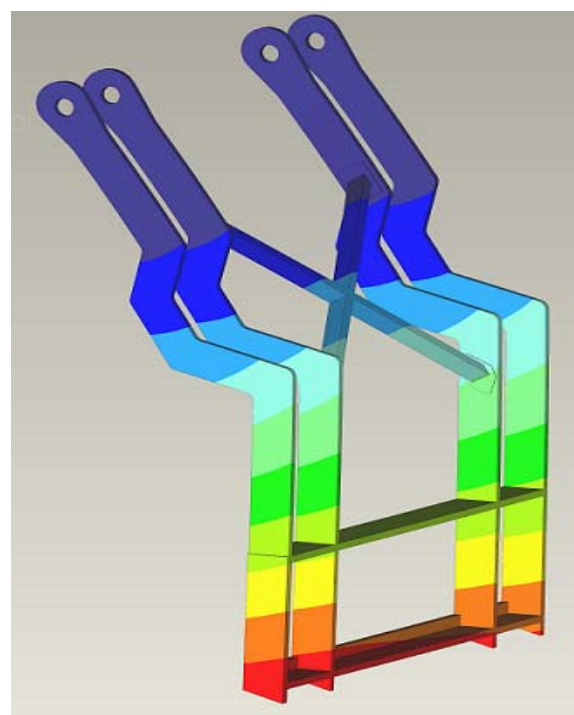

A

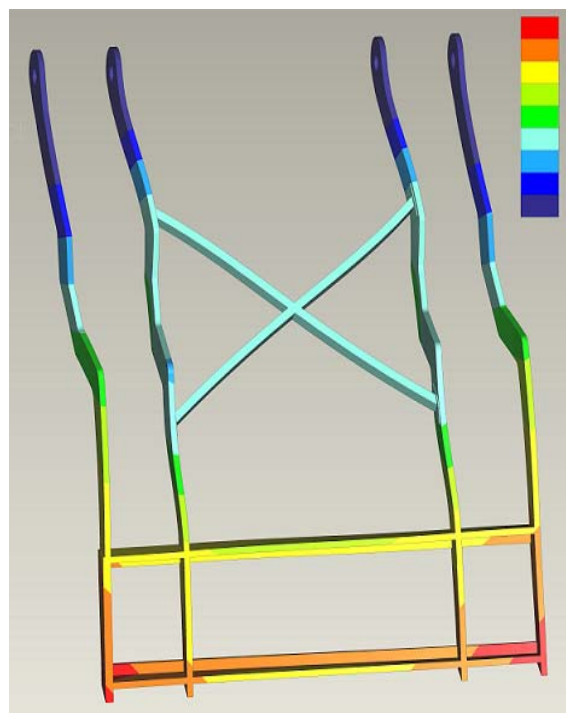

B

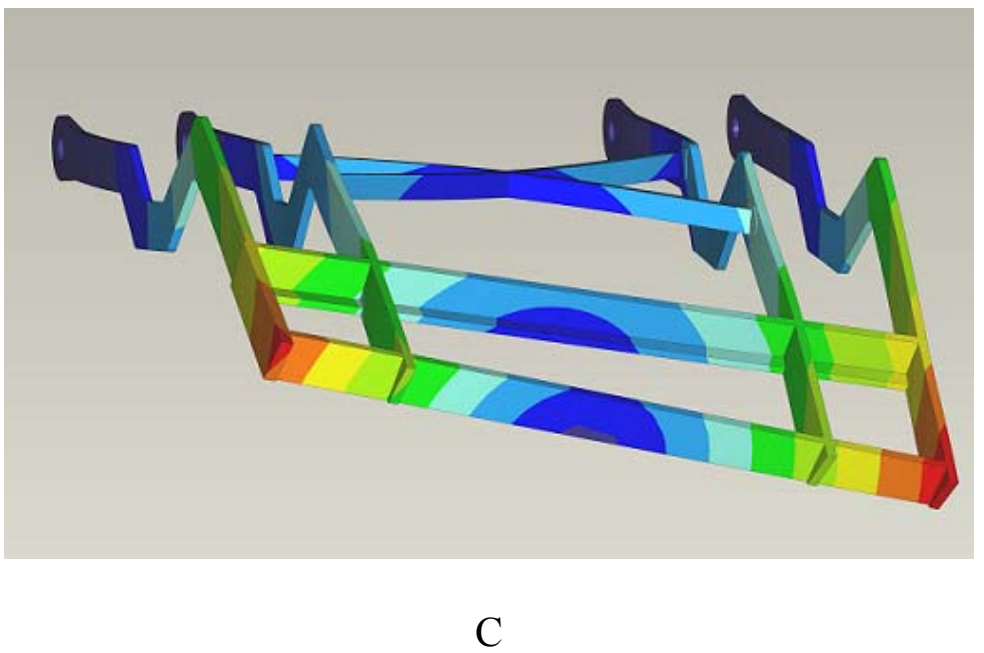

Figure 3-B: (A) Mode 1 with a node (Fore-Aft Motion) at 16hz, (B) Mode 2 with 1 node (RightLeft Motion) at 18hz, (C) Mode 3 with center node (Torsion Motion) at $22 \mathrm{~Hz}$. 


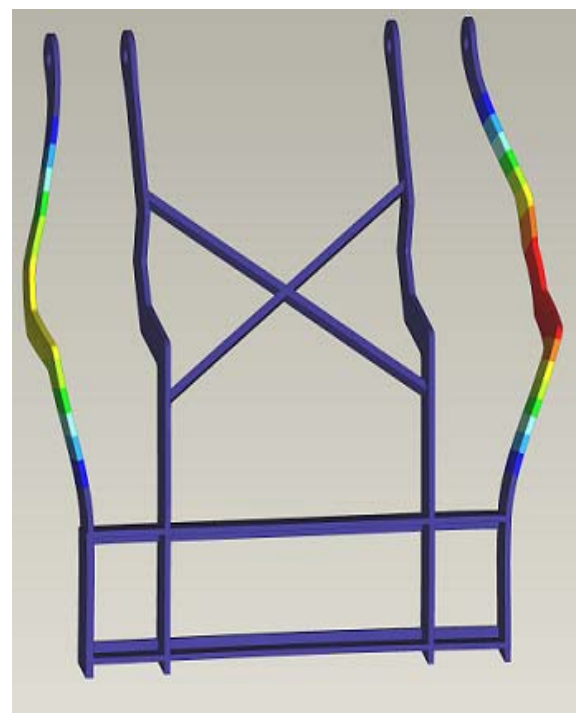

$\mathrm{D}$

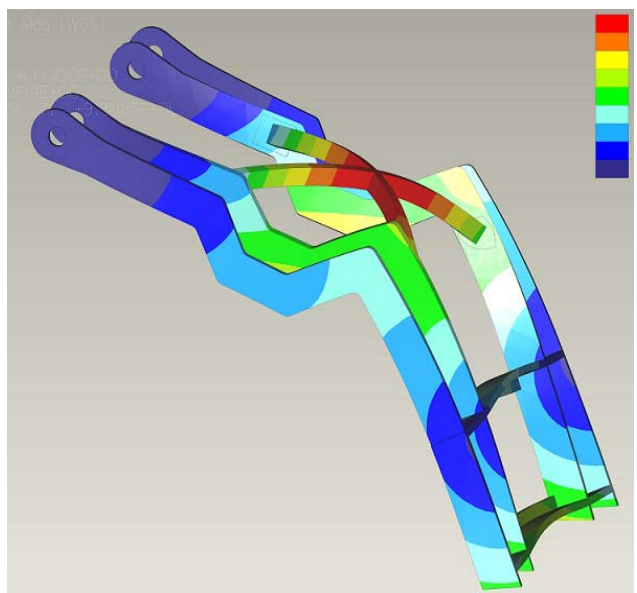

$\mathrm{F}$

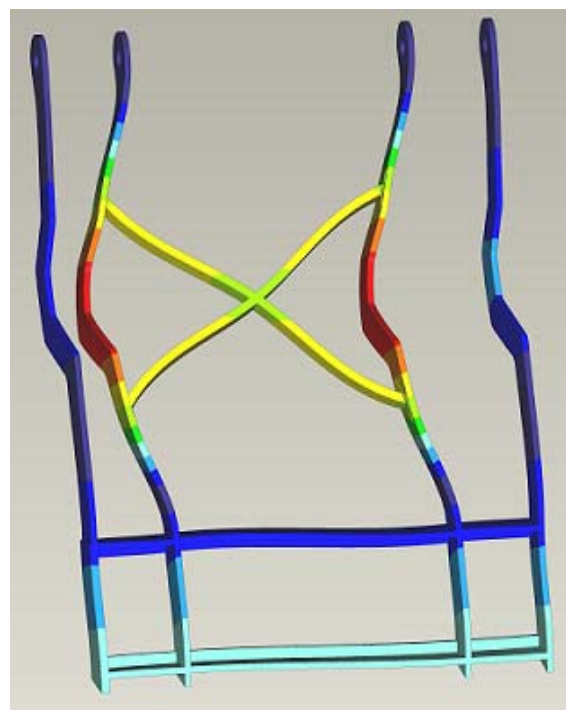

$\mathrm{E}$

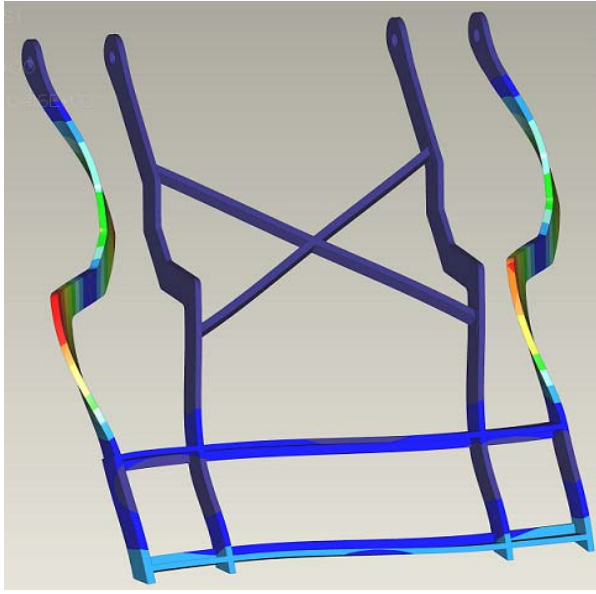

G

Figure 4-B: (D) Mode 4 with 2 nodes (Right-Left Motion) of outer arms at 47hz, (E) Mode 6 with 2 nodes (Right-Left Motion) of center piece at $58 \mathrm{hz}$, (F) Mode 7 with 2 nodes (Fore-Aft Motion) at 93hz, (G) Mode 8 with 3 nodes (Right-Left Motion) of outer arms at 104hz. 


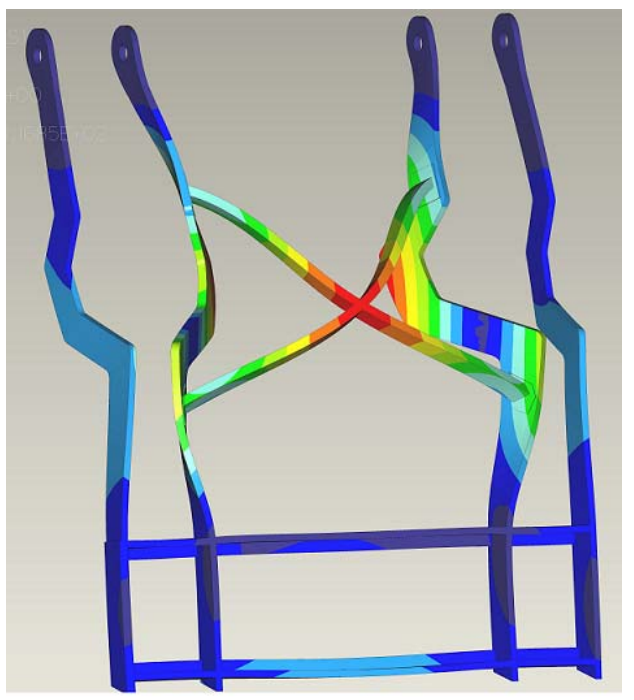

Figure 5-B: Mode Shape 10 with 3 nodes (Torsion Motion) of center Cross-Brace at 117hz. 


\section{Part C: Arm with Center Cross-Brace and Side V-Braces.}

Table 5-B: Natural Frequencies of Mechanical Arm Structure with Center Cross-Brace and Sid V-Brace Supports.

\begin{tabular}{|c|c|c|}
\hline \multicolumn{3}{|c|}{ Arm w/Cross Brace and V-Braces } \\
\hline Mode & Natural Frequencies & Convergence (\%) \\
\hline 1 & 16 & 0.2 \\
2 & 22 & 0.7 \\
3 & 47 & 1.4 \\
4 & 89 & 1.5 \\
5 & 94 & 0.4 \\
6 & 121 & 0.5 \\
7 & 125 & 0.9 \\
8 & 135 & 1 \\
9 & 141 & 1 \\
10 & 145 & 1.2 \\
\hline
\end{tabular}

Table 6-B: P-Pass Convergence within 10\% of Modal Frequency.

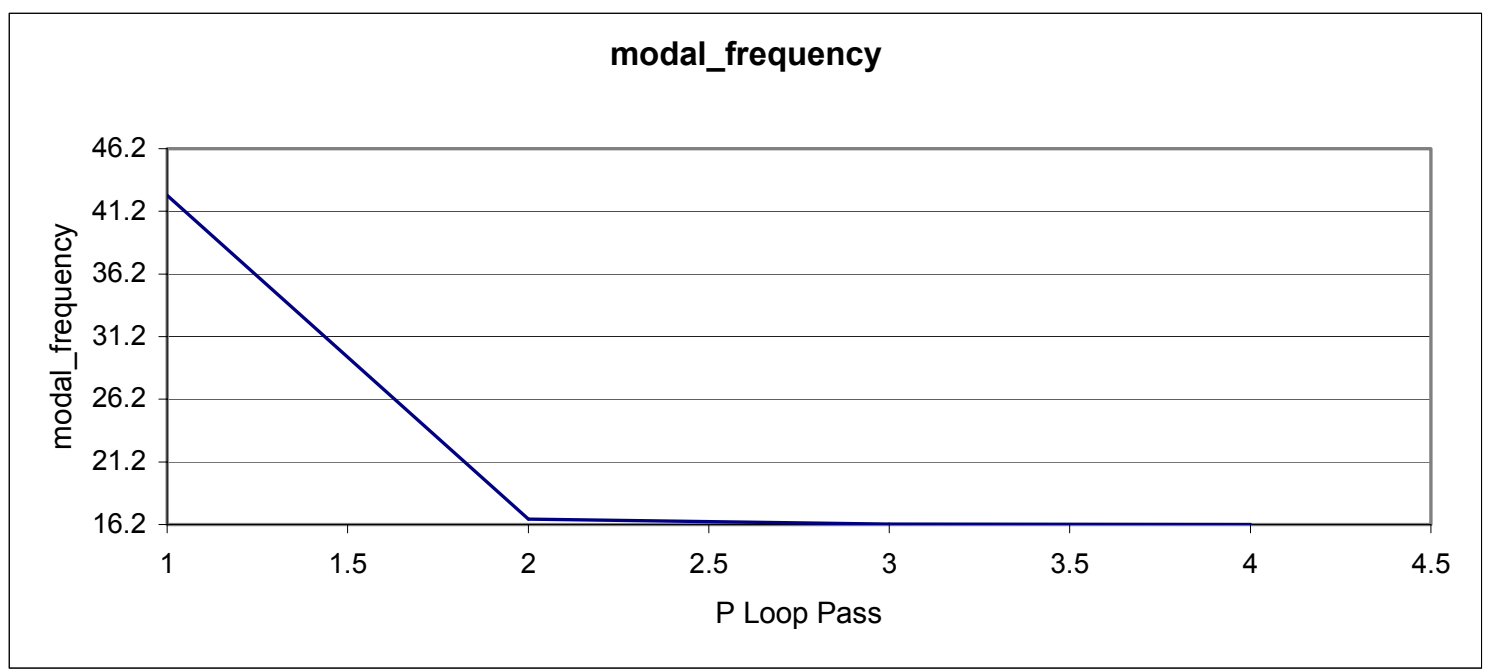




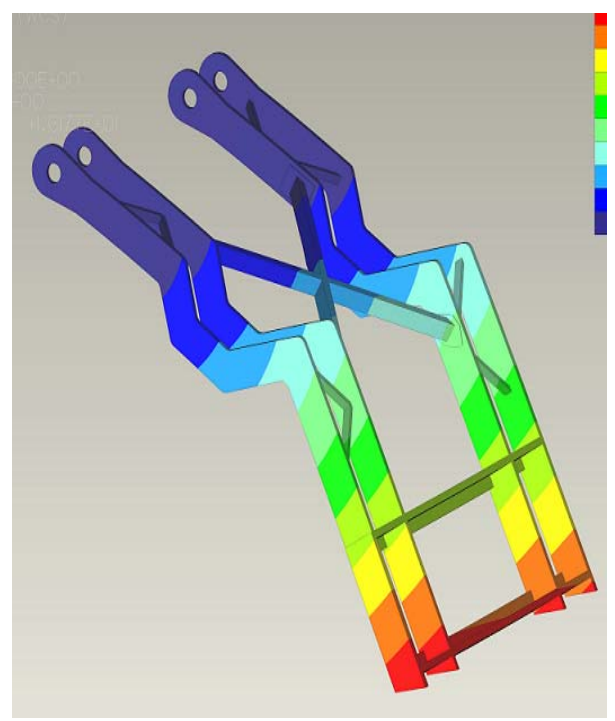

A

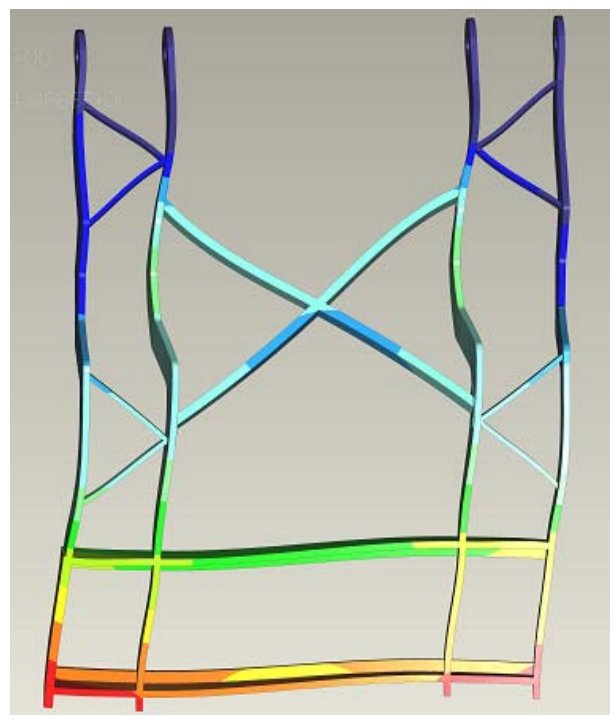

C

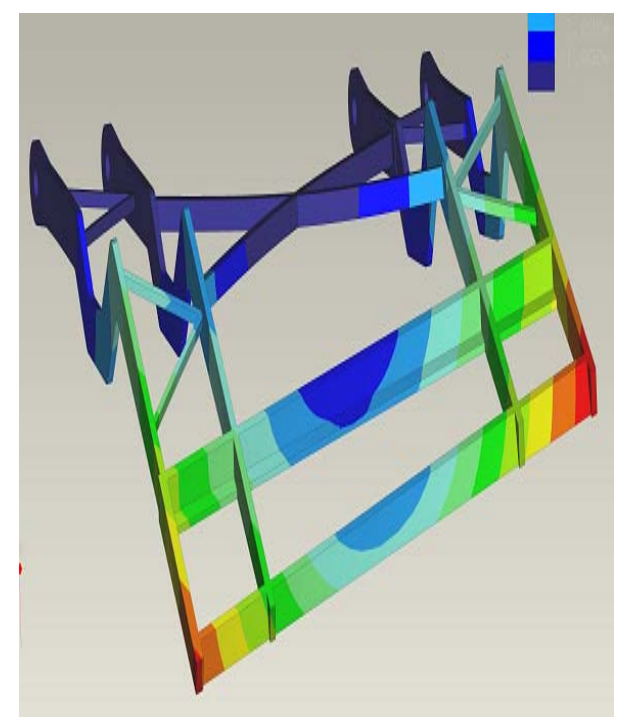

B

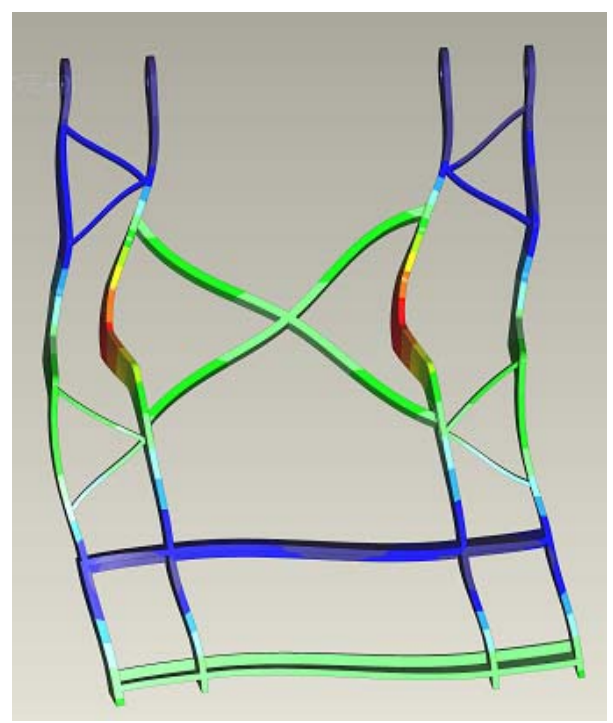

D

Figure 6-B: (A) Mode 1with 1 node (Fore-Aft Motion) at 16hz, (B) Mode 2 with center node (Torsion Motion) at 22hz, (C) Mode 3 with 1 node (Right-Left Motion) at 45hz, (D) Mode 4 with 2 nodes (Right-Left Motion) at $89 \mathrm{hz}$. 


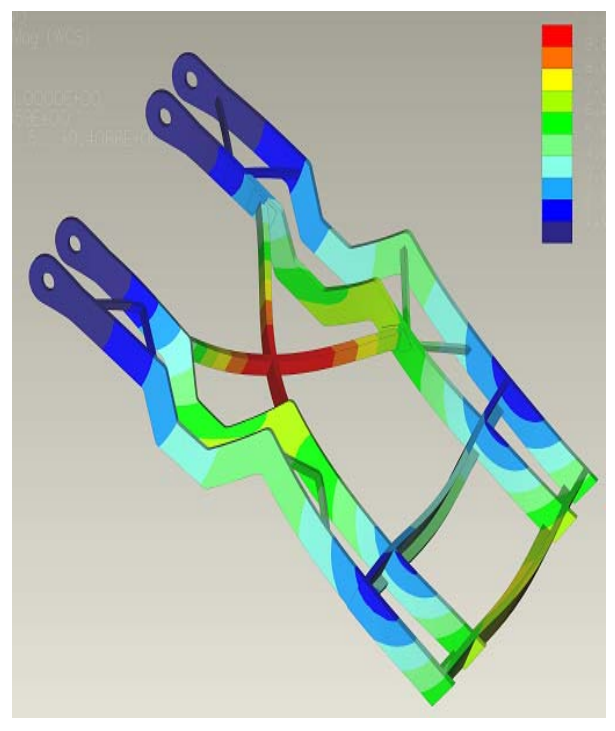

$\mathrm{E}$

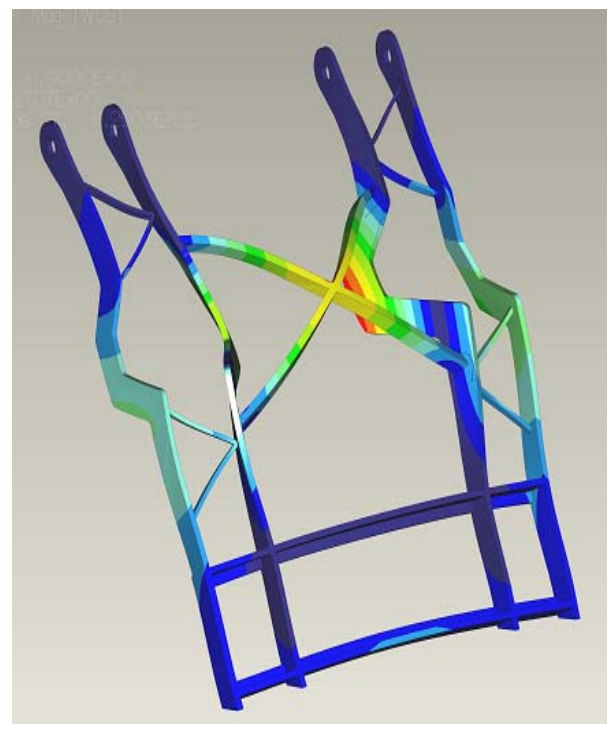

G

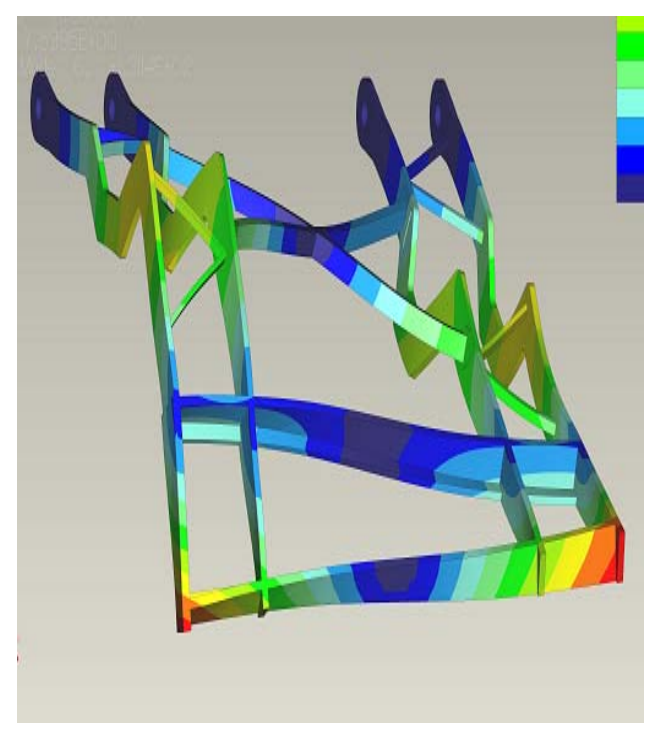

$\mathrm{F}$

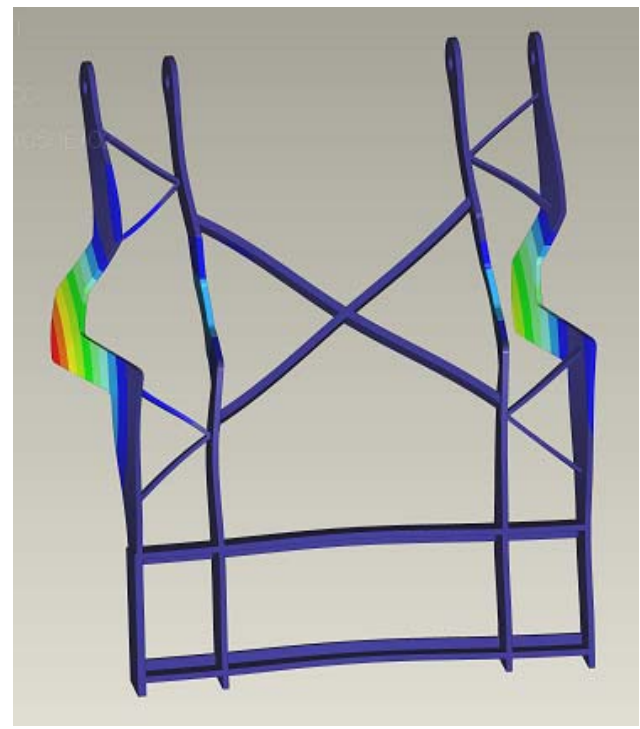

$\mathrm{H}$

Figure 7-B: (E) Mode 5 with 2 nodes (Fore-Aft Motion) at 94hz, (F) Mode 6 with center node (Torsion Motion) and 2 bending nodes (Fore-Aft Motion) at 121hz, (G) Mode 7 with 2 nodes (Bending and Twisting Motion) of Center Brace at 125hz, (H) Mode 9 with 2 nodes (Torsion Motion) of two outer arms at $141 \mathrm{hz}$. 


\section{$\underline{\text { Study \#2 }}$}

\section{Part A: Pod Frame}

Table 7-B: Natural Frequencies of Pod Frame

\begin{tabular}{|c|c|c|}
\hline \multicolumn{3}{|c|}{ Pod Frame } \\
\hline Mode & Natural Frequencies & Convergence (\%) \\
\hline 1 & 56 & 1.2 \\
2 & 68 & 0.9 \\
3 & 87 & 1.3 \\
4 & 88 & 1.3 \\
5 & 118 & 0.9 \\
6 & 140 & 0.9 \\
7 & 162 & 1 \\
8 & 170 & 0.8 \\
9 & 175 & 1.2 \\
10 & 186 & 0.8 \\
\hline
\end{tabular}

Table 8-B: P-Pass Convergence within 10\% of Modal Frequency for Pod Frame.

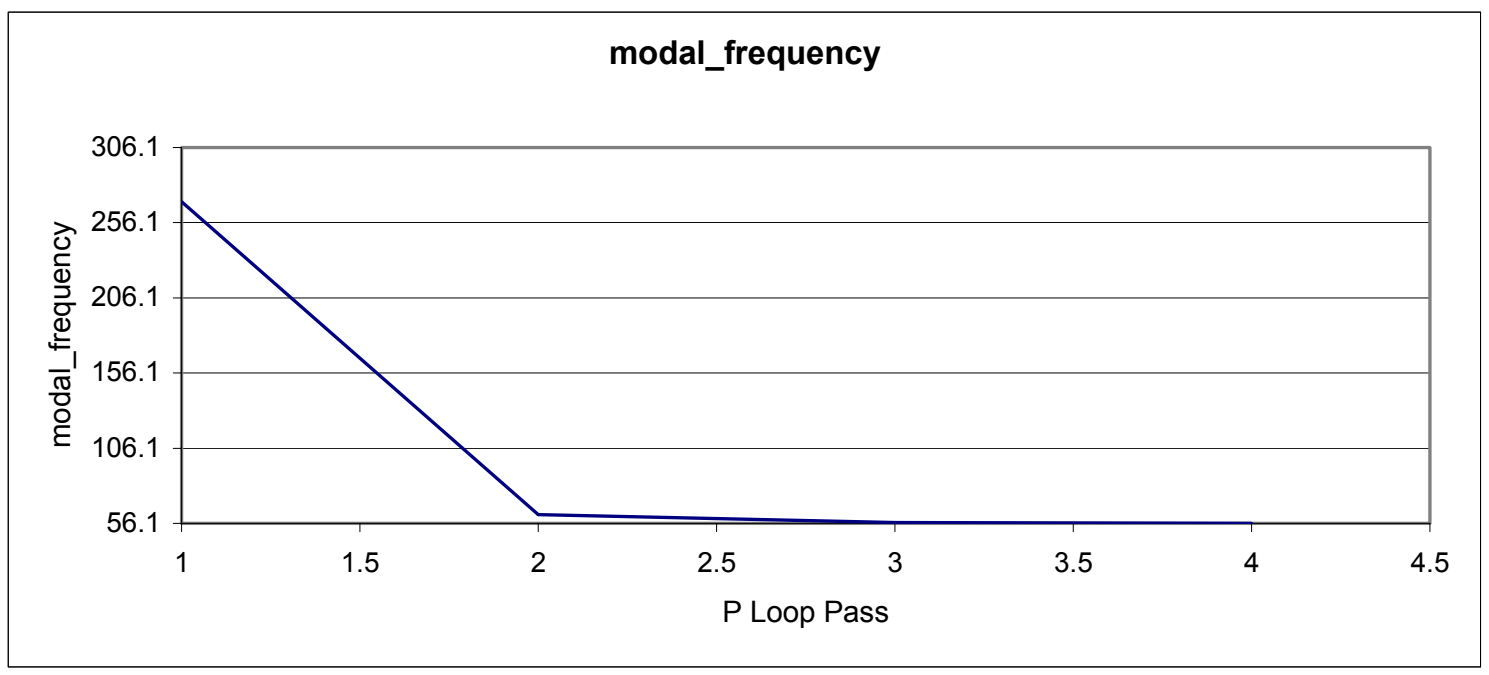




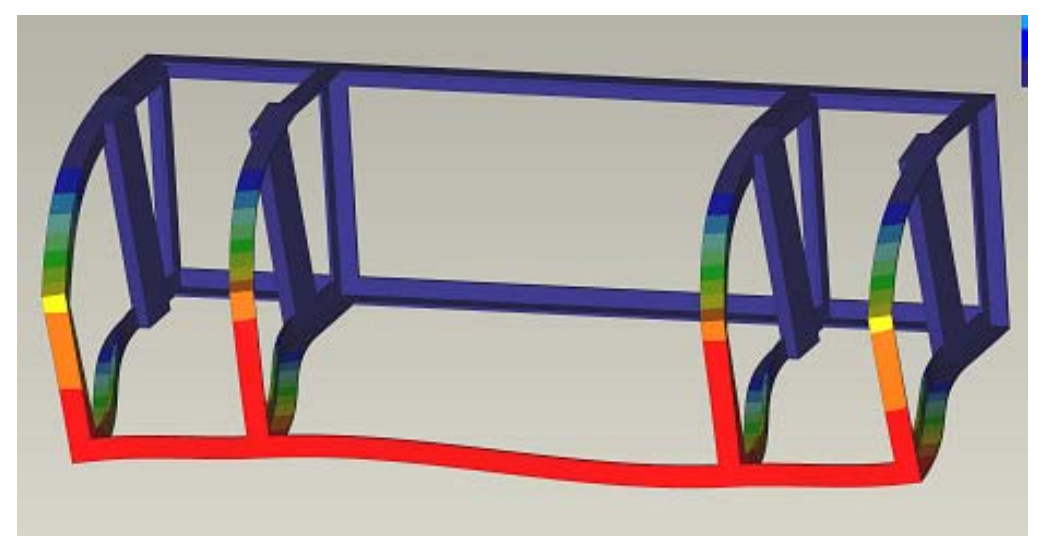

A

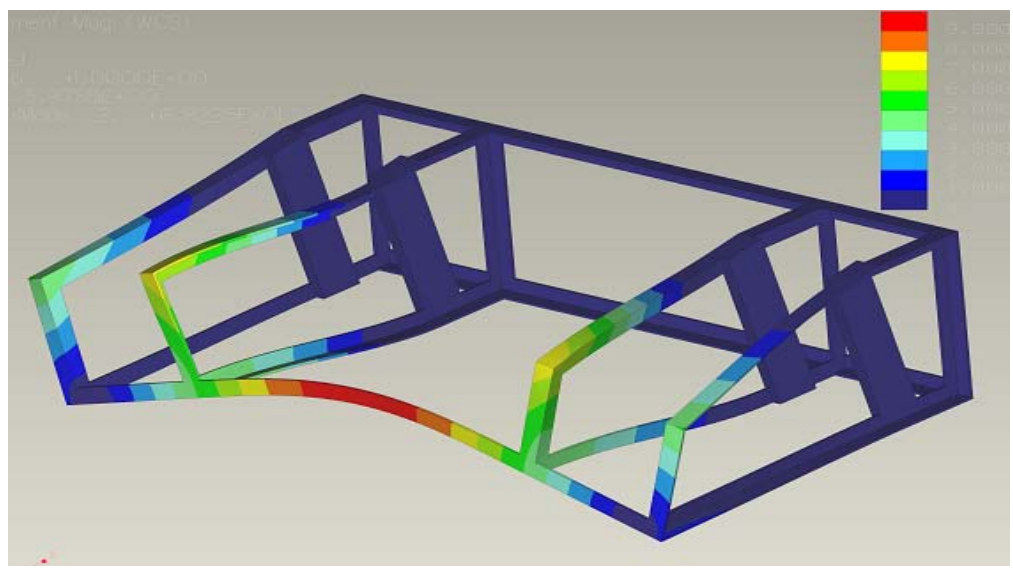

B

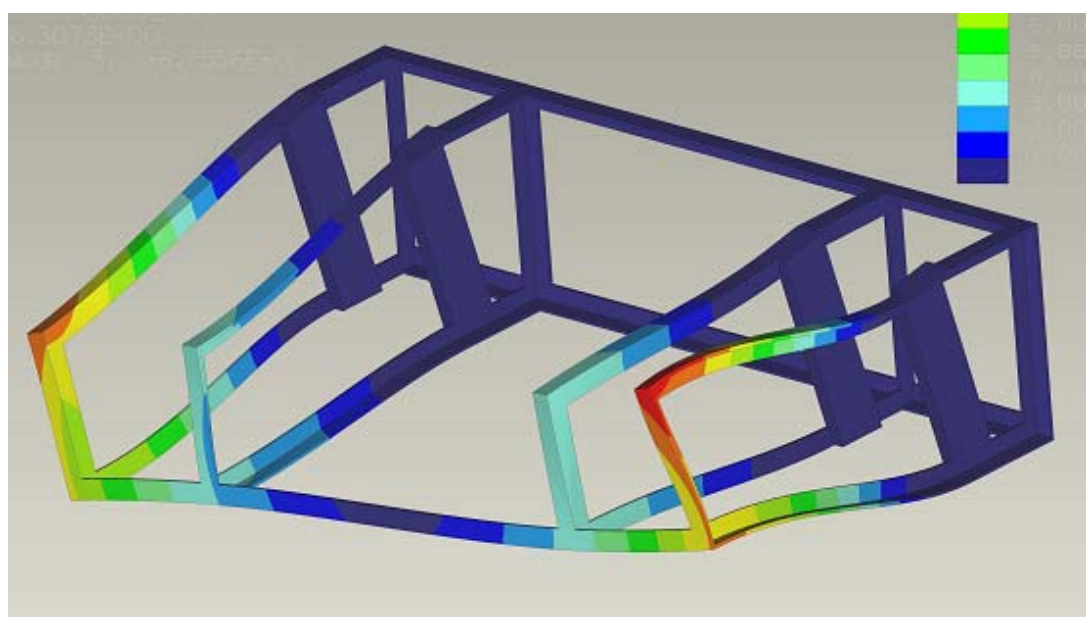

$\mathrm{C}$

Figure 8-B: (A) Mode 1 with 1 node (Right-Left Motion) at 56hz, (B) Mode 2 with 3 nodes (Torsion Motion) at 68hz, (C) Mode 3 with center node (Torsion Motion) at 87hz. 


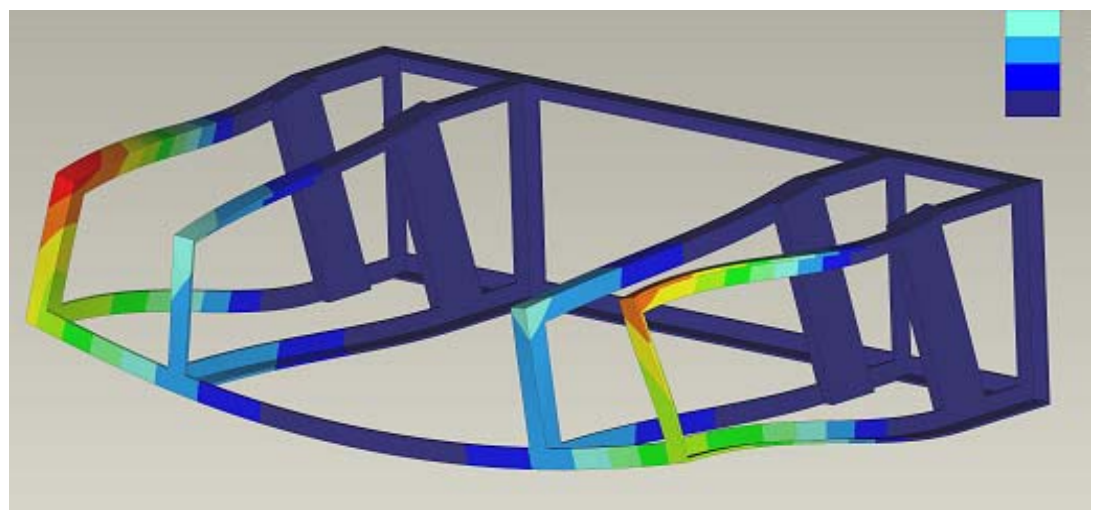

$\mathrm{D}$

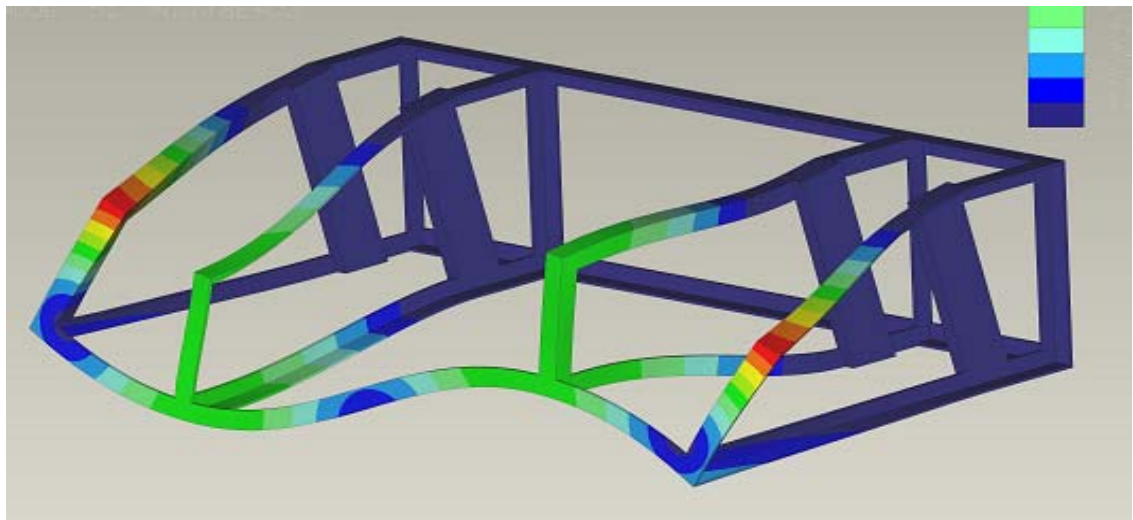

$\mathrm{E}$

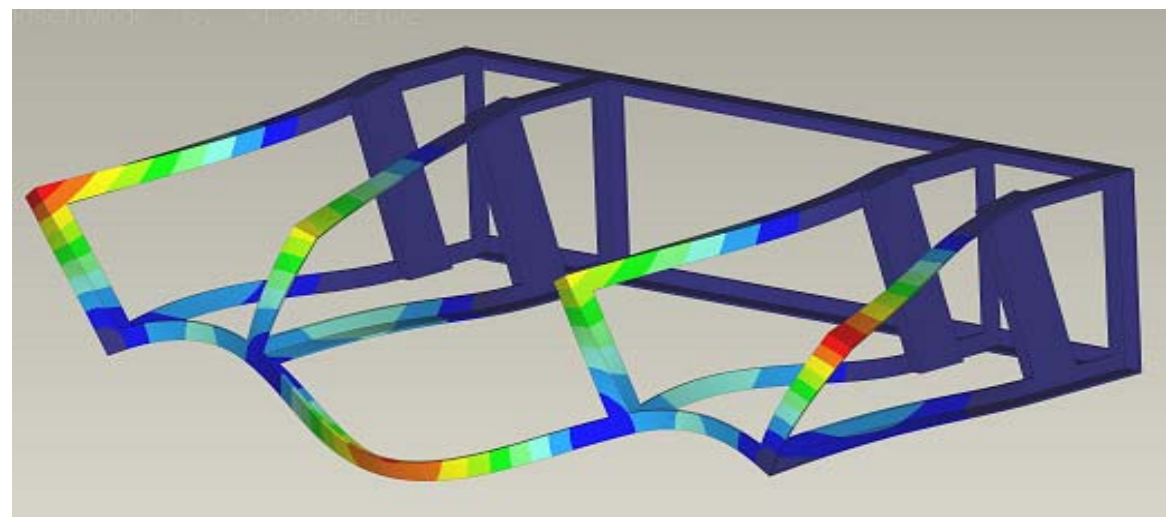

\section{$\mathrm{F}$}

Figure 9-B: (D) Mode 4 (Torsion Motion) at 88hz, (E) Mode 5 with 4 nodes (Torsion Motion) at 118hz, (F) Mode 6 with 5 nodes (Torsion Motion) at 140hz. 


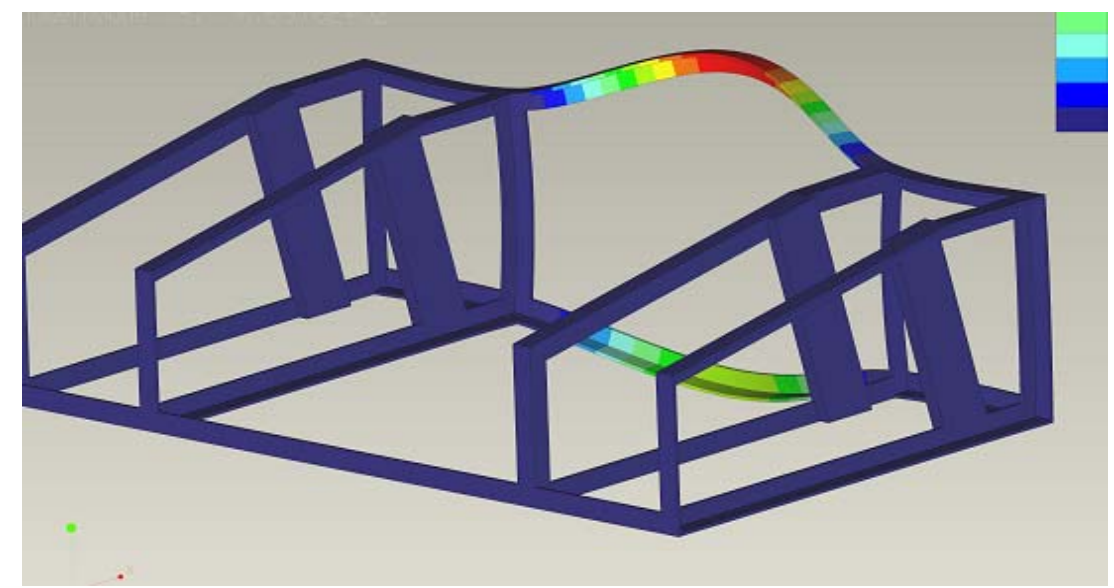

G

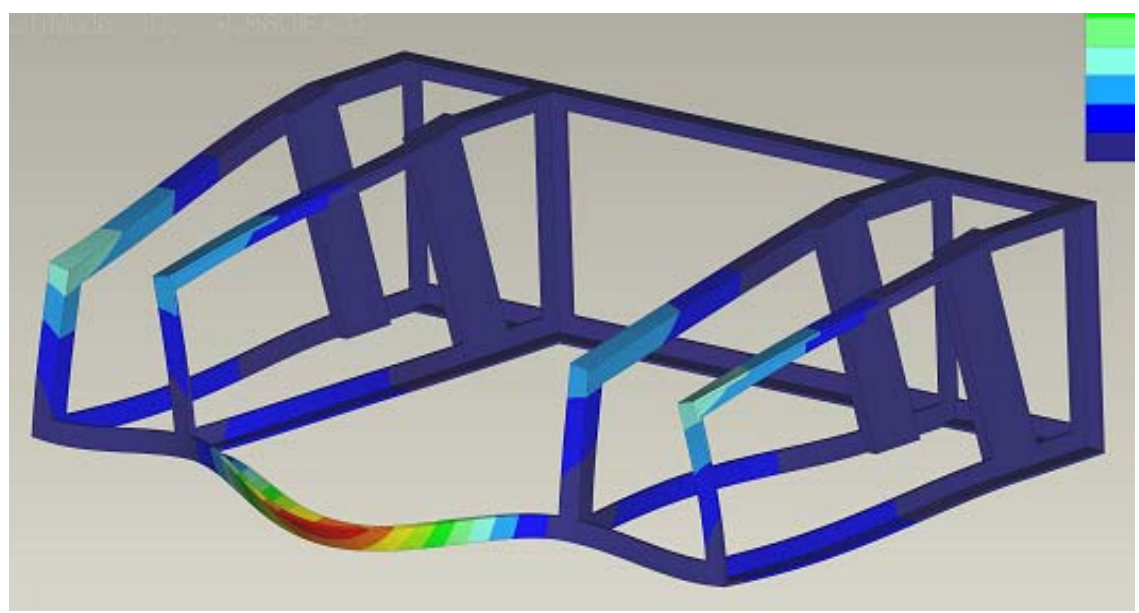

H

Figure 10-B: (G) Mode 8 with 2 nodes (Vertical Bending Motion) at 170hz, (H) Mode 10 with (Vertical Bending and Torsion Motion) at 186hz. 


\section{Part B: Pod Frame with $1 / 2$ inch Plat and 1/8-inch Side Panels}

Table 9-B: Natural Frequencies of Pod Frame with Plate and Panel Components

\begin{tabular}{|c|c|c|}
\hline \multicolumn{3}{|c|}{ Pod Frame with 1/2in Plate \& 1/4in Side Panels } \\
\hline Mode & Natural Frequencies & Convergence (\%) \\
\hline 1 & 60 & 3.1 \\
2 & 92 & 1.7 \\
3 & 108 & 3.6 \\
4 & 147 & 2.2 \\
5 & 154 & 4 \\
6 & 170 & 0.7 \\
7 & 175 & 0.9 \\
8 & 175 & 1.3 \\
9 & 209 & 4.5 \\
10 & 224 & 4.5 \\
\hline
\end{tabular}

Table 10-B: P-Pass Convergence within 10\% of Modal Frequency for Pod Frame with Skin.

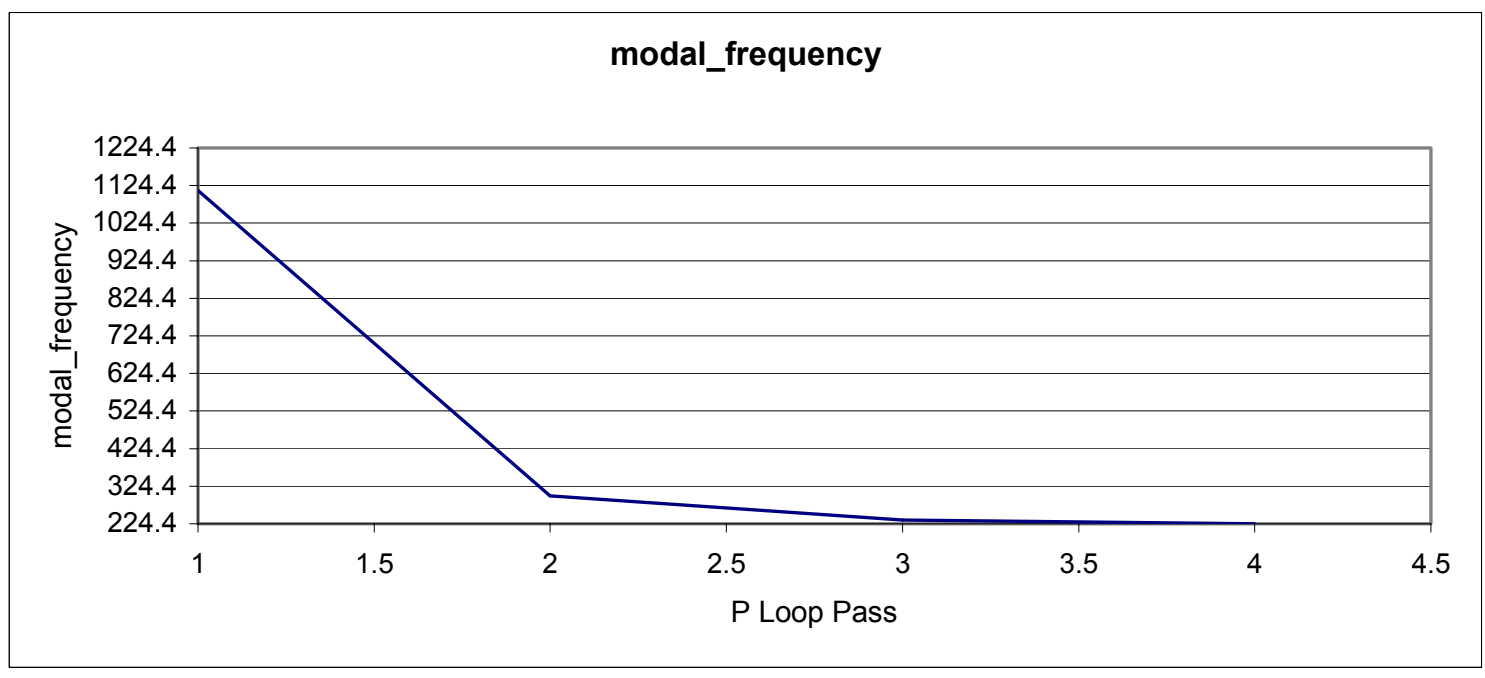




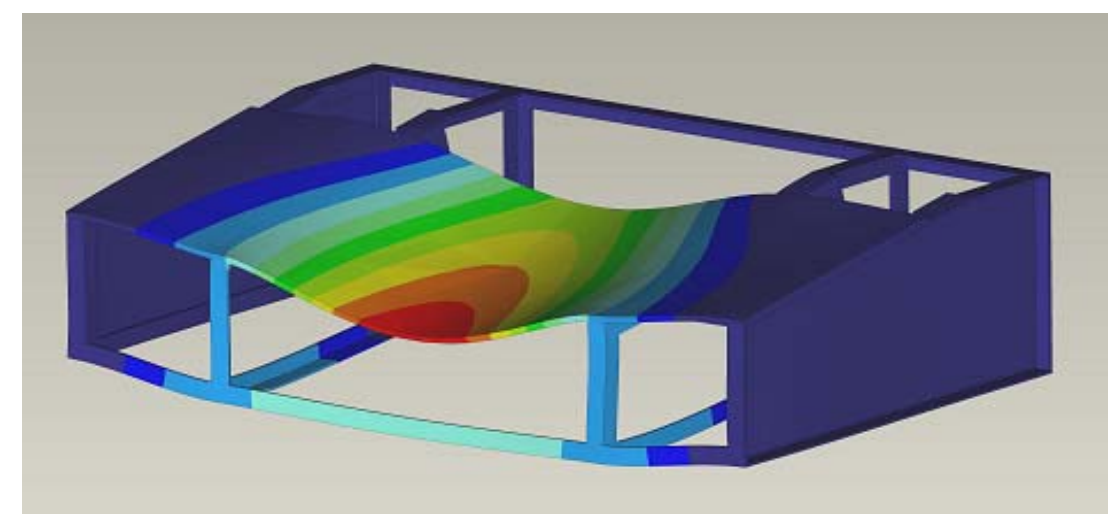

A

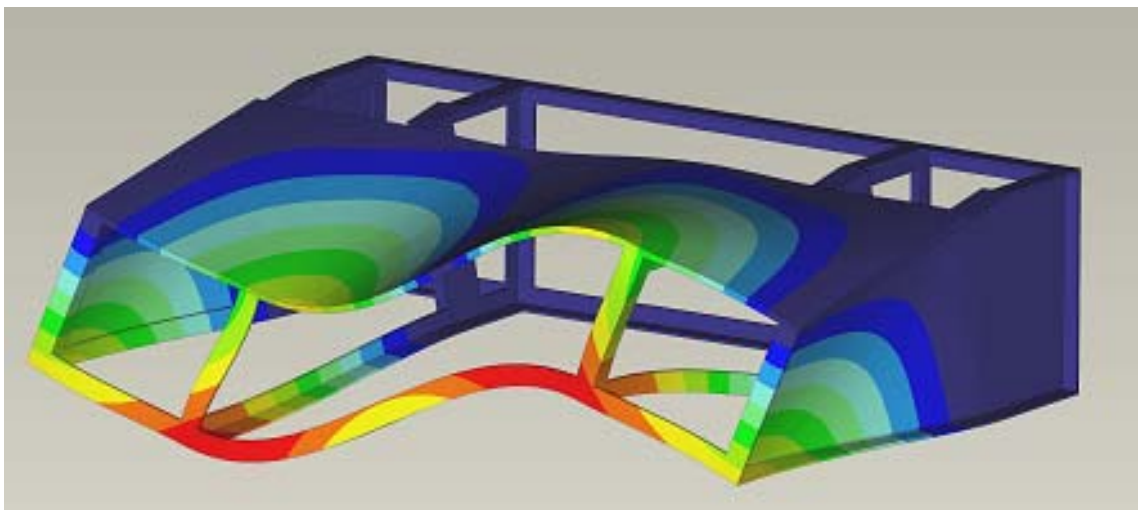

B

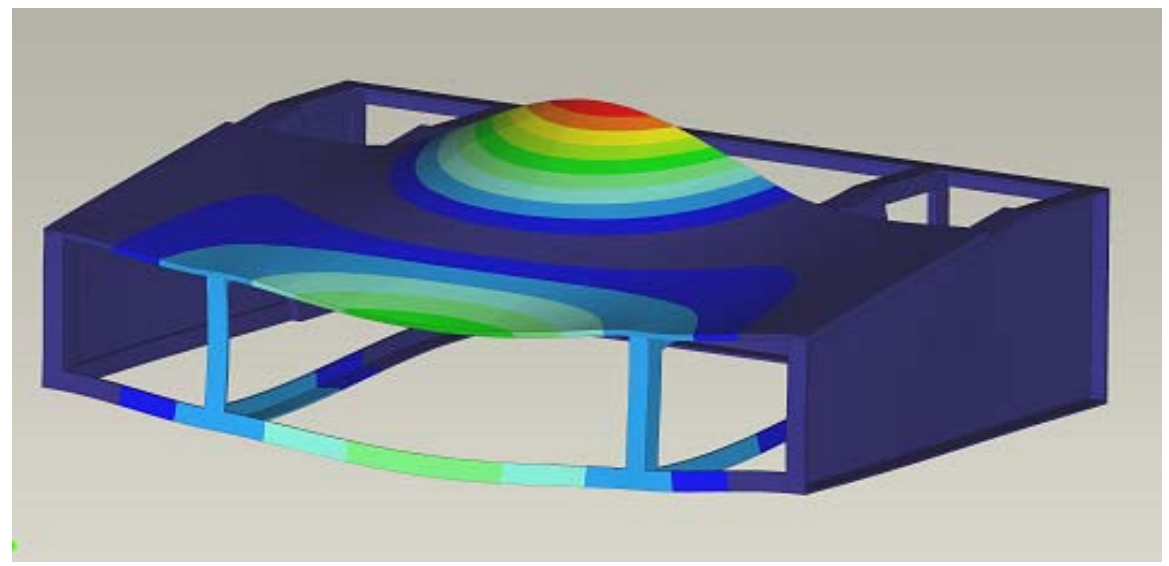

$\mathrm{C}$

Figure 11-B: (A) ) Mode 1 with 2 nodes (Vertical Bending Motion) at 60hz, (B) Mode 2 with 3 nodes (Vertical Bending and Torsion Motion) at 92hz, (C) Mode 3 with 3 nodes (Torsion Motion) at $108 \mathrm{hz}$. 


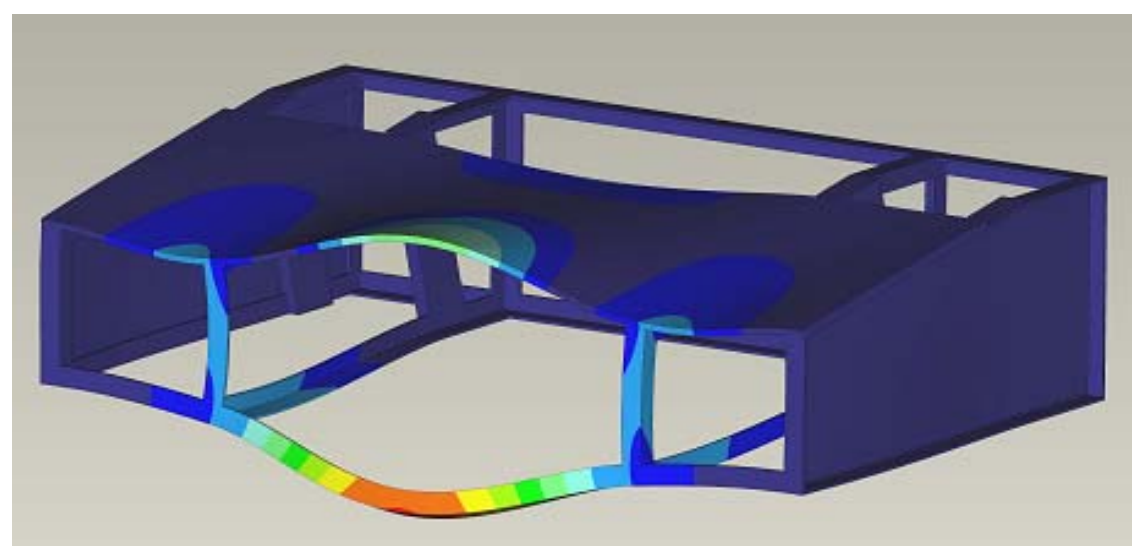

$\mathrm{D}$

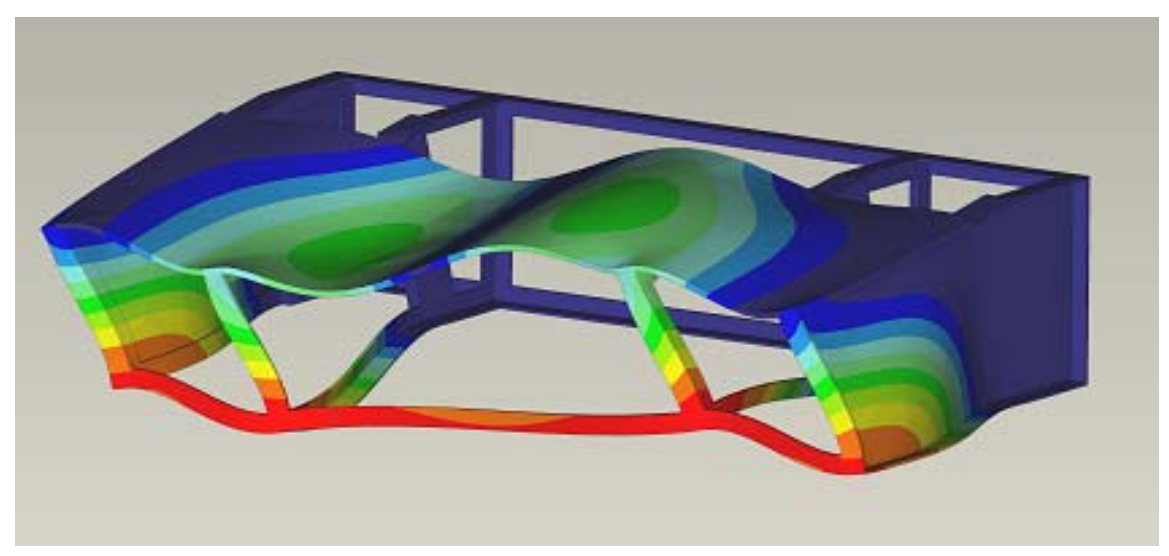

$\mathrm{E}$

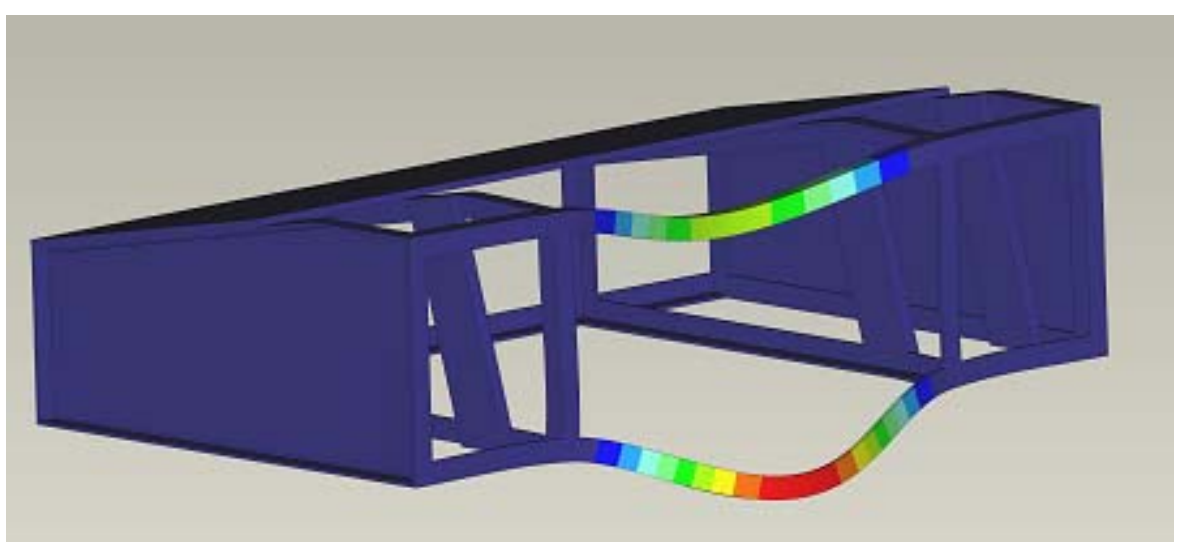

$\mathrm{F}$

Figure 12-B: (D) Mode 4 with 3 nodes (Vertical Bending Motion) at 147hz, (E) Mode 5 with 4 nodes (Vertical Bending and Torsion Motion) at 154hz, (F) Mode 7 with 2 nodes (Vertical Bending Motion) at $175 \mathrm{hz}$. 


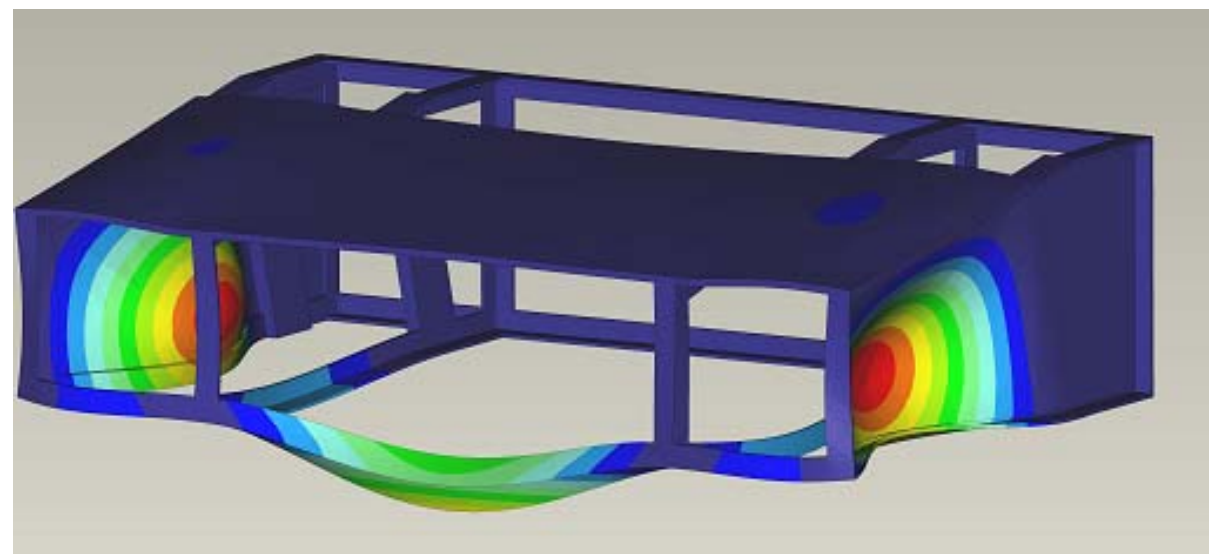

G

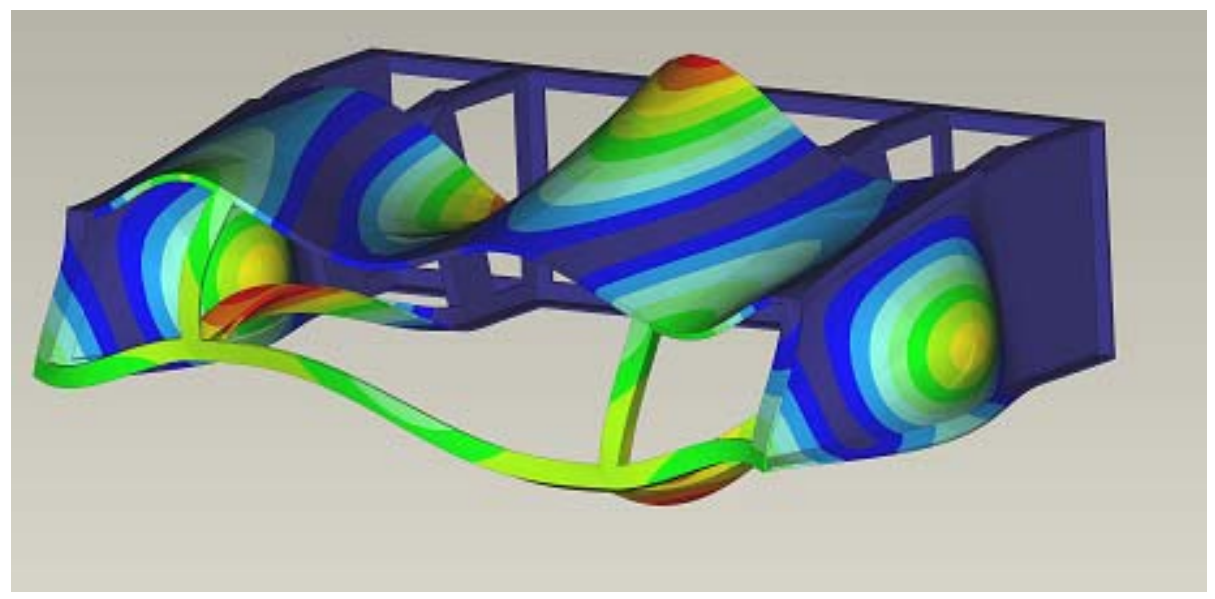

$\mathrm{H}$

Figure 13-B: (G) Mode 9 with 4 nodes (Vertical Bending Motion) at 209hz, (H) Mode 10 with 6 nodes (Vertical Bending and Torsion Motion) at 224hz. 


\section{Study \#3}

Part A: Complete Arm/Pod System with Center Cross-Brace and Modified Pod

Table 11-B: Natural Frequencies of Arm/Pod System with Cross-Brace and Pod Skin

\begin{tabular}{|c|c|c|}
\hline \multicolumn{3}{|c|}{ Arm/Pod System with Cross-Brace and Pod Skin } \\
\hline Mode & Natural Frequencies & Convergence (\%) \\
\hline 1 & 11 & 1.4 \\
2 & 12 & 0.3 \\
3 & 14 & 1 \\
4 & 40 & 1.6 \\
5 & 43 & 1.5 \\
6 & 47 & 1 \\
7 & 51 & 1.4 \\
8 & 55 & 0.9 \\
9 & 73 & 2.7 \\
10 & 82 & 1.6 \\
\hline
\end{tabular}

Table 12-B: P-Pass Convergence within 10\% of Modal Frequency for Arm/Pod System.

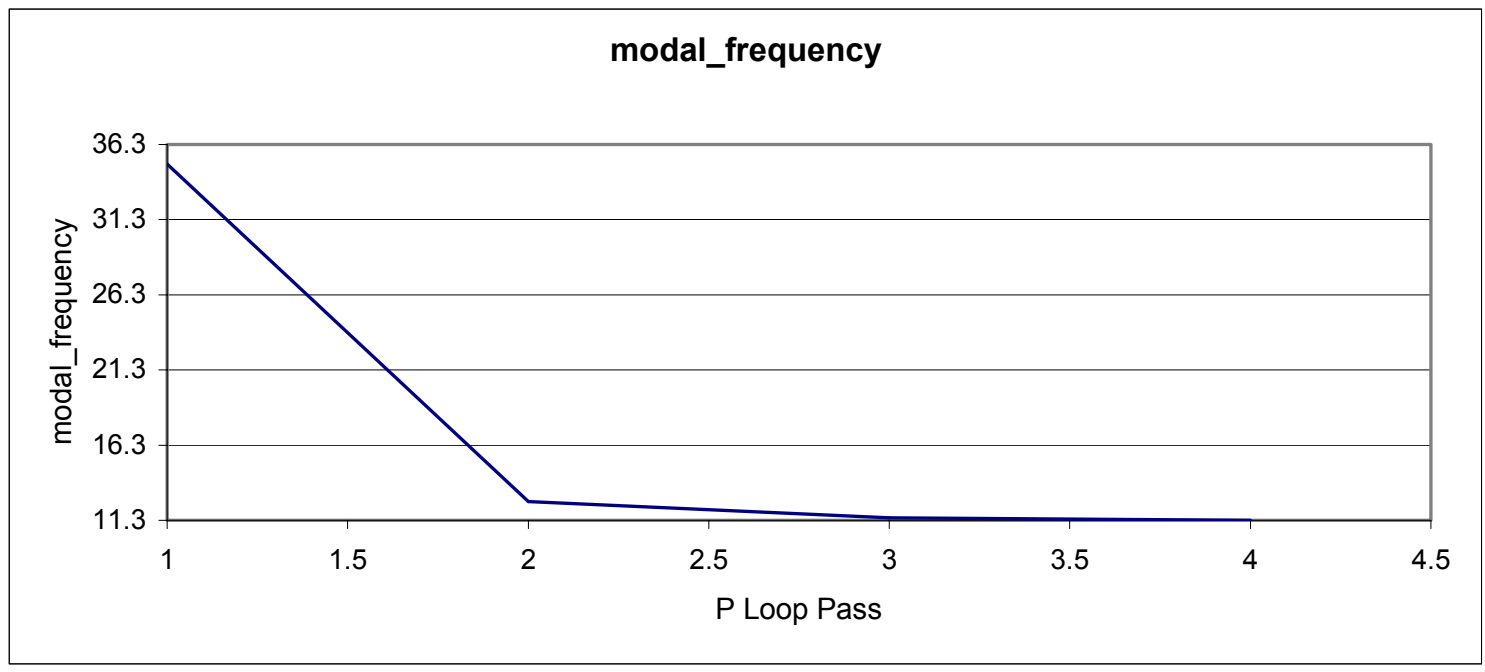




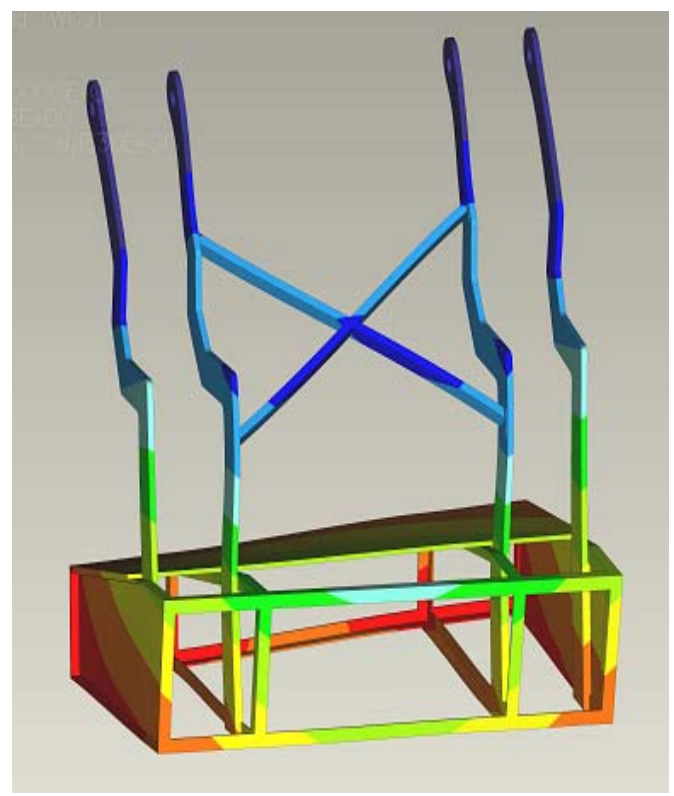

A

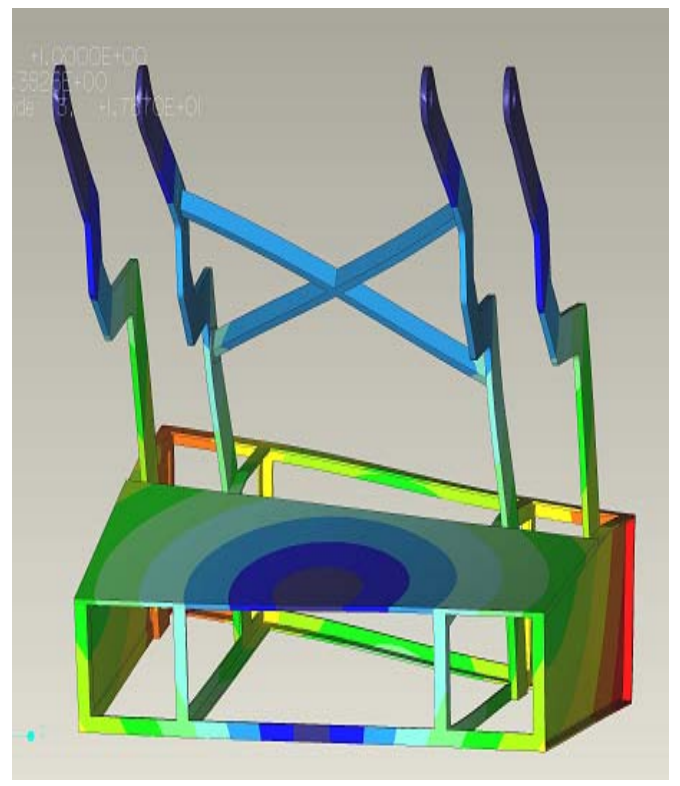

$\mathrm{C}$

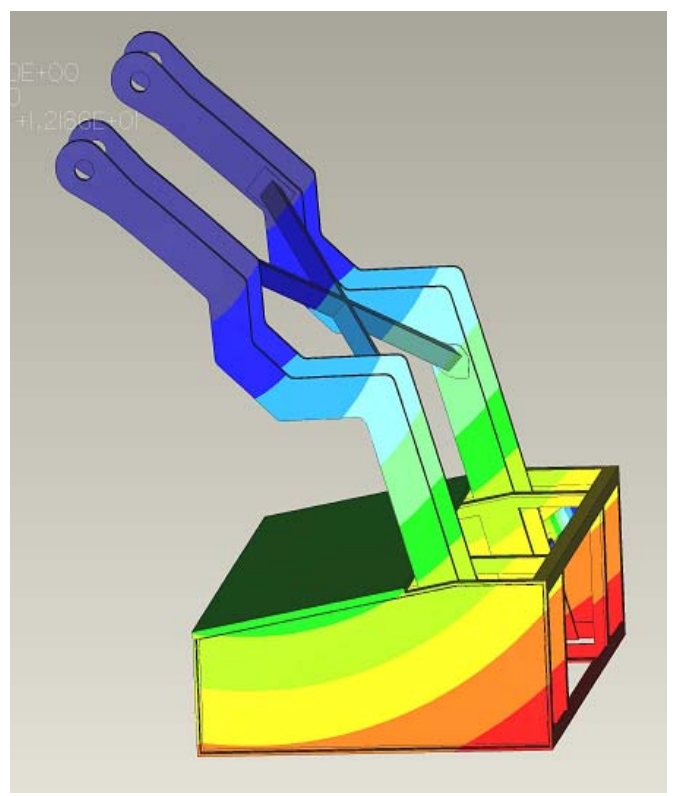

$\mathrm{B}$

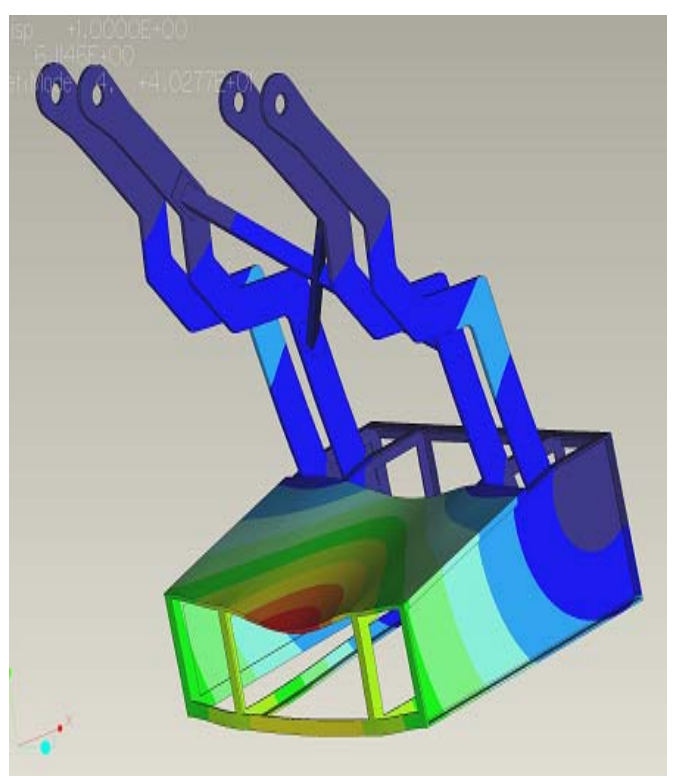

$\mathrm{D}$

Figure 14-B: (A) Mode 1 with 1 node (Right-Left Motion) at 11hz, (B) Mode 2 with 1 node (Fore-Aft Motion) at 12hz, (C) Mode 3 with center node (Torsion Motion) at 14hz, (D) Mode 4 with 2 nodes (Lateral Torsion Motion) at 40hz. 


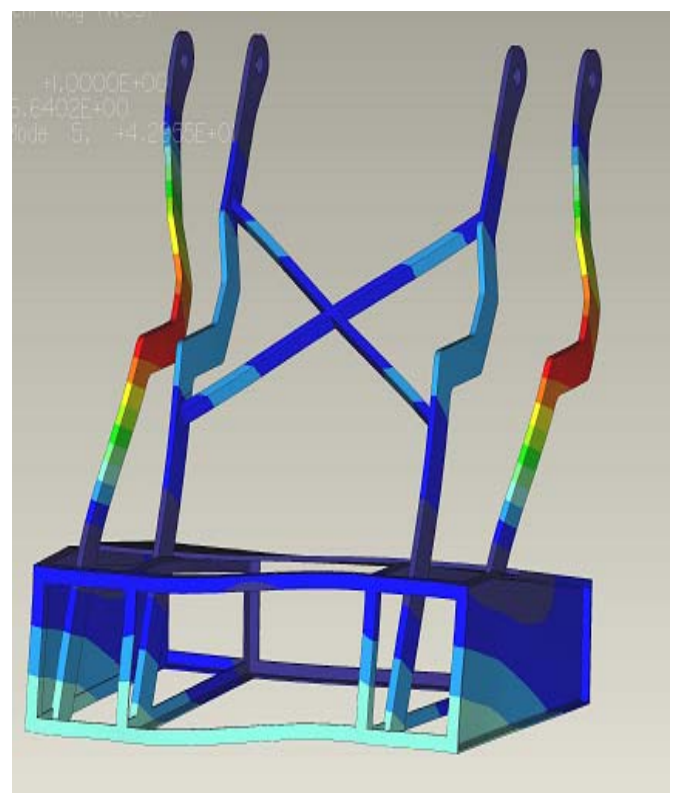

$\mathrm{E}$

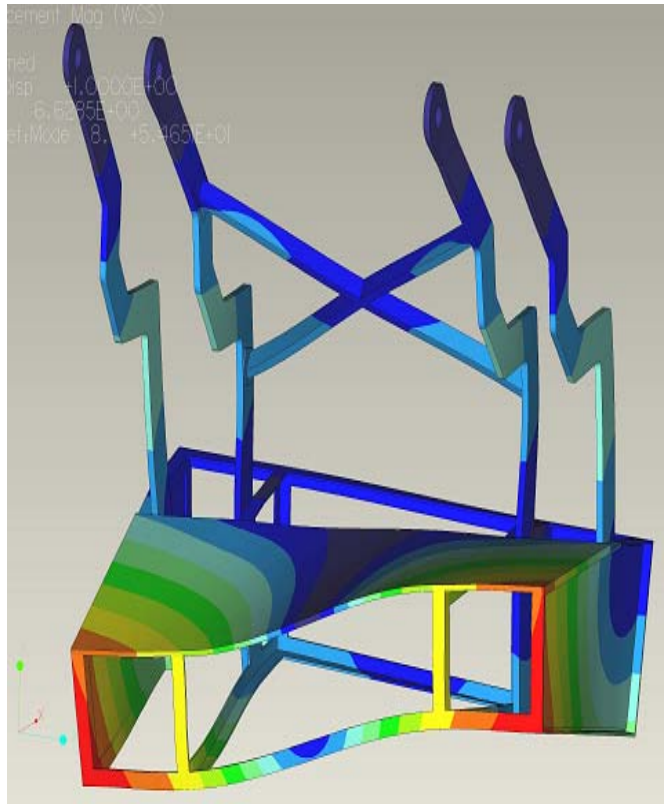

G

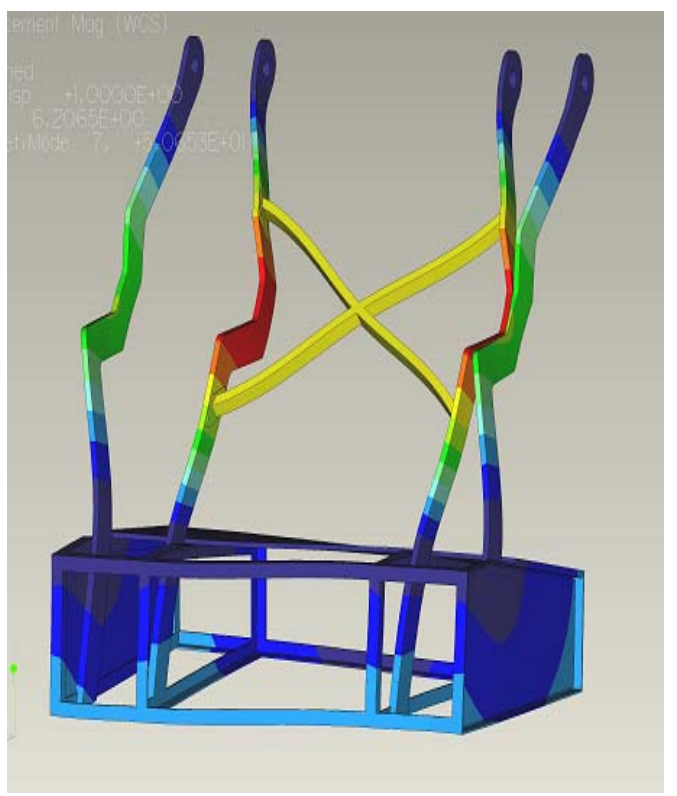

$\mathrm{F}$

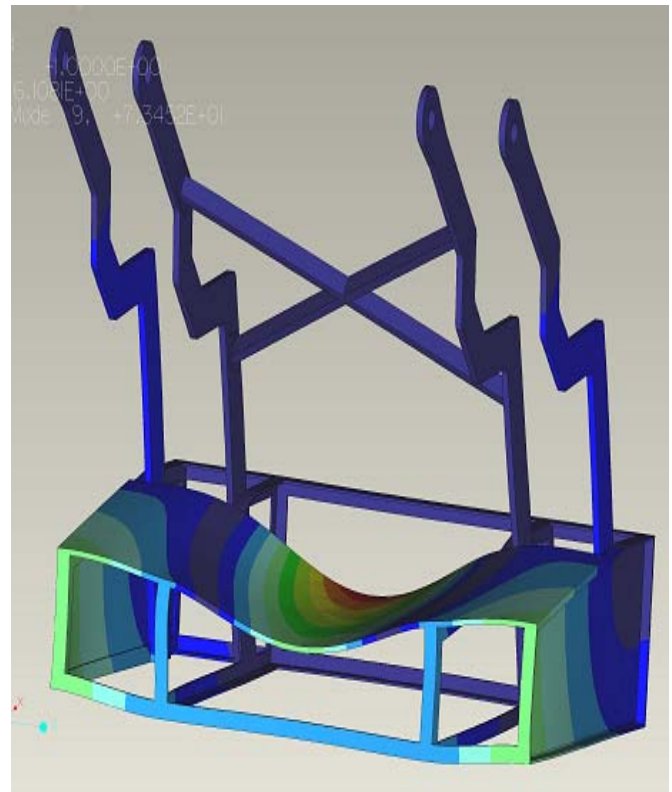

$\mathrm{H}$

Figure 15-B: (E) Mode 5 (Right-Left Motion) of outer Arms at 43hz, (F) Mode 7 with 2 nodes (Right-Left Motion) at 51hz, (G) Mode 8 with 4 nodes (Multiple Torsion Motion) at 55hz and (H) Mode 9 with 5 nodes (Multiple Torsion Motion) at $73 \mathrm{hz}$. 


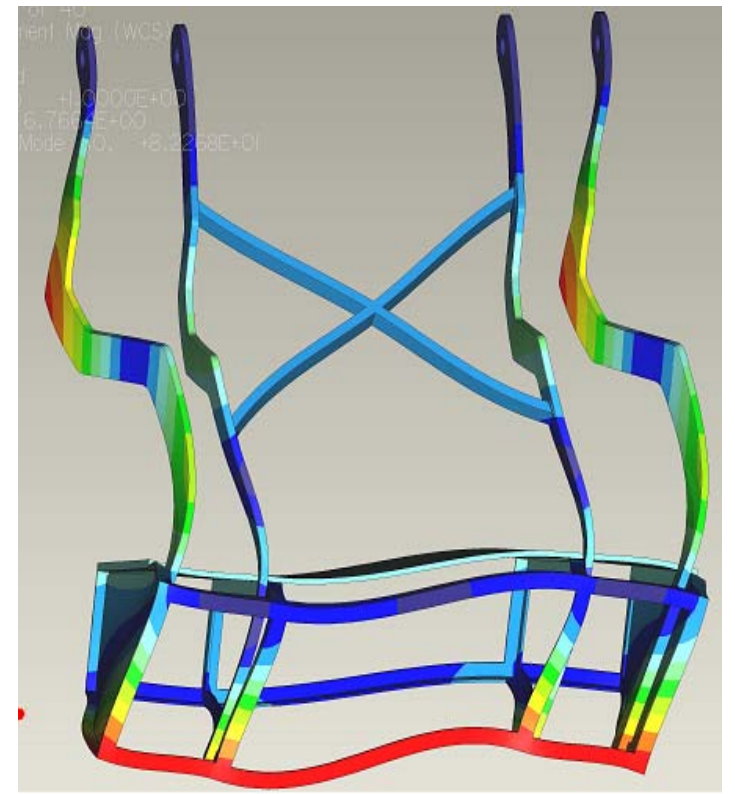

Figure 16-B: Mode 10 with 3 nodes (Right-Left Motion) at 82hz. 
Part B: Complete Arm/Pod System with Center Cross-Brace, V-Braces and Pod Skin

Table 13-B: Natural Frequencies of Arm/Pod System with Cross-Brace, V-Braces and Pod Skin

\begin{tabular}{|c|c|c|}
\hline \multicolumn{3}{|c|}{ Arm/Pod System with Cross-Brace, V-Braces and } \\
Pod Skin Components \\
\hline Mode & Natural Frequencies & Convergence (\%) \\
\hline 1 & 12 & 0.2 \\
2 & 18 & 0.7 \\
3 & 31 & 1.6 \\
4 & 40 & 1.3 \\
5 & 55 & 0.8 \\
6 & 73 & 1.9 \\
7 & 74 & 2.6 \\
8 & 92 & 2 \\
9 & 111 & 2.3 \\
10 & 118 & 2.2 \\
\hline
\end{tabular}

Table 14-B: P-Pass Convergence within 10\% of Modal Frequency for Arm/Pod System.

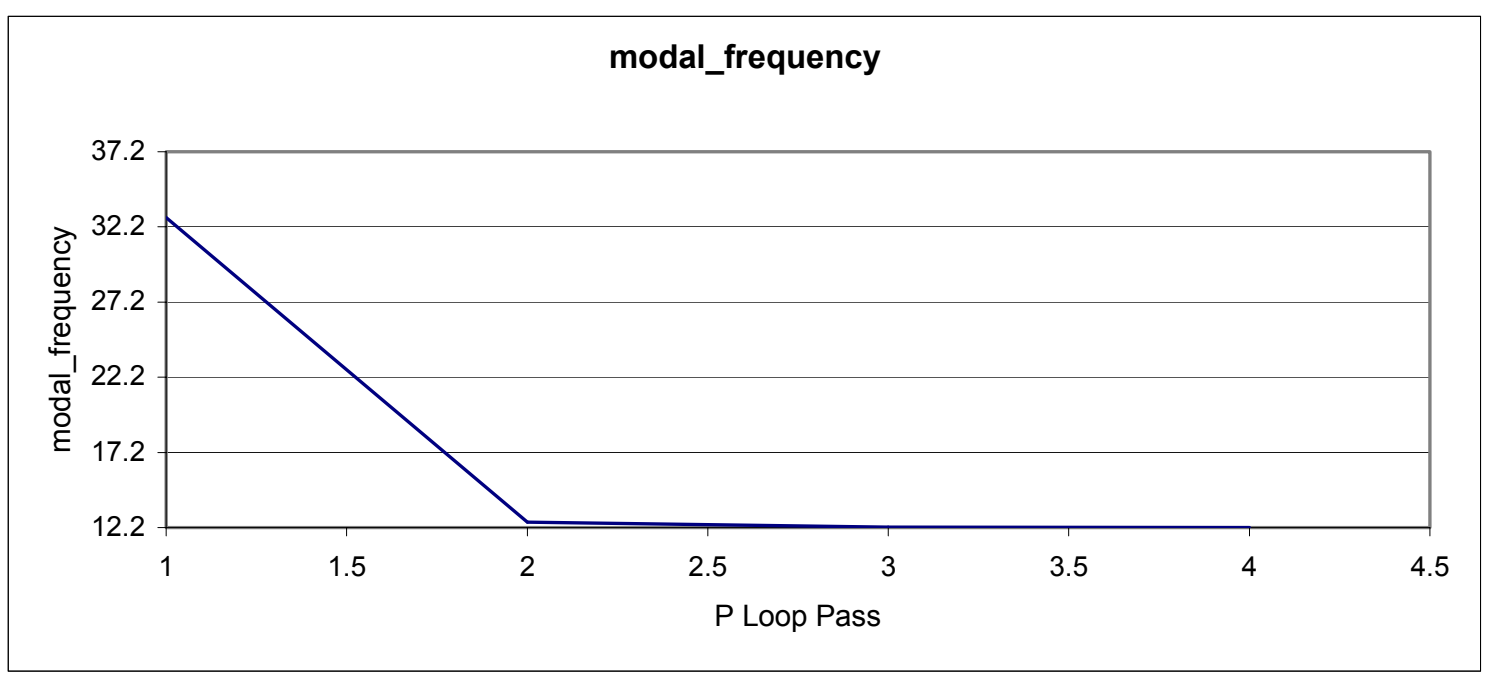




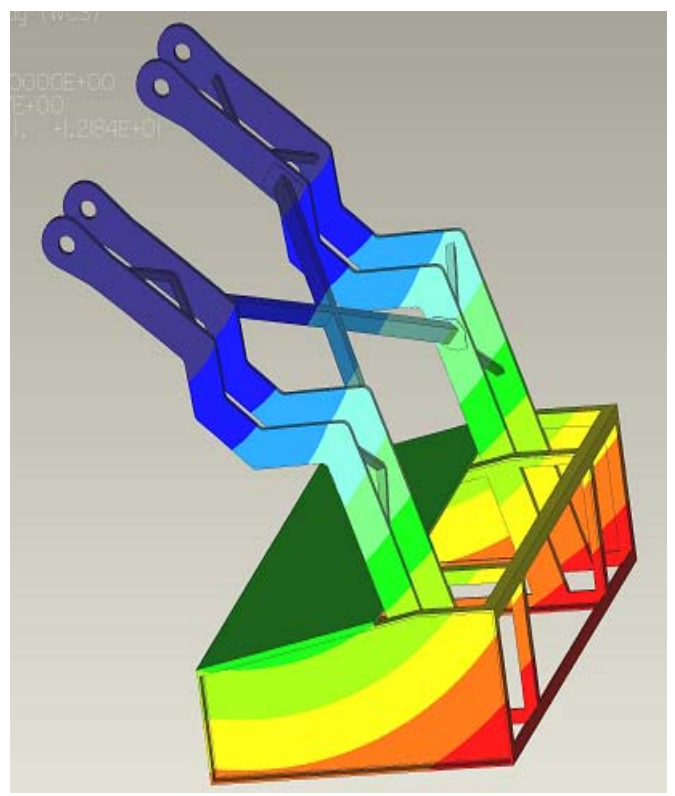

A

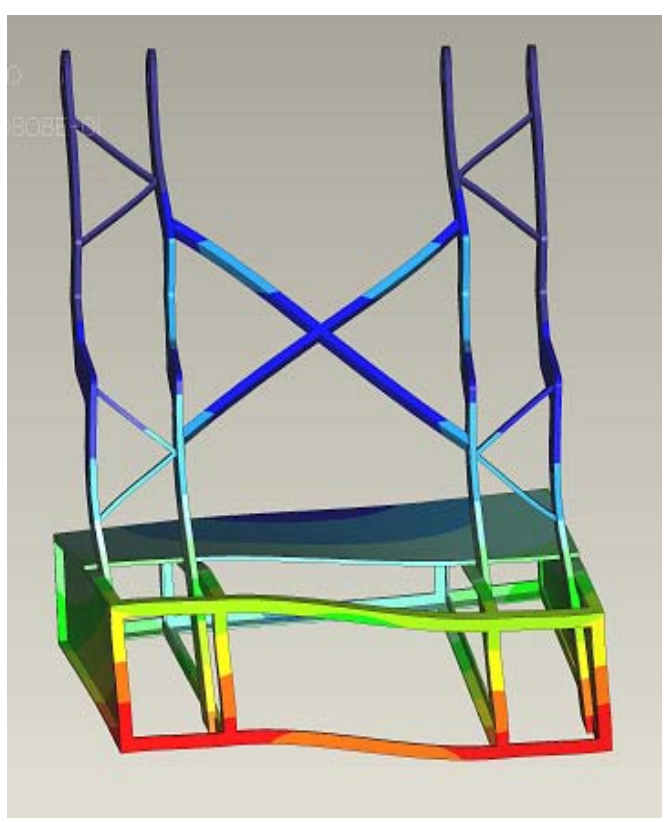

$\mathrm{C}$

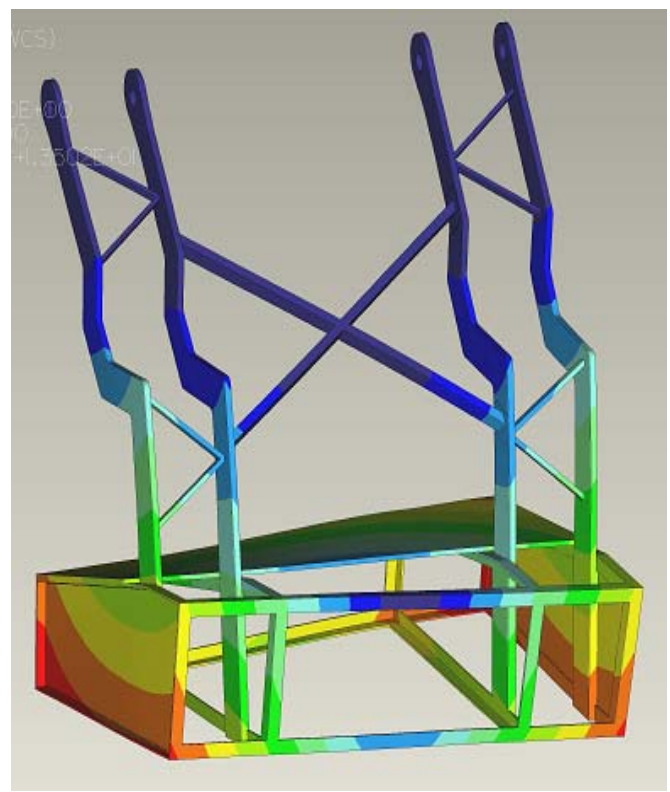

$\mathrm{B}$

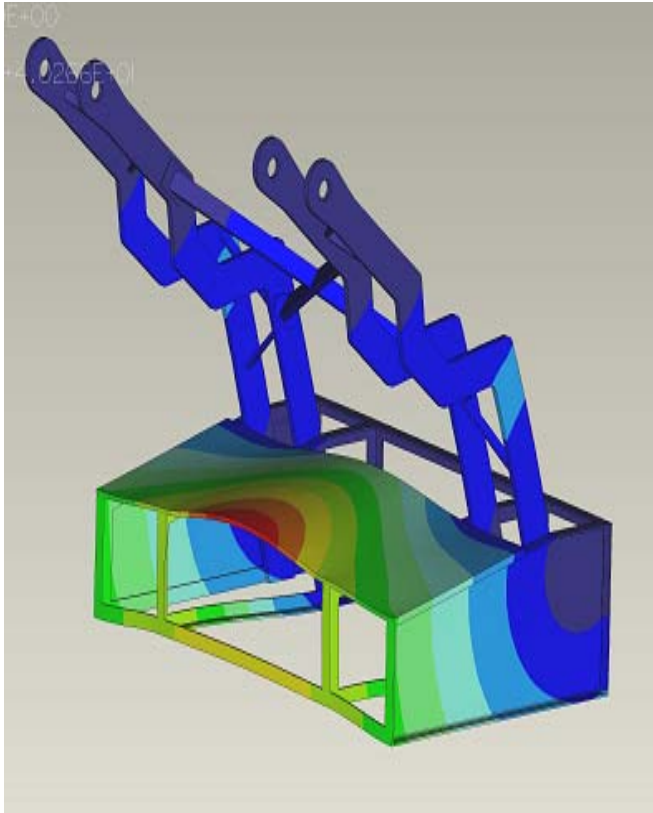

$\mathrm{D}$

Figure 17-B: (A) Mode 1 with 1 node (Fore-Aft Motion) at 12hz, (B) Mode 2 with center node (Torsion Motion) at 18hz, (C) Mode 3 with 1 node (Right-Left Motion) at $31 \mathrm{hz}$ and (D) Mode 4 with 2 nodes (Torsion Motion) at 40hz. 


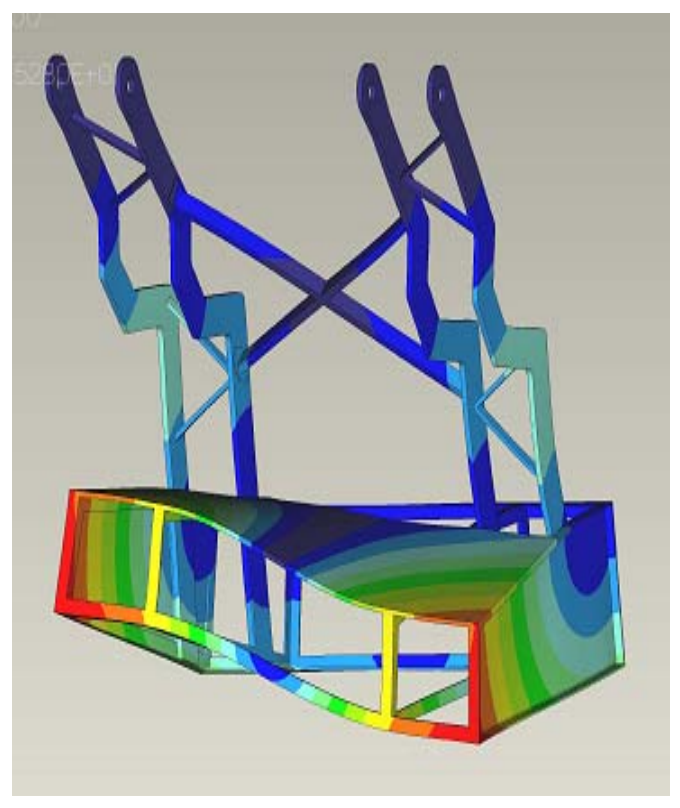

E

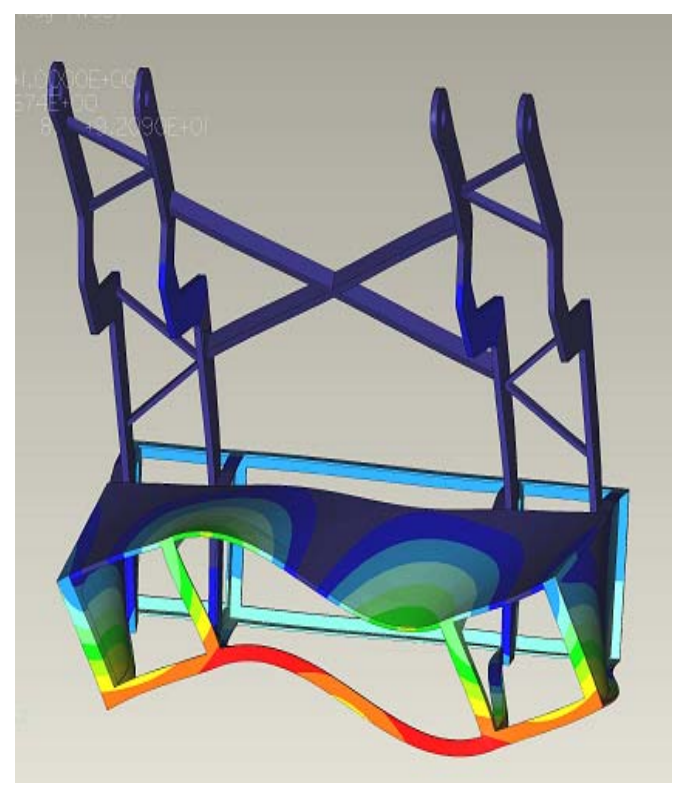

G

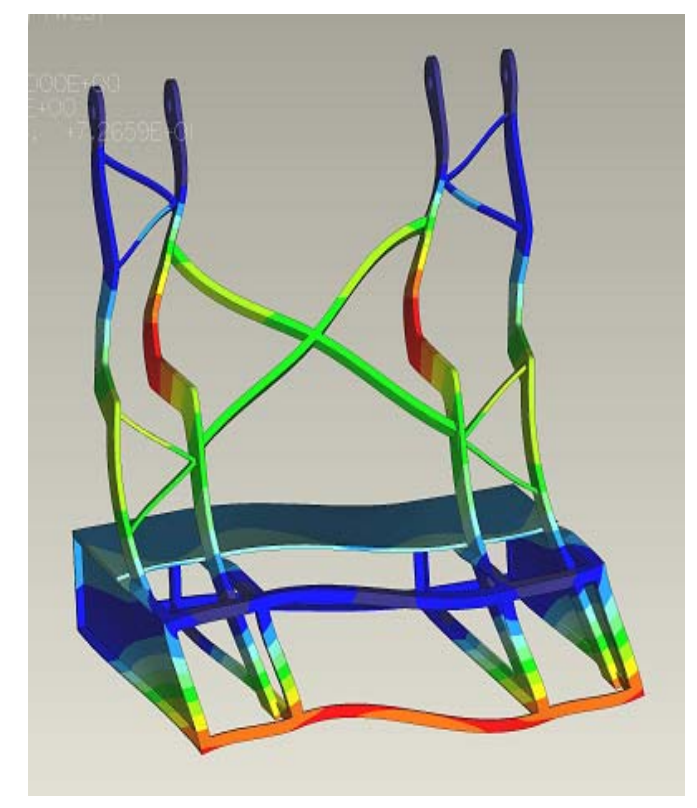

$\mathrm{F}$

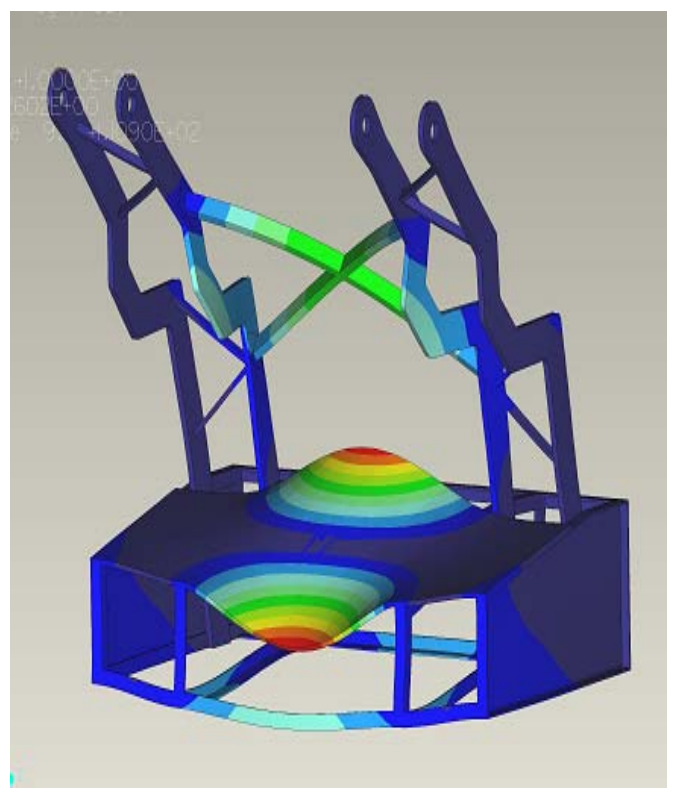

$\mathrm{H}$

Figure 18-B: (E) Mode 5 with 3 nodes (Multiple Torsion Motion) at 55hz, (F) Mode 6 with 2 nodes (Right-Left Motion) at 73hz, (G) Mode 8 with 4 nodes (Multiple Torsion Motion) at $92 \mathrm{hz}$ and $(\mathrm{H})$ Mode 9 with 3 nodes (Multiple Bending Motion) of Cross-Brace and 1/2inch Plate at $111 \mathrm{hz}$. 


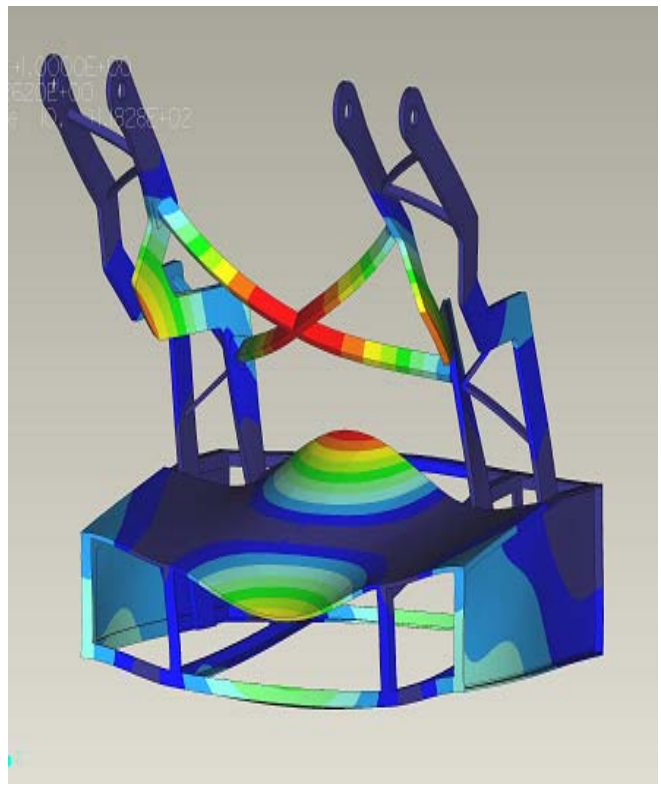

Figure 19-B: Mode 10 with 6 nodes (Multiple Bending and Torsion Motion) at 118hz. 
Appendix C

\section{Matlab Programs}

(FFT, Averaging 4 Data Sets) 


\section{FFT [21]}

\%load data into Acc using csvread(")

time=Acc(:,1);

$\operatorname{lpx}=\operatorname{Acc}(:, 2)$;

$\operatorname{lpy}=\operatorname{Acc}(:, 3)$;

$l p z=A c c(:, 4)$

$\mathbf{h p x}=\operatorname{Acc}(:, 5)$;

hpy=Acc(:,6);

hpz=Acc(:,7);

to $=$ time $(1,1)$;

$t=($ time-to) $) \mathbf{2 5 6 0}$;

$h \times g=(h p x-2.53) / .1$

hyg $=($ hpy-2.5)/.097;

hzg $=($ hpz-2.5)/.098;

$\operatorname{lxg}=(\operatorname{lpx}-2.53) / .202$

$\operatorname{lyg}=(\operatorname{lpy}-2.47) / .203$;

$\operatorname{lzg}=(\operatorname{lpz}-2.47) / .197$

$\operatorname{mhpx}=\operatorname{mean}(\mathrm{hxg})$;

mhpy=mean(hyg);

$\operatorname{mhpz}=\operatorname{mean}(\mathrm{hzg})$;

$\operatorname{mlpx}=\operatorname{mean}(\mathbf{l x g}) ;$

mlpy=mean $($ lyg);

$\operatorname{mlpz}=\operatorname{mean}(\mathbf{l z g}) ;$

hxgn=hxg-mhpx;

hygn=hyg-mhpy; 


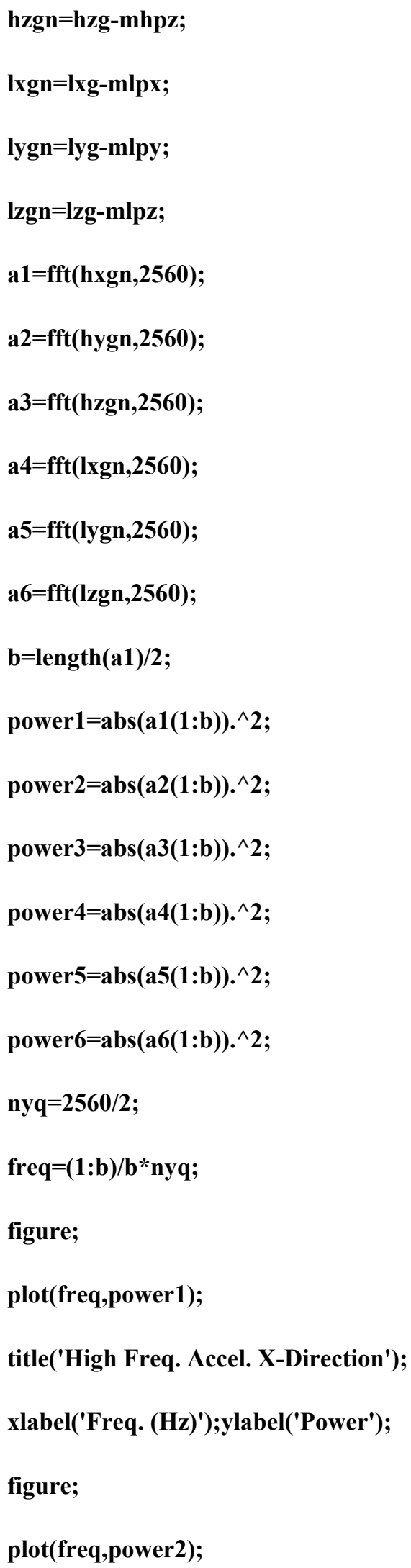


title('High Freq. Accel. Y-Direction');

xlabel('Freq. (Hz)');ylabel('Power');

figure;

plot(freq,power3);

title('High Freq. Accel. Z-Direction');

xlabel('Freq. (Hz)');ylabel('Power');

figure;

plot(freq,power4);

title('Low Freq. Accel. X-Direction');

xlabel('Freq. (Hz)');ylabel('Power');

figure;

plot(freq,power5);

title('Low Freq. Accel. Y-Direction');

xlabel('Freq. (Hz)');ylabel('Power');

figure;

plot(freq,power6);

title('Low Freq. Accel. Z-Direction');

xlabel('Freq. (Hz)');ylabel('Power');

figure;

$\operatorname{plot}(\mathbf{t}, \mathbf{h x g})$;

title('Scaled Data for X-Direction High Freq. Accel.');

xlabel('Time (sec)');ylabel('Acceleration (g)');

figure;

plot(t,hyg);

title('Scaled Data for Y-Direction High Freq. Accel.'); 
xlabel('Time (sec)');ylabel('Acceleration (g)');

figure;

$\operatorname{plot}(t, h z g)$;

title('Scaled Data for Z-Direction High Freq. Accel.');

xlabel('Time (sec)');ylabel('Acceleration (g)');

figure;

$\operatorname{plot}(t, \mathbf{l x g})$

title('Scaled Data for X-Direction Low Freq. Accel.');

xlabel('Time (sec)');ylabel('Acceleration (g)');

figure;

plot(t,lyg);

title('Scaled Data for Y-Direction Low Freq. Accel.');

xlabel('Time (sec)');ylabel('Acceleration (g)');

figure;

$\operatorname{plot}(t, \mathbf{l z g})$;

title('Scaled Data for Z-Direction Low Freq. Accel.');

xlabel('Time (sec)');ylabel('Acceleration (g)'); 
Program Utilized to Average Four Data Sets [21]

\%load data into A, B, C using csvread(")

time1=A(:,1);

time2=B(:,1);

time3=C(:,1);

time4=D(:,1);

$\mathrm{hpx1}=\mathrm{A}(:, 5)$;

$\operatorname{hpx} 2=B(:, 5)$;

hpx3=C(:,5);

hpx4=D(:,5);

hpy1=A(:,6);

hpy $2=B(:, 6)$;

hpy3 $=C(:, 6)$;

hpy4=D(:,6);

$\operatorname{hpz1}=\mathbf{A}(:, 7)$;

$\operatorname{hpz2}=\mathbf{B}(:, 7)$;

$\operatorname{hpz3}=\mathbf{C}(:, 7)$;

hpz4=DC(:,7);

to1=time1 $(1,1)$;

to2=time2 $(1,1)$;

to3=time3(1,1);

to4=time4(1,1);

t1=(time1-to1)/2560;

t2 $=($ time2-to2)/2560;

t3=(time3-to3)/2560; 
t4=(time4-to4)/2560;

hxg1=(hpx1-2.53)/.1;

hxg2=(hpx2-2.53)/.1;

hxg3=(hpx3-2.53)/.1;

hxg4=(hpx4-2.53)/.1;

hyg1=(hpy1-2.5)/.097;

hyg2=(hpy2-2.5)/.097;

hyg3 $=($ hpy3-2.5)/.097;

hyg4=(hpy4-2.5)/.097;

hzg1=(hpz1-2.5)/.098;

hzg2=(hpz2-2.5)/.098;

hzg3=(hpz3-2.5)/.098;

hzg4=(hpz4-2.5)/.098;

$\operatorname{mhpx1=mean}(\mathbf{h x g 1})$;

$\operatorname{mhpx2}=$ mean(hxg2);

$\operatorname{mhpx3=mean}(\mathbf{h x g 3})$;

mhpx4=mean(hxg4);

mhpy1=mean(hyg1);

mhpy2=mean(hyg2);

mhpy3=mean(hyg3);

mhpy4=mean(hyg4);

mhpz1=mean(hzg1);

mhpz2=mean(hzg2);

mhpz3=mean(hzg3);

mhpz4=mean(hzg4); 


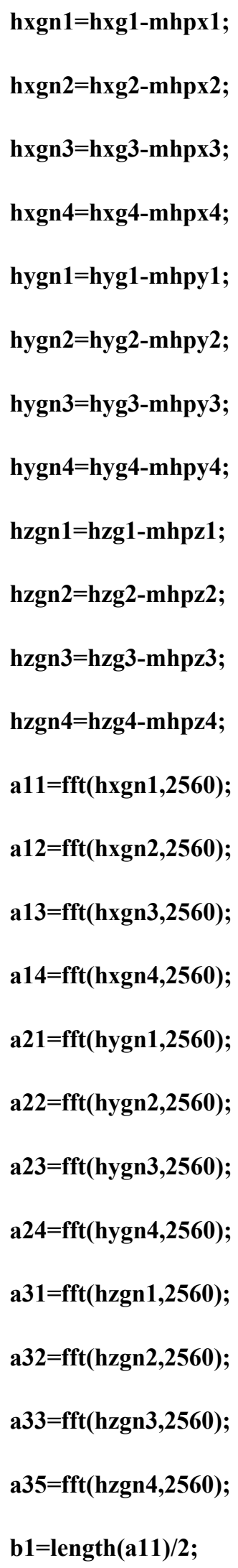




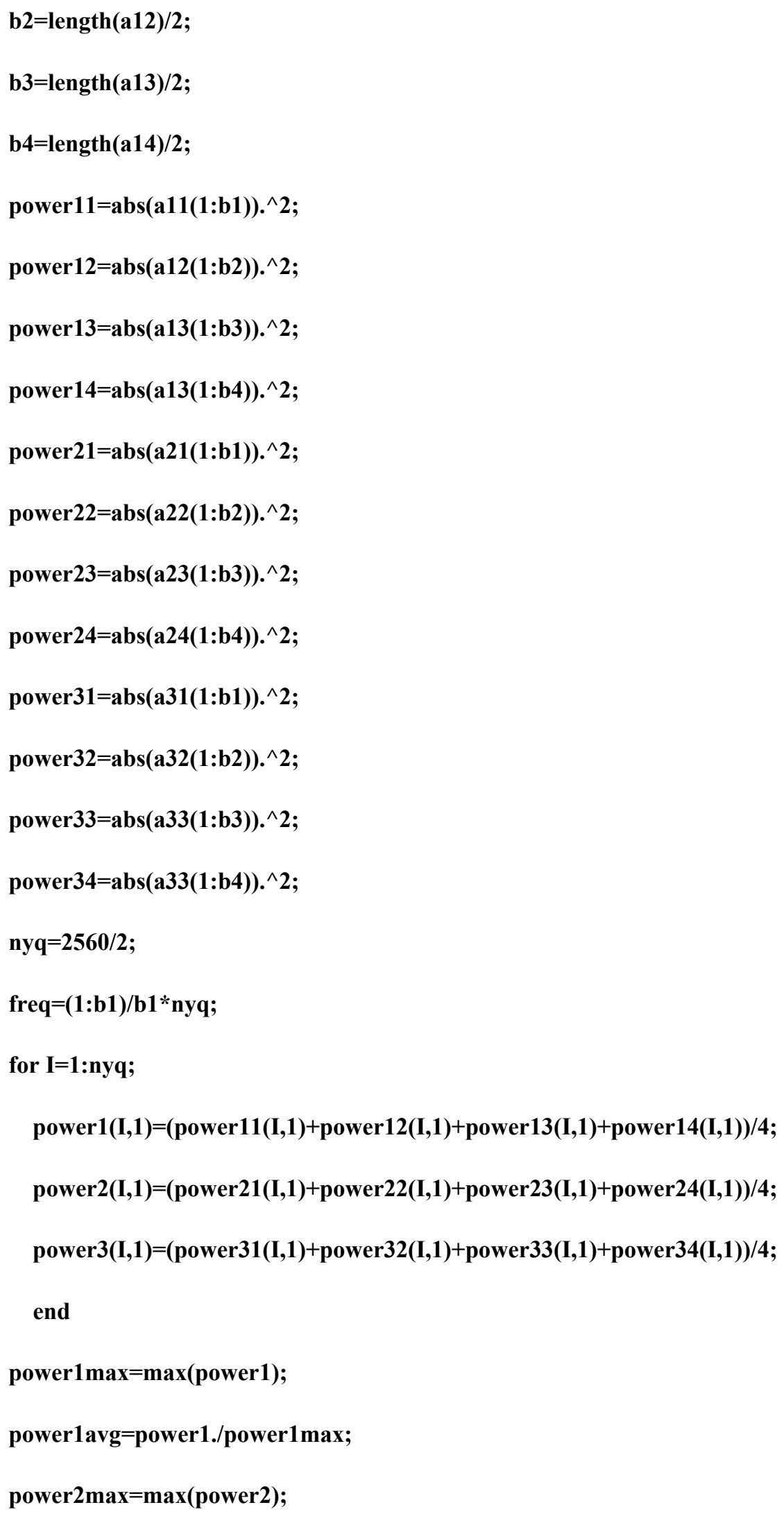




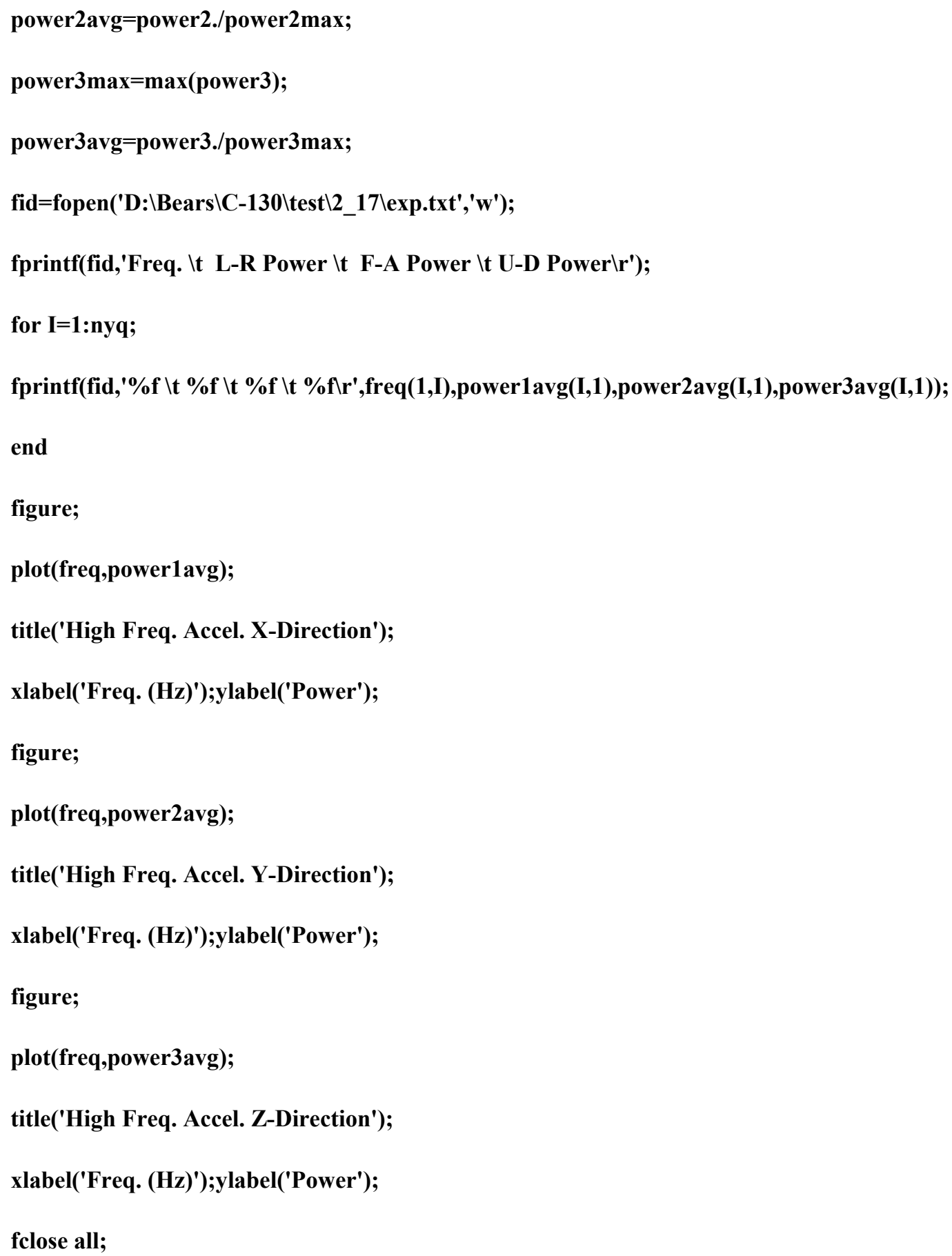


Appendix D

Engineering Drawings 


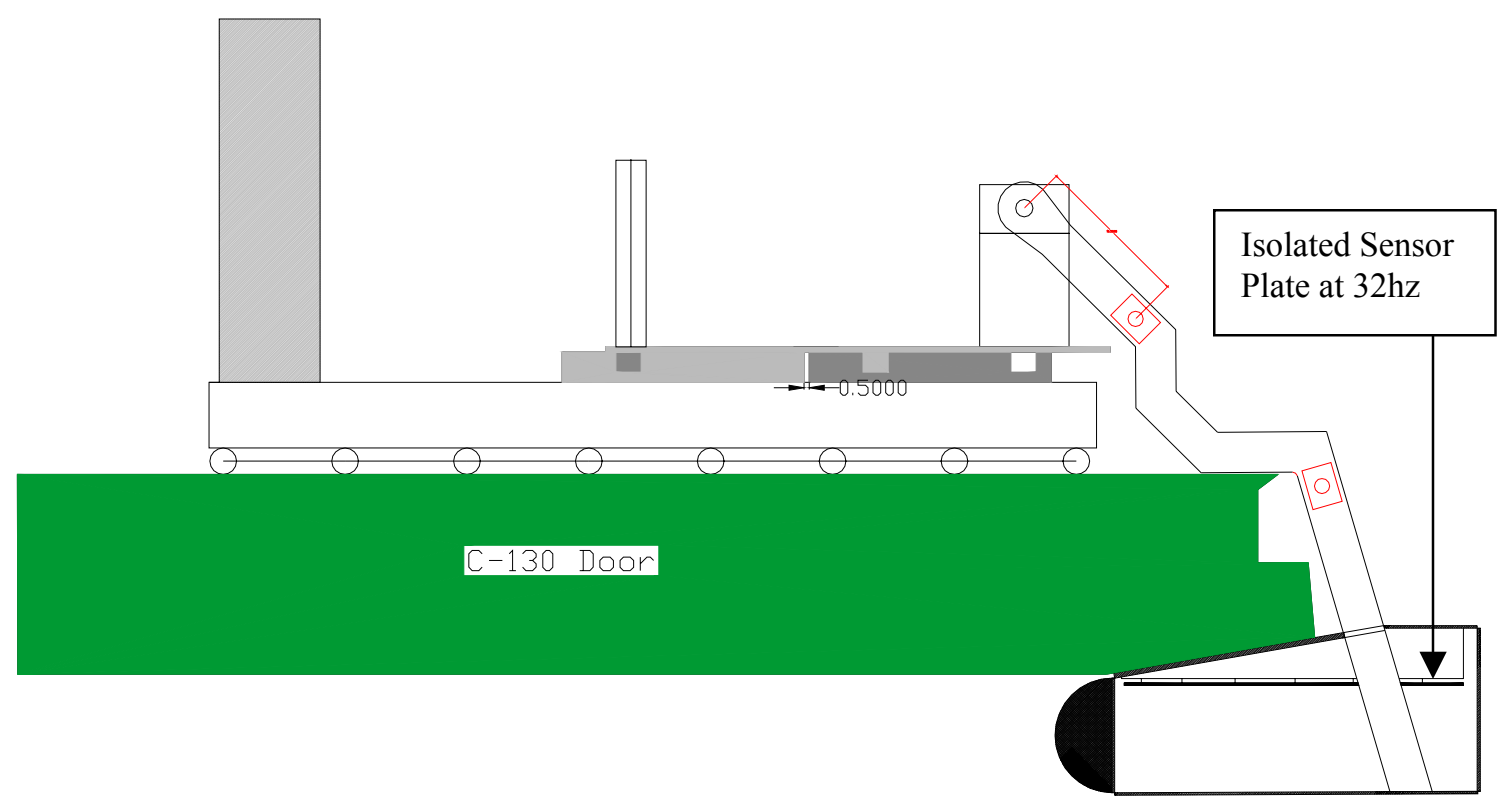

Figure 0-D: AutoCAD drawings of mechanical Arm/Pod system mounted on C-130 Ramp.

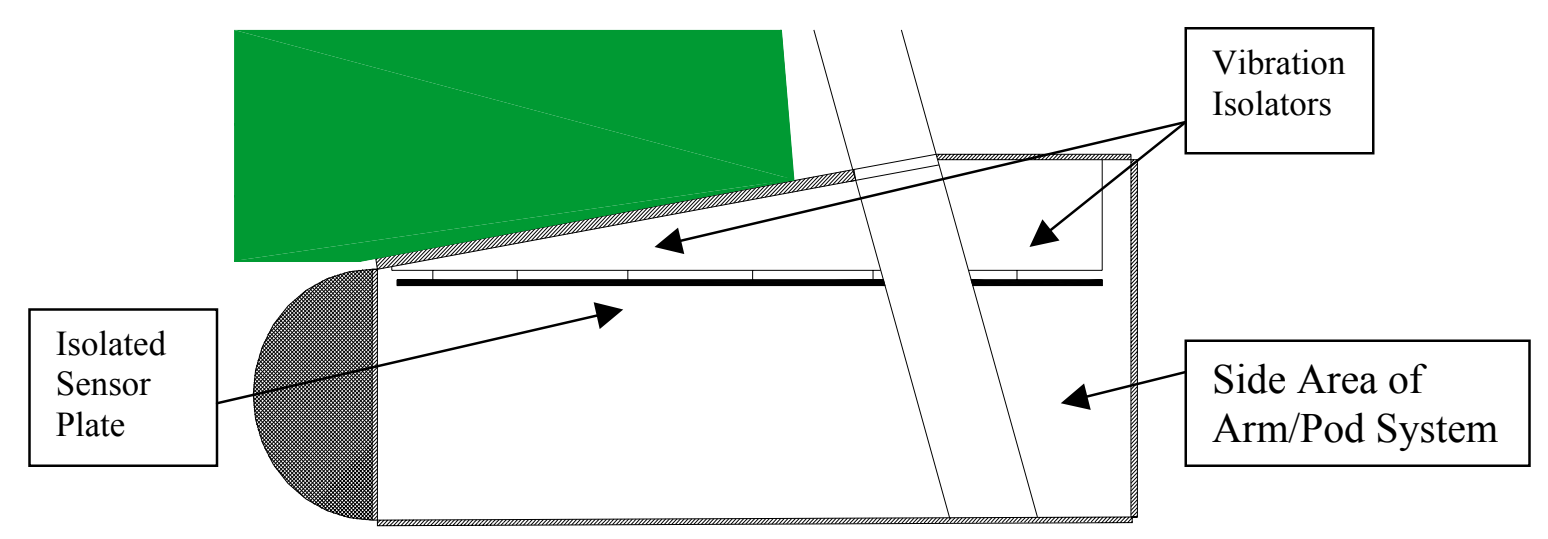

Figure 1-D: Zoomed picture of vibration isolators and isolated sensor plate. 


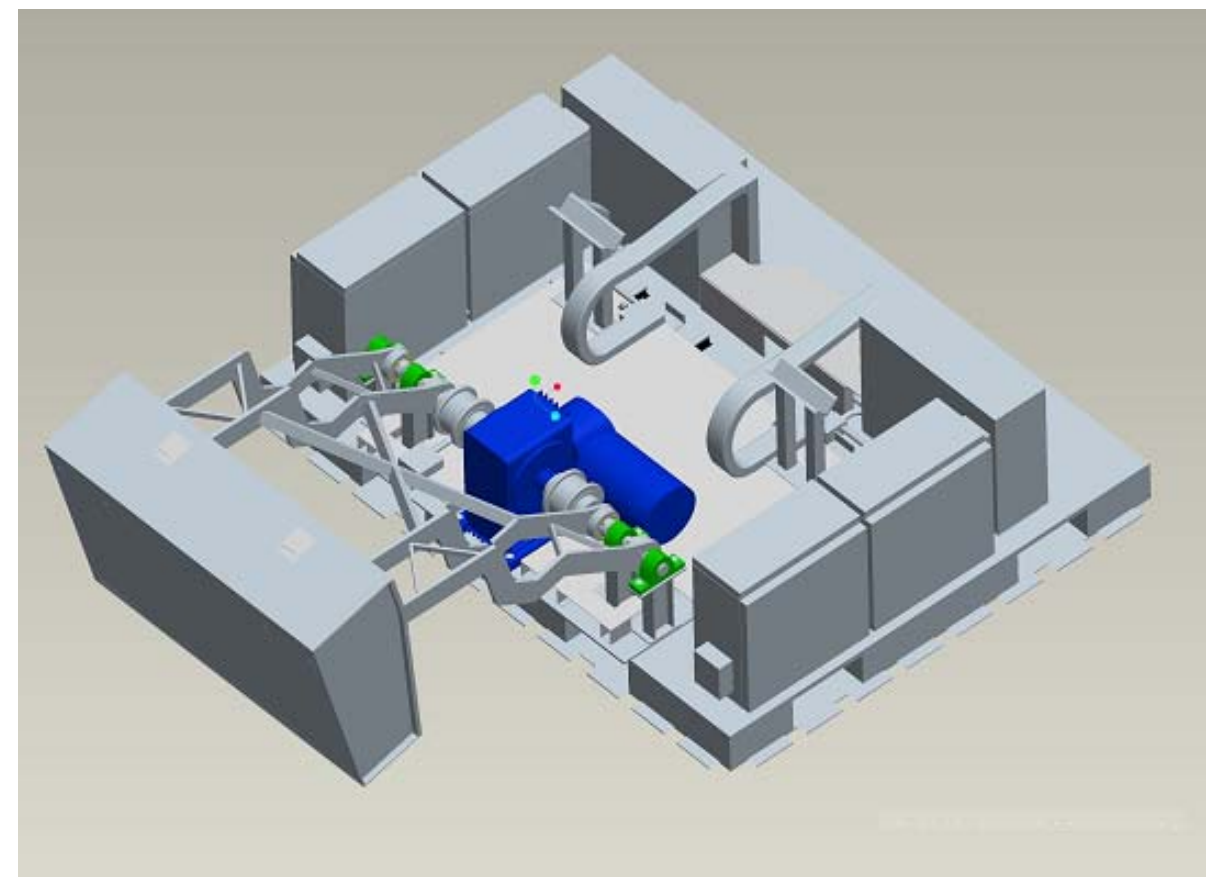

Figure 2-D: Ideal Mechanical Arm/Pod System for C-130 Project Oculus.

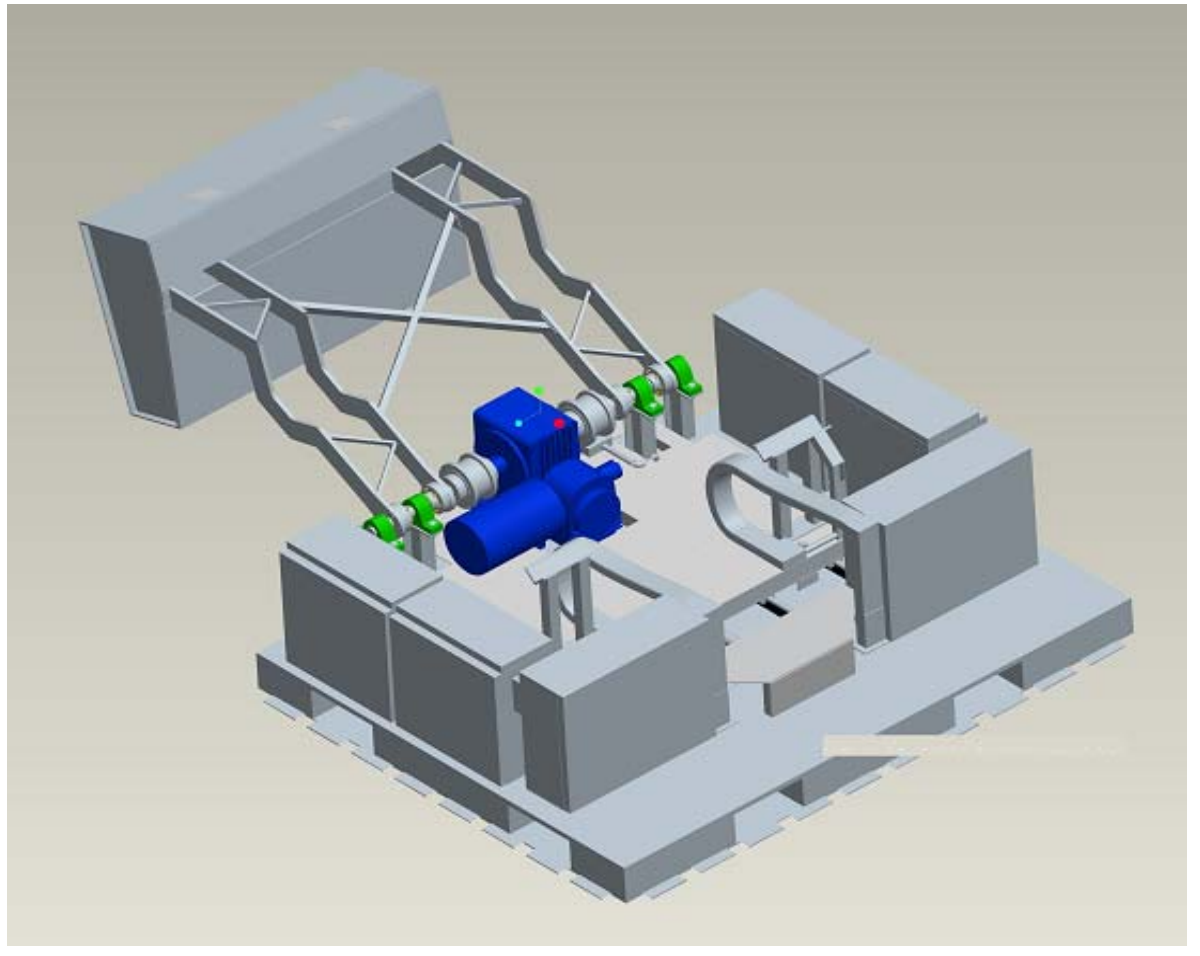

Figure 3-D: Ideal Mechanical Arm/Pod System for C-130 Project Oculus (back view). 